\title{
Age and the City
}

Reducing the issue of social isolation in older persons

and elderly through the development of an intergenerational housing scheme

Kara Schoch 


\title{
Age and the City
}

\author{
by
}

Kara Schoch

A 120-point thesis

submitted to the Victoria University of Wellington

in partial fulfilment of the requirements for the

degree of Master of Architecture (Professional)

Victoria University of Wellington

School of Architecture

2019 


\section{Acknowledgements}

To my supervisor Rosie Scott, thank you for your

guidance, pep talks and continued faith in myself and my research over the past year, your support has been invaluable.

To Mum, Dad and Hayley, thank you for your support over the last five years and for letting me constantly bombard you with architecture chat even though you had no idea what I was talking about.

To my friends, my flat mates and Abby, thank you for your unwavering encouragement and positivity throughout architecture school. 


\section{Abstract}

Social isolation and loneliness affecting a large number of older persons and elderly is a prevalent issue in today's society. Current older persons and the Baby Boomer generation approaching this age are far more independent than previous generations. Their perception of 'retirement' has a negative connotation due to society's pressures and value placed in remaining independent and useful. The current model of aged care housing, although existing in many forms catered towards different levels of care, is generally seen as a last resort and an acceptance of being dependent on others for day-to-day things. This has led to a trend of ageing in place, in homes which are arguably too big for a single person or couple and often not equipped to adapt to bodily decline. With reducing mobility, this can restrict the residents' ability to socially interact and engage with their communities.

This research investigation analyses the role architecture plays in contributing to this issue and looks at opportunities for improvement through the design of a mixed urban housing development designed to meet the physical and social needs of older persons.

Four strategic design tactics were formed during the early design investigations. They directly address the researches aims and objectives through social and spatial means. These tactics are: Tactic 1 - Urban Location, connecting residents to the city, parks and a nearby school; Tactic 2 - Social Circulation is developed to facilitate incidental and planned interactions in the circulation spaces of the developments; Tactic 3 - Mixed Housing provides a range of apartments suited to older persons, students and families; Tactic 4 - Shared Amenities provides health services, leisure activities and a cafe for residents and the wider public to enjoy.

The design investigation found that making circulation a primary focus allowed for a stronger relationship between the site and building and allowed for more opportunities for interactions between residents and the public. This research argues that these tactics working together, will provide better outcomes for older persons in health and well being and should be considered as a new and better model of older persons housing. 


\section{Contents}

Abstract vii

$\begin{array}{ll}\text { Introduction } & 10\end{array}$

Chapter 1: $\quad 17$

Situating the work

$\begin{array}{ll}\text { Literature Review } & 18\end{array}$

History of Aged Housing in New Zealand

Ageing in Traditional vs Western Societies

Loneliness and Social Isolation

Ageing in Place

Intergenerational Interaction

Project Review

Aged Care Housing

Co-Housing

Urban Housing

Chapter 2:

Site Studies

Site Selection and Analysis

Site Selection Criteria

Site Analysis

Chapter 3:

Schematic Design

Early Design Response

Site Organisation

Social Street

Massing Models

Circulation

Walk through

The Four Tactics 
Chapter 4:

Experimentation

Expansion of ideas

Form

Concept One: Soft Form

Concept Two - Urban Design Up

Concept 3: The Ramp

Chapter 5:

Design Development + Resolution

Refining

Residents Timeline

Concept Two: Urban Design Up

Tactic One: Urban Location

Tactic Two: Social Circulation

Tactic Three: Mixed Housing

Tactic Four: Shared Amenities

Chapter 6:

Final Design

Age and the City: An Intergenerational, Urban Housing

Scheme

184

Strategic Diagram

Floor Plans

Sections

Walk through Views

Conclusion

Works Cited

List of Figures

Appendix 


\section{Introduction}

Research Question:

As New Zealand's population ages and demand for housing for older persons increases, can a new direction in housing be created which challenges the prevailing stigma of aged care housing, by providing better social, health and support benefits for its residents? 
This research lies within the context of aged care environments in New Zealand, by addressing the stigma associated with such environments as well as the issue of loneliness and social isolation in our elderly and older persons. The research aims to design a response to these issues by developing an alternative to suburban, rural and hospital model aged care environments through a mixed residential urban housing designed specifically with the needs of older persons, in order to provide a more positive ageing experience.

The research investigation started by exploring the issue of loneliness and social isolation that a lot of New Zealanders are currently experiencing, in particular older persons and elderly. The Ministry of Health defines older persons as $65+$ and elderly as $80+$, within these groups a Ministry of Social Development survey in 2016 found that $12.5 \%$ of people felt lonely all or most of the time in the last 4 weeks, a statistic that is increasing. This issue s growing due to the increase in importance of independence within the Baby Boomer generation. This fierce want and pressure from society to age in place means individuals are left living in houses, too big for themselves and not adapted to their changing needs in mobility and mental decline. Architecture was found to bring an opportunity to be the catalyst for improvement.

This research looks at what contributes to stigmatised aged care and what architectural solutions can be found to combat this. The research takes place through design, by developing an urban housing development in Wellington City which is mixed residential and intergenerational while using multiple tactics to tackle the complex social and health needs of older persons.

This research aims to develop a suitable option of housing for older persons and elderly which supports their unique wants and needs as well as providing an environment with reduced stigma. There is little consideration for accessibility in New Zealand's existing urban residential developments. Providing these changes with a focus on circulation not only allows the building to serve elderly and accessible residents but also makes the spaces more vibrant and healthier for all residents.

The methodology for this research investigation was design led research. This design research is approached by developing a design response to a research question that allows the response to be tested and resolved through design. This involved sketches and digital documentation, responding to site conditions in coordination with established criteria from literature review research into what will improve elderly quality of life and reduce stigma. The final design response establishes four tactics - urban location, social circulation, mixed housing and shared amenities. Design investigations focused on these key areas as they address the research question most directly. Development through spatial planning, plan iterations, and form and material explorations resulted in a primary focus on circulation design and resolution in the areas of the four tactics. 


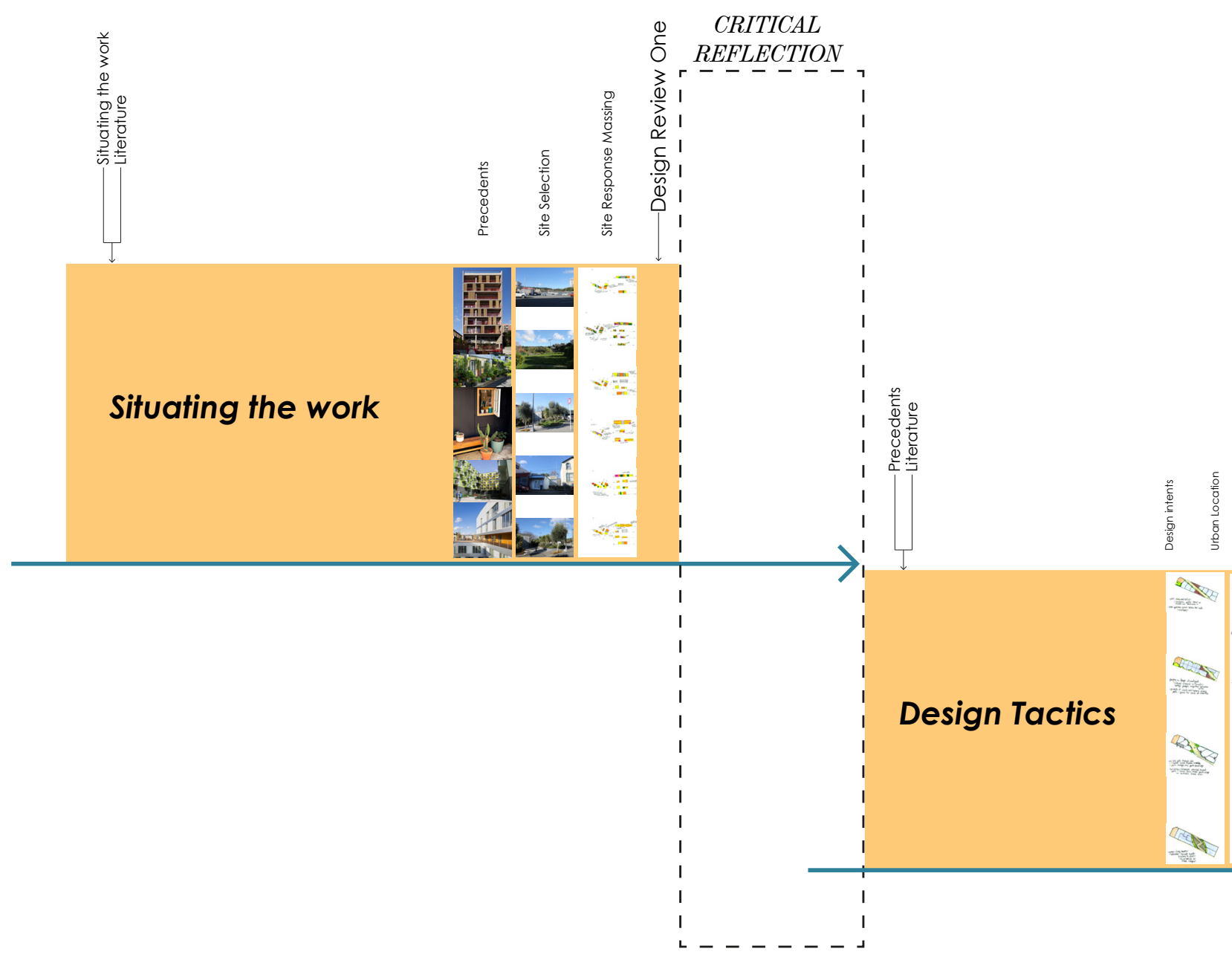

\section{Research Methodology}

This diagram was developed early in the research and maps out the process in which the investigation was undertaken. 


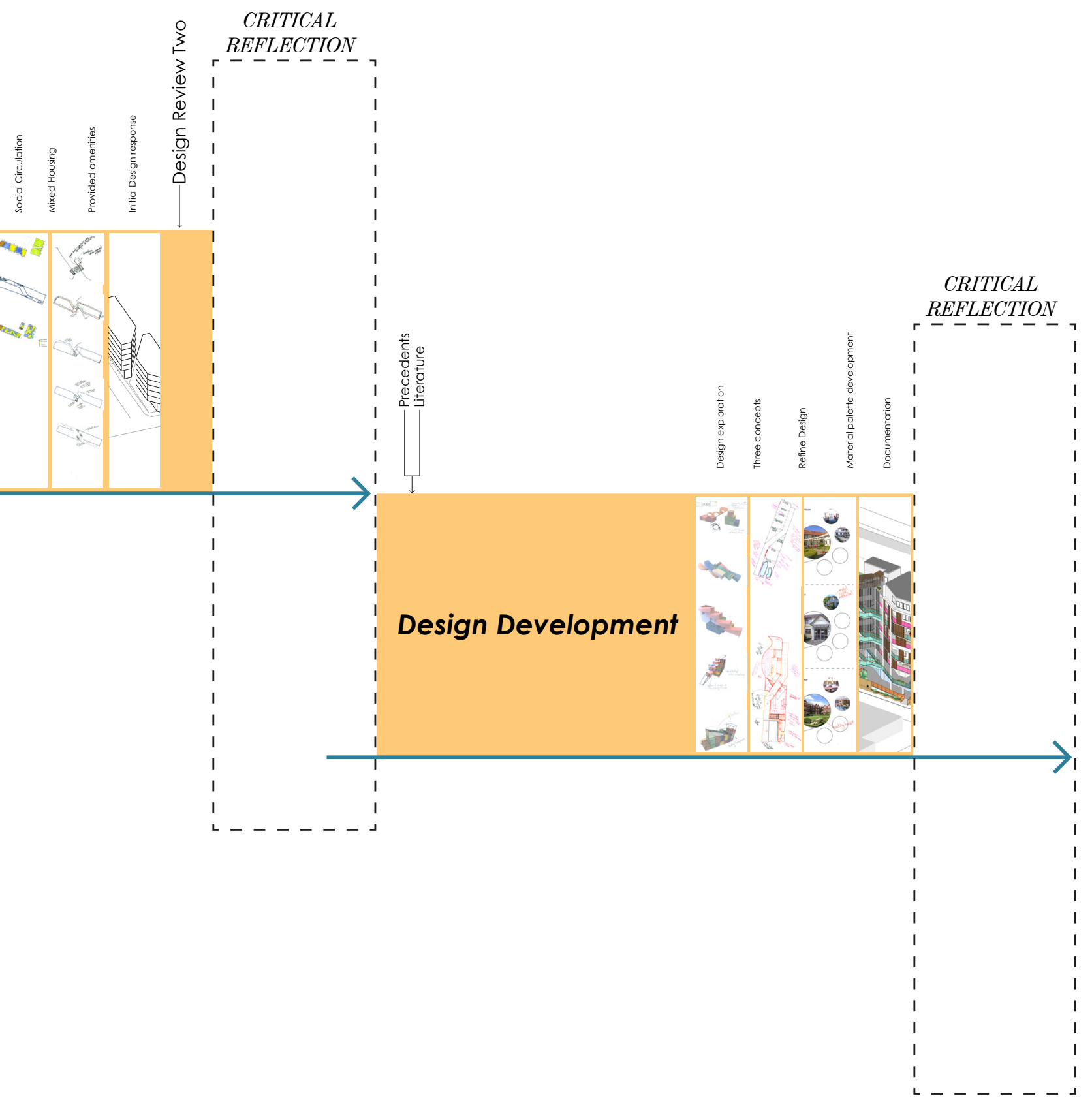


The central aim of this research is to develop

a new and better architectural model for older

persons housing, which will better meet the

social, cultural, health and well being needs of

older persons and elderly.

Through this new housing model, the research aims to:

- Reduce the stigma associated with older persons' housing.

- Reduce loneliness and social isolation in older persons and elderly.

- Explore strategies to promote intergenerational interaction. 


\section{Through the preliminary research in the literature and project review, the following five objectives have been established in order to meet the research aims. These are:}

\section{Choose an Appropriate Site \& Context:}

- Selection of an appropriate urban site that provides proximity to amenities (shopping/markets, museums, banking, social services and public transport) to test design experiments around interaction in an established area of activity.

\section{Promote Social Interactions:}

- Develop a social street within the site which engages public interaction and provides accessible circulation to park and surrounding/ provided amenities.

- Provide common spaces integrated with social circulation between floors to encourage activity and facilitate incidental interaction, as well as planned social interaction in barbecue/ function areas.

\section{Provide Support Services:}

- Provide on-site health care amenities and living support which serve the residents as well as the public and neighbouring school, including a general practice medical centre, physiotherapy and massage, gym, pool and café/ restaurant which can also function as catering/meal support for residents as needed.

\section{Develop a Contemporary Material Palette:}

- Create a material palette reflective of contemporary aesthetic and environmental concerns, of materials informed by a comparison study of aged care and urban housing. This palette re-imagines the recognisable and unsympathetic to context aged care aesthetic typical today in order to encourage a shift towards a positive perception of such facilities.

\section{Provide Mixed, Flexible Housing Options:}

- Provide a variety of apartment sizes that can service many different residents at different stages of need. This includes families, nursing/health support staff, couples and single elderly and older persons. Mixed size apartments, and an opportunity for co-housing, are catered toward multiple generations and family dynamics. 


\section{Chapter 1:}
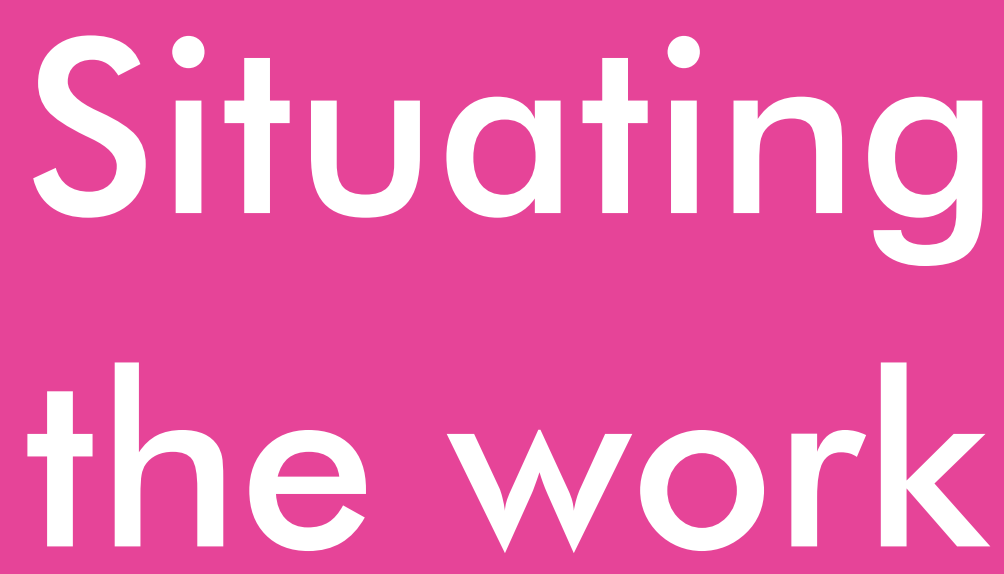

Literature \& Project Review 


\section{Literature Review}

This research is concerned with finding an architectural response to a health and social condition, therefore much of the literature reviewed relates to the health and well being of elderly. 
The range of ideas encompassed in this literature review reflect the amount of issues surrounding elderly and older persons in New Zealand and their living arrangements. In order to gain a wide perspective on this topic the following have been discussed and critically reflected on:

- The history of aged housing in New Zealand

- Perceptions of ageing and social position of the elderly - a cultural comparison

- A comparison of loneliness and social isolation and their impacts on the elderly's quality of life

- How the idea of ageing in place has been used in New Zealand

- The impact of intergenerational interactions on the elderly

Glossary of Key Terms

- Elderly - people aged 80 years old or over.

- Older Persons - people aged 65 to 80 years old.

- Middle Aged - people aged 45-64 years old.

- Traditional Societies - indigenous cultures pre European colonisation.

- Western Societies - First world societies influenced by capitalism and dominating culture in their country.
This literature review will look at the issues surrounding housing for older persons and elderly in New Zealand (Statistics New Zealand, National Population Projections), and the stigma surrounding this housing type. First the history of housing people as they age in New Zealand will be discussed to draw some conclusions on why perceptions of care homes and retirement hold the negative connotations that they do today. Secondly, a comparison will be made between selected indigenous cultures and their approaches to caring for their elderly and western cultural practices. The aim of this comparison is to shed light on different issues each group faces, to consider the social position that elders hold in traditional cultures and how this differs to westerns culture, and may be impacting the negative perception of aging in western culture. Thirdly, the consideration of loneliness and social isolation as key issues facing elderly today, how they have come to hold such negative value on a large percentage of the population - to understand what architecture can do to reduce these issues. The concept of ageing in place will be looked at fourth in its relationship with how older people want to live vs how they need to be living as they age, and how this idea could be adapted into a prospective retirement housing model. Lastly intergenerational interaction is looked at for its benefits for both old and young and how architecture can influence and facilitate these relationships and break down ideas associated with elderly interactions and manipulation/ abuse. 


\section{History of Aged Housing in New Zealand}

New Zealand has an ageing population, with 15\% of the population being $65+$ in 2016 there is a $90 \%$ probability of this increasing to $21-26 \%$ in 2043 and 24-33\% in 2068 (Statistics New Zealand, National Population Projections). With this there is an increasing demand for housing options catered towards this group. The Baby Boomer generation holds the mass of this population and is the cause for this growth, however; trends do not suggest a return to a youth dominated population in the future. To design housing for future older people we need to understand how aged care and housing got to where it is today.

The history of aged care in New Zealand begins with Māori traditions and values around their kaumātua or elderly. Traditionally the eldest mokopuna (grandchild) would be raised by their kaumātua in order to pass on knowledge and skills to the next generation. Kaumātua are held in high esteem as they hold the knowledge and power to make decisions for their whānau in terms of land and conflict resolution. The average life expectancy of Maori before European colonisation was around 40 years old, meaning from around age 30 people could be deemed kaumātua (Rawinia Higgins). However in the 1980's the New Zealand government set the minimum age for being considered a kaumātua at 70 years old. The distinction defines the difference between being a grandparent or elderly (Tipuna/ Tupuna) and being considered of kaumātua status to their hapu. Elderly and kaumātua are both regarded highly by cultural rules and traditions and by having these positions of prestige as something to aspire to the attitude towards ageing is more positive.

During colonisation a large number of Europeans immigrated to New Zealand, a majority of them being single men (Metadata). Given the gender imbalance, many of these settlers never married and had no family for support as they aged and became unable to work. Benevolent institutions were set up in the 1860's to house these people. They "were grim, uncomfortable places. They had infirmaries and cancer wards, but inmates suffering from dementia were sent to mental institutions."(Williams) These became places where people went to die with little regulations around how staff treated residents they gained a negative perception which prompted the government to define guidelines for these places which continue to develop today (McCabe).

In the late 1800's to early 1900's developments into care homes were made by churches and private run homes, as well as homes for former soldiers (Swarbrick). A village style retirement living was developed for more independent elderly and older persons and more care homes for dependent persons. As regulations were put in place the quality of this care continued to improve (Swarbrick). 


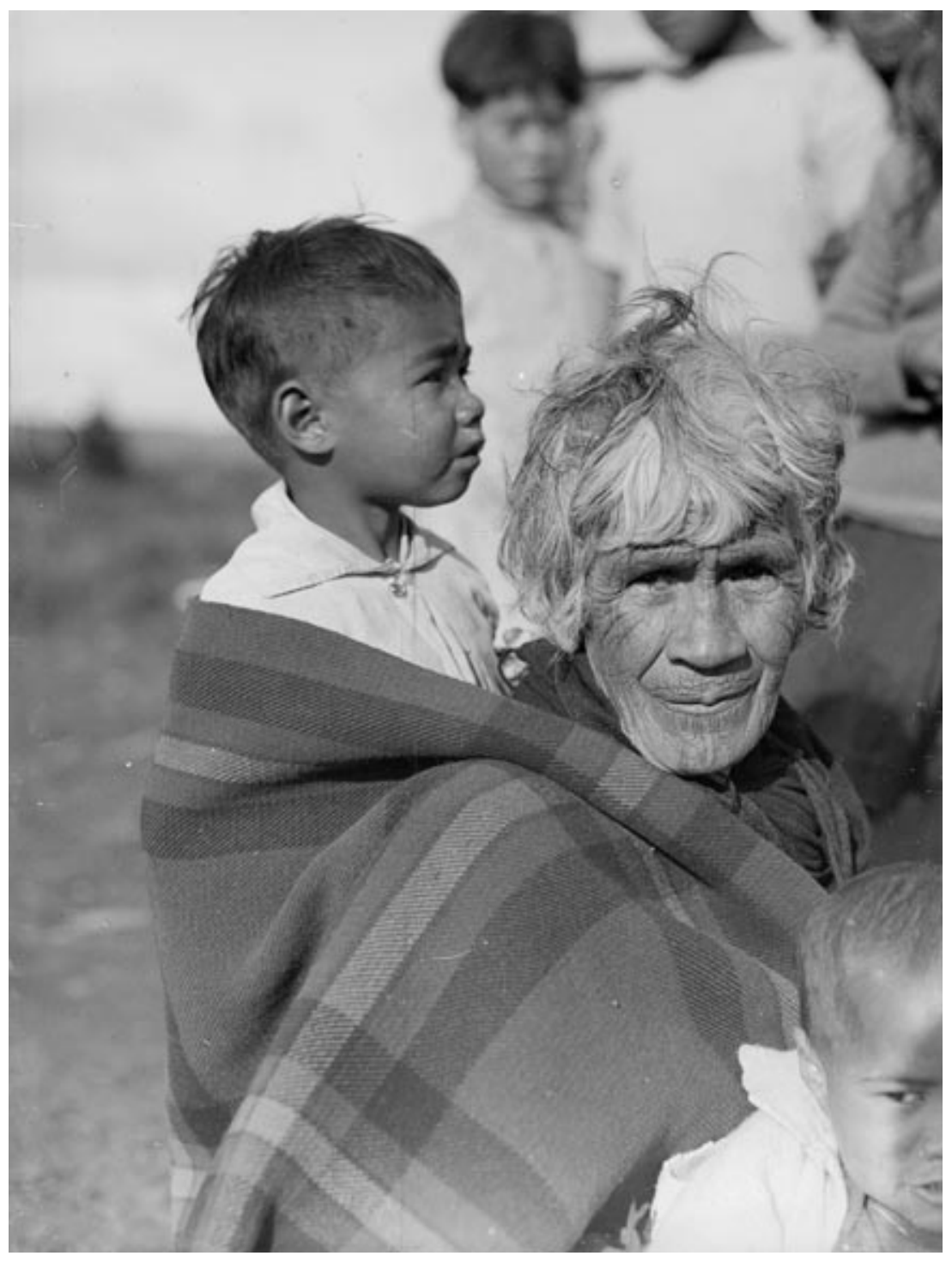

Fig. 1.1

Haehaeora Te Rangitakatu is shown here carrying her mokopuna (grandchild) on her back in 1948. Elders often played a significant role in raising their mokopuna. 
The New Zealand Planning Council's 1979 report on social welfare refers to the isolation of the aged population as one of a number of social problems that 'did not previously exist.' (Council, New Zealand Planning).

The autonomy of people going into residential care shifted from the state initiating these systems to help elderly with no other option, to the choice of the people, as the population evened out. Care homes became help for people who needed 24 hour care or whose families did not have the means to look after them. There leads to the issue of how much impact the elderly's adult children have on the decision for them to go into care. Establishing a negative connotation with care homes and the independence and autonomy elderly would lose in the process or choice to relocate their lives. Although thus is not always the case, it is a contributor in stopping people from considering alternate forms of housing as they age.

Elderly living in care homes arose from the necessity of looking after those who had no family to care for them. In modern times it is still a popular option for people who need care or are downsizing at some stage in their retirement. The 2013 census reports that $92 \%$ of older persons $(65+)$ live in private dwellings, with 59.3 percent aged 65-74 years, 31.0 percent aged 7584 years and 9.7 percent aged $85+$. Of those living in private dwellings $51 \%$ live in couple only households, $28.8 \%$ live alone and the remaining live with their adult children, other family or in mobile homes/ other forms of private accommodation. Those not living in private dwellings ( $8 \%$ of total $65+$ population) $88 \%$ are in residential care homes with the rest in hospitals or other forms of temporary accommodation (Zealand, 2013 Census QuickStats about people aged 65). Aged care has transformed the way older people are treated in New Zealand and even with far better management and regulations in the aged care industry there is still issues with the current means of care.

Looking forward, the next generation transitioning into retirement is the so named Baby Boomers, born between 1945 and 1964, post World War 2. The boom in this population means the number of older persons will be larger than ever before resulting in housing and care will become more of an issue. A shift in the approach to what housing will look like for these people is required for a number of reasons, including the fact that the baby boomers are far more independent and active than previous generations, and it is possible that they consider themselves more youthful than previous generations at the same age, and therefore will not be comfortable living in the stigmatised retirement homes or villages or aged care residences. This perception has developed from the history of what care homes meant for the people living in them, but even with the different typologies catered to different needs today, the stigma still surrounds these places. 


\section{Ageing in Traditional vs Western Societies}

In Jared Diamonds book The World Until Yesterday he compares traditional and western societies and their treatment of elderly as a means of understanding what we can learn about the ageing process and how to embrace it to improve the future of elderly care and perception. By traditional societies he is referring to "tribal societies, which constituted all human societies for most of human history, (which) are far more diverse than are our modern, recent, big societies."(Diamond, Jared. "How Societies Can Grow Old Better") Western societies are considered from an American perspective. In this comparison the ideas Diamond proposes will be applied to more relevant cultural contexts for a New Zealand study.

Diamond talks about the main difference between western and traditional societies as being the perception of ageing. The variation being, "the usefulness of old people and the society's values."(Diamond, Jared, How societies can grow old better, 212-214) In western society ageing is feared, it is perceived as a negative aspect of life and preventative measures are taken to avoid it. Where as in traditional societies ageing is embraced, it represents knowledge and power. In Papua New Guinea farming societies “older people are cared for. They are fed. They remain valuable. And they continue to live in the same hut or else in a nearby hut near their children, relatives and lifelong friends."(Diamond, Jared. "How Societies Can Grow Old Better" ) Their purpose shifts to that of childcare and passing on tradition. Diamond poses the Western society puts such importance on physical strength and independence that when those things deteriorate as we age, the perception of our worth deteriorates, and the elderly become a burden (Diamond, The World Until Yesterday, 212-214). This could be a cause for the delay in retirement we see today.

In China, Japan and Korea three quarters of elderly live with their adult children, with China having adopted a law in 2013 in which children are required to visit their elderly parents 'often' no matter how far away they live. This approach intends to remedy the distance felt between elderly and their adult children when they go into retirement and prevent loneliness (Diamond, Jared, How societies can grow old better, 212-214). The Elderly Rights Law is "hard to put this law into practice, but not impossible" as described by Zhang Yan Feng, a lawyer with Beijing's King \& Capital Law Firm (Hatton) and failure to abide can result in fines or jail time. This radical approach to combating loneliness in elderly has been debated but ultimately its purpose reflects a Chinese virtue of tending to elders spiritual needs (Wong). There is no information on the success of this new law on loneliness levels in Chinese elderly, however implementing the law has raised awareness of the issue- a refusal to accept changes from societies ideals they once upheld. 
The main difference, or issue, in how elderly are treated in non western societies compared to western societies derives from the perception of the value of aging. If older persons can retire in a place which facilitates their unique skills and allows them to explore the benefits of aging, a shift in the perception of their value can begin to happen.

To tie this into New Zealand's specific experience with their treatment and perception of elderly the comparison between Māori Kaumātua and New Zealand European elderly is explored. As described in the Ageing in New Zealand chapter kaumātua play an important role in the passing on of traditions and teaching mokopuna in their communities. Along with this comes the pressure of accepting such a role. Life for a prestigious elder could be considered busier than their middle aged life, this has changed over time with responsibility and willingness of Māori elders (Rawinia Higgins, 103). The prescription of a kaumātua role is one which historically would be willingly accepted however over time with a diminishing amount of knowledge being passed on and increasing pressure of responsibility and time that comes with the role there is a resistance (Rawinia Higgins, 103). A study Te Pumanawa Hauora done on 400 kaumātua in 1997 through Massey University assessed the cultural, social, economic and personal factors impacting their lives (Rawinia Higgins, 104). The study found that generally the elders were secure in their cultural identity and half reported very good or excellent health. A journal

\section{"Kaumātua measure good health not so.much by the presence of illness as, the capacity to participate.}


article by Massey University KAUMĀTAUTANGA Reciprocity: Māori Elderly and Whānau (Rawinia Higgins, 102), has compared this study with another done on 700 Māori households and found that positive self-assessment of the elders health is in contrast to the high levels of disability or ongoing medical treatment they experience. They suggest that "Kaumātua measure good health not so much by the presence of illness as the capacity to participate." (M.H.Durie) Their perception of good health is based on the activities they can still do and the interactions they can still have with whānau and hapu. A reflection of Maori society shifting its expectations put onto elders and reassigning appropriate roles to these people which value their worth and plan on their strengths.

Representation of different culture in aged care in New Zealand tells a story of the difference in the relationship to ageing within western New Zealand culture and other cultures in our society. The diagrams below show the over representation of Europeans in aged care facilities in New Zealand. This could be representative of the relationship white-western society has with its elderly. Stigma surrounding going into a care home comes from, in part, the loss of independence and autonomy of making the decision to move into one as stated in the Ageing in New Zealand section. However it can also develop from younger generation's attitude toward elderly. A study The Impact of Age Stereotypes on Self-perceptions of Aging Across the Adult Lifespan by Dana Kotter-
Grühn and Thomas M. Hess at Department of Psychology, North Carolina State University looks at stereotypes of people at different ages and their impact on negative, positive and neutral reactions to people of that demographic. This study looked at the opinions of adults 18-92 and were separated into three groups 18-35 - younger adults, 36-60 - middles aged adults and 61-92 - older adults. To gain a perspective on when these stereotypes begin to have an impact on self-worth (Dana Kotter-Grühn, Thomas M. Hess, 568-71).

"This study was primarily motivated by whether the activation of positive age stereotypes can foster positive self-perceptions of aging." (Dana KotterGrühn, Thomas M. Hess, 568)

Ultimately the study found that the exposure to negative and positive stereotypes did not negatively and positively change the way the participants viewed ageing or their experience with ageing in the middle age and older adult groups (Dana Kotter-Grühn, Thomas M. Hess, 568-71). However from this study we can see that from the younger adults group there is a clear bias toward a preference of looking younger "thus, already in young adulthood a bias toward a young physical appearance can be observed.” (Dana Kotter-Grühn, Thomas M. Hess, 568) Tying into ignoring bodily decline and preventing these stages of life.

This highlights where the issue derives, but little is 

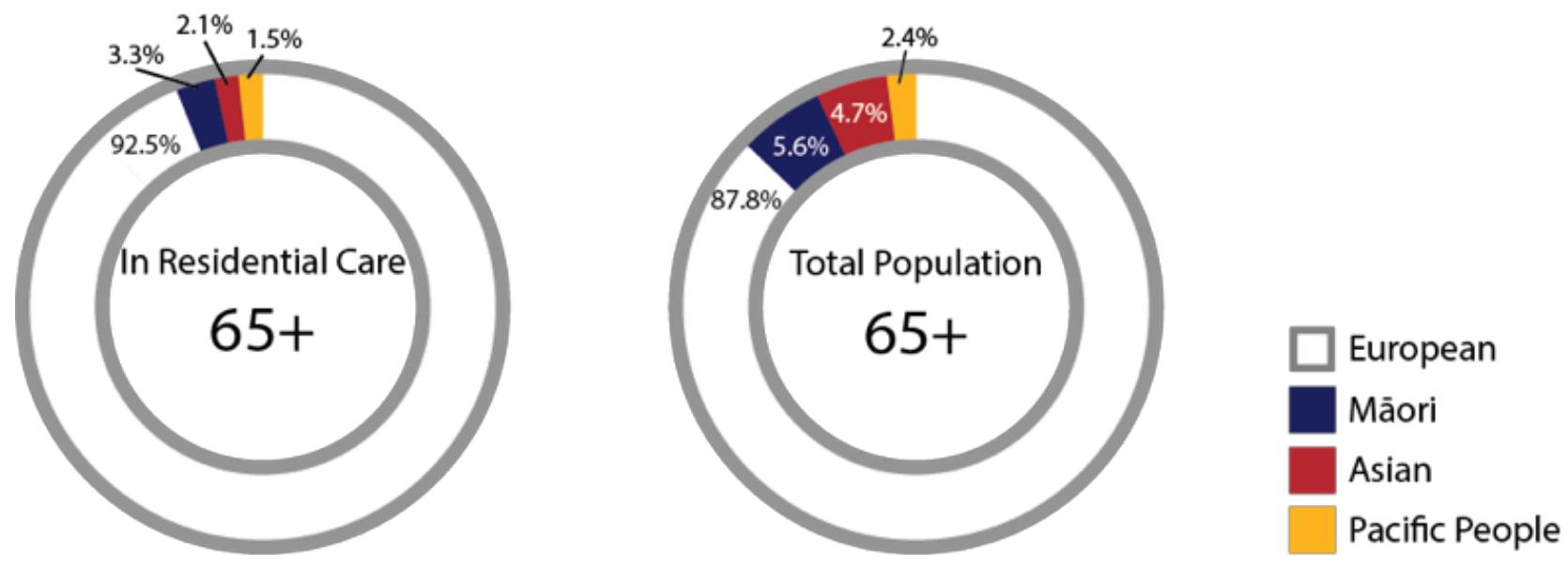

Fig. 1.2

Representation of New Zealand's largest ethnicities in aged care housing

vs, total percentage of these ethnicities in New Zealand's older persons

and elderly demographic

done to promote a positive reflection of ageing, and when positive portrayal of elderly stereotypes have little positive impact on elderly's self-perception or attitude towards ageing a more integrated approach for all demographics is needed.

\section{Loneliness and Social Isolation}

Loneliness is an issue facing many elderly and older persons in New Zealand, with 22\% saying they've felt lonely some or all of the time in a 2016 survey of people across the country (Statistics New Zealand, The Social Report). This issue has an impact on the mental, emotional and physical well being of the elderly and continues to be a leading issue in the support of our ageing population Julianne HoltLunstad, Timothy B Smith, 987). Loneliness is shared among every demographic however in the elderly is has a particular negative impact when coinciding with general health and mental deterioration as people age (Age UK, Loneliness and Isolation). This research is focusing on the impact and areas of lives that social isolation and loneliness effect in order to determine where solutions could encourage a preventative model of living for people before they become at risk of experiencing dangerous levels of loneliness.

The difference between loneliness and social isolation is subjective and objective. Loneliness is the gap between a persons desired level of social contact and their actual levels of social contact. It is the perceived quality of the person's relationships and the impact 


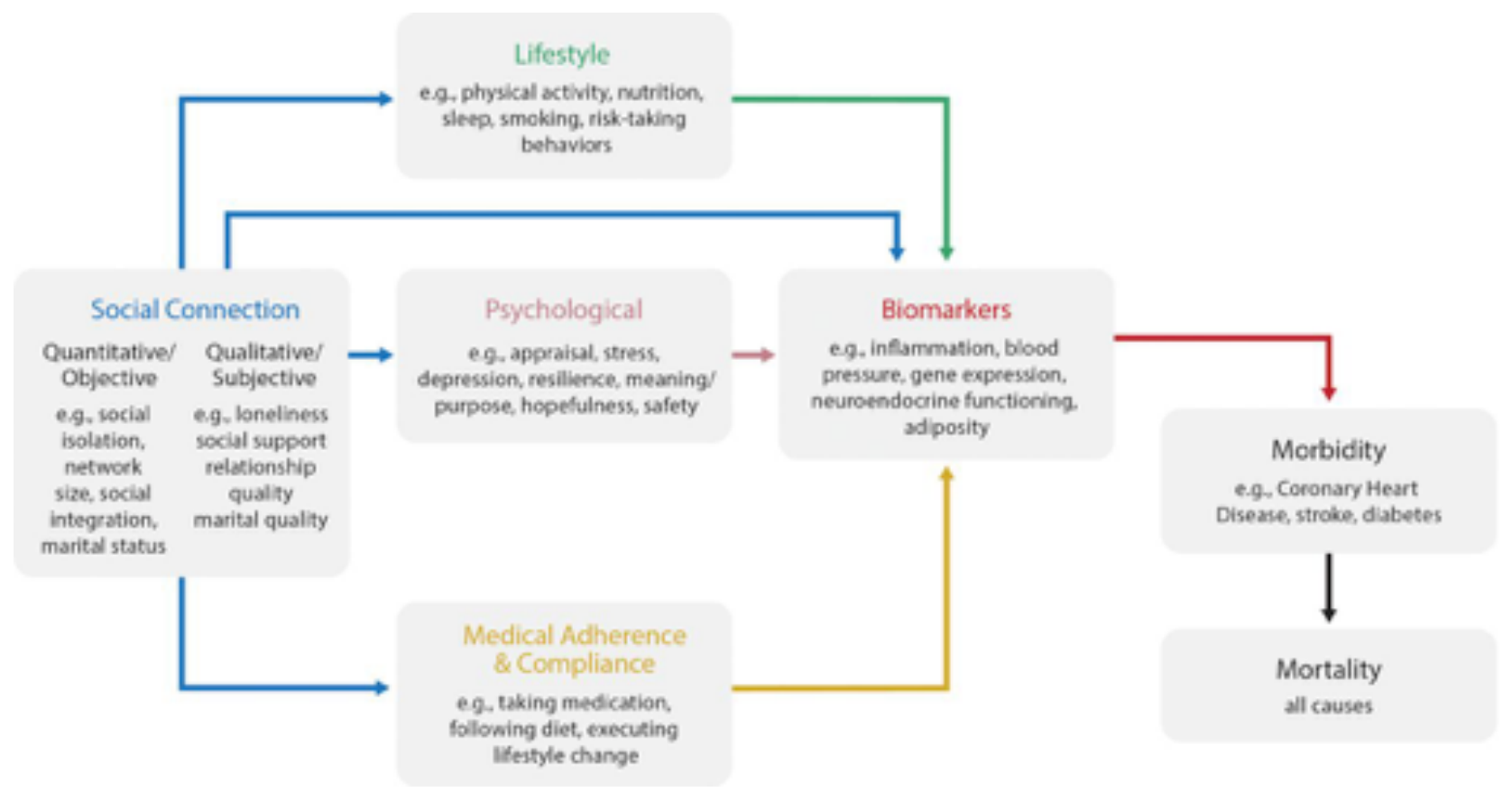

this has on an individual's emotional well being (Age

Fig. 1.3

UK, Loneliness and Isolation). It is very personal to

Diagram showing the progression of negative effects social issues each individual.

can have on elderly's physical and mental health. Architecture aims to improve psychological, lifestyle and medical.

Social isolation is the measure of contacts a person has, it is not about the quality but the quantity. Measuring that number of times and how long someone interacts with another human on a daily basis, regardless of the quality of that contact. People can be socially isolated but not feel high levels of loneliness (Care Connect). It is also far easier to remedy social isolation than loneliness, as a clear measure for loneliness is difficult to assess. A sense of community is important in people's lives in order to reduce social isolation, having an obligation in a community to take care of and check on others allows at risk individuals to interact readily.

The architectural issue relates more to social isolation, a solution to an objective problem of designing spaces where more interactions could be facilitated. Social isolation (or lack thereof) has a relationship with loneliness, the quality of relationships and a person's subjective feelings are not measurable, however they can be impacted through design experiments enforcing interaction and public versus private space. This diagram above18 was developed by Dr Julianne Holt-Lunstad at Brigham Young University, USA 
in a study looking at the effects loneliness has on cardiovascular disease in elderly. It outlines issues that affect the development of loneliness and isolation in elderly. The first topic Social Connection considers the issues in which this research aims to address, to be a preventative tool in reducing the risk of flow on lifestyle, psychological and health risks.

A Ministry of Social Development survey in 2016 found that $12.5 \%$ of those aged $75+$ reported feeling lonely all, most or some of the time during the last four weeks (Statistic New Zealand, The Social Report). This trend is seen around the world and confirms the need for preventative measures to be taken in how people live as they age in order to reduce these numbers.

Designing in an area with dense activity, particularly with different age groups, can encourage the contact elderly have with others. Sharing spaces where activities are occurring facilitates new experiences for the elderly. As a design issue, this allows the exploration of how architecture can complement social interaction and encourage positive behaviours.

\section{Ageing in Place}

"Aging in place is ambiguous. It is a complex process, not merely about attachment to a particular home but where the older person is continually reintegrating with places and renegotiating meanings and identity in the face of dynamic landscapes of social, political, cultural, and personal change." (Janine L. Wiles, 358)
This description of ageing in place sets up the context for what is important and will be explored within this topic

In 2016, 300 New Zealanders aged 56-92 were interviewed and participated in focus groups to gain clarity on the concept of ageing in place and help answer the question 'What is the ideal place to grow older?’ (Janine L. Wiles, 357).

The study found these results:

Aging in place was defined as "remaining living in the community, with some level of independence, rather than in residential care"(Davey, Nana, de Joux, \& Arcus, 2004, p. 133).

It was found to be a larger focus than people just wanting to remain living in their homes. A sense of place focuses on the people, the services and reliability of those in the community (Janine L. Wiles, 357). The familiarity of people and the environment are what makes it attractive to those looking at retirement housing options. It is tied to a sense of identity, independence and autonomy.

A key idea that arose from the participatory studies with older persons was that, ageing in place is the sense of community and family that encourages older people to feel comfortable and looked after. Loss of such connections is a main deterrent to moving or retiring elsewhere. This ties into the importance of the quality and kind of relationships they form, even later in life (Janine L. Wiles, 357-366). 


\section{Intergenerational Interaction}

Social interaction is an important part of life as people age, with fewer friends and family these connections made with others provide support and understanding. There are many differentimportant relationships elderly have, that with their adult children and grandchildren (if they have them), with peers and neighbours, with those in care with them (if applicable) however more casual relationships do not occur as often. Such as that between university students and elderly that are not related.

"The moral health of a socrety is plainly visible in the reay it treats its most yulnerable members, especially the aged.

(Harris, Johanna)
Connections with children is particularly helpful. Play benefits all ages, from children to older adults, and is essential to well-being. Both younger and older people benefit in four main areas this type of intergenerational interaction; Social- verbal and nonverbal communication skills and working as a team, Psychological/ Emotional- nurturing and having feelings heard, expressing feeling and self-esteem or pride when completing a task, Physical- exercising motor skills and Cognitive- staying on task and learning new skills (Graves, 42-49). According to research the inclusion of facilitating intergenerational play into a housing typology catered toward older persons suggests a positive impact on their well being through the interactions (Graves Lindsay, Davis Elizabeth, Larkin Stephen B.). The ability to teach and learn as well as the consistency of social interaction are all benefits. This type of interaction has been successfully tested with preschool aged children. Downshall 


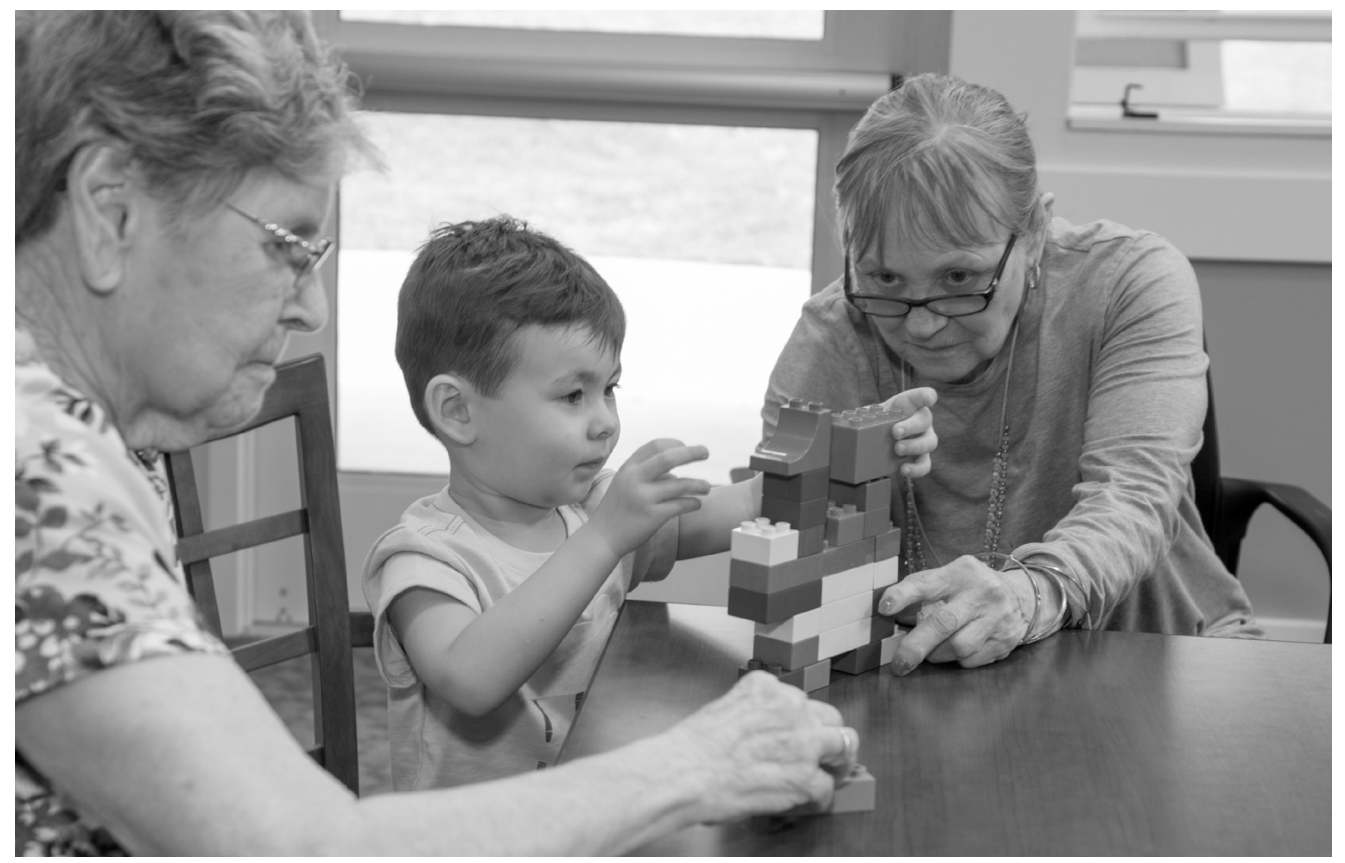

Fig. 1.4

Two older persons playing with a student visiting Northpointe Christian

Schools, Grand Rapids.

Primary school in Essex, UK hosts a day centre where local elderly come and interact with the children. Using the idea of cognitive stimulation therapy the elderly are stimulated with interaction and activities and the pupils $87 \%$ of which speak English as a second language gain confidence and communication skills (Weale, Sally). This interactions impacts as described by the aged care staff as that of giving them a sense of authority and something to look forward too. This program was designed by consultant psychiatrist Dr David Hinchcliffe and includes elderly who have experienced depression or are at risk of becoming socially isolated. "Social interventions are a valuable part of someone's treatment, along with the biological and psychological interventions. Post-recovery they are helpful in reducing social isolation, loneliness and a risk of relapse." (Weale, Sally) The benefits for the children include "positive changes in perceptions and attitudes about older people, increased self- confidence, better behaviour in school, increased selfmanagement skills and higher standardised reading test scores." (Weale, Sally) This is part of a movement in England called United for all Ages, their concern is with bringing people of all ages together in every community to learn and grow while tackling issues around ageism and care.

Residential and Care Centre Humanitas in Holland is an aged care facility which offers free accommodation to university students in return of companionship for the elderly residents (Harris, Johanna).

"Saying hello, sharing a joke, bringing fish from the market: It's the little joys of everyday life that the students bring to the seniors at Humanitas." Jansen, Tiffany R.) This model of housing provides an incentive for university students and ensures elderly are maintaining social interaction and engaging in new 
activities and conversations.

With other aged care facilities in Holland and across Europe following this precedent, the positive impact of intergenerational interaction is beginning to be implemented in a permanent and inclusive way to change the impact loneliness has on elderly.

\section{Summary}

This literature review discusses a range of topics within the realm of aged care and housing for elderly. Forming an architectural response based on the provided context allows an improvement in the health and social well being of elderly and older persons.

This history of aged care housing in New Zealand established that these housing models, being originally established for dependent elderly and being pushed out to the suburbs, contributes to the perception of this housing being negative and stigmatised, despite the advances in aged care housing for different levels of dependency.

The usefulness of elderly is something that is will utilised in many cultures, but largely ignored in western society. Attributes such as childcare, knowledge, teaching and storytelling are all things, which can emphasised to increase the elderly's sense of purpose and can be better incorporated into modern aged care to reduce the stigma around dependency and loss of autonomy.
The physical and mental effect of loneliness and social isolation effect everyone differently, but undoubtedly have a negative impact over time. The quality of interactions, although immeasurable, is an important aspect to combating the effects of this. Providing opportunities to form new connections or facilitate incidental ones will aid in reducing the impact of loneliness and social isolation.

The definition of ageing in place is varied and dependent on the individual, but one key finding from the research into this topic is the importance of community. Whether it's establishing a new one or retaining an existing one, this sense of community allows a safety and an acceptance or involvement for elderly, which is important in them retaining independence.

The last topic looked at intergenerational interaction and the positive impacts that these interactions can have on all age groups. The main finding being the benefits of intergenerational living, in a structured environment with benefits outside of those when interacting, such as the university students having free rent at an aged care facility. This type of housing model encourages residents to engage in interactions, even if they do not initially understand the benefits.

These topics have set up a foundation from which the research can built upon and gives an idea of the types of precedents that tackle similar issues within aged care housing. 
These key principles were derived from the literature review as elements which will contribute to a better ageing experience for older persons and elderly. 

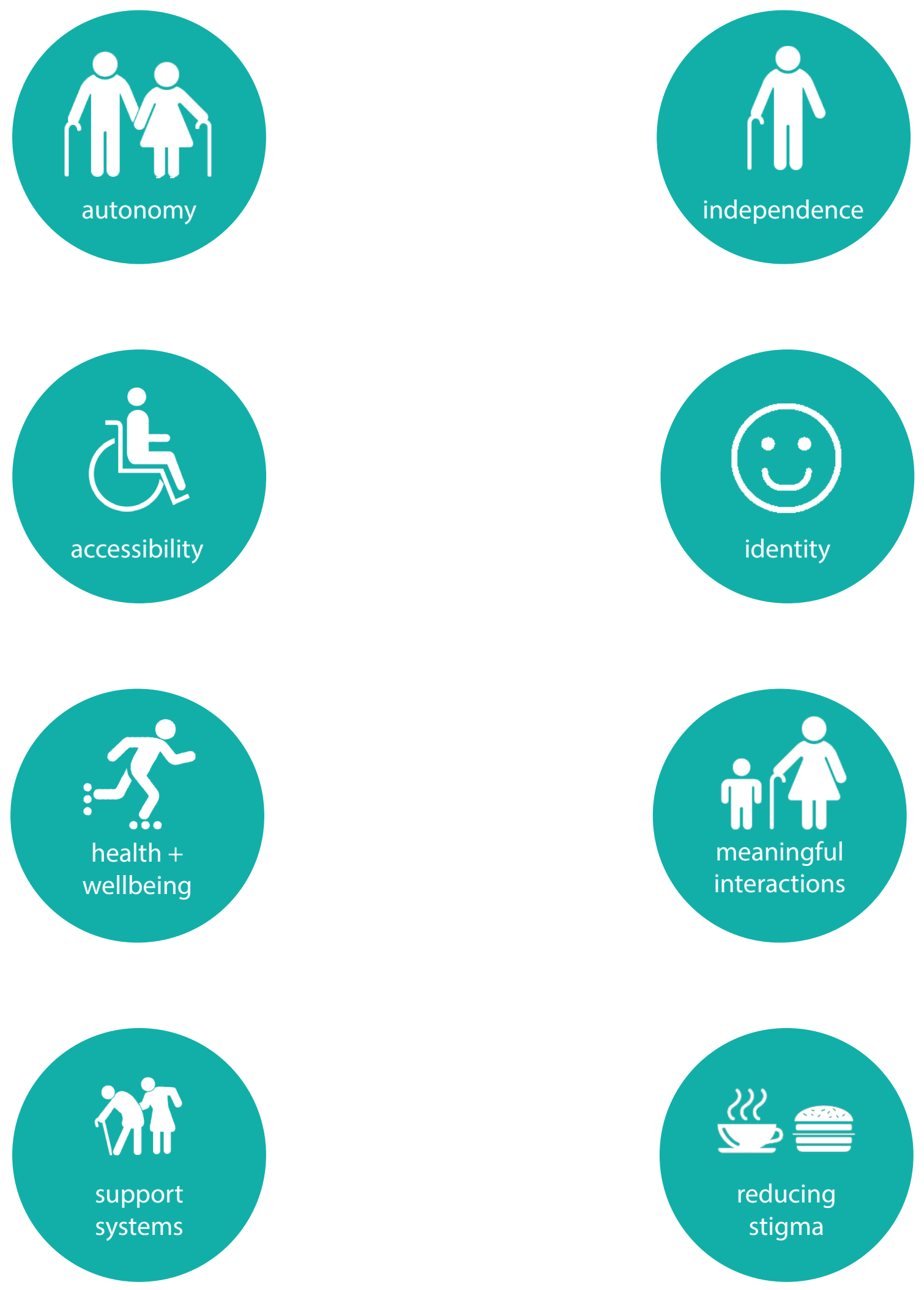


\section{Project Review}

The projects being reviewed in this research is split into three categories, Aged Housing, Co-Housing and Urban Housing. Each model is examined to see what it offers towards healthy, positive housing for older persons. 


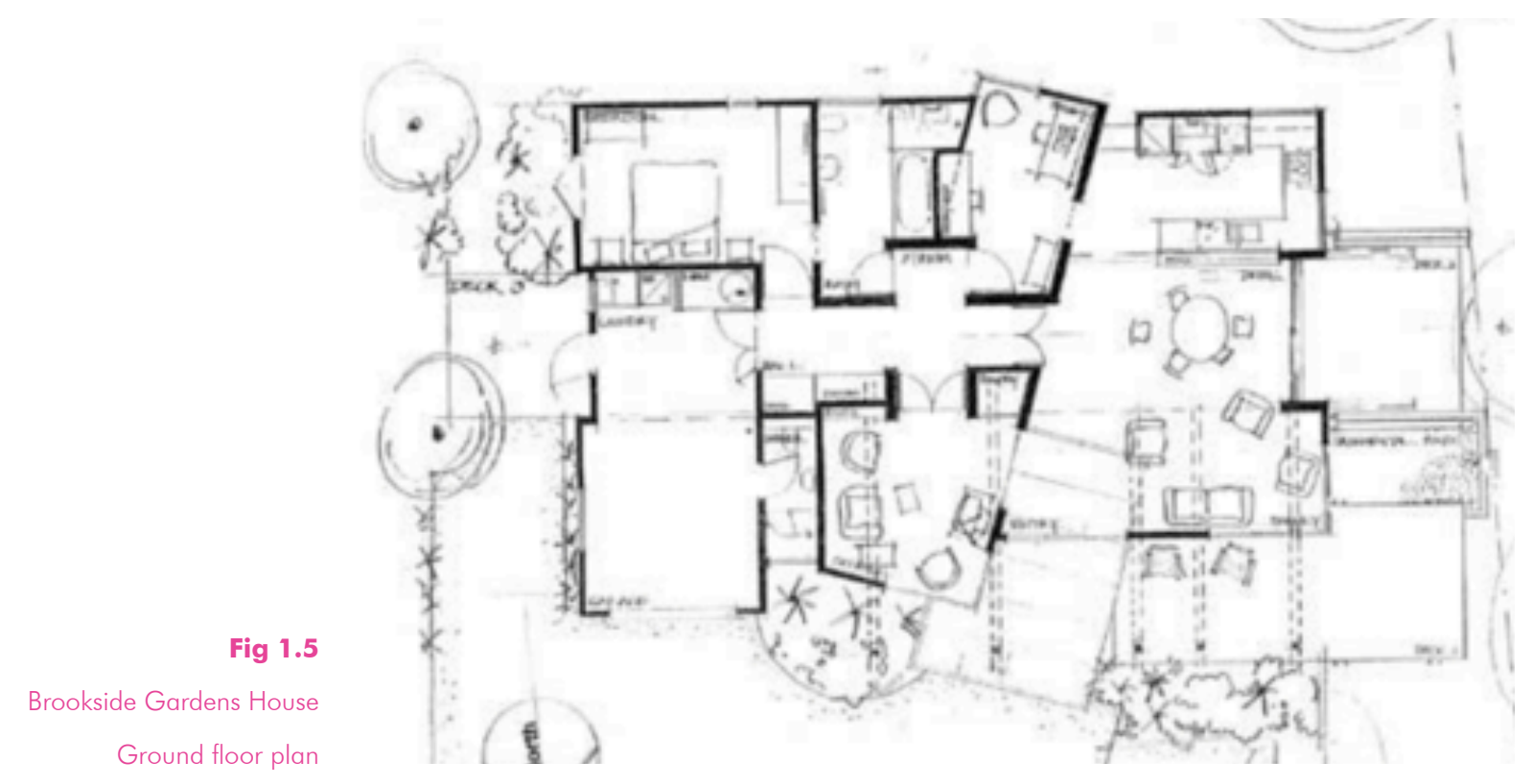

\section{Aged Care Housing}

Brookside Gardens House, Red Design Architects, Nelson, New Zealand, 2004

This is a low-density residential project designed for an elderly couple. It changes the perception that "Some architects and developers might regard mobilityfriendly design as an impediment to good architecture, since it may signal the residents' age and physical status." (Mark Taylor, Laurie Buys, 58) However with a new younger owner living in the dwelling, there was no compromise to the elegance or perception of the house. An adaptive nature is achieved through; well integrated ramps, stairs and modern materials (Mark Taylor, Laurie Buys, 57-59).

"The surveys and charrettes found that 'participants preferred low to medium density housing with walkable access to public transport and human scale

shops and services within an age-diverse community." (Mark Taylor, Laurie Buys, 59)

The adaptability of this house comes from the planning, instead of widening doors and hallways the open plan allows a free flow through all common spaces as well as providing audio and visual connections throughout for safety.

Minimising traffic flow through the building through circulation routes, planning to minimise distances between essential journeys, visual communication between main areas of the dwelling are beneficial design elements which can be combined with bench heights and seating types for further accessible design (Mark Taylor, Laurie Buys, 57-59). This project proves the ability to design age appropriate housing in a way that is comfortable and suitable for all ages, without highlighting accessibility requirements as temporary additions and DIY elements. 


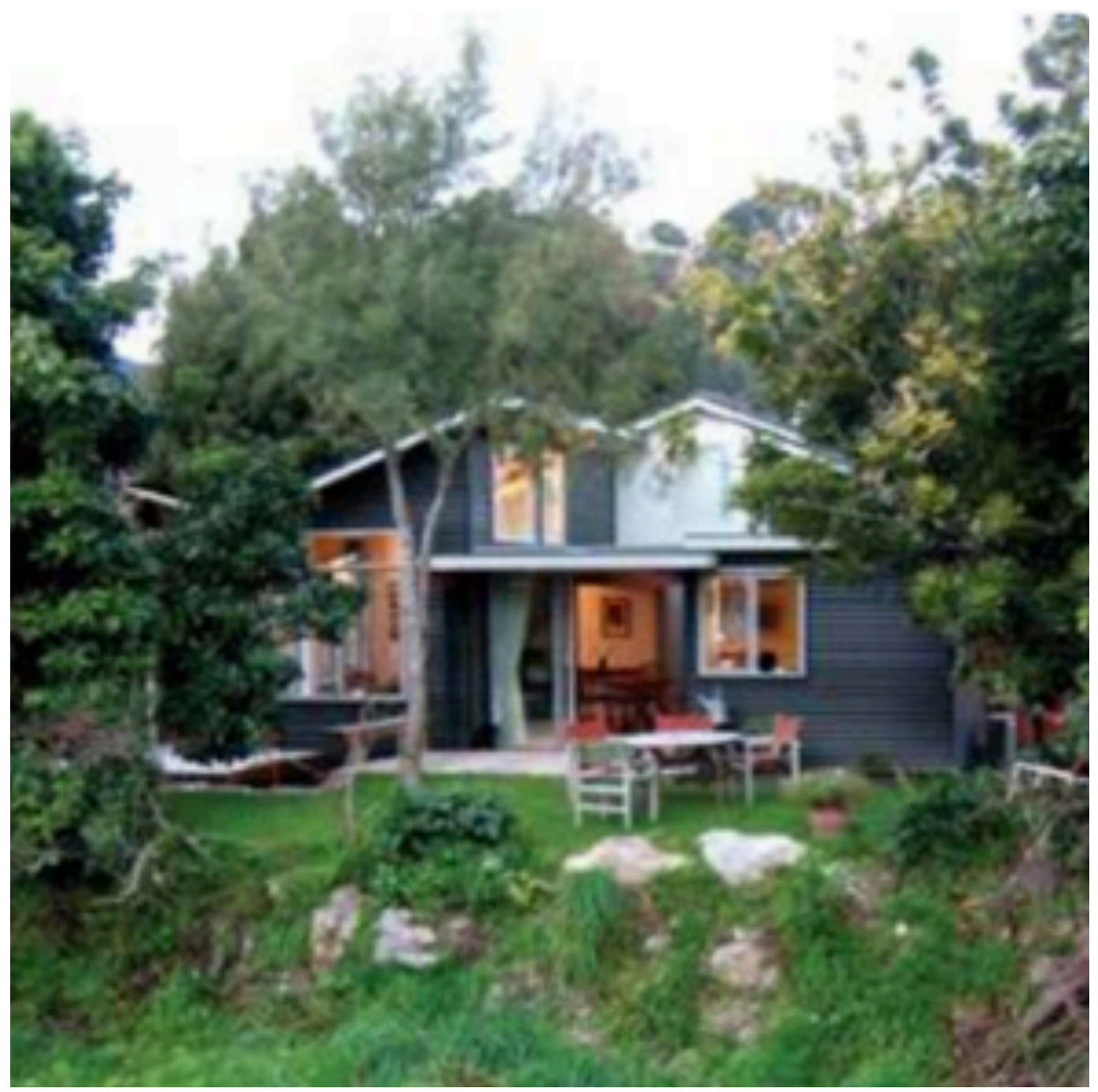

Fig. 1.6

Brookside Gardens House, front entrance 


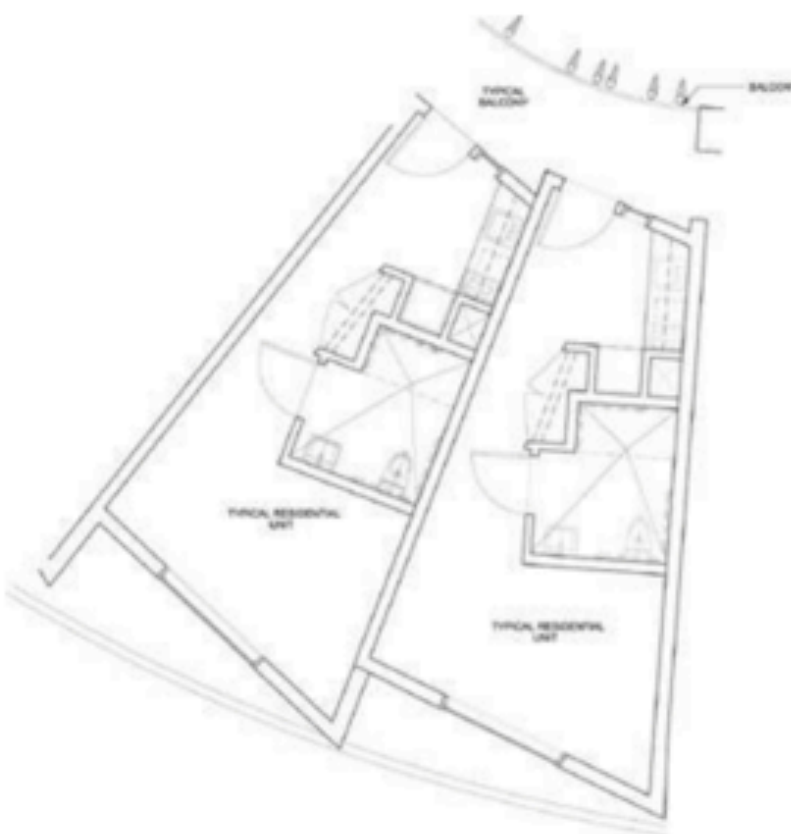

Fig. 1.7

New Carver Apartments, example apartment plan

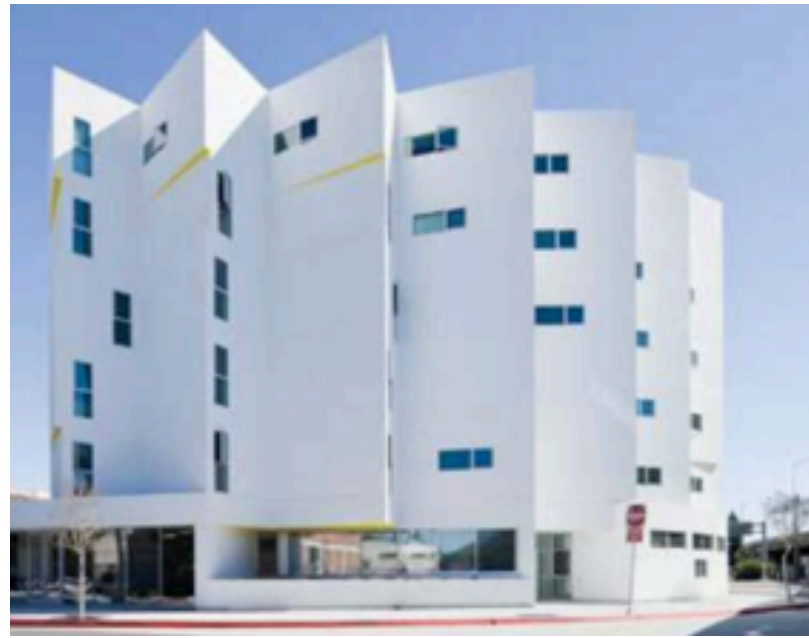

Fig. 1.8

New Carver Apartments, exterior

New Carver Apartments designed by Michael

Maltzan Architecture in Los Angeles.

This apartment building has 97 units for formerly homeless elderly and disabled residents (Maltzan, Michael).

"By incorporating communal spaces - kitchens, dining areas, gathering spaces and gardens - into the Carver's raised form, as well as medical and social service support facilities into the plinth beneath, the project encourages its residents to reconnect not only with each other, but also with the world outside its doors." (Maltzan, Michael).

This building houses individuals who are already stigmatised by society, in their later years of life.

The importance of 'active' in elderly/ older persons lives and how this building celebrates the within the shared courtyard and the playful exterior form.

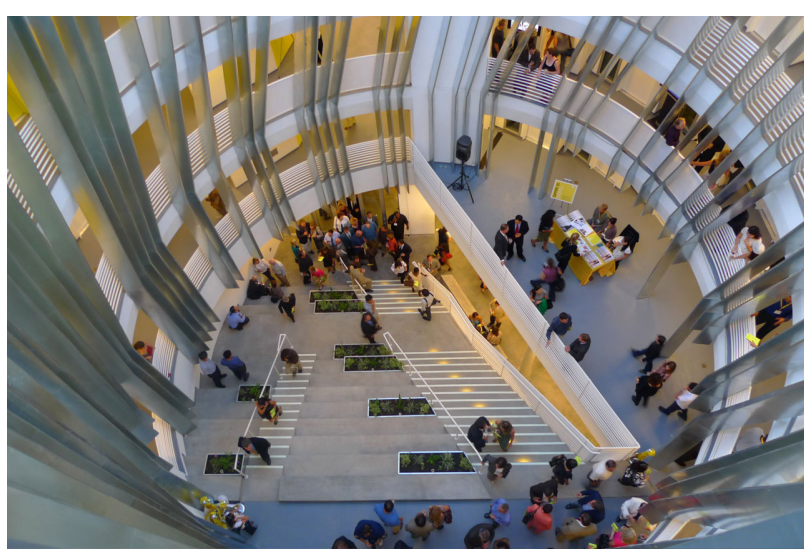

Fig. 1.9

New Carver Apartments, atrium space 
Elderly Residential Home, Paris, by architects Atelier Zündel Cristea

This elderly residential home in Paris is merged with a preschool. The childcare is located on ground floor with elderly residential on the floors above. The inset orange floor in the centre of the vertical façade is designated as shared/mixed-use space for the preschool and elderly residents (Cristea, Atelier Zündel). This integrates the functions throughout the building while retaining privacy and adequate separation. The interior of this building uses coloured walls and floors to navigate the space and recognise shared, circulation and private spaces (Cristea, Atelier Zündel). This is a visual cue, which benefits both the young and old occupants through recognition techniques and sensory engagement/ stimulation. Although this building is not designed for independent living by definition it is still pushing away from the 'village' rhetoric that aged care frequently uses which holds value in their separateness and can be isolating. This facility, by engaging multiple generations, is reducing that isolation.

These Aged Care Housing precedents highlight some important issues for elderly and older persons which architecture can either reduce or contribute too. Having simple and clear circulation pathways with the use of colours for recognition and defining spaces can allow elderly to navigate the building more easily. This research also raised an issue of residents having to more between models of care depending on age of type of aid required. This puts not only financial stress on residents but creates a culture of ignoring and hiding the ageing process as to remain in their current living situation. Creating a housing model which can fluctuate with residents growing needs and level of care they require (instead of defining a criteria to reside there) will be an asset in allowing independence to elderly and older persons for a long period of time.

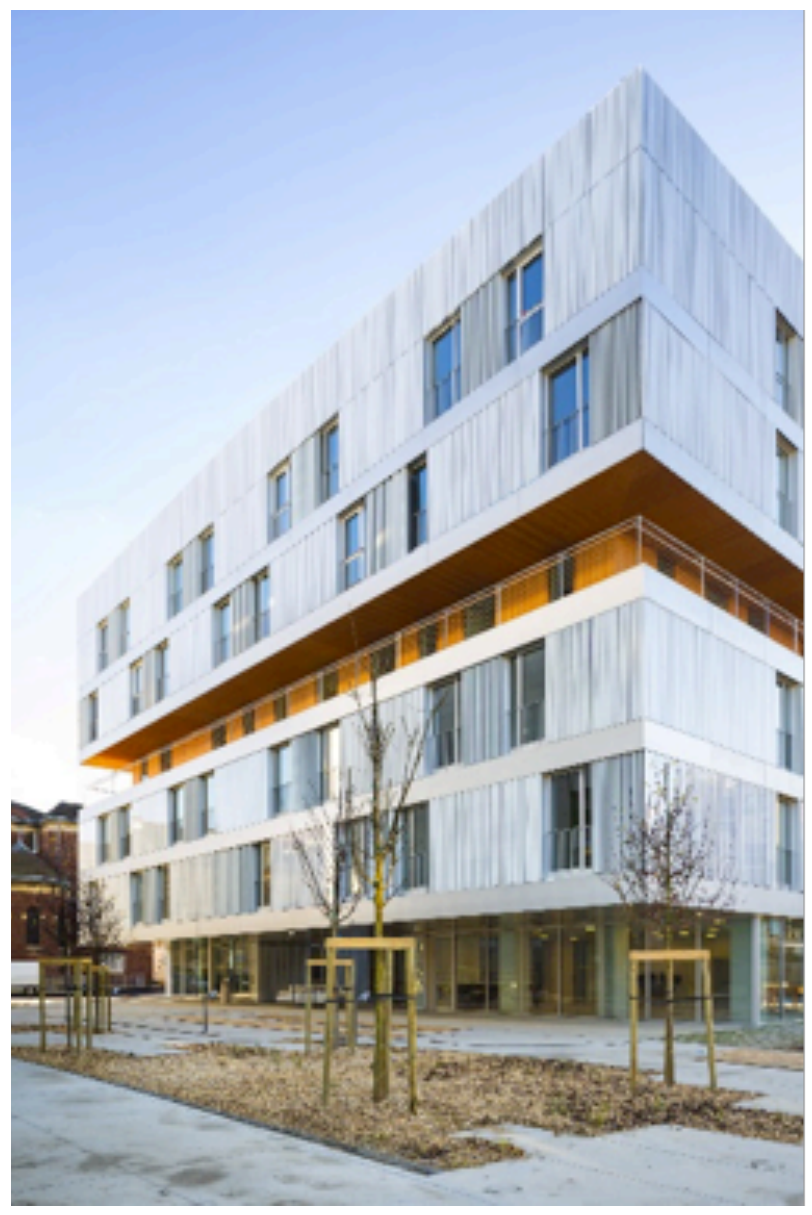

Fig. 1.10

Elderly Residential Home, exterior 


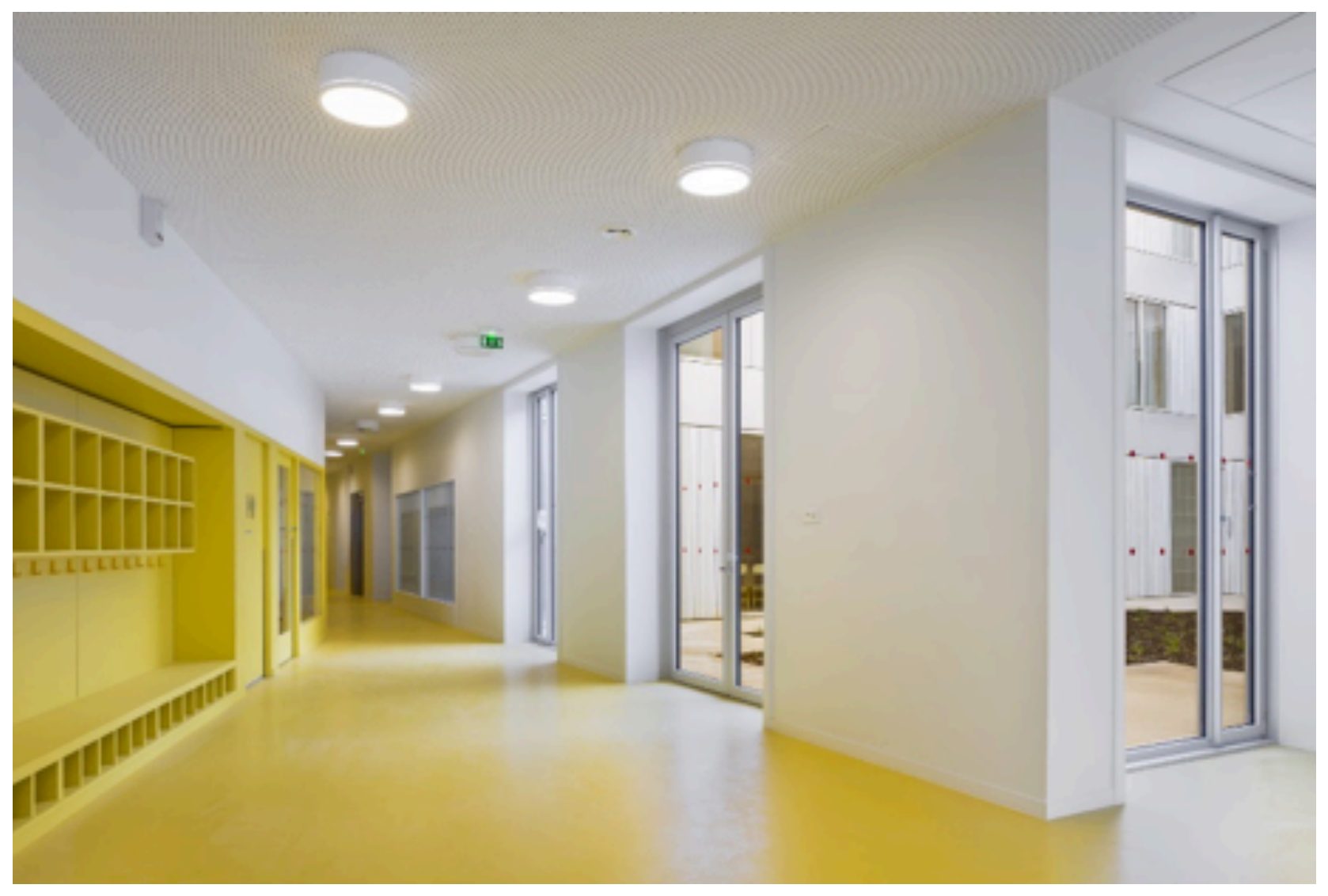

Fig 1.11

Elderly Residential Home, Internal circulation space with yellow floors and walls for clear recognition and differentiation of space. 


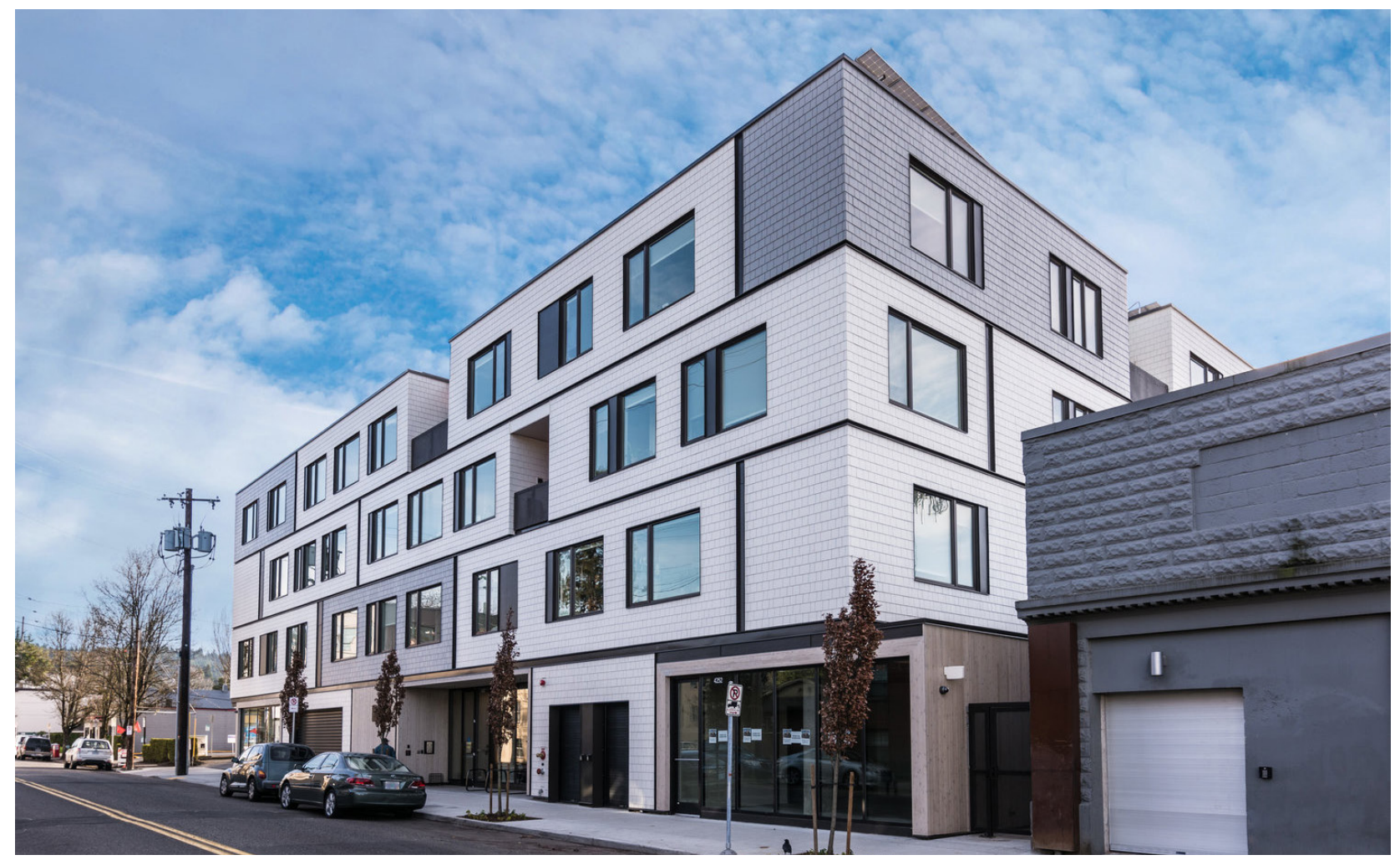

Fig. 1.12

PDX Commons, street view.

\section{Co-Housing}

PDX Commons- Works Progress Architecture

Another larger scale of co-housing is PDX Commons in Portland Oregon. This community was set up by its residents and owned/ operated by its 55-80 year old occupants. The design is $\mathrm{U}$ shaped apartments around an open central courtyard- similar to most co-housing developments. With common facilities only the fourth edge this allows visual connection to the other residents and provides passive surveillance (States, The Cohousing Association of the United). The flexibility of having guests stay begins to implement some of the benefits of intergenerational activity.
The residents in this development pride themselves in being independent and living autonomously into their old age (States, The Cohousing Association of the United). The building itself, from the street reads as an urban housing block, not noticeably designed for seniors. The establishment of community within a space such as this helps with the determinants of how old/ dependent someone gets as to them needing to move on to higher level care. There is still some questions around how the residents moving on would be enforced which still letting them retain their autonomy- is that possible? 


\section{Abbeyfield Retirement Housing}

Abbeyfield retirement housing is currently the only model of co-housing for mainly older persons in New Zealand. It is low-density affordable accommodation for independent elderly located in sub urban areas. Residents are typically between 65 and 75 . With 17 of these facilities currently in New Zealand, they are growing in popularity (Abbeyfield). This proves a want for people in suburban areas to have alternate aged housing options and a positive attitude to ageing in place. These apartments are designed with furniture and bench heights, suitable to a range of needs (Abbeyfield). One critique is the age limit set on occupation in these units arising some issues around autonomy and defining how old is too old to live independently when in reality every person will be different. There is a grey area of ageing v. bodily decline in which these models of aged care housing are not successfully accommodating for.

Abbeyfield housing has meals provided on site, however all other duties are the responsibility of the residents (Abbeyfield).

There are different levels of independence people can have within co-housing models that take it from being more of a retirement village typology with on site nurses to a fully independent co housing model of separate units for individuals or couples and shared spaces. Rules or restrictions around age or mobility/ decline which would make an individual no longer eligible for this type of accommodation feeds into the stigmatisation of ageing and bodily decline. Creating an environment in which people live in denial and try to hide decline or health needs out of either embarrassment or financial strain in moving / relocating.

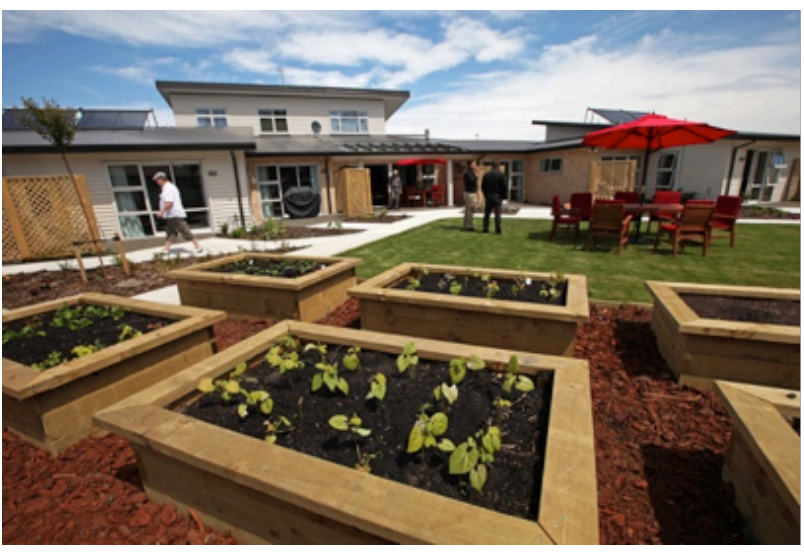

Fig. 1.13

Abbeyfield courtyard vegetable garden

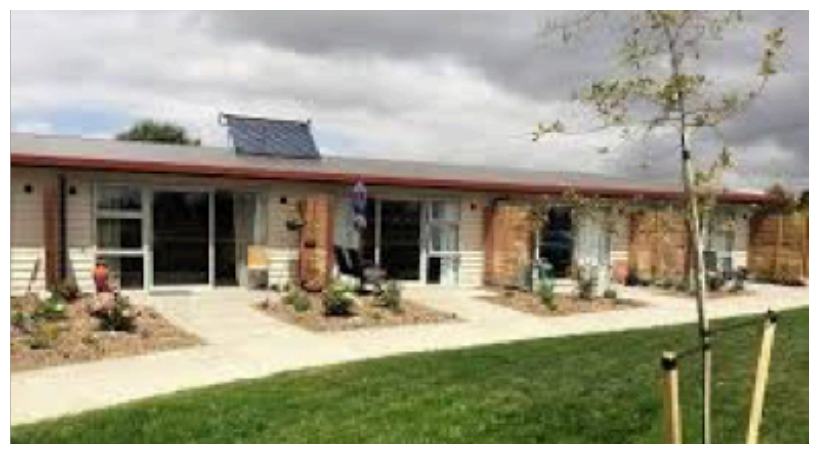

Fig. 1.14

Abbeyfield apartment porches 


\section{Common House-Grace Kim of Schemata Workshop}

This Seattle Washington example of co-housing outlines the benefits intergenerational living can have. The design process recognised the importance of residents forming a community they desired good design alone is not enough "priority (is) given to building social cohesion among residents during the design and construction process." (Kim, Grace) There is a focus on longevity of home ownership and therefore community. "We have very intentionally re-defined the commonly held value of the home as investment commodity, instead prioritising the longevity of the community" (Kim, Grace) The residents who occupy this residential development had input into the design and construction of it, forming relationships and strategising from before they moved in helped in establishing their unique community.

"The construction of the community will nurture both the individual and the family" (Kim, Grace).

The ground floor occupies the architecture practiceschemata workshop- in which some residents own/ work (Kim, Grace). Having employment for residents on ground floor can bring a sense of closeness faster with more programmed interactions. Having common cooking and laundry facilities forces people to interact in a more incidental manor. As well as balconies overlooking common spaces and visual connections between apartment living spaces.

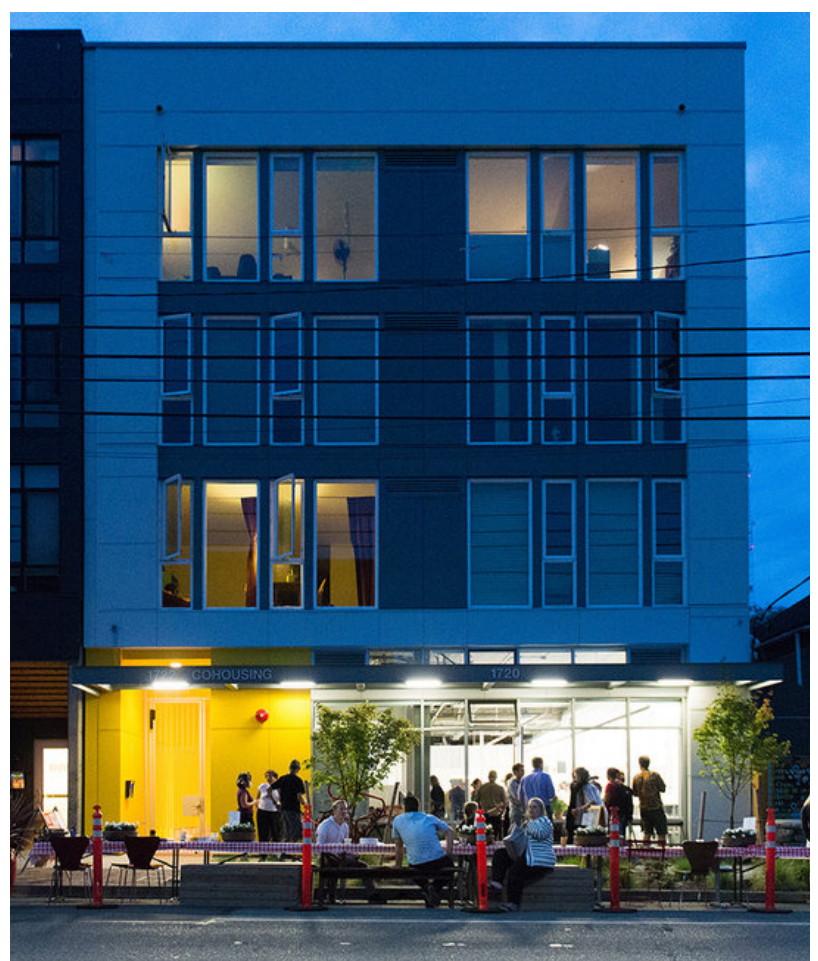

Fig. 1.15

Common House exterior

These Co-Housing precedents evoke qualities of community and intergenerational living which this research investigation aims to provide. The use of passive surveillance, resident activities in shared spaces and a level of visual connection between apartments all contribute to a functioning co-housing model. 


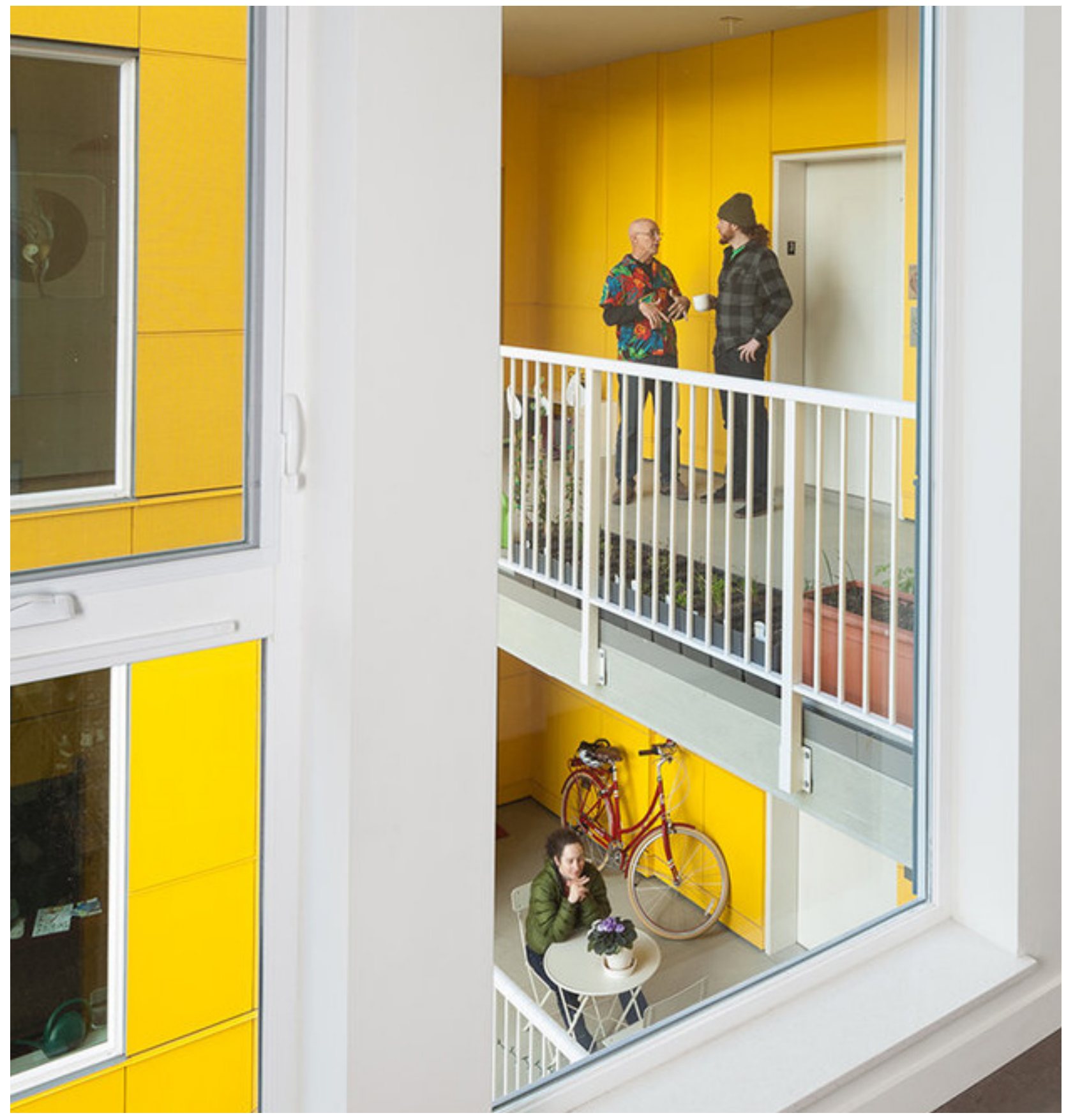

Fig. 1.16

Common House residents interact on different floors circulation 


\section{Urban Housing}

Via Verde (the Green Way), 2012, Bronx NY, Dattner Architects with Grimshaw architects.

This housing complex creates an intergenerational community through an urban housing model with carefully considered shared space design (Dattner Architects, Grimshaw). Via Verde combines rental and owned properties, with single studios to three bedroom apartments for anyone including seniors living alone or with families. Their public plaza accommodates farmers markets and community events which integrate well into the urban context as they directly serve the needs of the surrounding community (Dattner Architects, Grimshaw).

The design has differentiating typologies for groups of tenants with different needs and family sizes (Dattner Architects, Grimshaw).

The use of outdoor circulation and roof space as communal area opens up more areas of interaction under different conditions, serving all different functions. The circulation also travels down the seven floors of the building into the shared courtyard, allowing a sense of journey through the space. The stairs have leisure and access size thread and depth to allow dwelling and movement simultaneously.

The design merges the surrounding low-rise neighbourhood with other high-density housing in the area through the form 'stepping' towards the lower density (Dattner Architects, Grimshaw). Being a bridge between typologies the need for differentiation in function, especially at ground level, becomes clear. This project has a medical centre and pharmacy, convenient for residents but also a beneficial community facility.

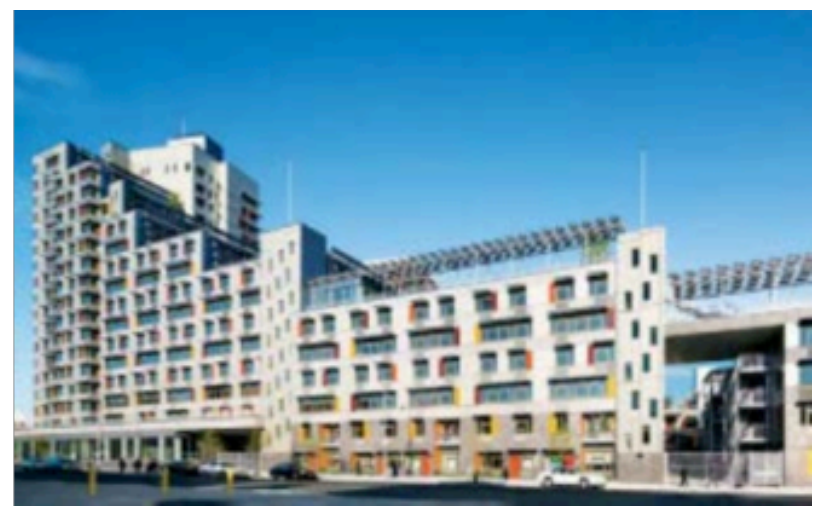

Fig. 1.17

Via Verde exterior

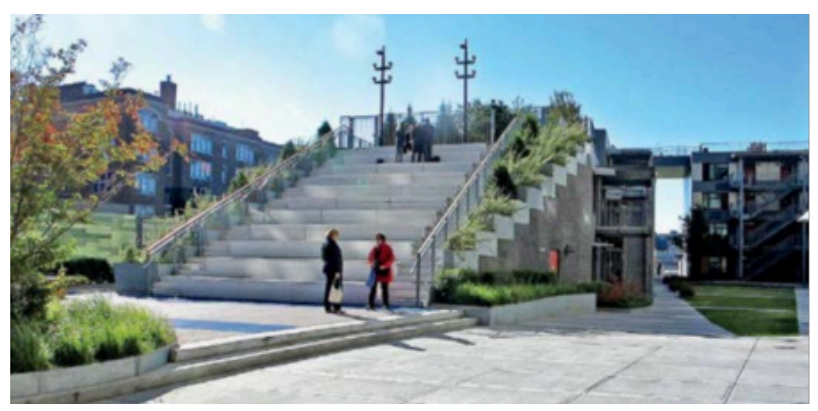

Fig. 1.18

Via Verde external circulation steps 


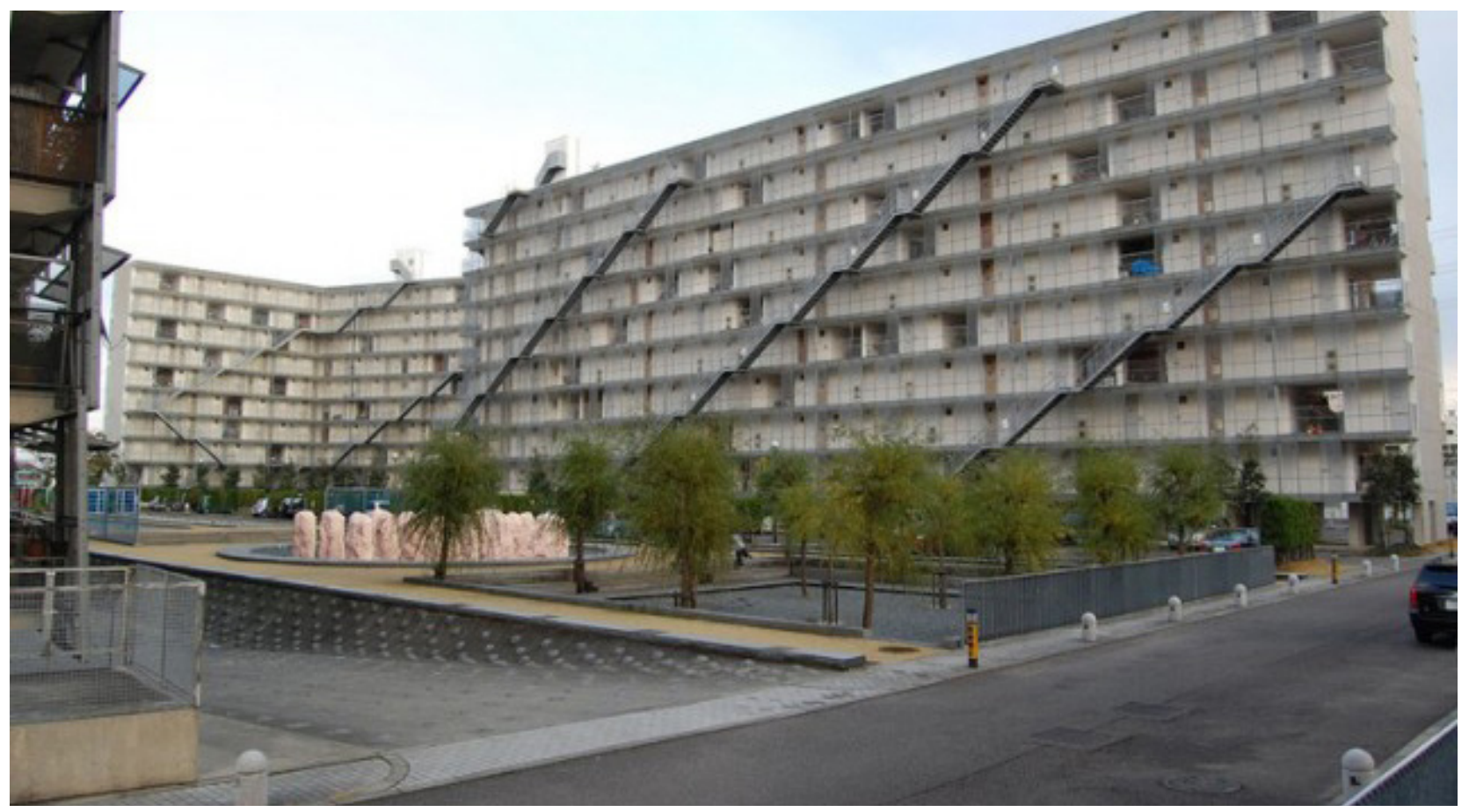

Fig. 1.19

Kitagata Apartments, SAANA, Japan

Kitagata Apartments facade

This high density urban housing block is one of four developments, each from different architecture firms, in this block. This development focuses on the configuration of apartments and rooms based on resident needs (Lenk, James).

There are voids through the gridded façade which allow light and natural ventilation into more of the apartments, as well as creating pockets for residents to dwell and interact (Lenk, James). The external stairs (accompanied by two internal lifts) place an emphasis on the use of the circulation. Placed specifically to serve a set number of apartments the stairs become a defining feature of the façade.

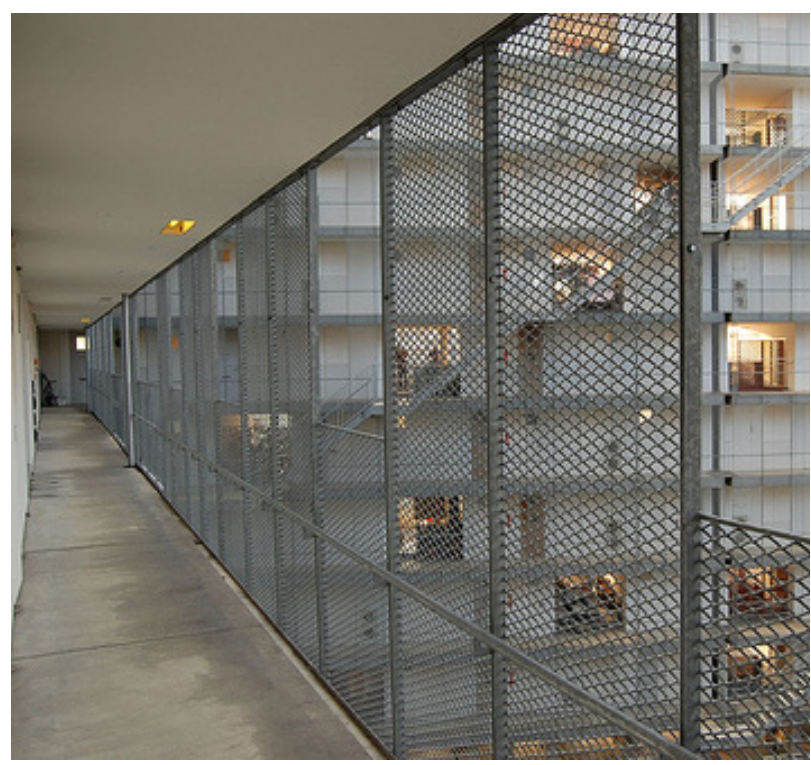

Fig. 1.20

Double heights spaces in apartments open up the tights dimensions in plan. 


\section{Residential Building- In Street Symphony.}

Gruposp Architects. Sao Paulo 2008

This residential development in Brazil has a heavy focus on circulation, both in its function and as a design feature (Alvaro Puntoni, João Sodré, Jonathan Davies). Ground floor courtyard- landscaped to remain open and emphasise the empty space between the buildings. Bridges change the ground floor height and allow the under croft space to hold vegetation (Alvaro Puntoni, João Sodré, Jonathan Davies). Both residential blocks "offer multiple forms of occupation, according to the life needs of its users" (Alvaro Puntoni, João Sodré, Jonathan Davies). Although not specifically catered towards an older demographic the acknowledgement of adaptive needs and uses remains the same as the basis of the research investigation.

The external circulation horizontal and vertical are described as "the space of meeting and co-existence" (Alvaro Puntoni, João Sodré, Jonathan Davies). With its stand out red colour, these areas are emphasised and celebrated in the architecture of the building.

These urban housing precedents highlight the importance in social space and healthy circulation. The use of internal and external circulation, having it a feature of the architecture indicates a priority of movement and accessibility to its residents.

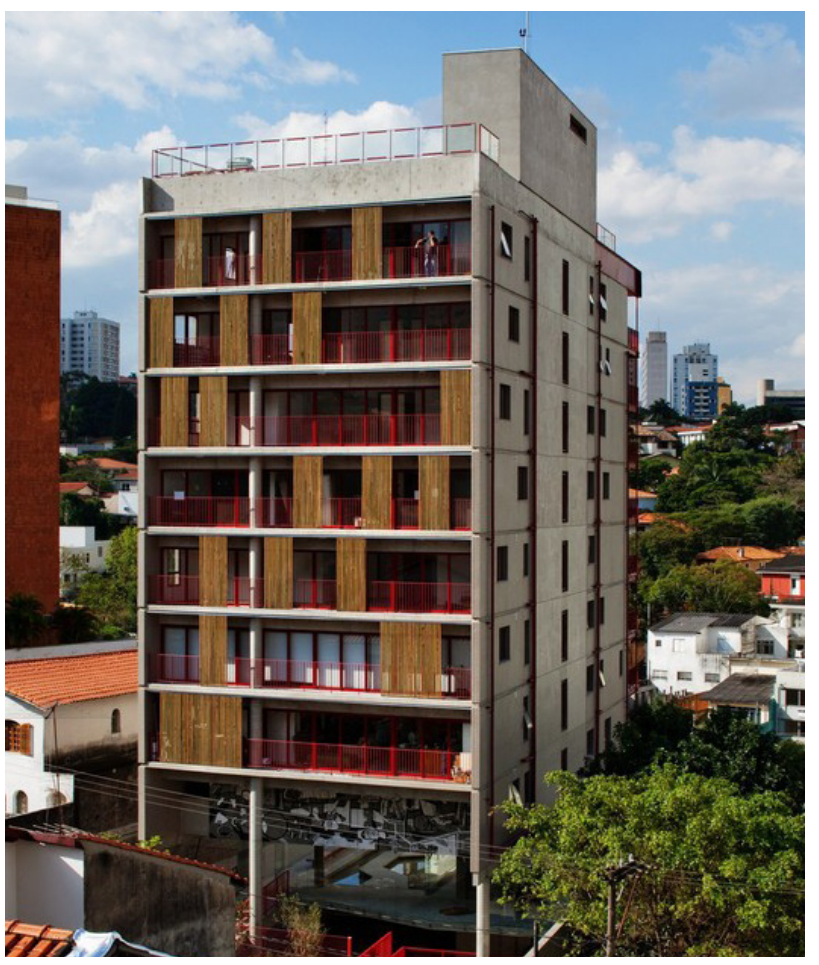

Fig. 1.21

Residential Building exterior

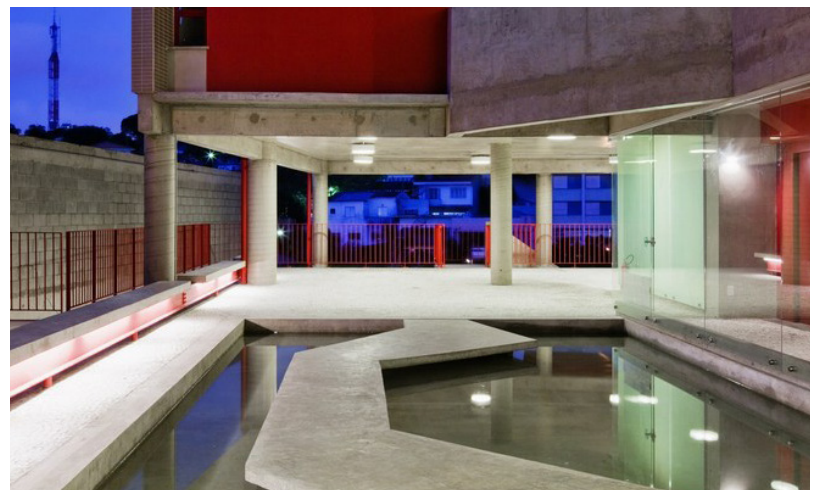

Fig. 1.22

Residential Building ground floor pathways 


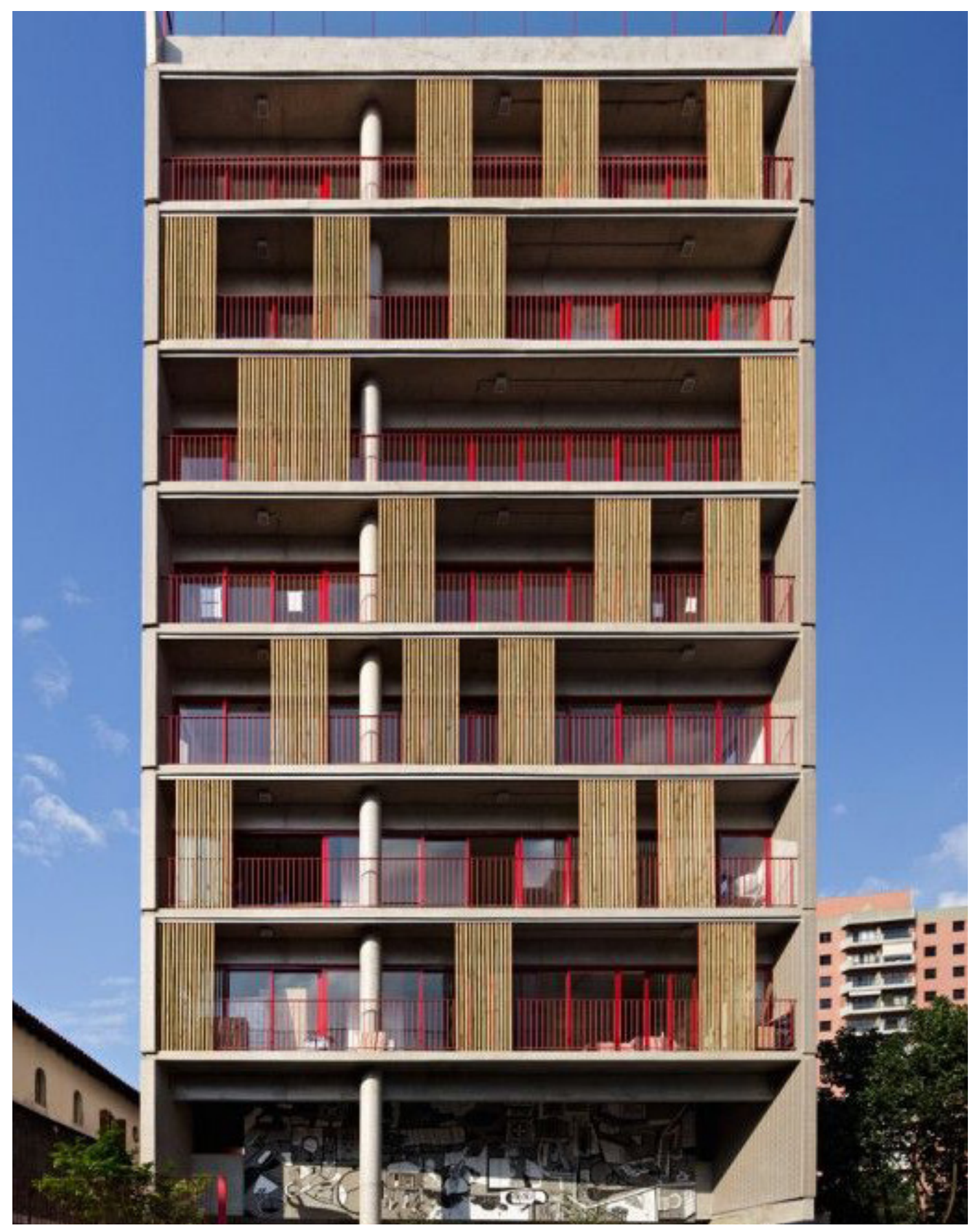

Fig. 1.23

Residential Building exterior highlighting the red balustrades and privacy screening 


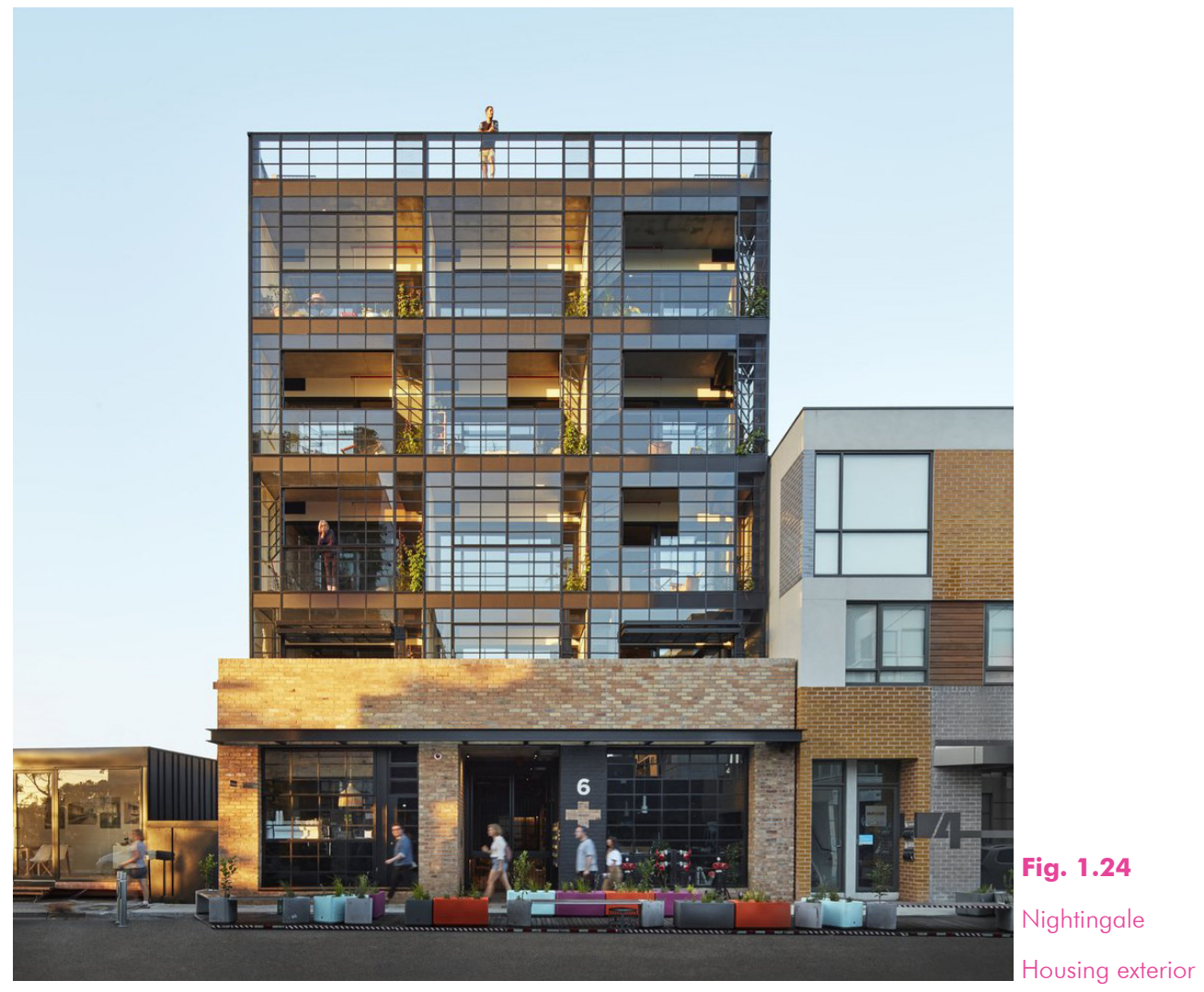

Nightingale Housing, Breathe Architecture. Melbourne

Nightingale 1, 2014, is the first of its type to interpret the German concept of Baugruppe - meaning building group (HOUSING, NIGHTINGALE). This type of residential design focuses on community oriented living, in consultation with the clients; this building was designed to their specific needs and wants as a group. The main principles of this type of design is sustainability in materials, environmental impact and social interaction (Papers, Assemble).

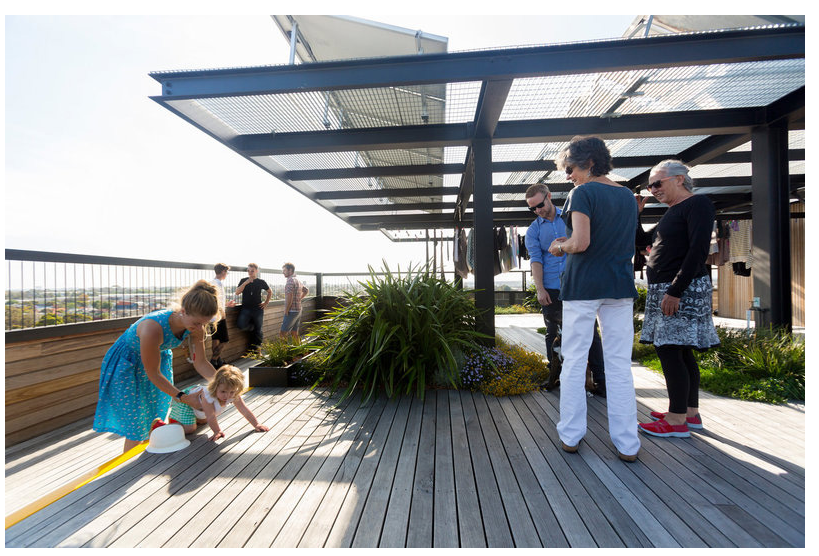

Fig. 1.25

Nightingale Housing, rooftop garden

This building facilitates incidental interaction between residents through its shared spaces, particularly the roof top garden that has a communal garden, washing areas and barbecue area. 


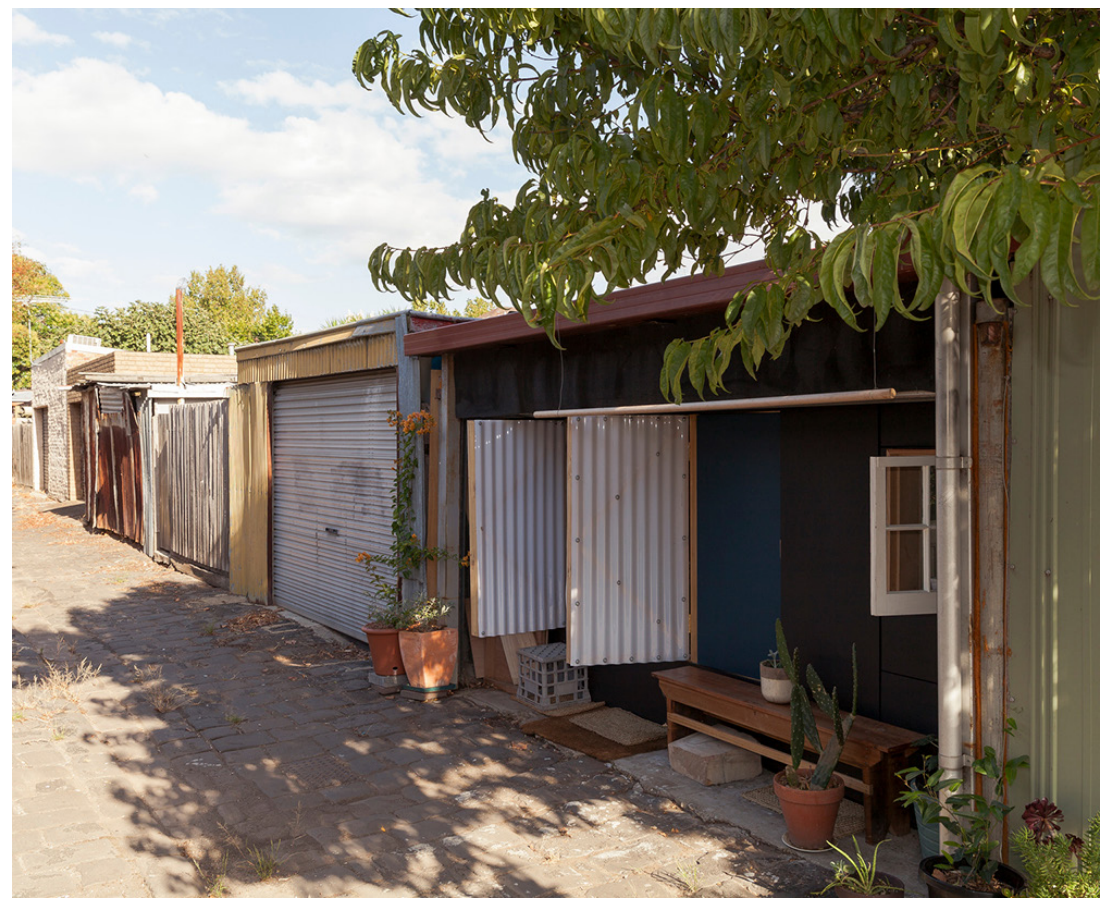

Fig. 1.26

Backyard Bungalow,

Backyard Bungalow- Murray Barker - Melbourne

Murray Barkers backyard bungalow is a garage adaptation which backs into rear lane. The design opens up the bedroom to the street and allows an interaction with passers-by (Papers, Assemble, Backyard Bungalows).

"Screening and shuttering can filter the level of engagement between public and private" (Papers, Assemble, Backyard Bungalows).

Shutters made from translucent polycarbonate open up to the lane fully or close to provide privacy (Papers, Assemble, Backyard Bungalows).

Simple bench with pot plants at road edge opens up a conversation of programmatic flexibility at street level.

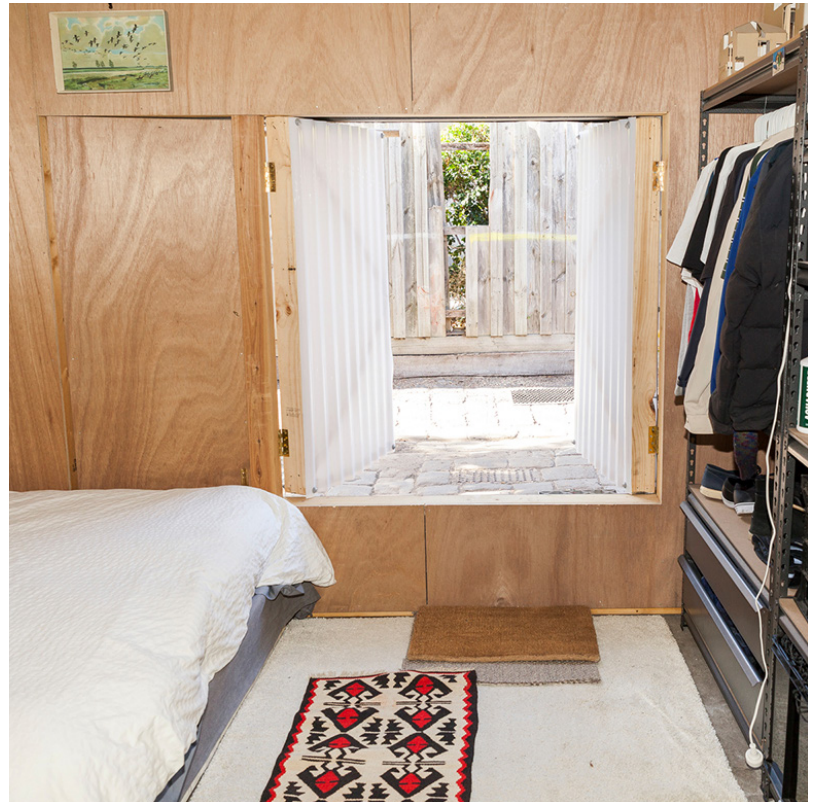

Fig. 1.27

Backyard Bungalow, interior view to street while remaining public. 


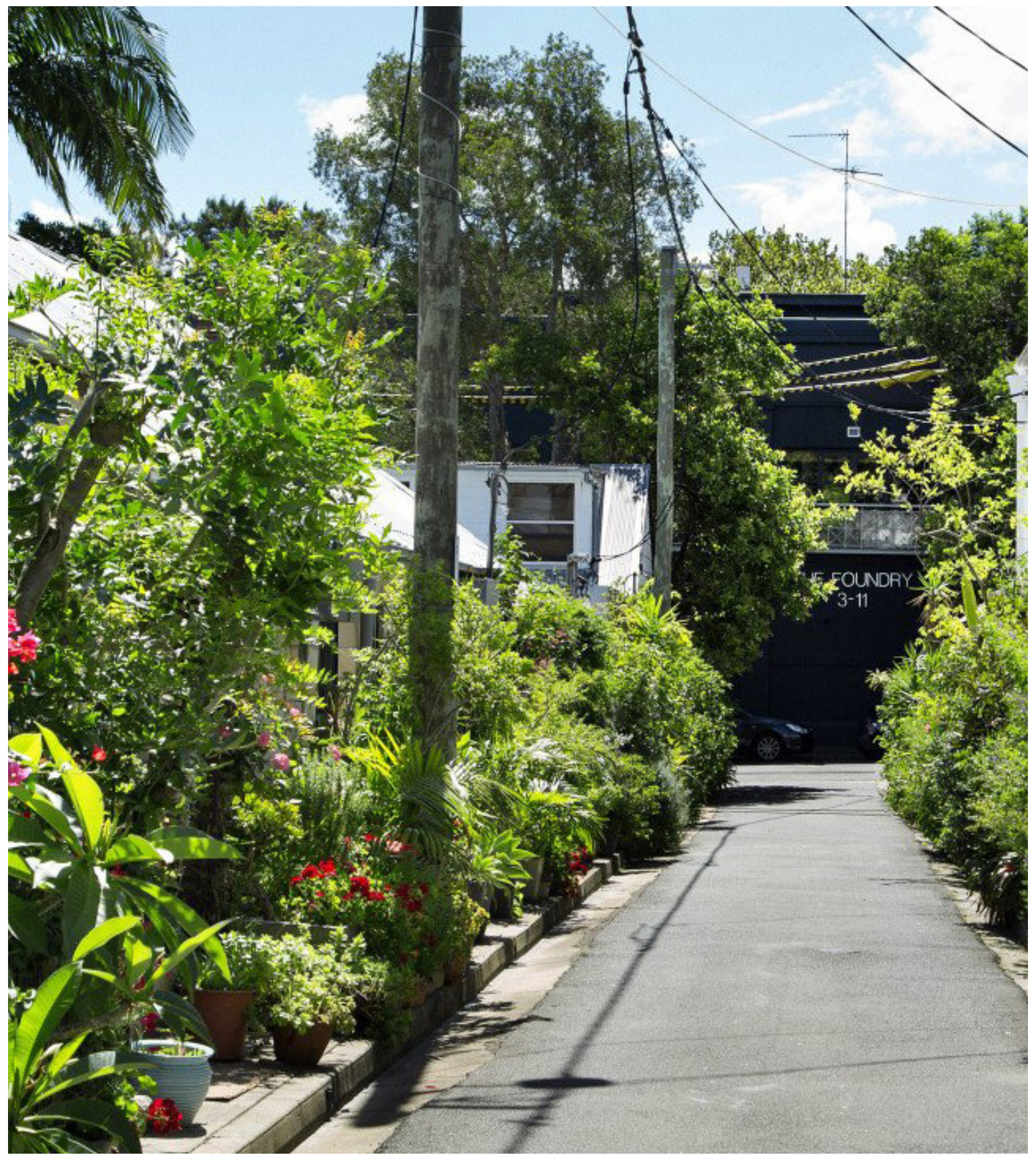

Fig. 1.28

Cat Alley 
Cat Alley- McElhone Place, Surry Hills, Sydney

Cat Alley celebrates incidental interaction through a community movement to make their shared street an occupyable and enjoyable space. Through each houses contribution to the green street, plants fill the edges with seats creating pockets where residents can enjoy the sun in a more vibrant and comfortable urban space (Reid, Georgina).

"Incorporating accessible and engaging green spaces into the most inner realms of our inner cities has to happen" (Reid, Georgina).

This type of community led development is made possible by individuals, local governments and developer led initiatives (Reid, Georgina).

"We don't have backyards. The street is our backyard." -Charlotte Roy - resident (Reid, Georgina).

Metaphor of non-human life around us- "living doesn't just happen behind closed doors but communally, on the street, in the garden, in shared living spaces" (Reid, Georgina).
The act of doing in this common space, whether it is gardening, re-potting after winter or sitting out for a coffee becomes a communal event and gives a richness to an urban environment.

Although this example of engaging people in the act of gardening caters more toward certain age groups or people who have the time, the premise of everyone accepting a sense of responsibility and working together for a better experience of their shared space is a quality this design aims to achieve.

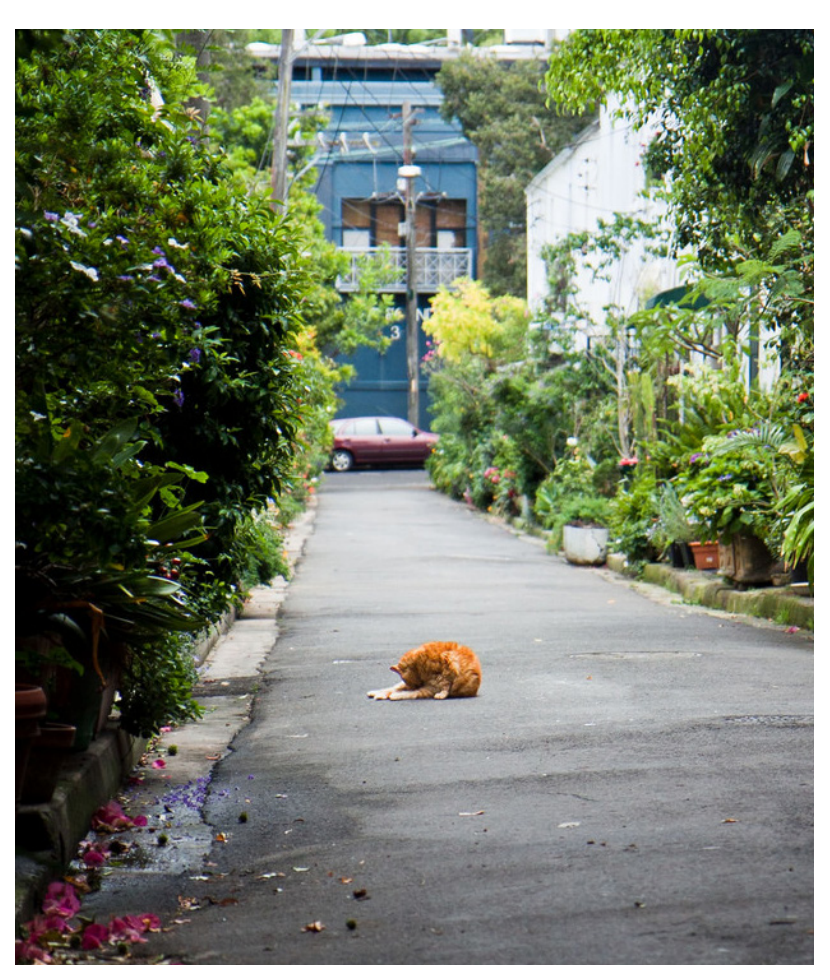

Fig. 1.29 
This project review forms an overview of the types of housing models which are going to contribute to the development of this research investigation. Creating better Aged Care Housing by using the most inclusive and accessible parts of good urban and co-housing. Prioritising visual and audible connections in spaces, accessible shared space- internal and external, the use of colour and architectural elements for recognition, having areas that facilitate incidental interaction and allowing a sense of ownership over space are some of the key findings in this project review. These finding will influence the direction and development of the project moving forward and begin forming a criteria for finding a site in which this type of housing model is best suited. 


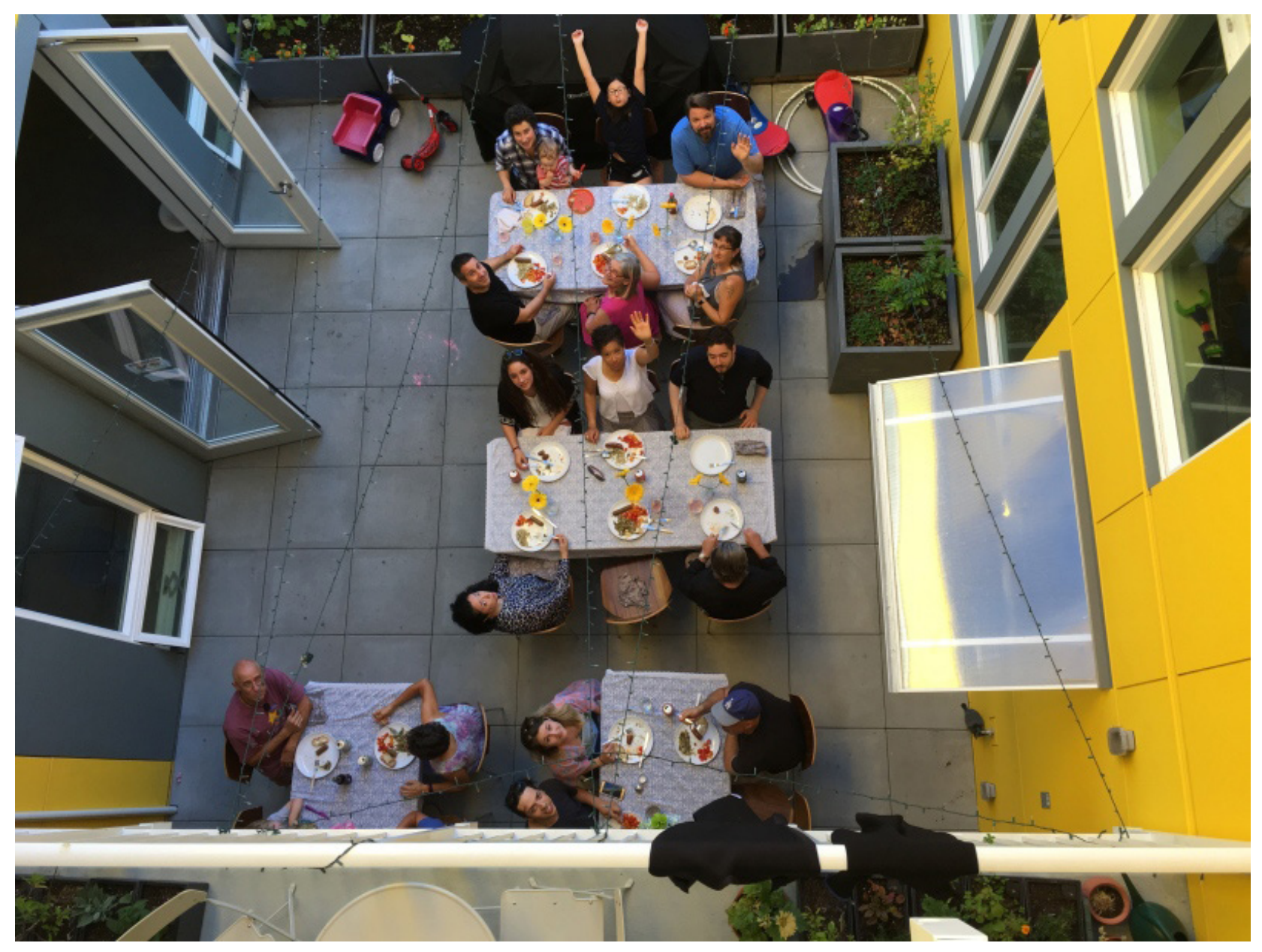

Fig. 1.30

Residents sharing a meal in the communal space at Common House 


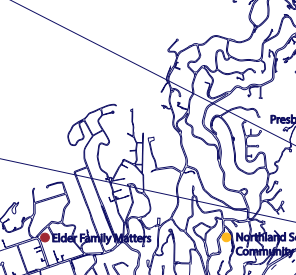

Ant

?

U

in

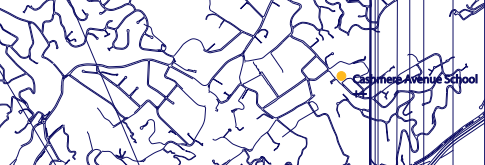

is

\{

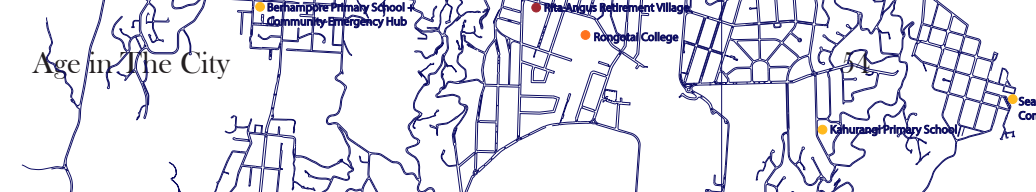




\section{Chapter 2:}
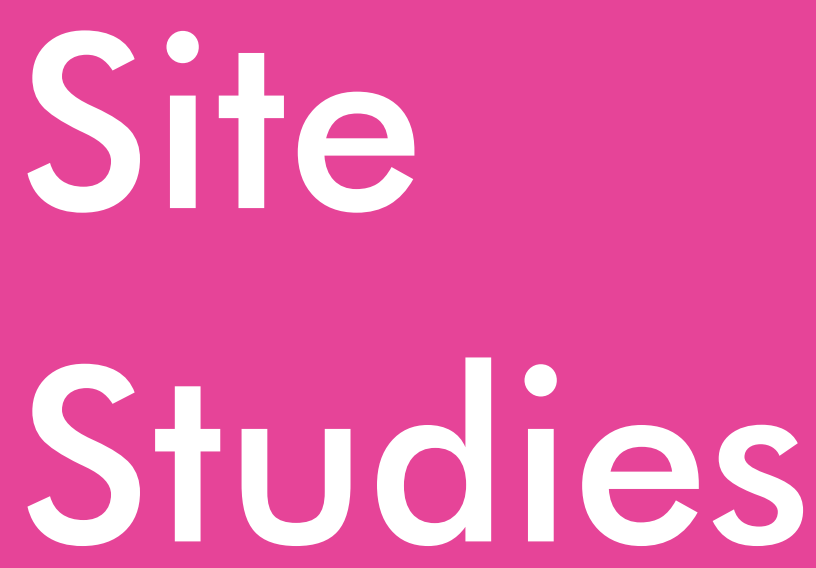

Site Selection and Analysis 


\section{Site Selection and Analysis}

The site selection process began with establishing the importance of intergenerational interactions from the literature review research, as well as finding many examples of aged care housing, which share space and location with preschools and childcare amenities. 


\section{Site Selection Criteria}

Facilitating intergenerational interaction provides elderly and older persons with the opportunity to form new friendships, impart knowledge and build a support system, which all together reduce their risk of social isolation and loneliness. This became the first criteria in my site selection process, looking at sites with a proximity to schools or education facilities.

\section{Process}

Establishing a site near a school would allow me to design amenities that would serve the residents and the school and allow for incidental interaction between the young and old. Selection began with looking at suburban schools around Wellington. Most aged care facilities are found in suburban locations as they make sense for a more traditional idea of ageing in place and staying close to existing communities. Sites from Seatoun to Karori and the Hutt Valley were analysed.

In total 13 schools were selected from every suburban school in Wellington. These were sites located closer to the city as well as towards and in the Hutt Valley. These sites were chosen for their potential space offered nearby for a development of this kind. In visiting these sites I learnt that the amenities which were closest to the sites would have a big impact on the practicality of the site. Being able to walk to different health, food and leisure amenities is important in older persons and elderly ageing experience in feeling like they can remain independent.

With this selection criteria established the suburban sites were narrowed down to plots near Randwick Primary School, Seatoun Primary School, Karori West Primary School and Raroa Intermediate. All of which offered potential in their established communities and proximity to schools however their walking distances to amenities was not meeting the criteria. This developed into a shift in how the selection of site was being chosen. 


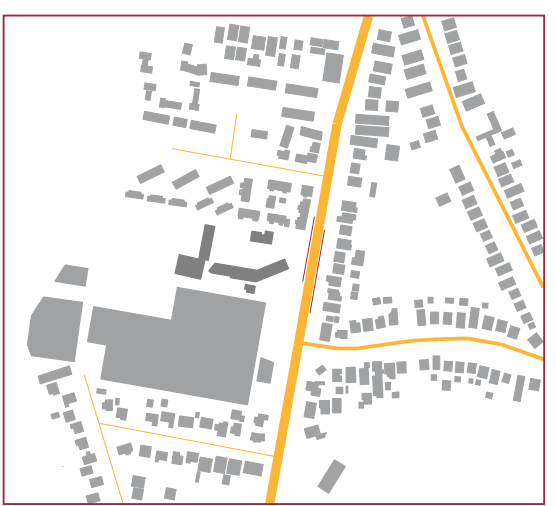

Road Hierarchy

Primary

Secondary

___ Drop off/ Pick up Zone

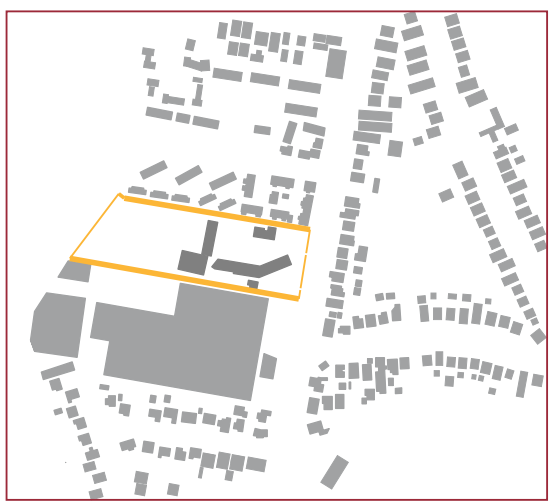

Barriers

to school grounds access

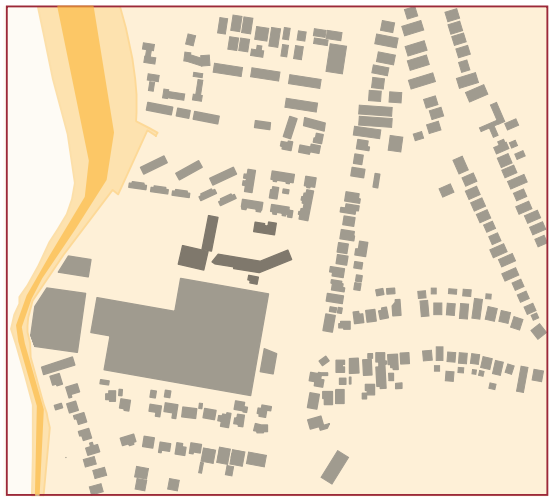

Topography

Key $1 \mathrm{~m}$ Contours

Low
$\square$ High
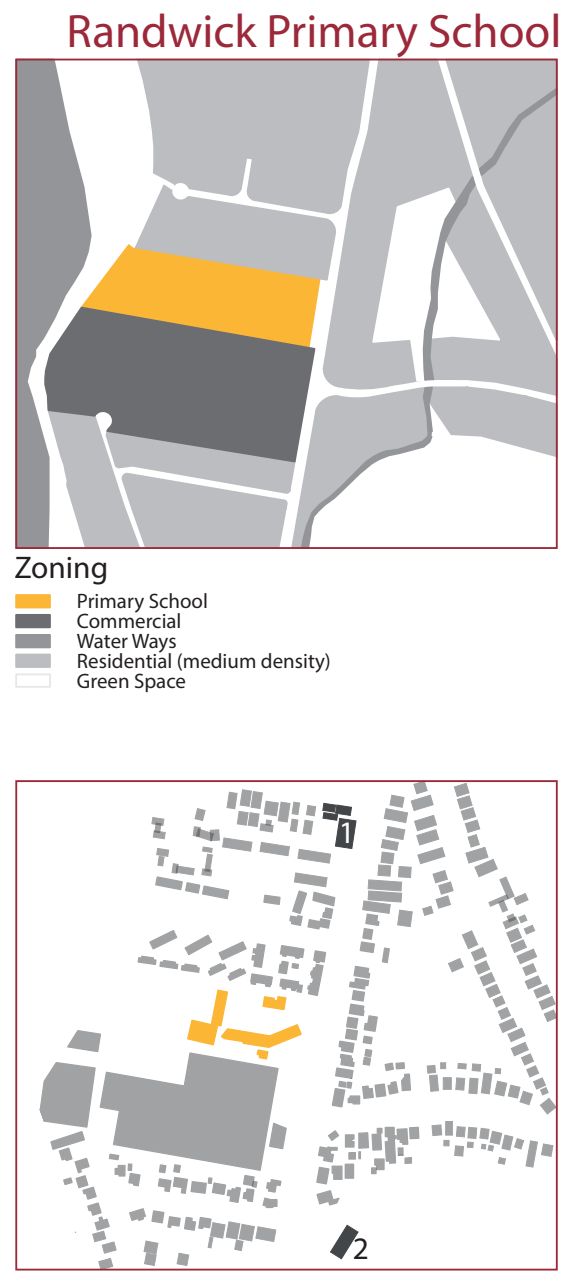

Public Amenities

1. Local Shops

2. Golf Club

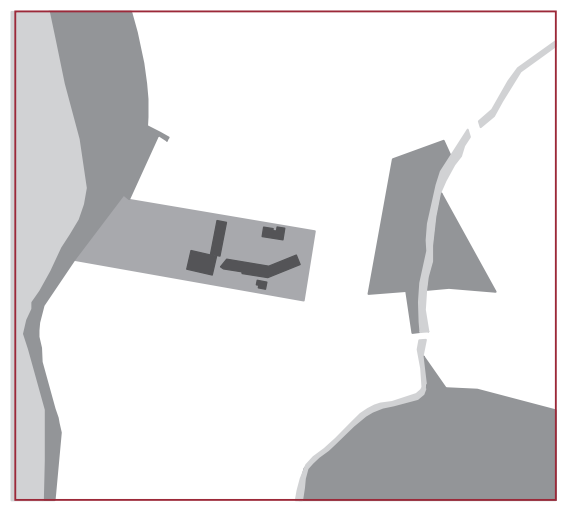

Park areas/

School grounds 


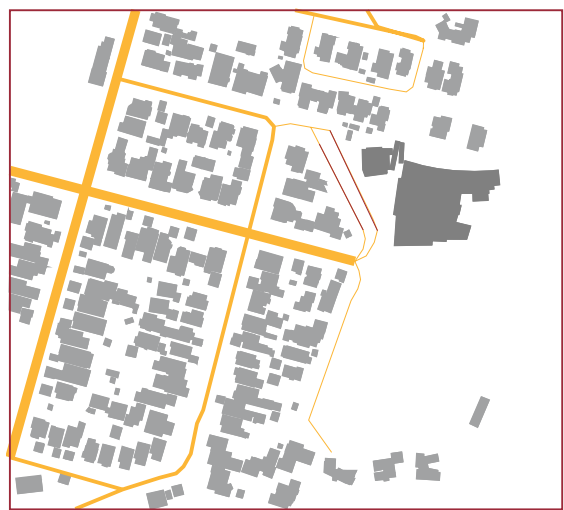

Road Hierarchy

Primary
Secondary
Tertiary
Drop off/ Pick up Zone

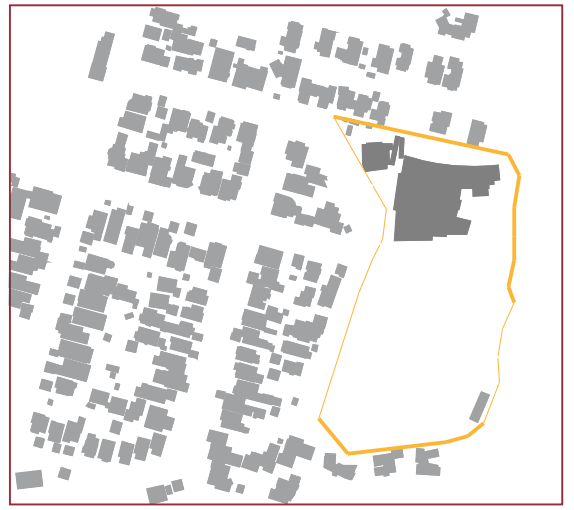

Barriers

to school grounds access

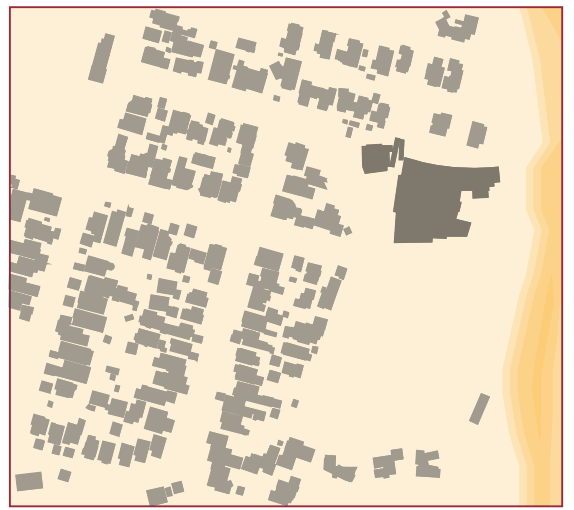

Topography

Key $1 \mathrm{~m}$ Contours

Low
0
High

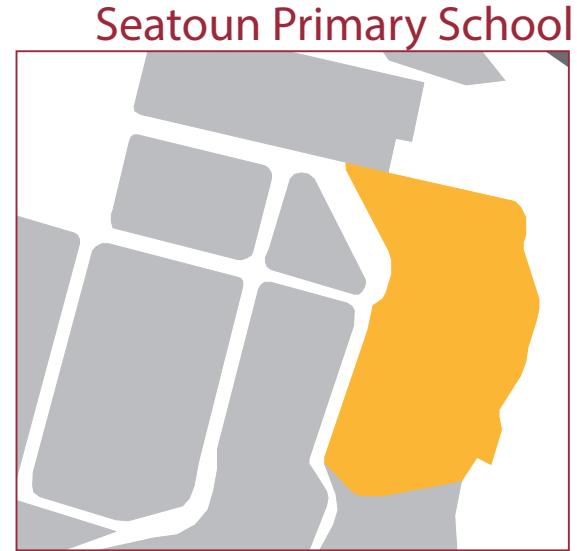

Zoning

Primary School
Residential (medium/low density) Green Space

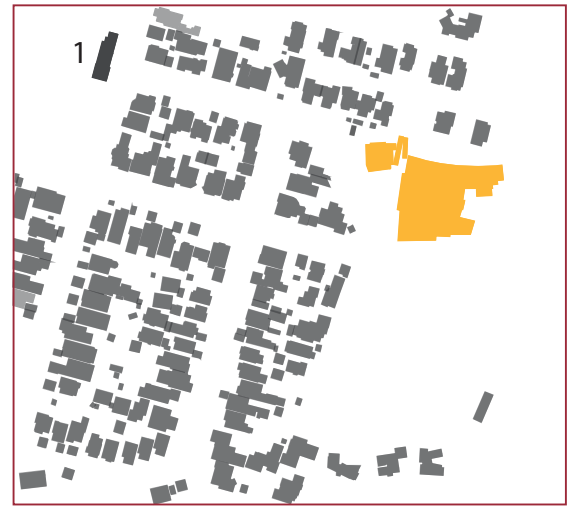

Public Amenities

1. Bus Stop/ Public toilets

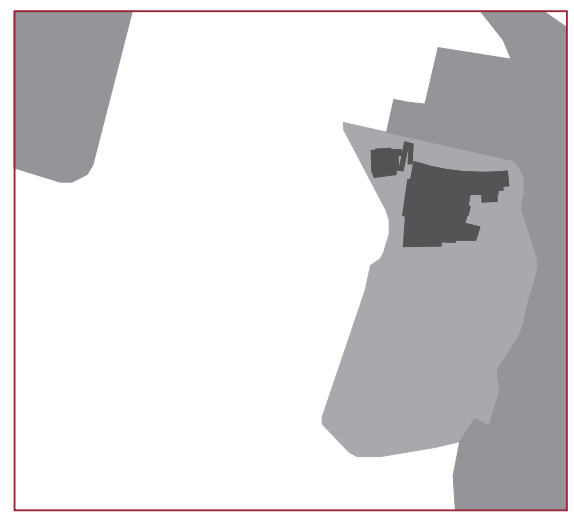

Park areas/

School grounds 


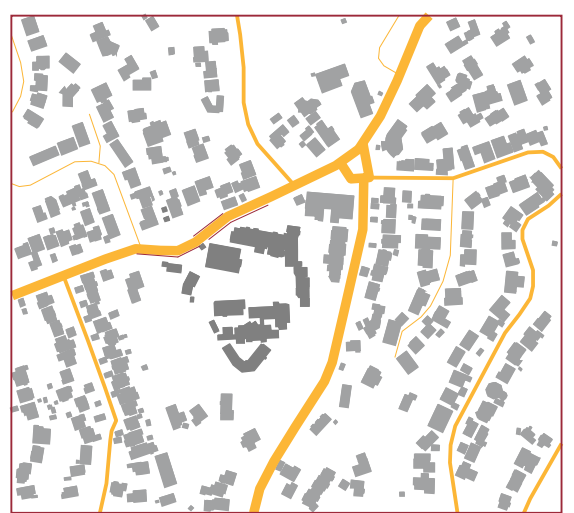

Road Hierarchy

$$
\begin{array}{ll}
\text { Primary } \\
\text { Secondary } \\
\text { Tertiary } \\
\text { Drop off/ Pick up Zone }
\end{array}
$$

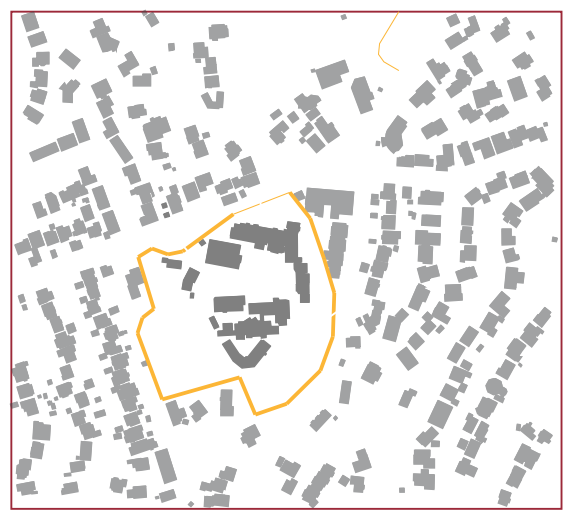

Barriers

to school grounds access

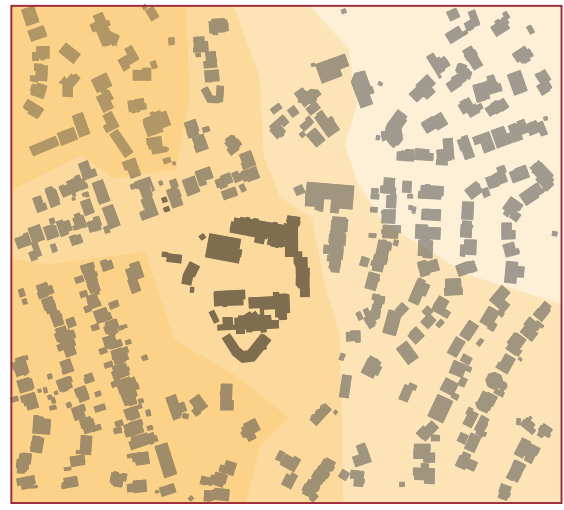

Topography

Key $1 \mathrm{~m}$ Contours

Low
Karori West Primary School

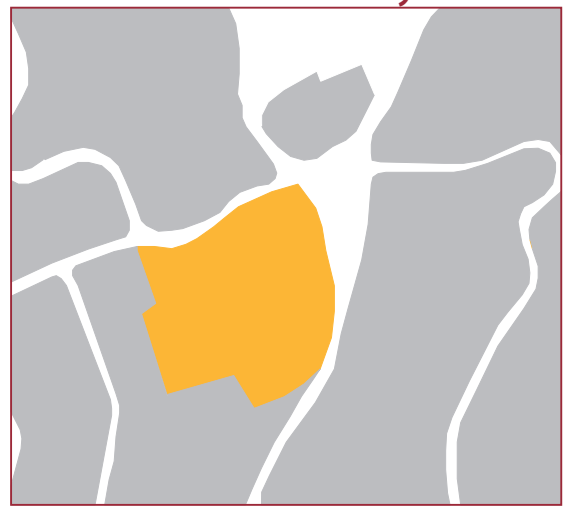

Zoning

Residential (medium/low density) Green Space

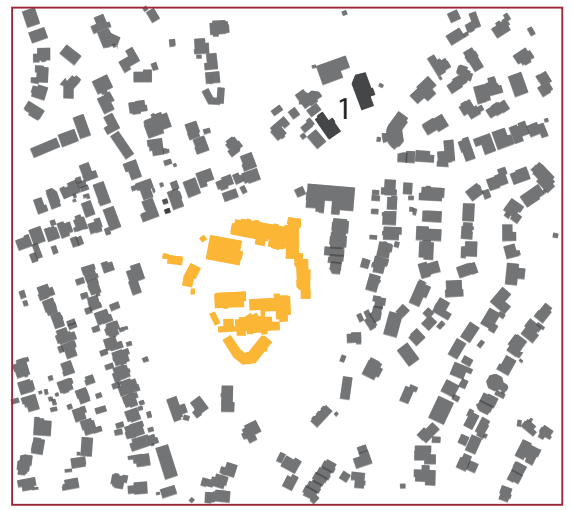

Public Amenities

1. Local Shops

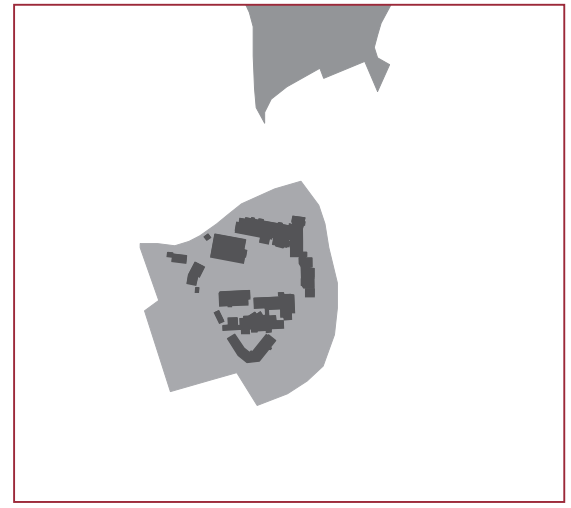

Park areas/

School grounds 


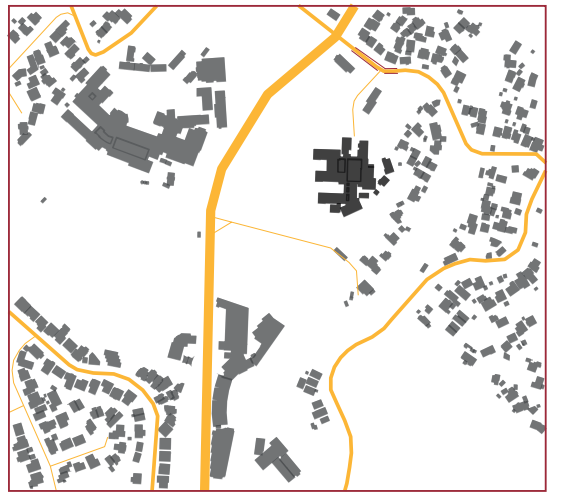

Road Hierarchy

Primary

- Secondary

___ Drop off/ Pick up Zone

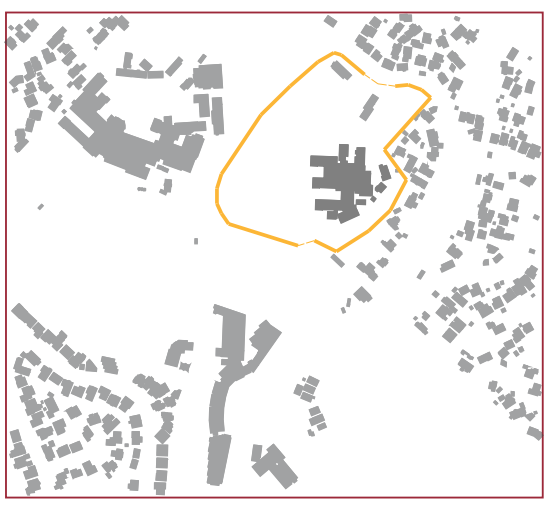

Barriers

to school grounds access

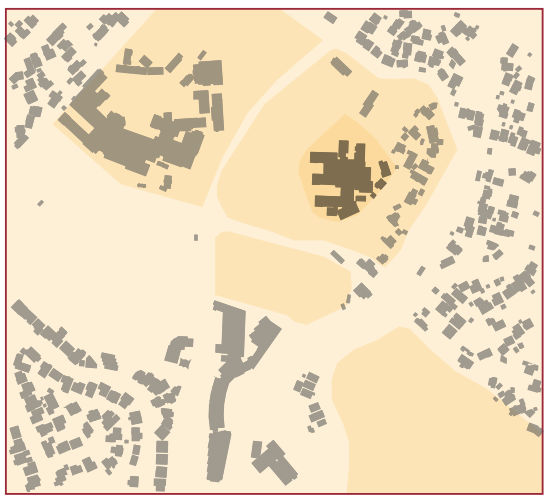

Topography

Key $1 \mathrm{~m}$ Contours

Low
High
Raroa Intermediate School

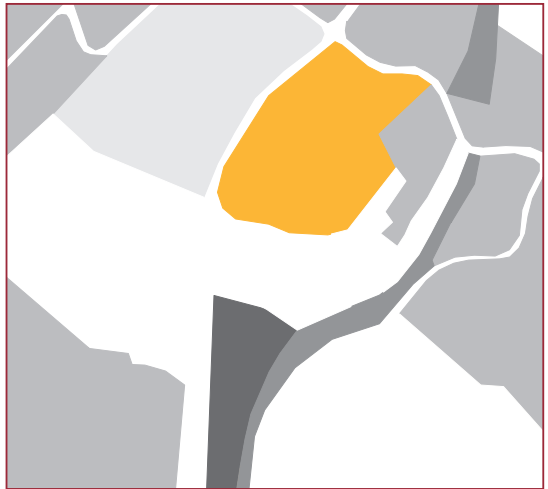

Zoning Primary School
Aged Care Home
Train Track
Residential (medium/low density)
Onslow College
Green Space

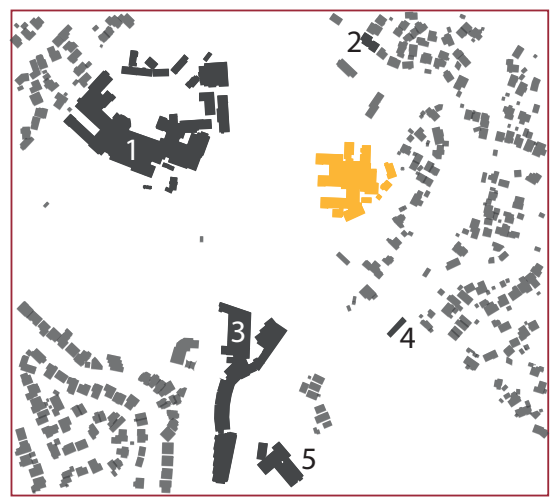

Public Amenities

1. Onslow College

2.Medical Centre

3. Care home

4. Raroa Train Station

5. Westmount School

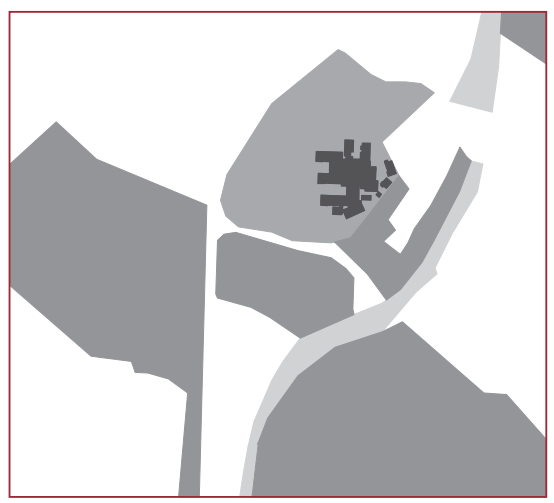

Park areas/

School grounds 


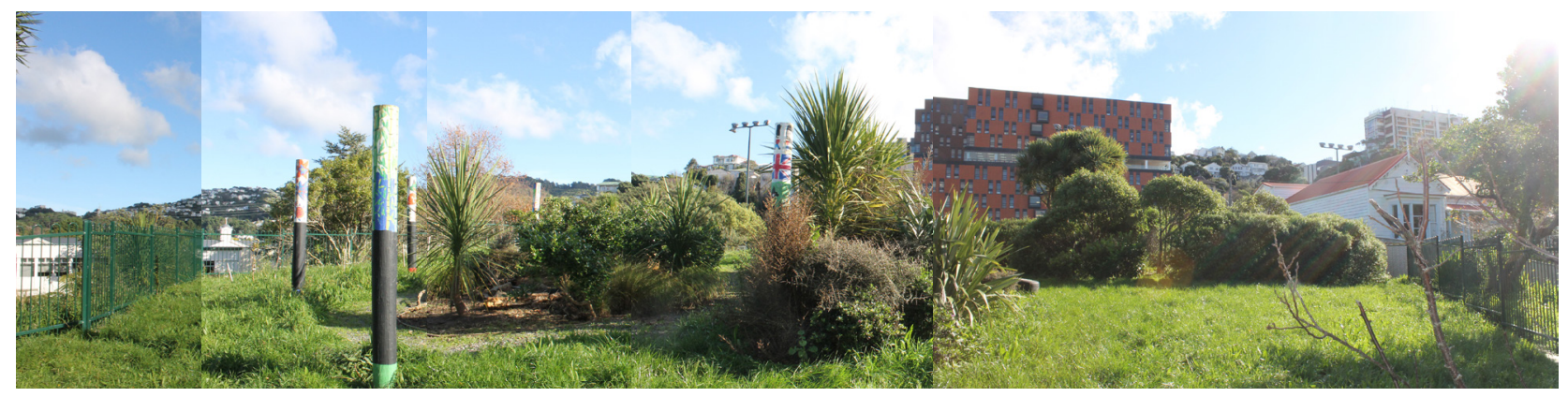

Fig. 2.1

Te Aro School site currently has a vegetable garden

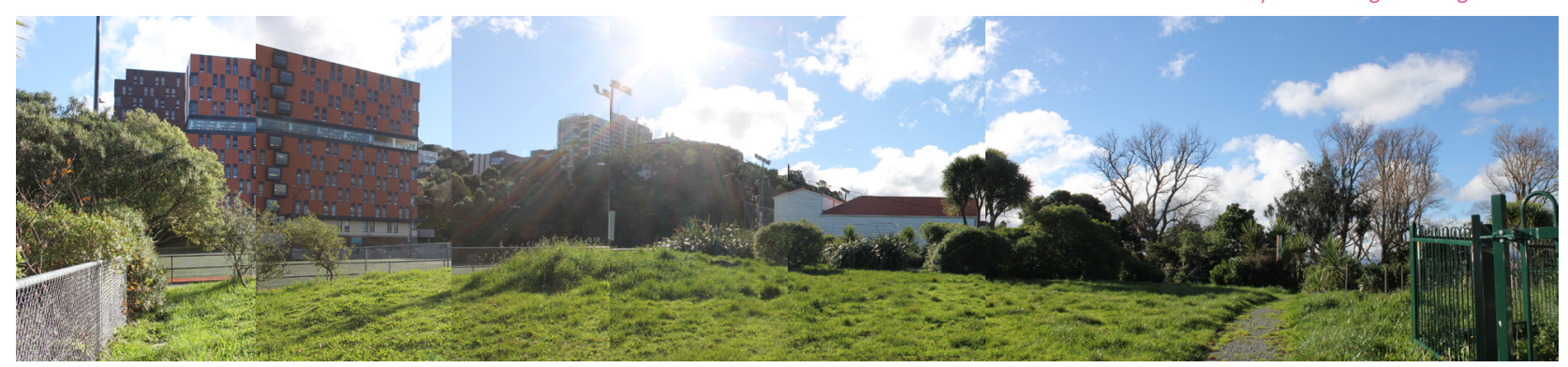

Fig. 2.2

\section{Selection}

While in the process of narrowing down and analysing these sites it became apparent the flaws in a suburban location in being able to appropriately test the design objectives. There was not enough opportunity for social interaction around sites, outside of school pick up and drop off and there was often large walking distances to shops or health care. The need for interaction and to activate the building became apparent that it was better suited to an urban location where there was higher foot traffic, more events happening and still an established sense of community. Keeping the idea of proximity to a school, more criteria were established in order to ensure selected sites were appropriate for the scope of this research. The site needed to be walking distance to main amenities (food, culture and social), have access to green space, have a typography which allowed the testing of accessibility around or through the site, be in an area in need of amenities, particularly health care and have safe entry points for residents.

Looking at all of the schools in Wellington City two sites were established which could work for the design research exploration. These were Te Aro school site, a patch of land next to the school and Boyd Wilson field, and Mt Cook school site, an empty lot currently used as a carpark bordering Pukeahu National War Memorial Park and Taranaki Street. Both sites had close proximity to amenities, had interesting typographies and bordered green spaces. Upon observation of both of these sites the decision between the two came down to the testing of accessibility on site. The Te Aro site has a steep typology and the Mount Cook site a more gradual typology. 


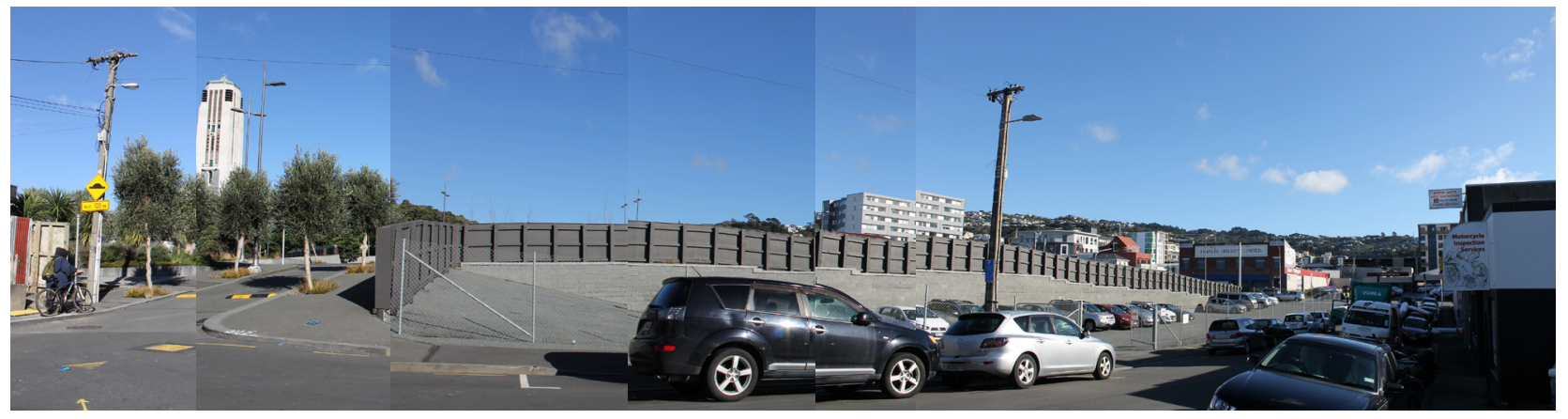

Fig. 2.3

Te Aro site from Martin Square

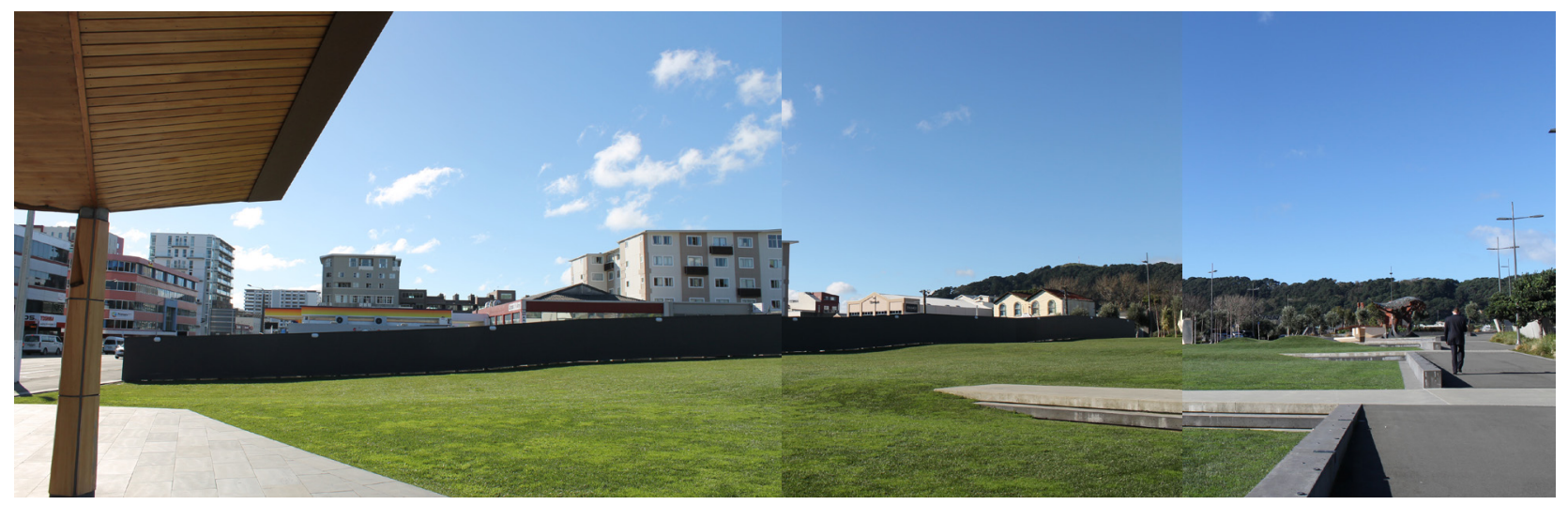

Fig. 2.4

Te Aro site from Taranaki Street

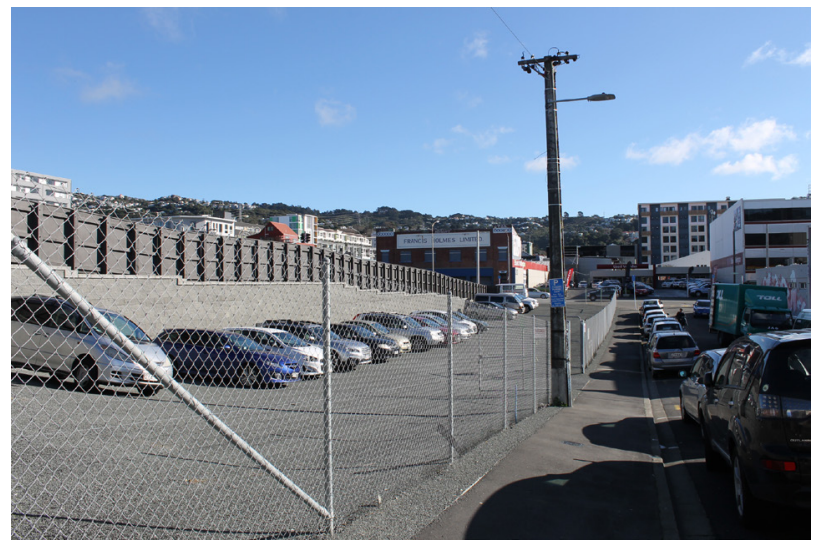

Fig. 2.5

Te Aro site is currently used as a carpark

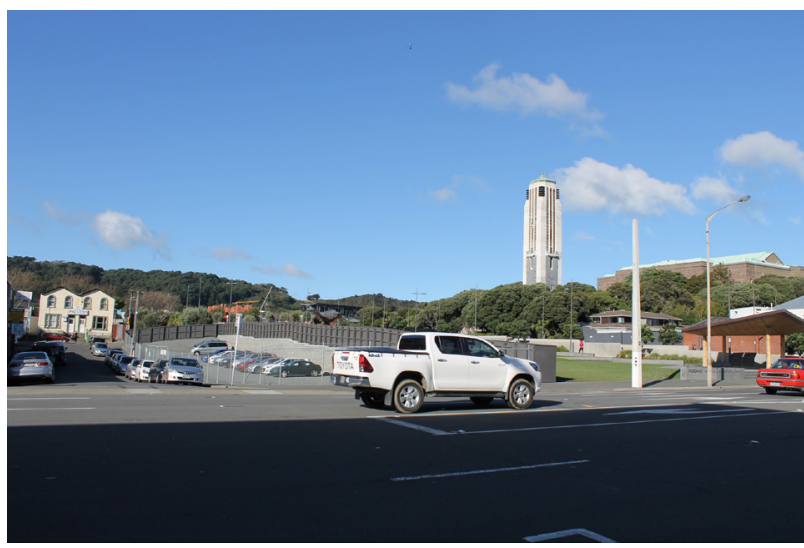

Fig. 2.6

Te Aro site boarders busy Taranaki Stree 


\section{Site Selection Criteria}
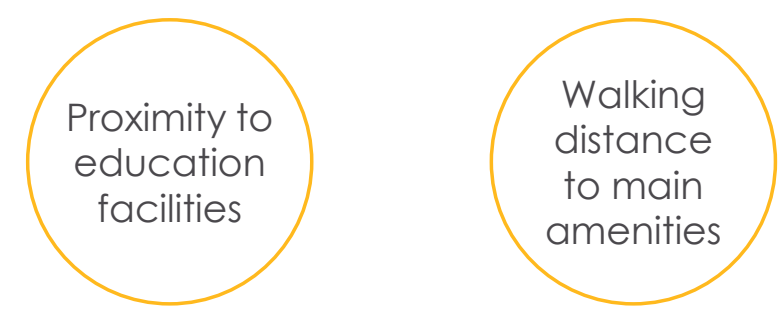

Need for amenities in the area

Safe entry to site for residents
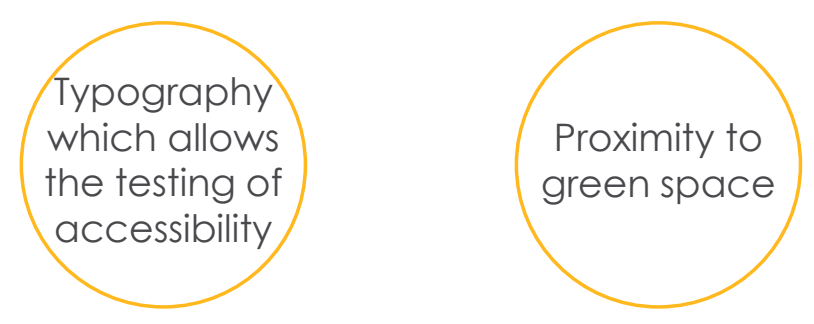


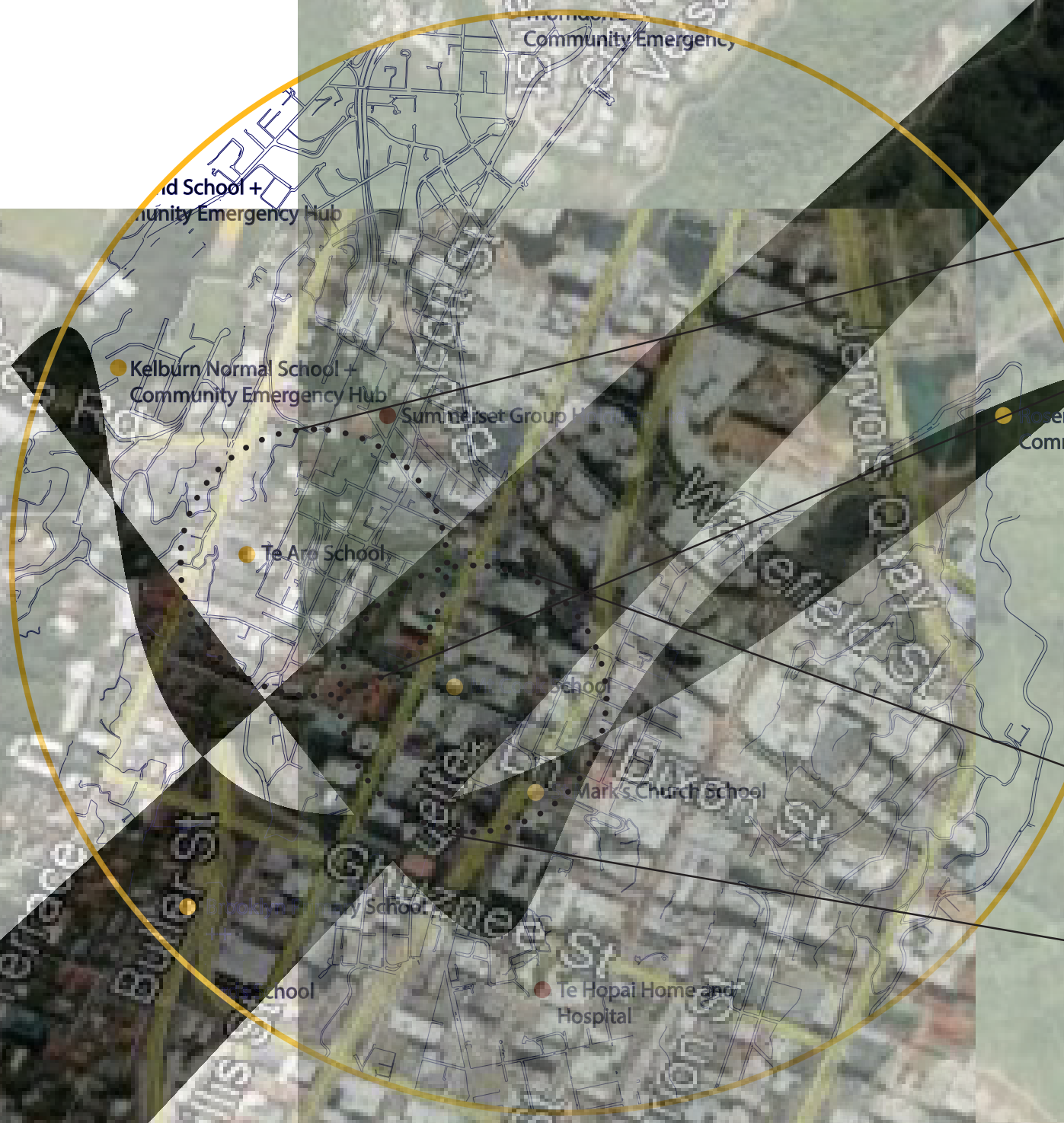


Ultimately the site next to Mount Cook school was chosen to move forward with in the design investigation because of its probability in future to be used for a residential block and a more suitable site for a housing development catered toward elderly and older persons. This site provided more space than the Te Aro school site and had a wider range in people for foot traffic around the site.

This site selection process resulted in a broad understanding of the architecture of primary schools in and around Wellington and how their surrounding land is being used. It also highlighted the importance of having urban aged care facilities. There is a vibrancy in putting older people into a busy city with adequate care for themselves, they can participate in the urban bustle and the public engagement. With the site and the amenities, it will provide will allow a higher chance of incidental interactions and forming meaningful connections on a daily basis for these people that would otherwise be isolated or lonely.

Through meeting the site selection criteria this site is deemed appropriate for testing the design research objectives and from here the design investigations began.

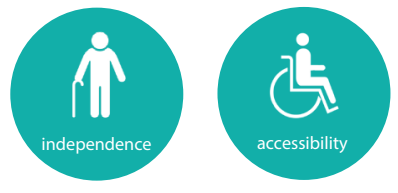




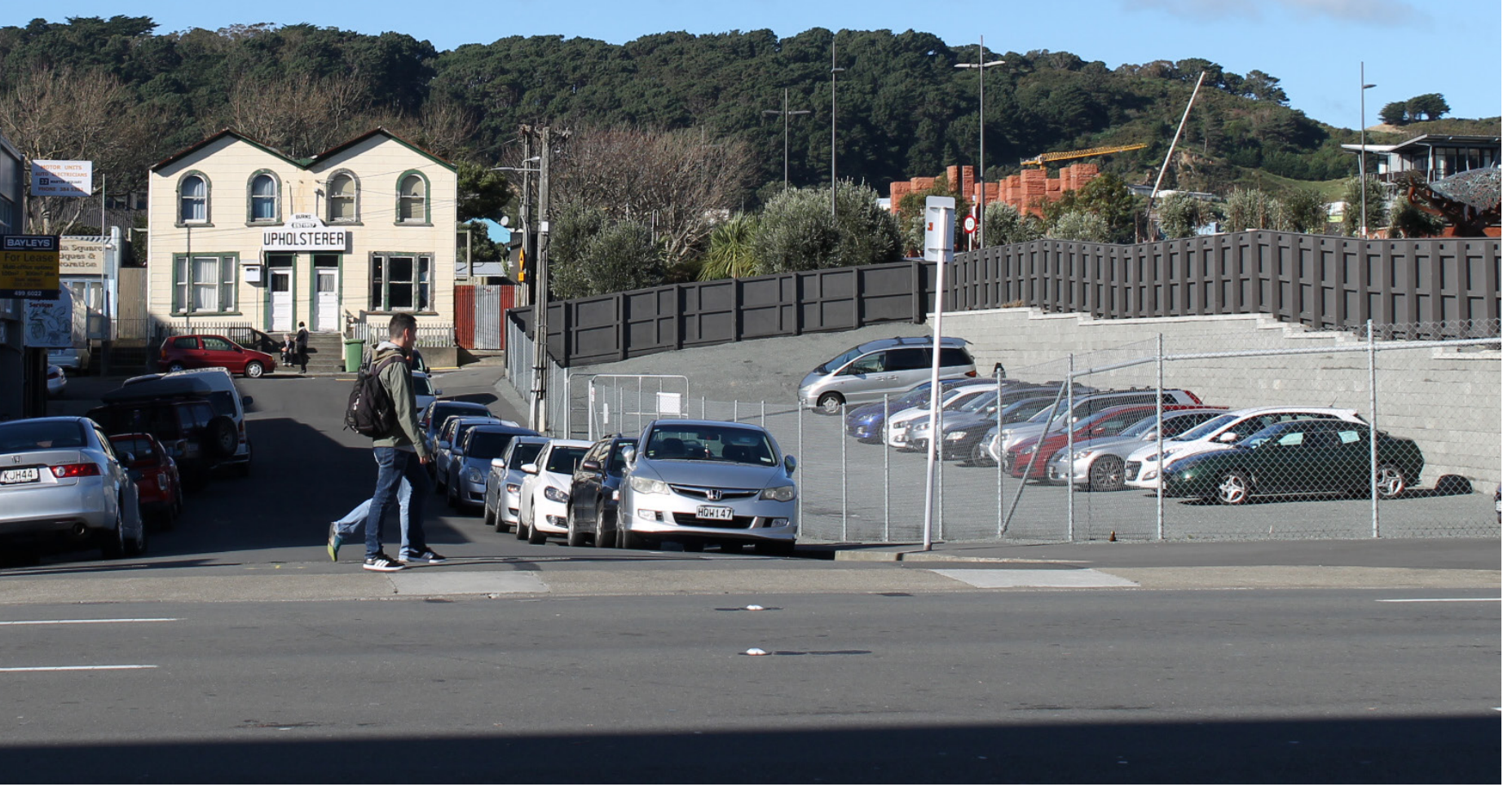

Fig. 2.7 


\section{Site Analysis}

The area although mainly industrial has a character likened to that of Cuba street with the Upholsters building and other colourful quirks. This site is in close proximity to Massey University, The Cube halls of residence, Victoria University Wellington's Faculty of Architecture and Design as well as Mount Cook Primary School and Preschool. This campus gives the opportunity to include accommodation for university students into the housing scheme- with more meaningful intergenerational interactions than a suburban site could offer.

One key limitation of the site is its inclusion in the Te Aro Corridor design guidelines. This guideline comes from the redevelopment of Pukeahu National War Memorial Park and the desire to keep the environment surrounding it consistent with that of the park. This means being sympathetic towards the viewpoints of the Carillion and using the same vegetation as the site. There is also a 27 metre height restriction on the site.

The site is walking distance to the waterfront, shopping facilities, Moore Wilsons Supermarket, Lighthouse Cinema and Te Papa museum with accessible footpaths provided on these journeys. The site analysis process consisted of sketching key viewpoints around the site, each highlighting a feature of the surrounding landscape of infrastructure and alluding towards journeys, which can be taken from this site, down Taranaki street or through the park.

The industrial area is in need of more food and healthcare amenities with the closest being Havana bar and Prefab eatery, both of which are a five minute walk away.

Meeting these criteria is the first step in achieving some of the design research objectives such as engagement with the social street is encouraged by the activity from the education facilities and safe entry for residents/ public. Providing health amenities objective is achieved through the proximity to green space (encouraging the therapeutic use of nature) as well as need for amenities in area, meaning the functions this development serves will be wanted and used by the surrounding public. 


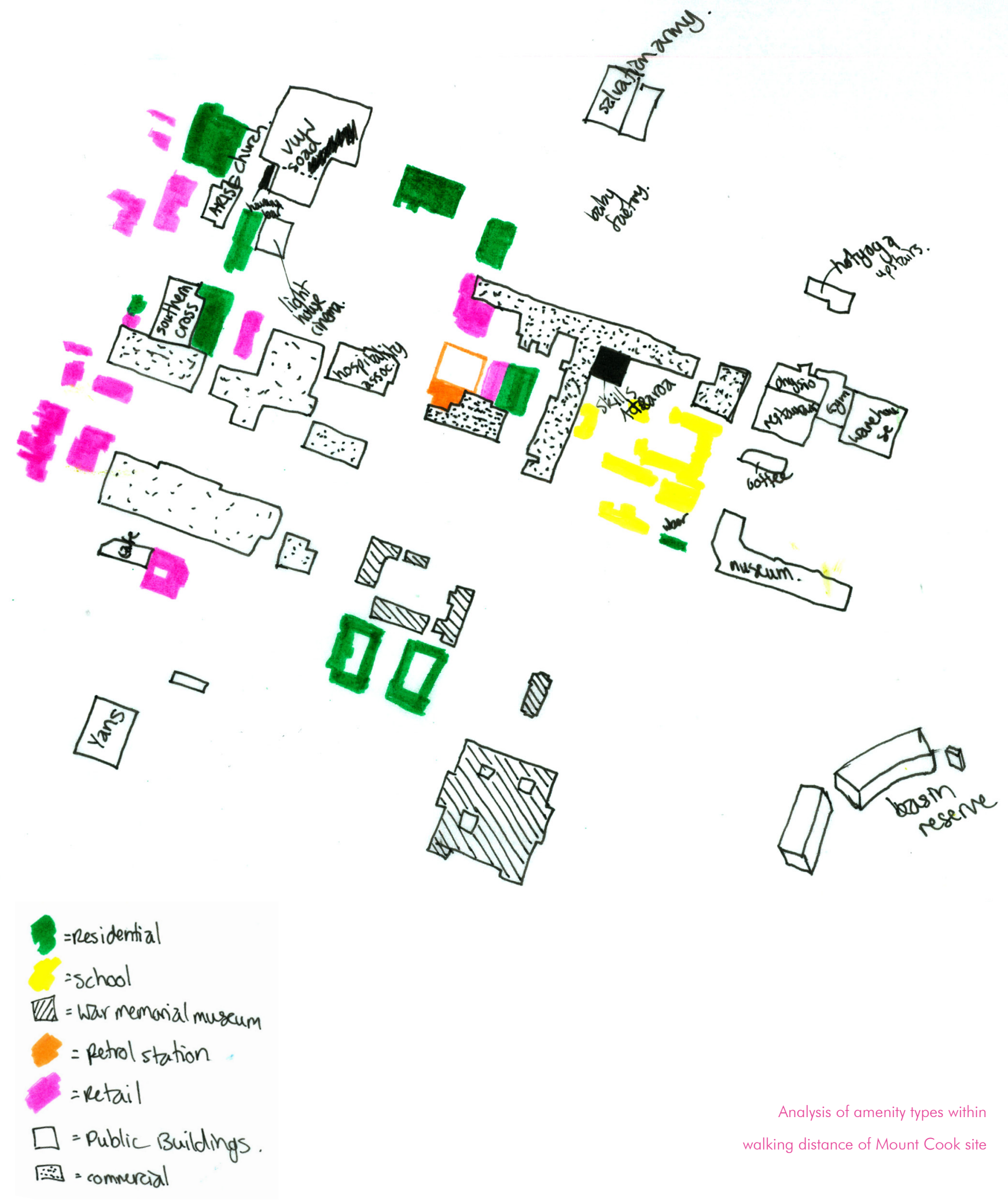




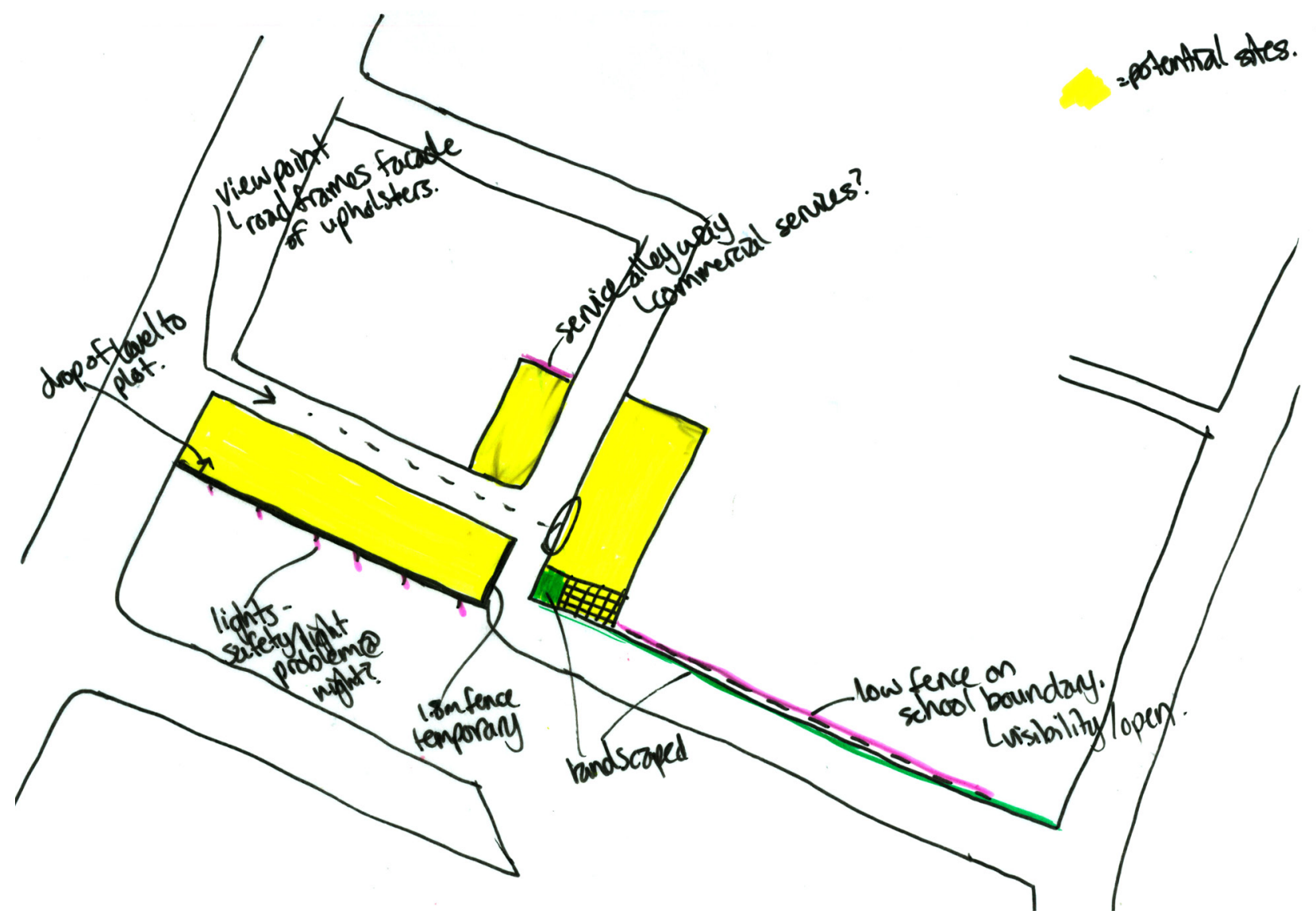

Three potential plots next to Mount

Cook School

The site analysis looked at the possibility of three plots near Mount Cook School.

Upon visiting and further analysing the site details were picked up on and mapped in these diagrams, such as the issue of light and safety at night along the park edge and the potential for creating new pathways to the school through the eastern plot, taking out some buildings. After some early sketches of circulation across the sites and the establishment of different groups occupying the site, as explained further in the next chapter, just one plot was chosen to move forward with developing a design.

The selected site is 70 metres long by 14 metres wide and has a 3.1 metre shift in ground floor height diagonally across. This typography allows an opportunity to test accessibility through the site for wheelchair and mobility scoot users. 


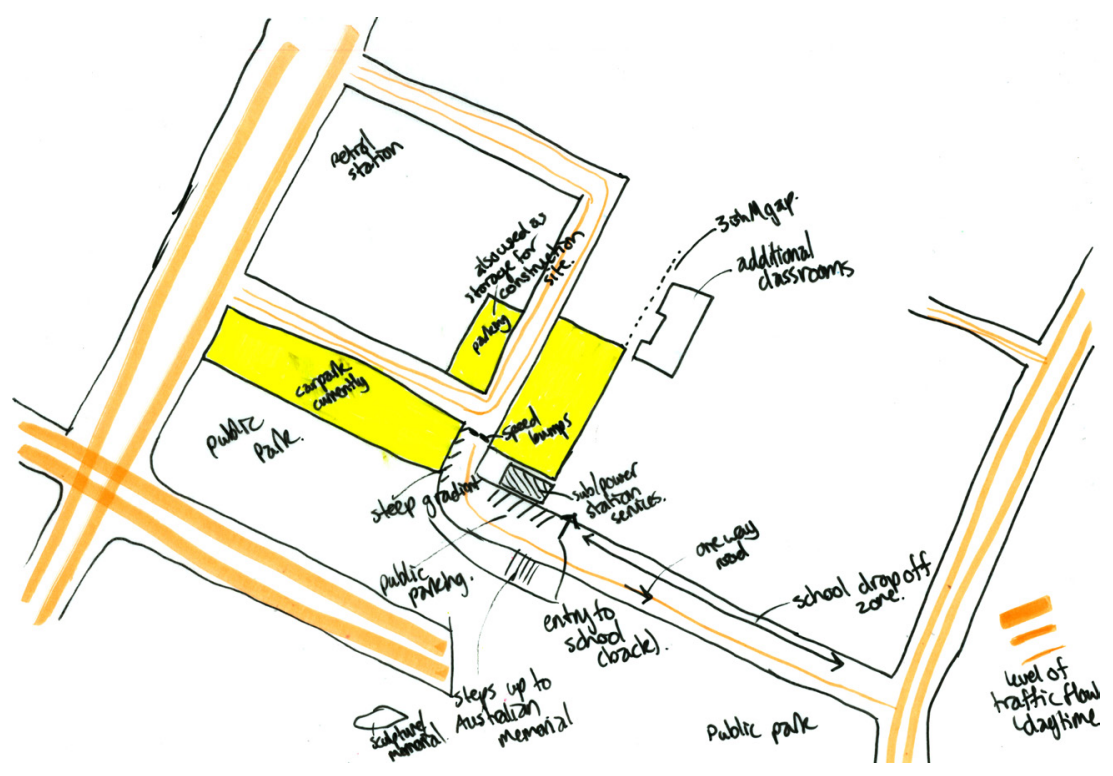

Mapping movement around the site

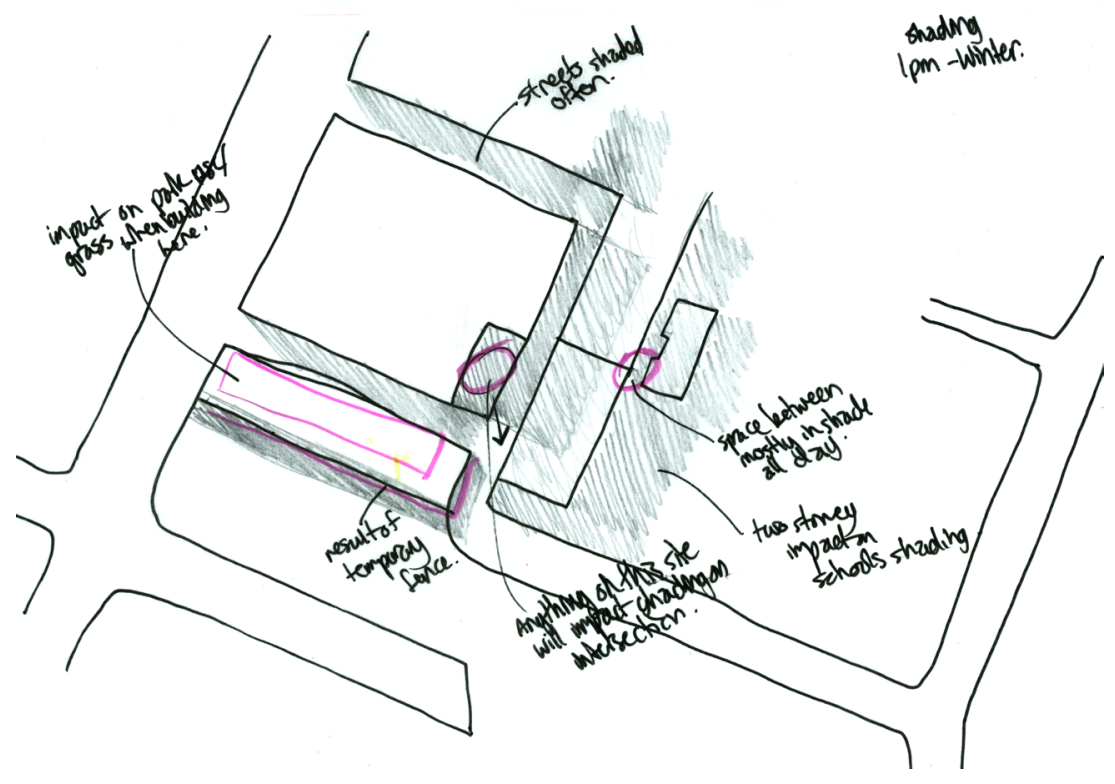

Mapping shadows from existing

structures on site 


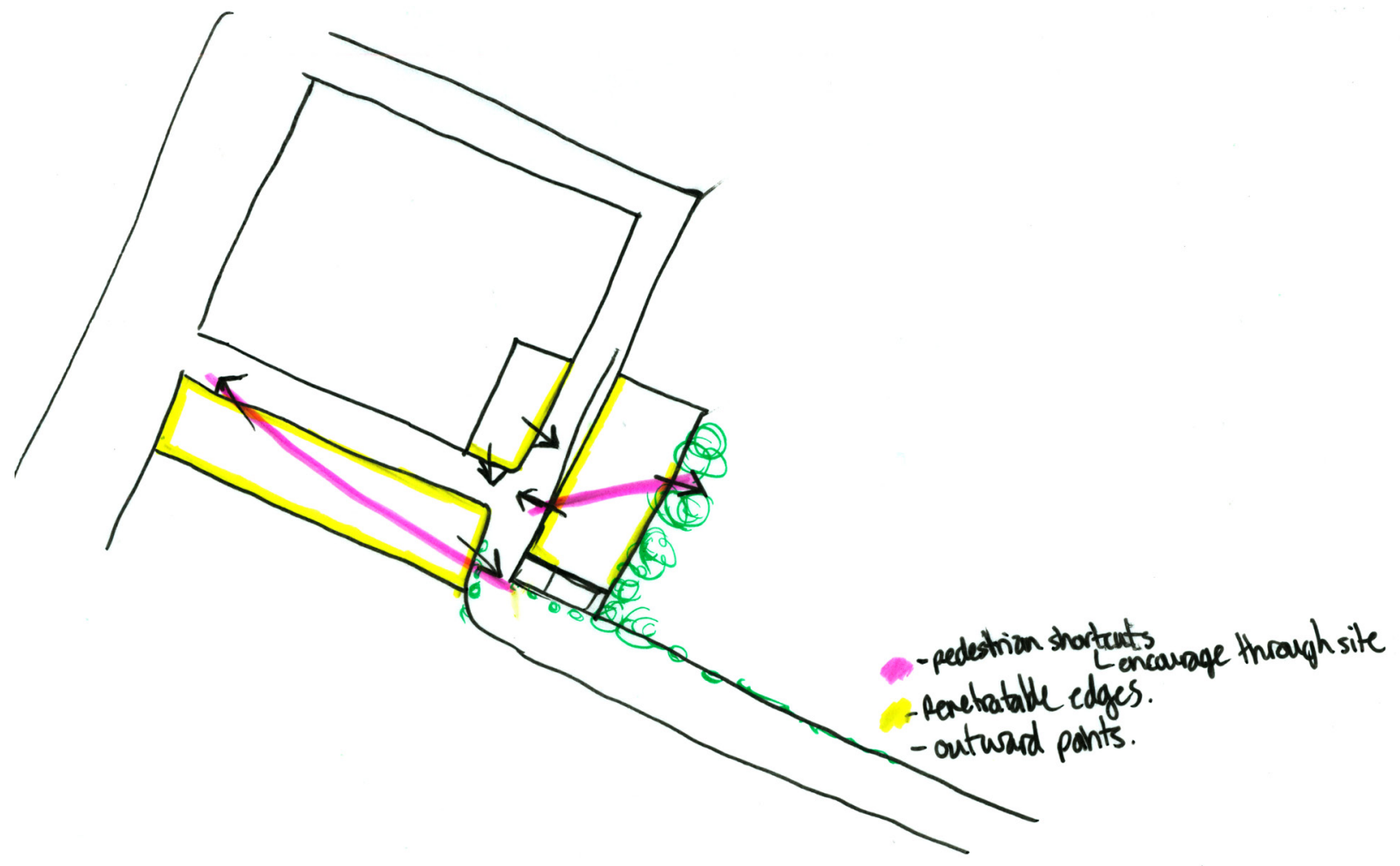

Potential circulation through the three plots,

leading to the selection of one plot 

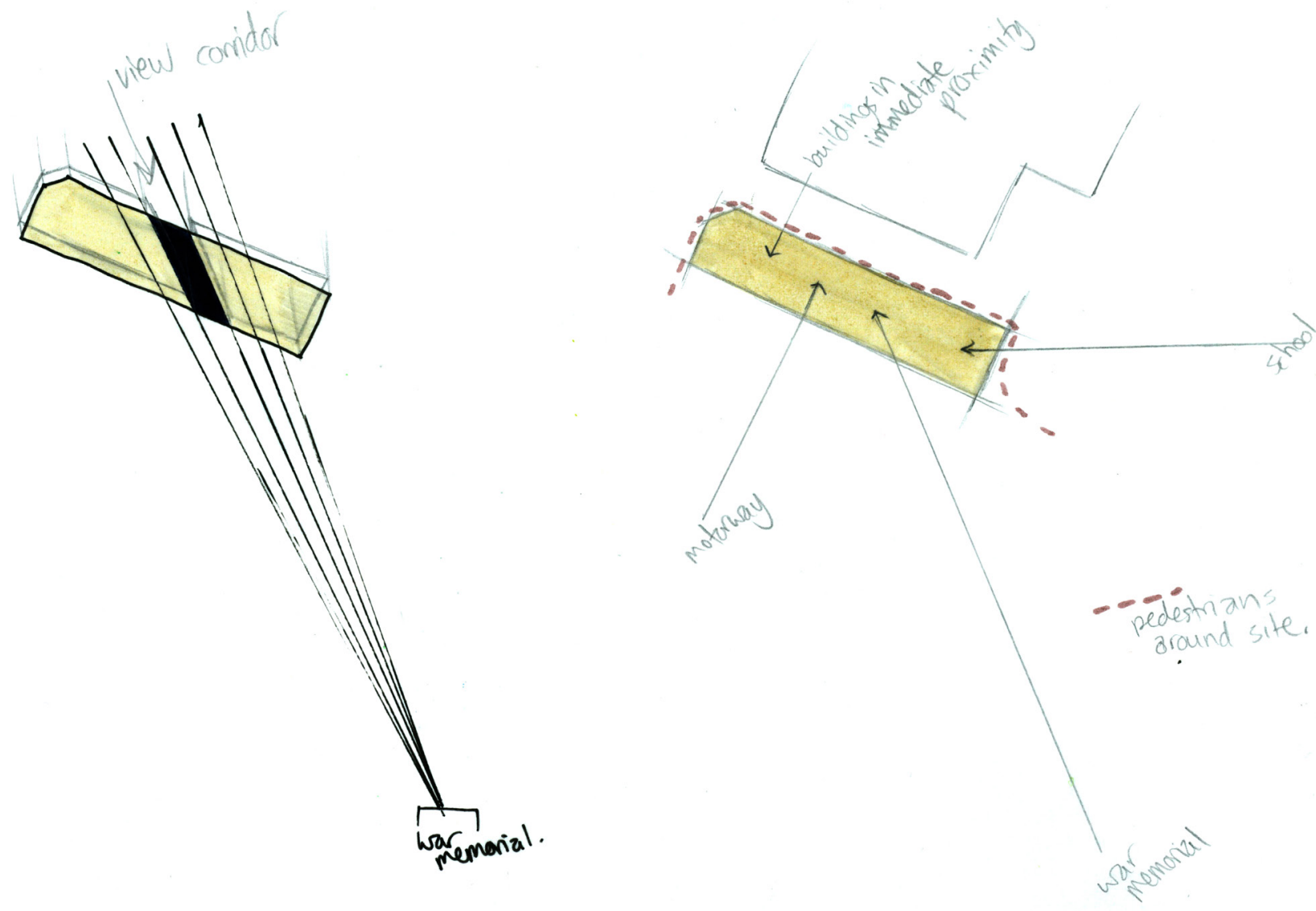

Looking at just one plot and how it could optimise the view points to the War Memorial Parks Carillion 


\section{Key Site Qualities}

\section{Urban Location}

iv

Tose to food and activity amenities

$1 \mathrm{~m}$ shift in typographý

Hximity to Public Park änd

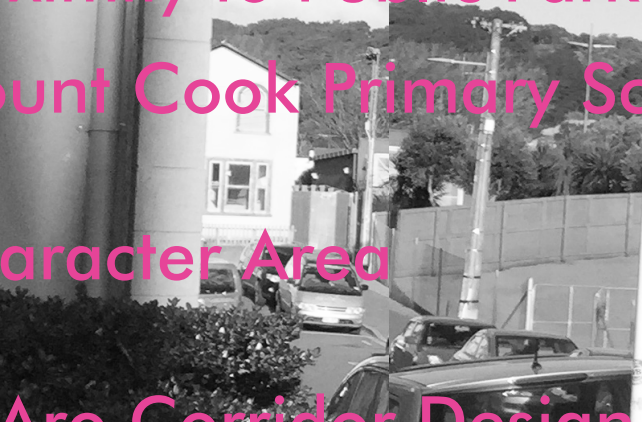

Te Aro Cordin.
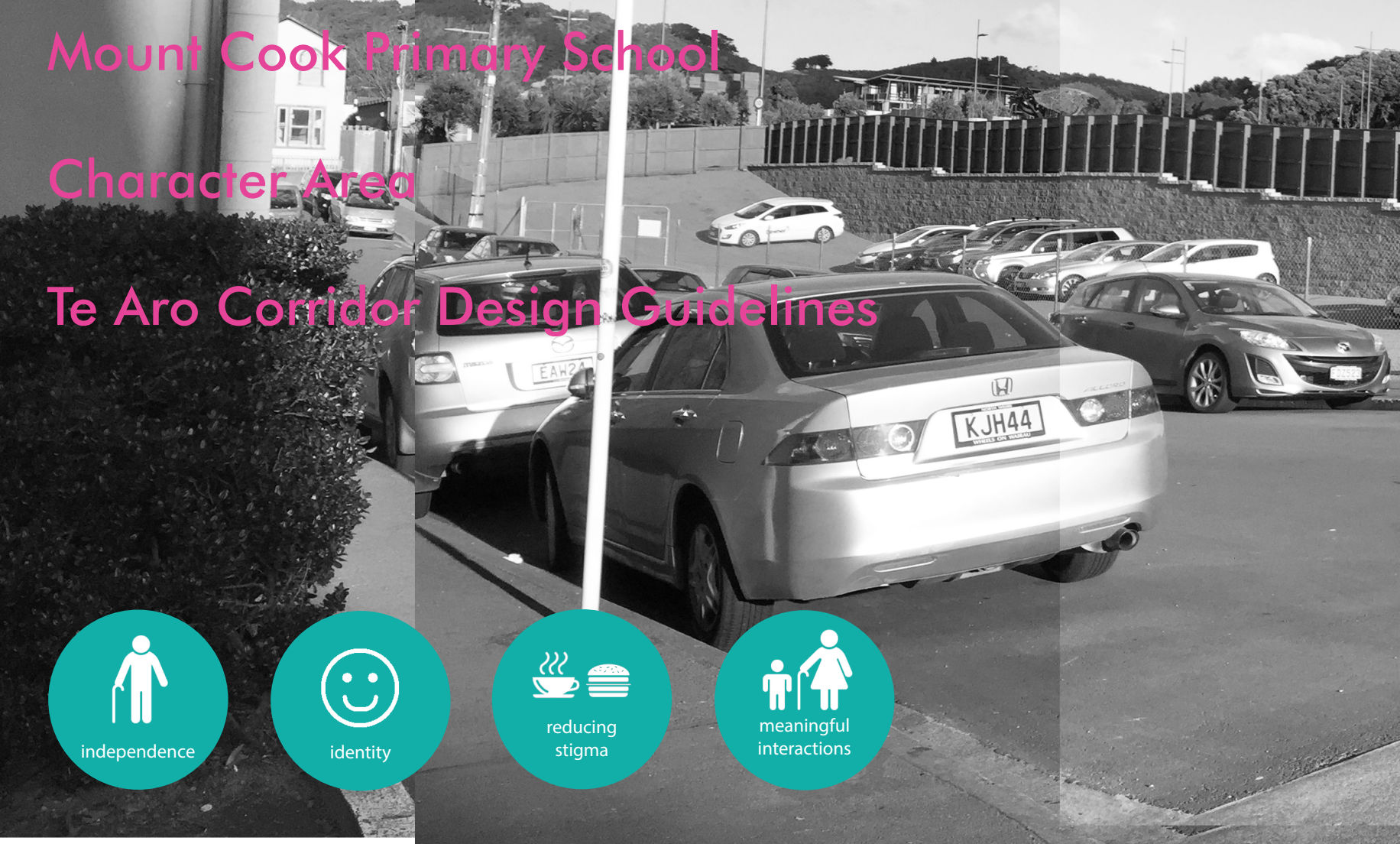

* 11 (1)
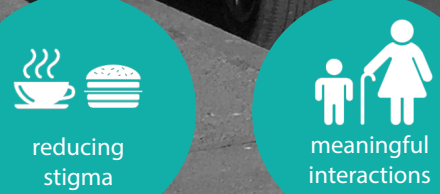


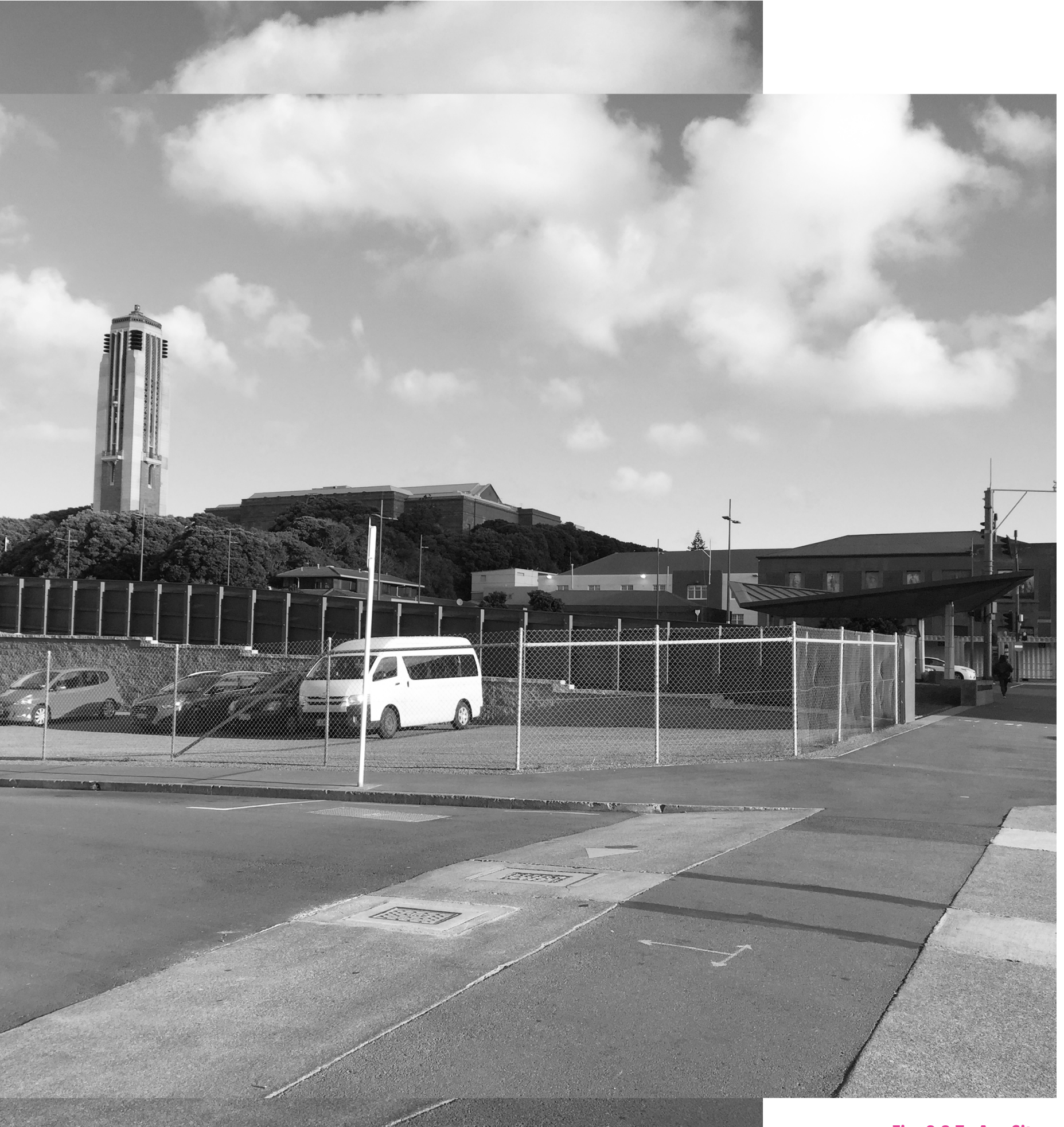

Fig. 2.8 Te Aro Site 



\section{Chapter 3:}
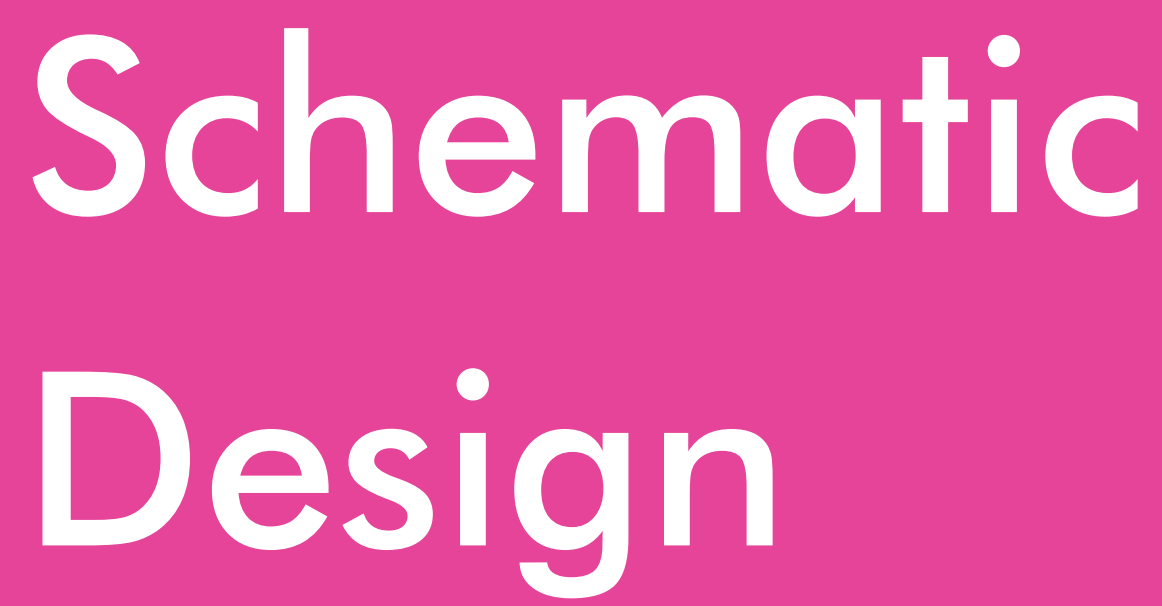

Site Organisation and developing the Design Strategy 


\section{Early Design Response}

Schematic Design develops the design response based on the literature, project and site research through establishing resident profiles, site planning/ massing, circulation focused design and establishing design tactics. 


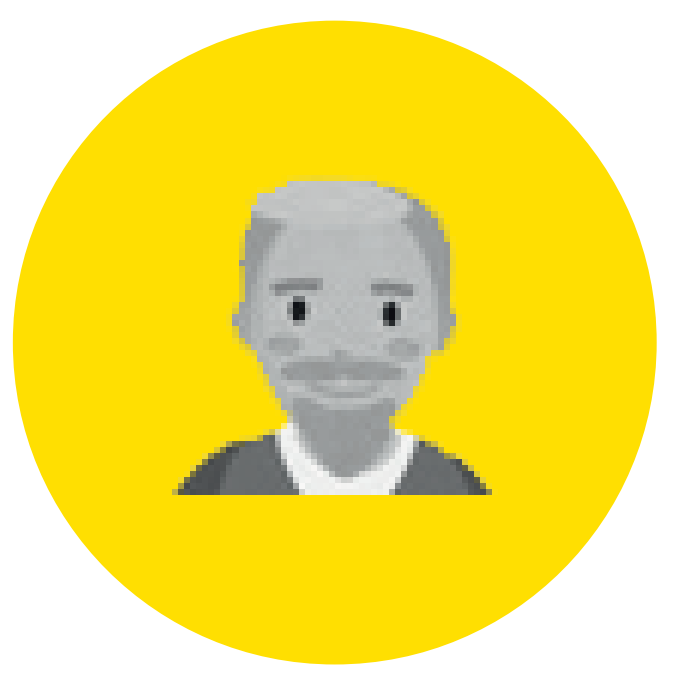

Elderly/ Older Person

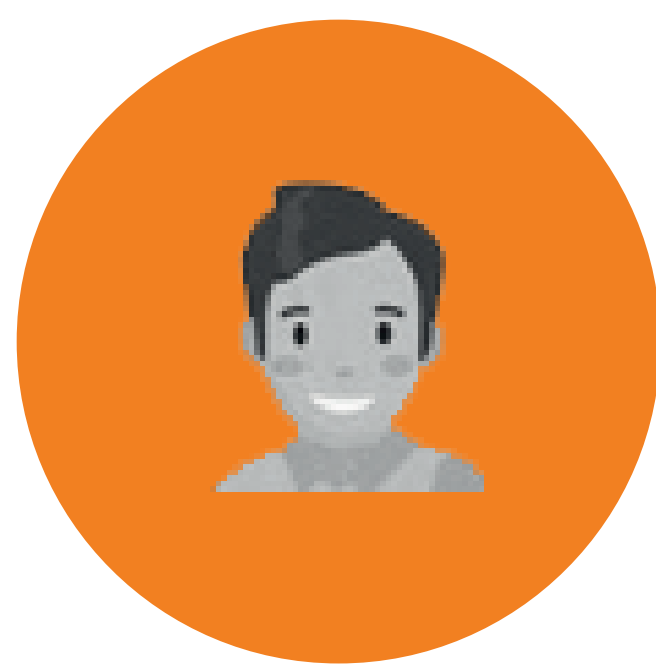

Other

\section{Site Organisation}

I created a hypothetical residents profile, different combinations of demographics that could occupy the building that the site caters toward hosting, such as university students, to bring the project from site analysis to a schematic design. This developed an investigation into the benefits and drawbacks of housing certain age groups together or separating groups by age. The following initial site planning iterations imagine the resident groups as elderly/ older persons (yellow) and other (orange) for an initial analysis of the placement of these groups around common spaces and interfaces with public amenities. The iterations also use pink to represent potential retail space, green for public space and hatching for common spaces. The iterations mainly test whether common spaces could be shared between floors and/or different user types. The establishment of these groups and colour coding them meant an organisation of form could begin to be tested. Originally I looked at creating zones on the different plots to spilt people up into different groups- more like some aged care which provides facilities you can move through as you age and your needs increase. Then these plots were reduced to just one, establishing that the design research would be better suited to one plot because it forces groups into one housing model and all relationships within that need to be considered in the design process. 

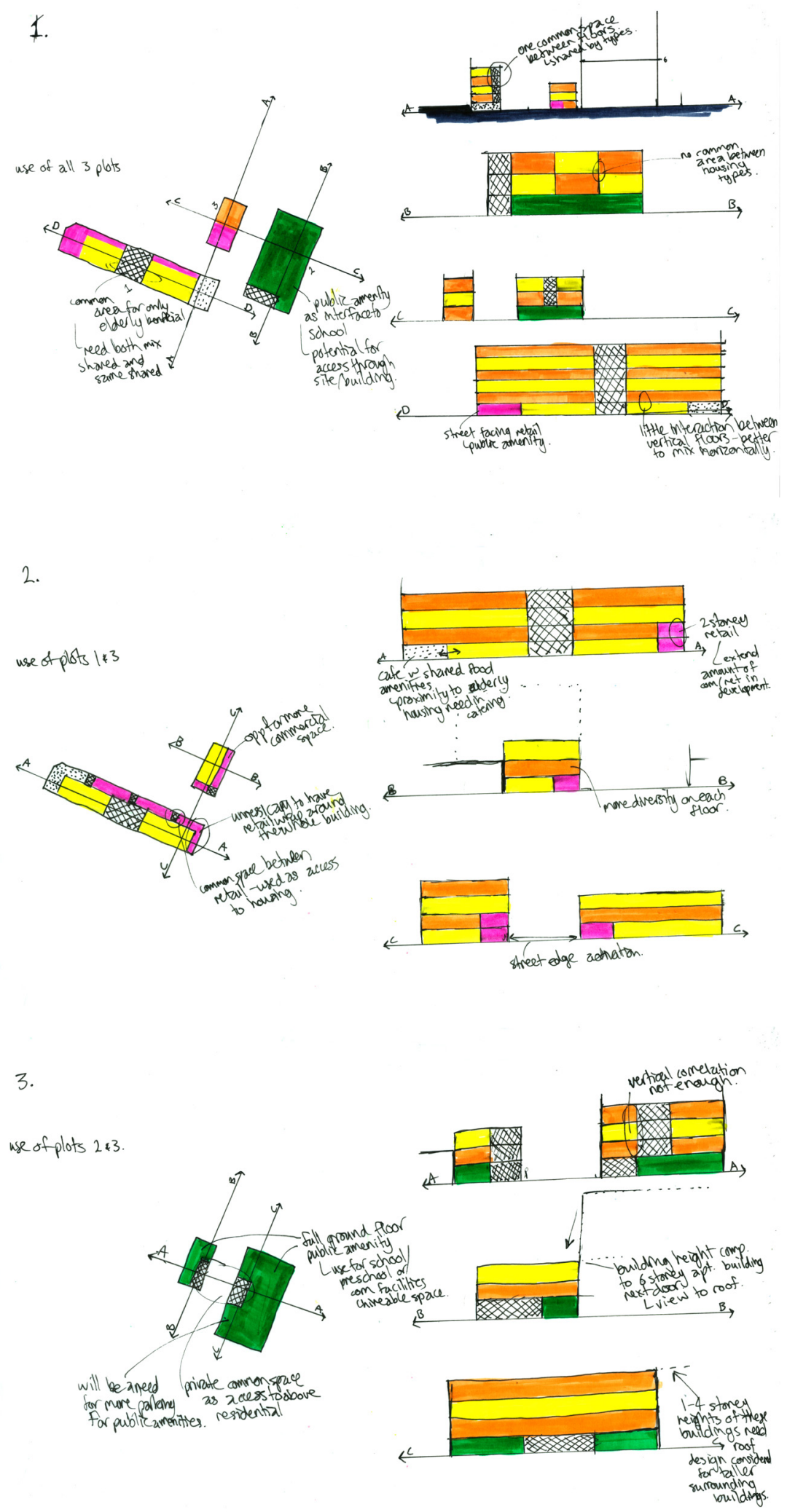
4.
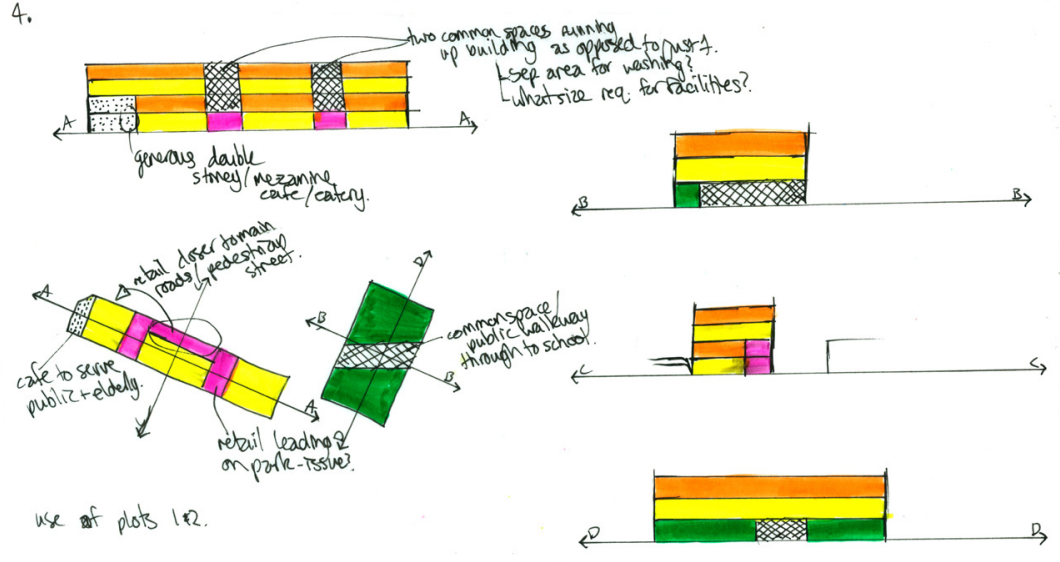

5.

Fully residential developent.

bocus on common spaces.
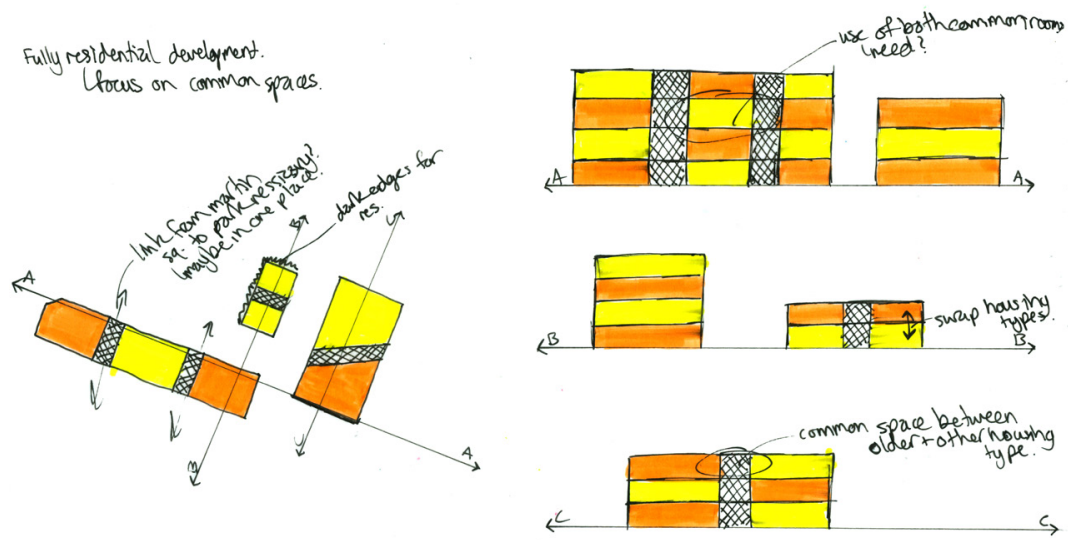

6.

All public - ground floor
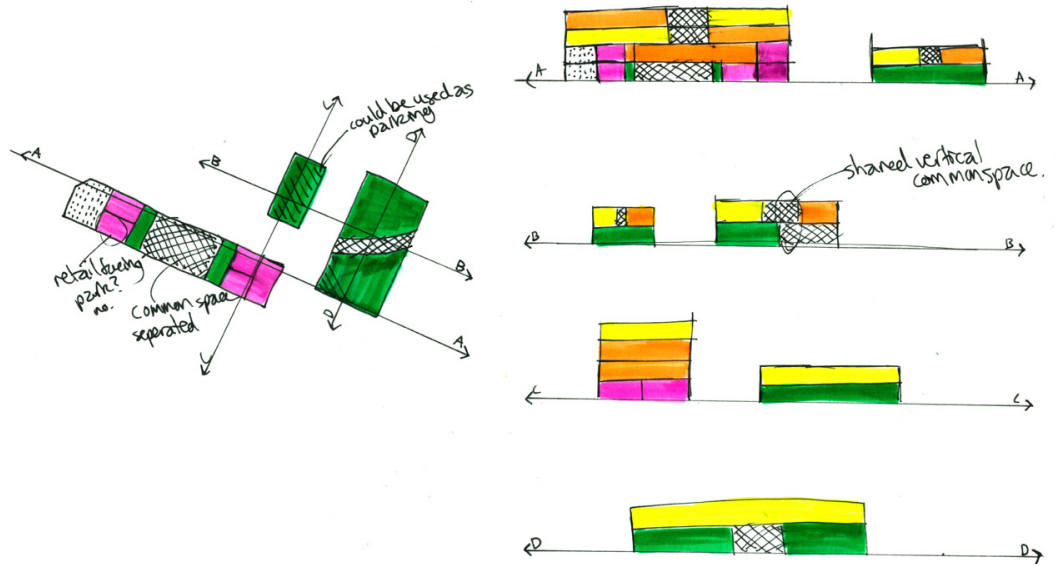


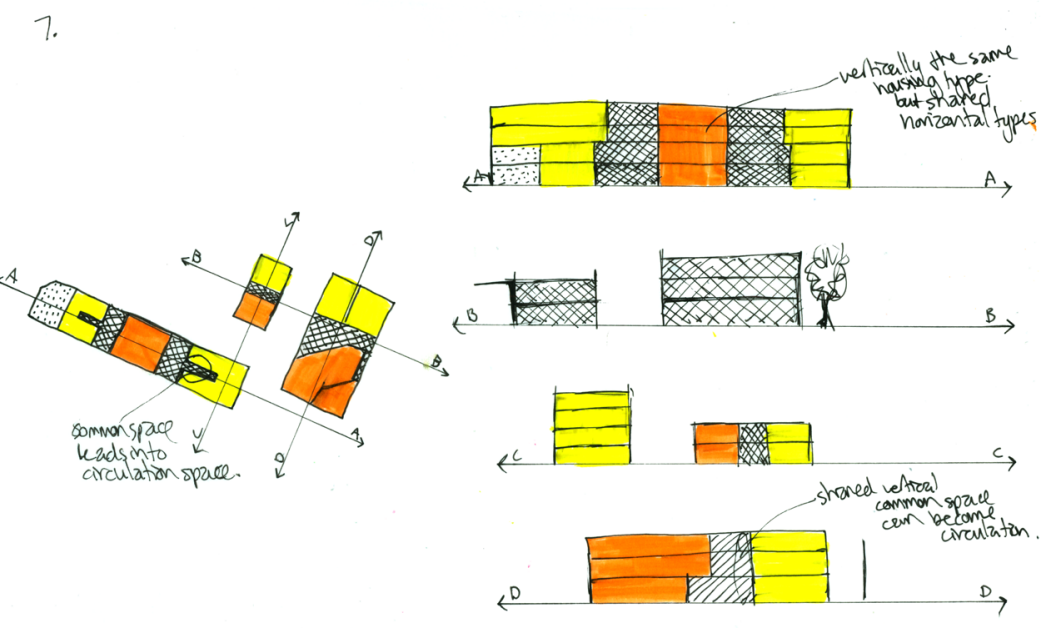

8

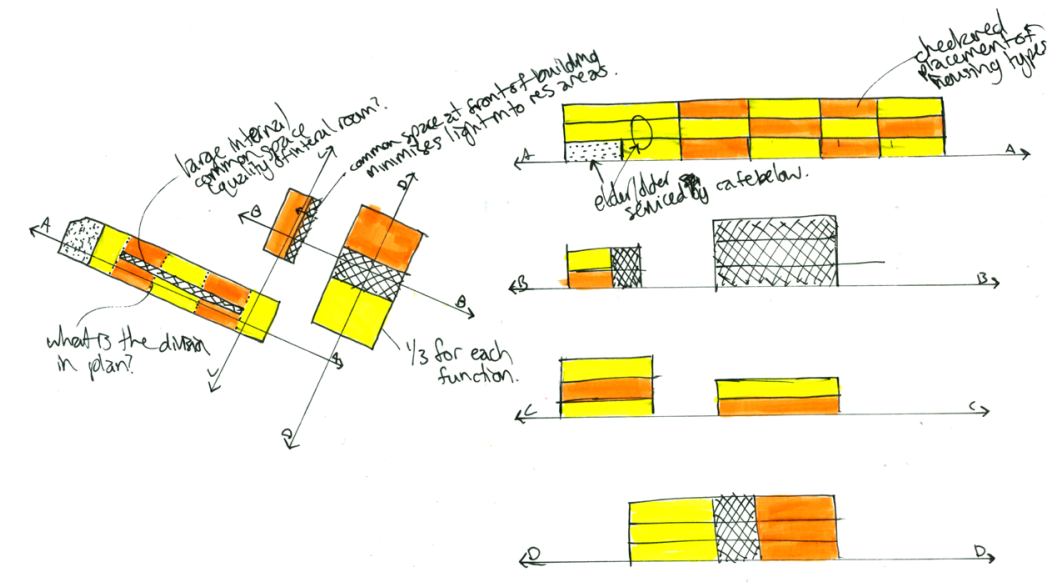

q.

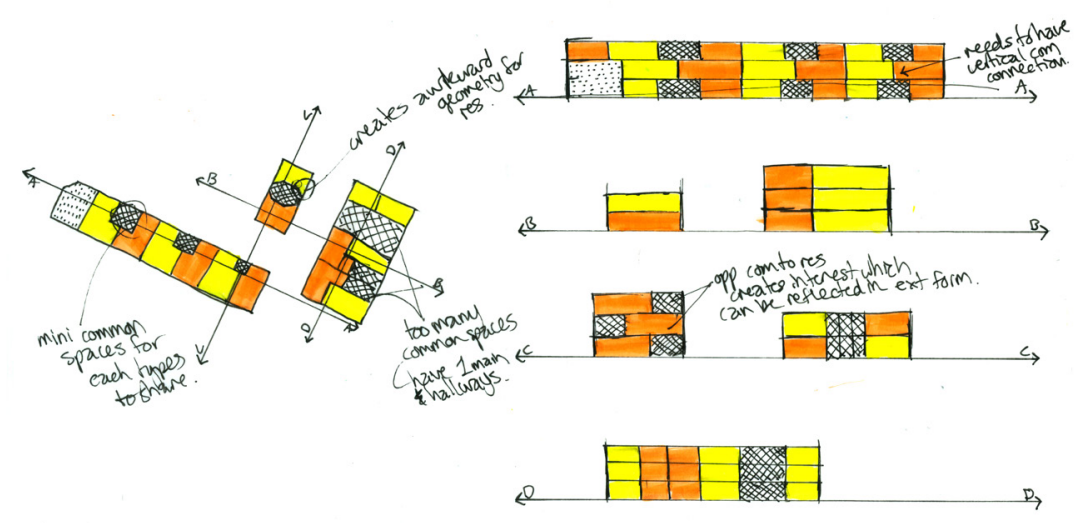




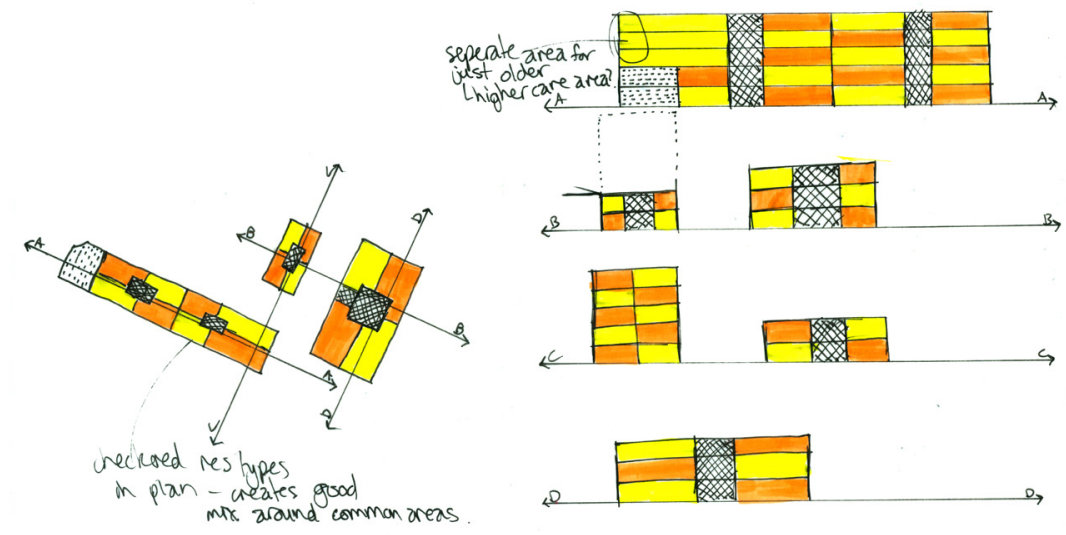

11.

Blocks withm a building

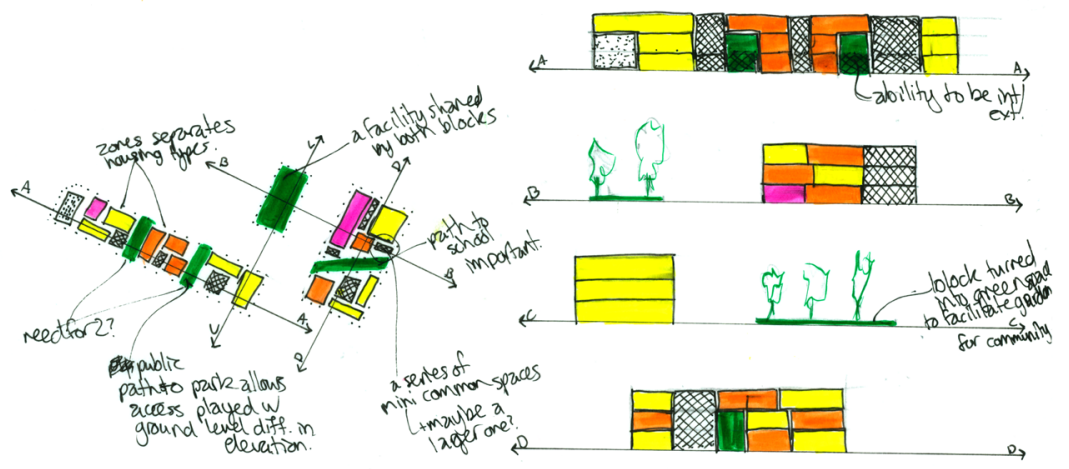

13.

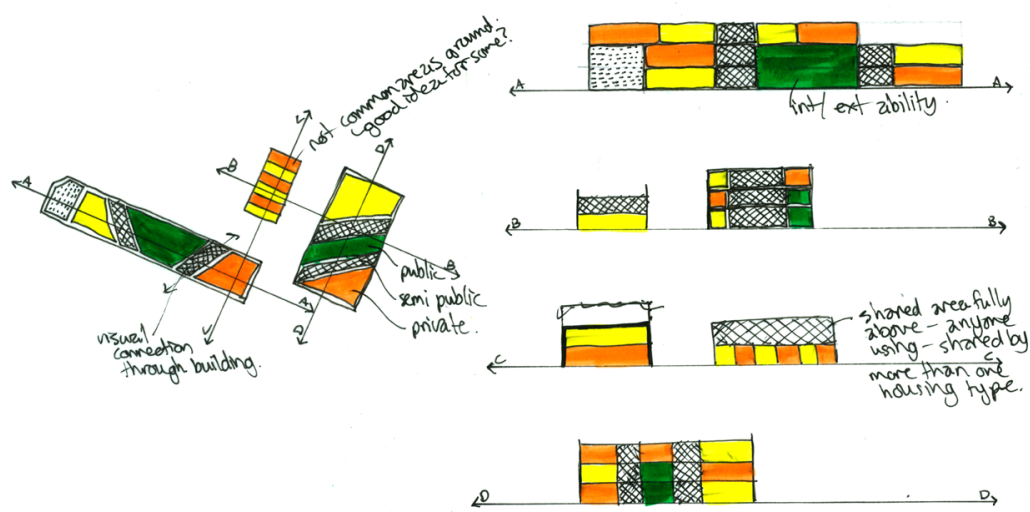


4
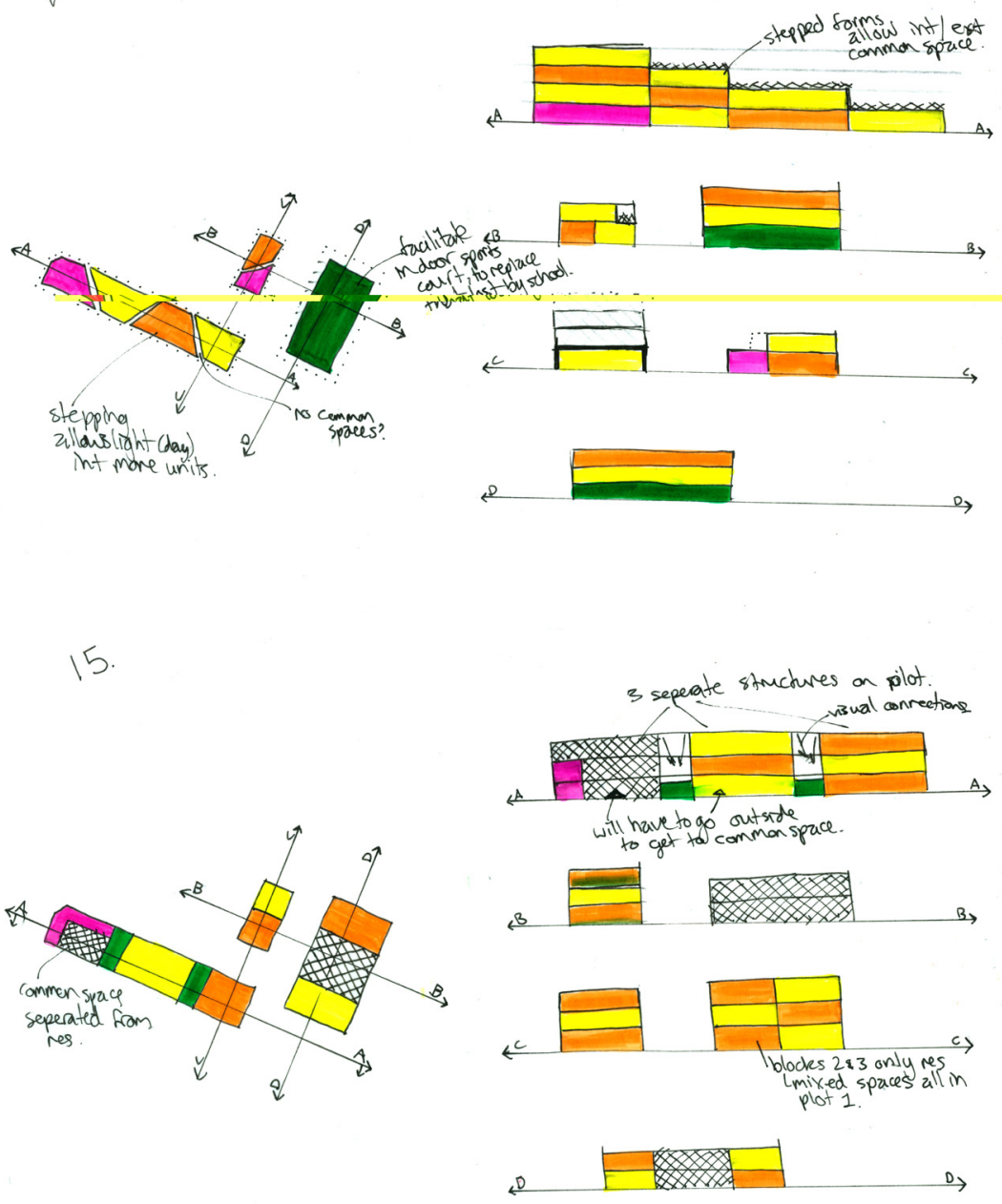

16.

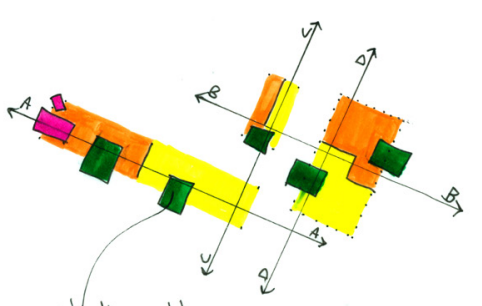

extending public space

beyond plot boundary - wout

using buit form - exagderation
of pulling peoplethto the space.
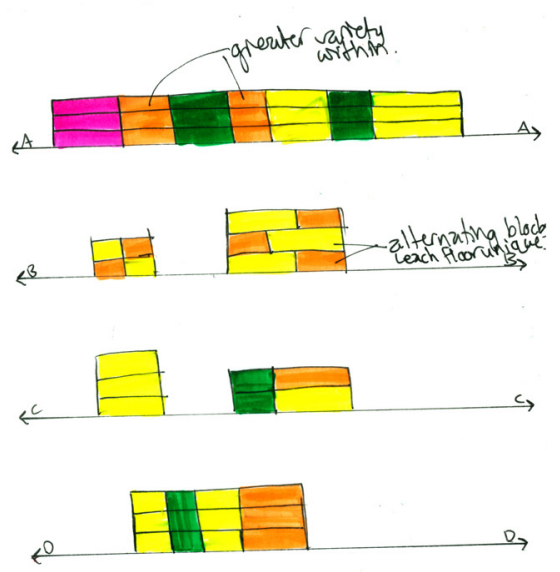


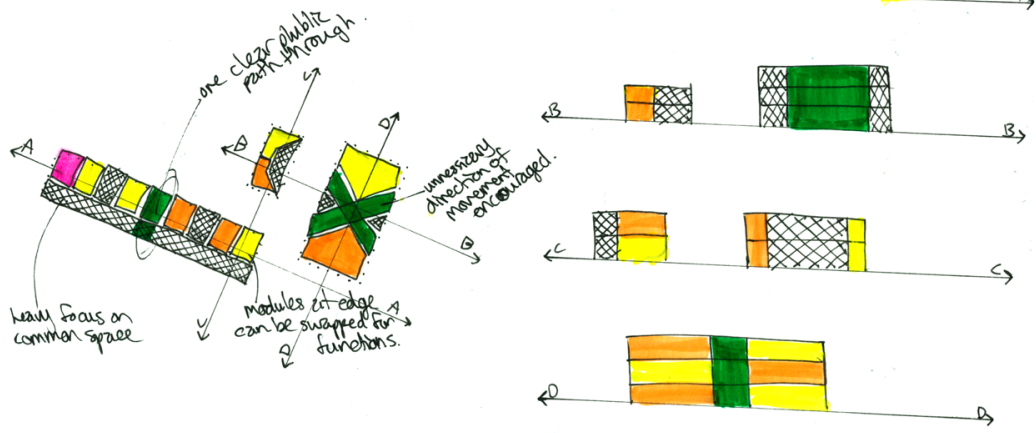

19
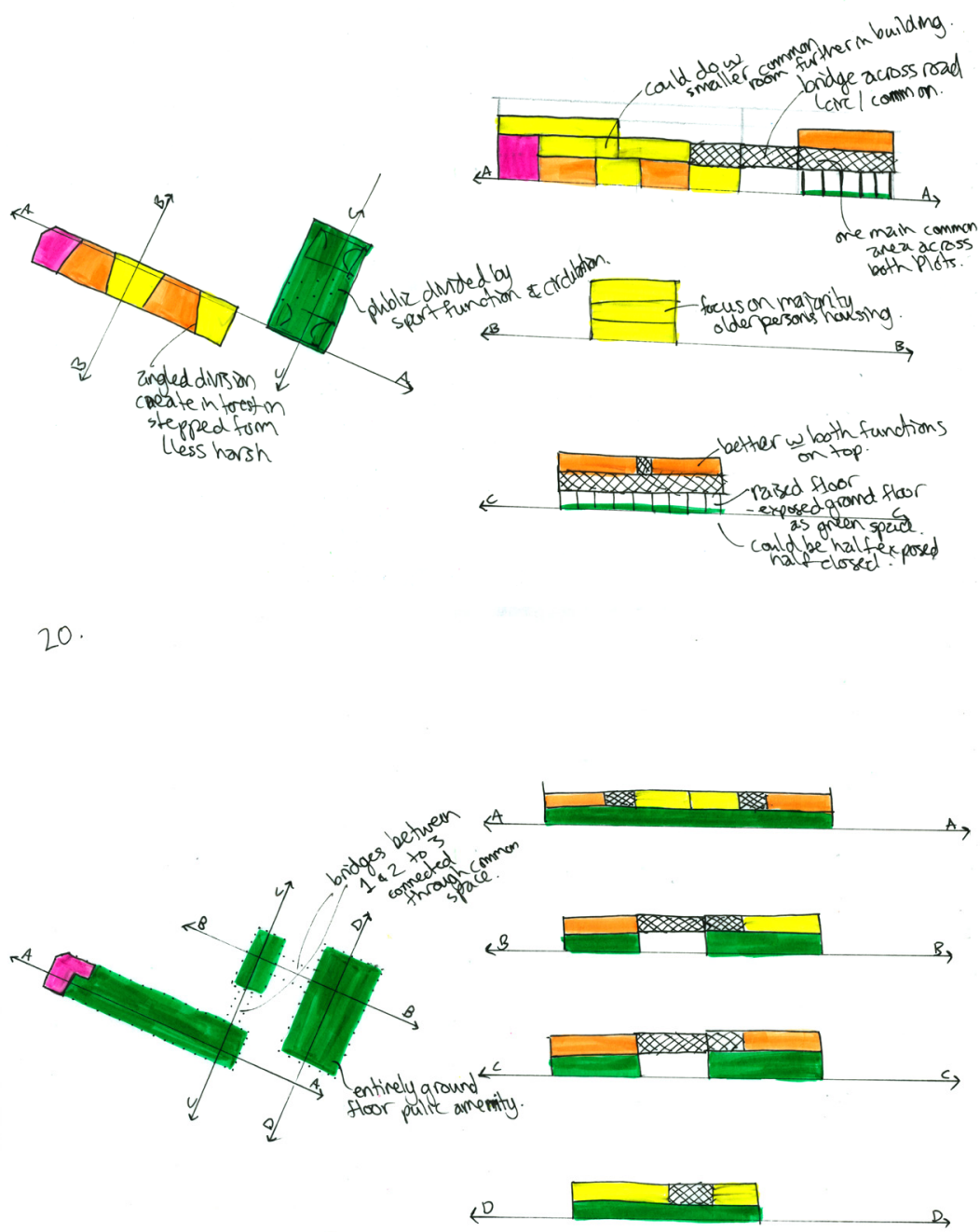


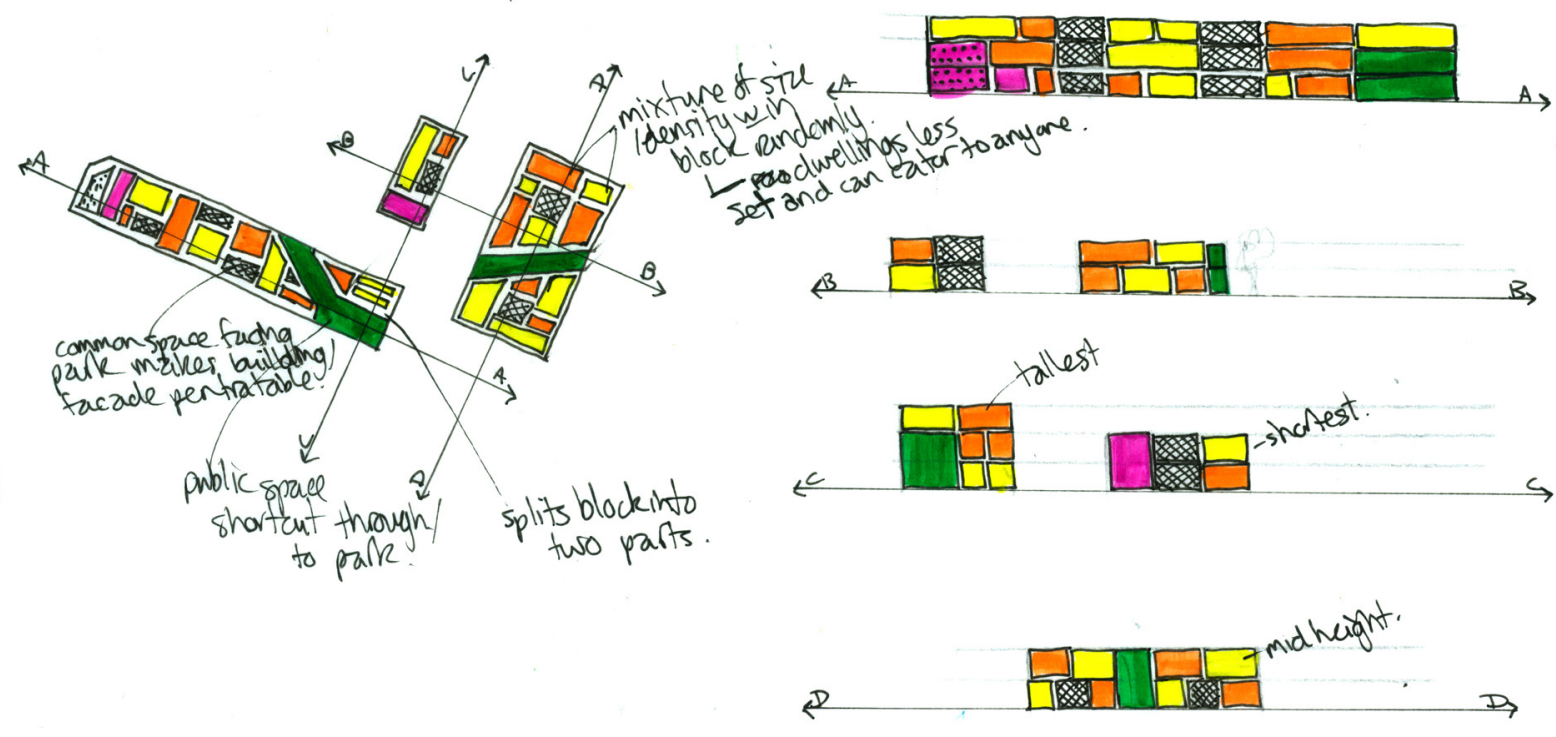

These site organisation studies highlighted some unacknowledged features of the site. Having common space and/or public facilities on the ground floor was the most successful in activating the edges of the site, it allows a threshold between public and private and maximises retail/ commercial space for the building to create revenue. Taking two different approaches for the ground floor entrances at street level and park level is required due to the change in typography, giving people access around the whole site with ramps and stairs. Common spaces shared between floors did not work because of complications with their accessibility for residents unable to use stairs, also providing common space for each floor means there is a more condensed group using the space creating more smaller communities. However the more generous the

common spaces the more people and activities they can facilitate. This is where the impact of generous circulation emerged as a key design driver. Incidental interactions are better facilitated when the user groups are divided among the floors and allow the building to develop naturally with users. One aspect of living in aged care which contributes to the stigma is the environment that is formed between elderly and older persons. There can be hostility in the rate of decline from residents from ignoring their own increasing needs to wanting to stay away from others who they fear are declining quicker. This research aims to combat that through the different resident types in the building, there is less of a concentration on what it means to be elderly and more on just living life. 


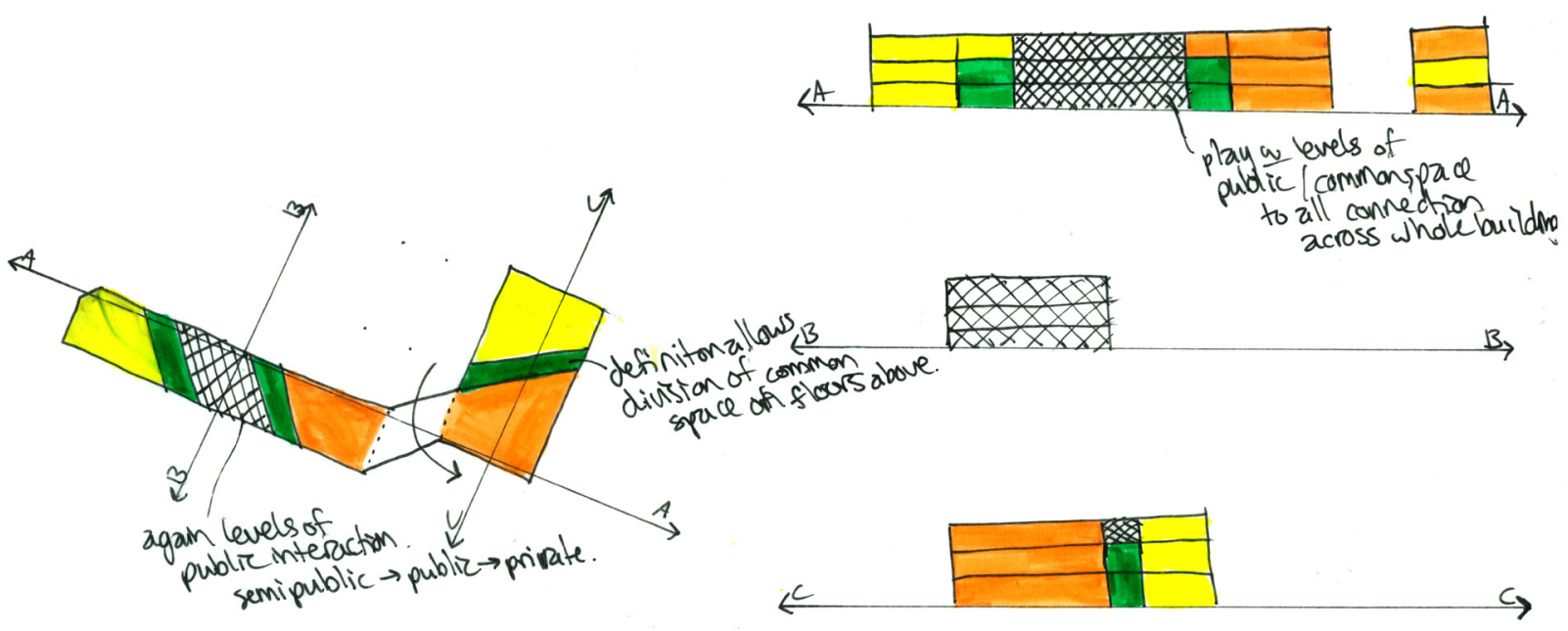

These two iterations were the most successful for their approaches to organising the spaces. The left drawing looked at the sites as whole buildings and broke them into 'rooms within rooms'. This allowed for a better understanding of the circulation between spaces.

The right drawing was the initial idea of having a public or common space cutting diagonally through the site, taking into consideration access to the park and natural pathway of passer-by. 


\section{Social Street}

Looking at wheelchair accessibility on the site, a series of design tests were done in plan and axonometric to test an idea of 'forming a street' through the site. This allows better access up to the park from Taranaki Street and avoids the steep corner at the North East corner of the site. This street could allow a threshold between the resident's entrance and use of the space and public access to amenities on ground floor and the park. This street also provides an area where incidental and planned interaction can be had simultaneously.

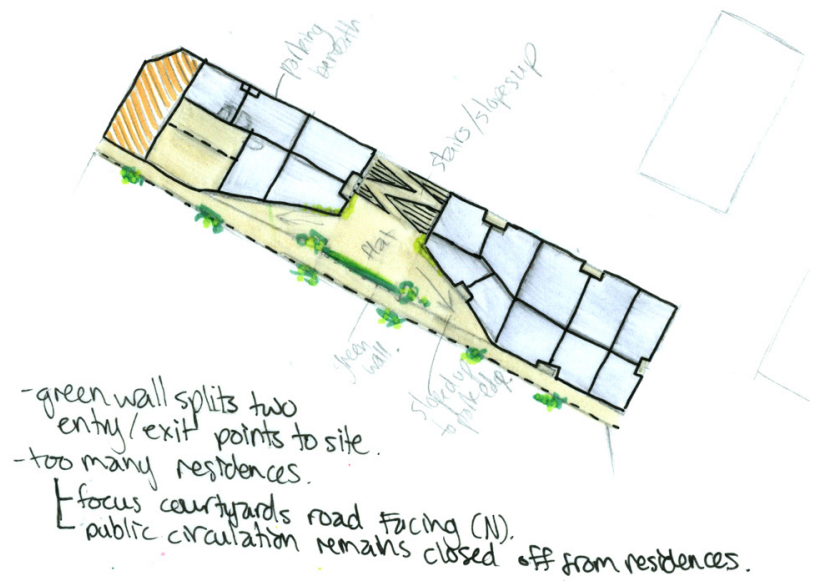

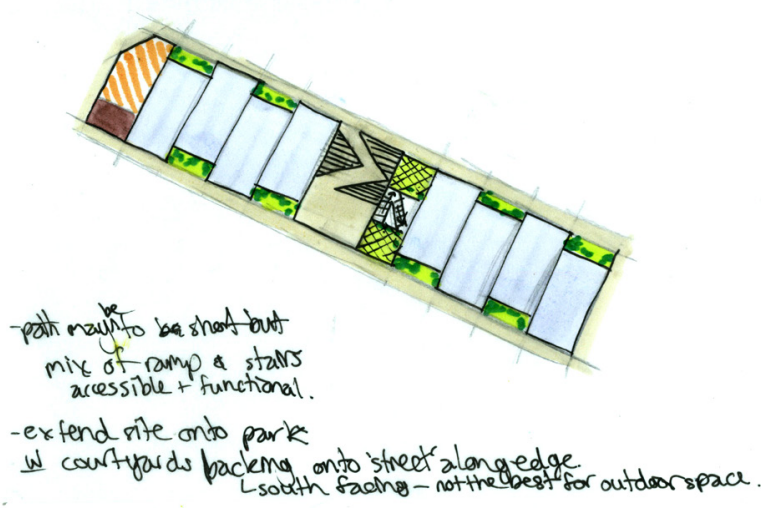

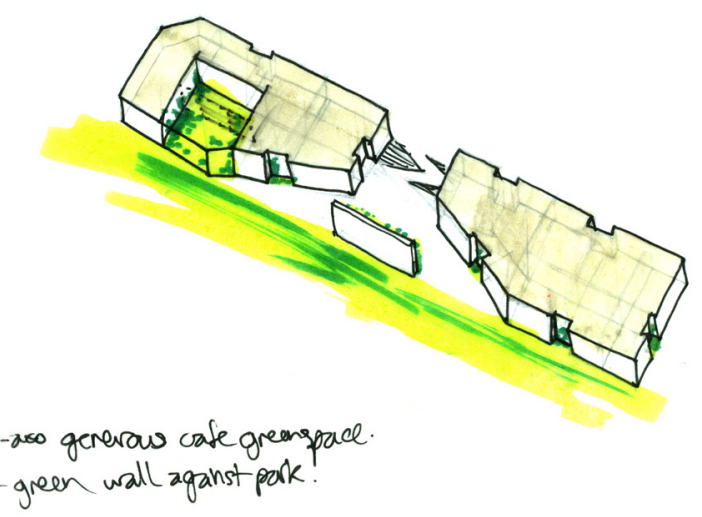



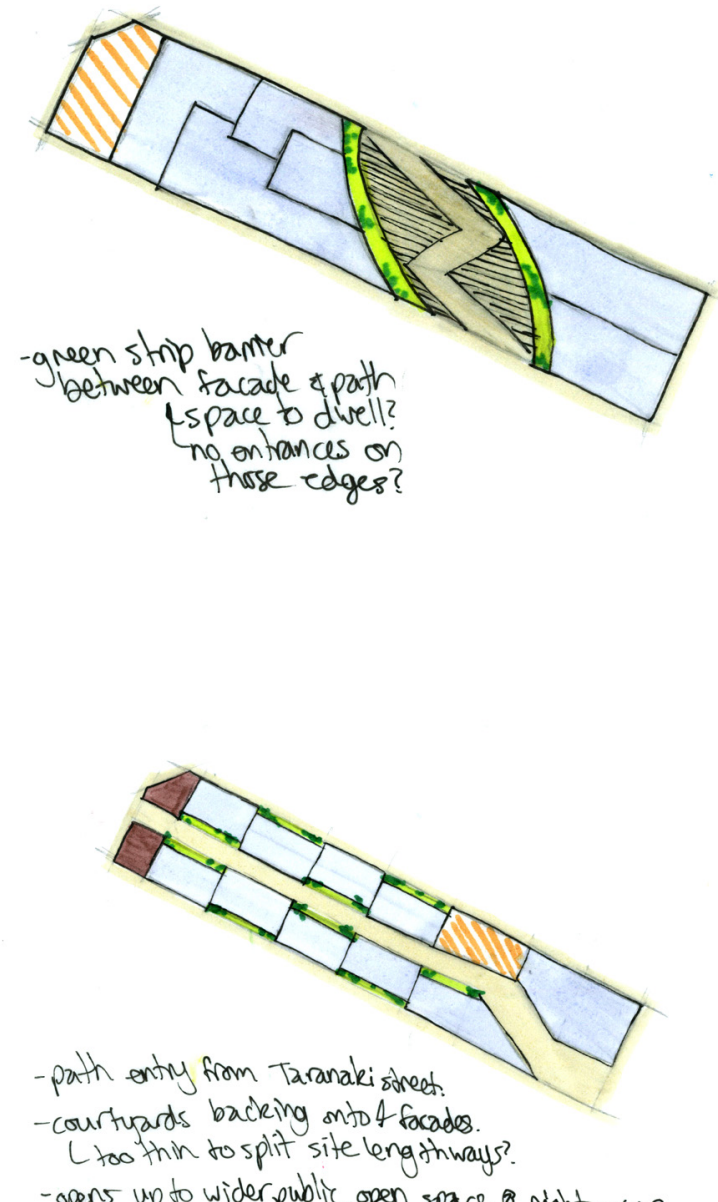

- opens up to wider public open space e reght corner.

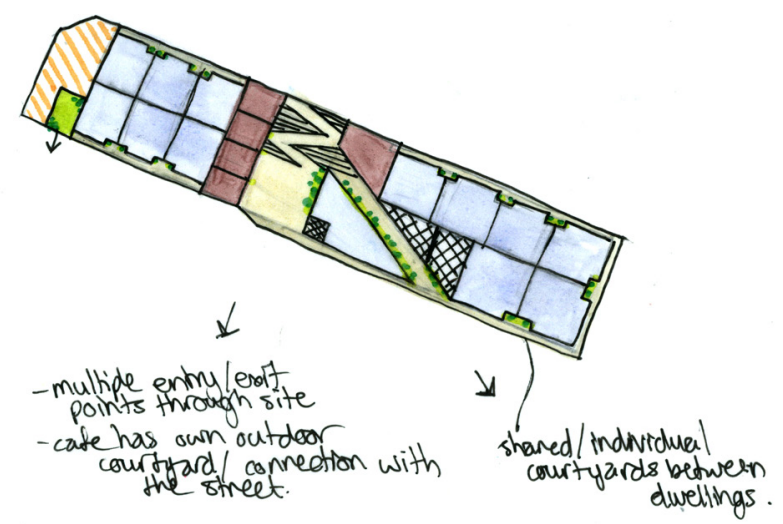

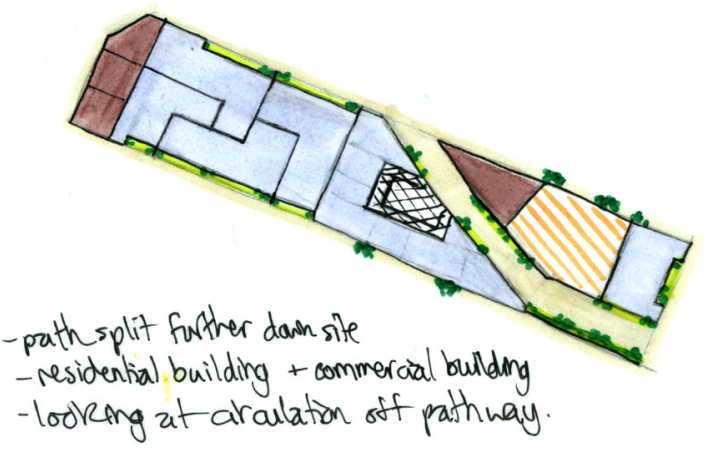

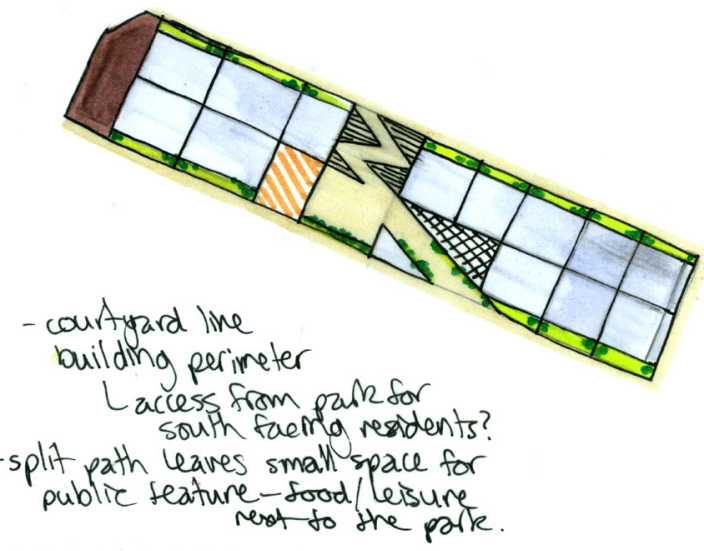

This series of iterations begin to develop the details of the ground floor circulation. Looking at getting public and residents through the site to either retail/ public amenities or private residences. These tests look at the relationship between public and private rather than between residents.

From these iterations it became clearer the importance of greenery in the circulation spaces and how movement through these spaces could begin to be influenced to facilitate incidental interactions. 

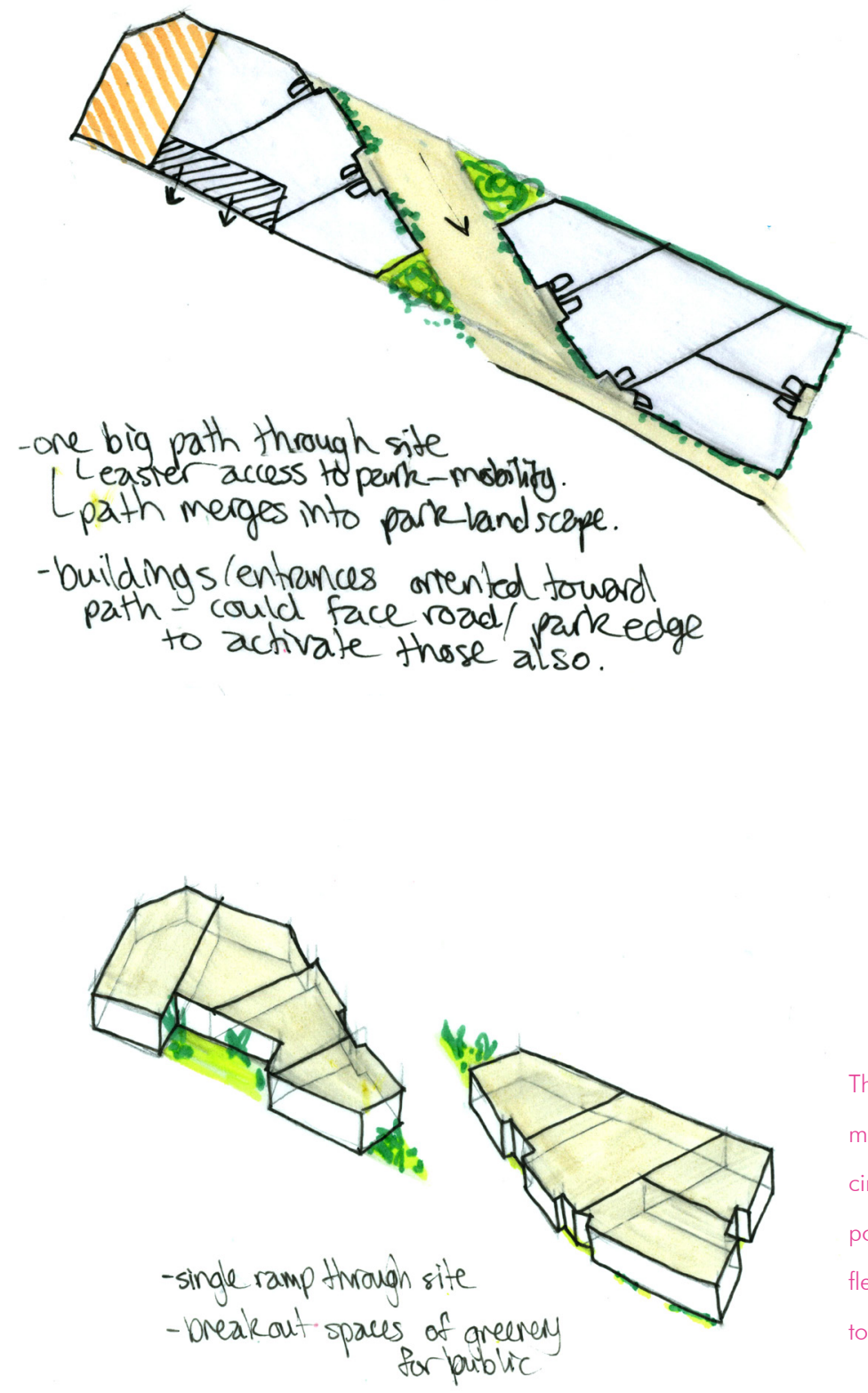

This iteration was chosen as the most successful as it had a central circulation, entrances and breakout points along the social street and had flexibility for the ramp form to develop to suit the sites typography. 

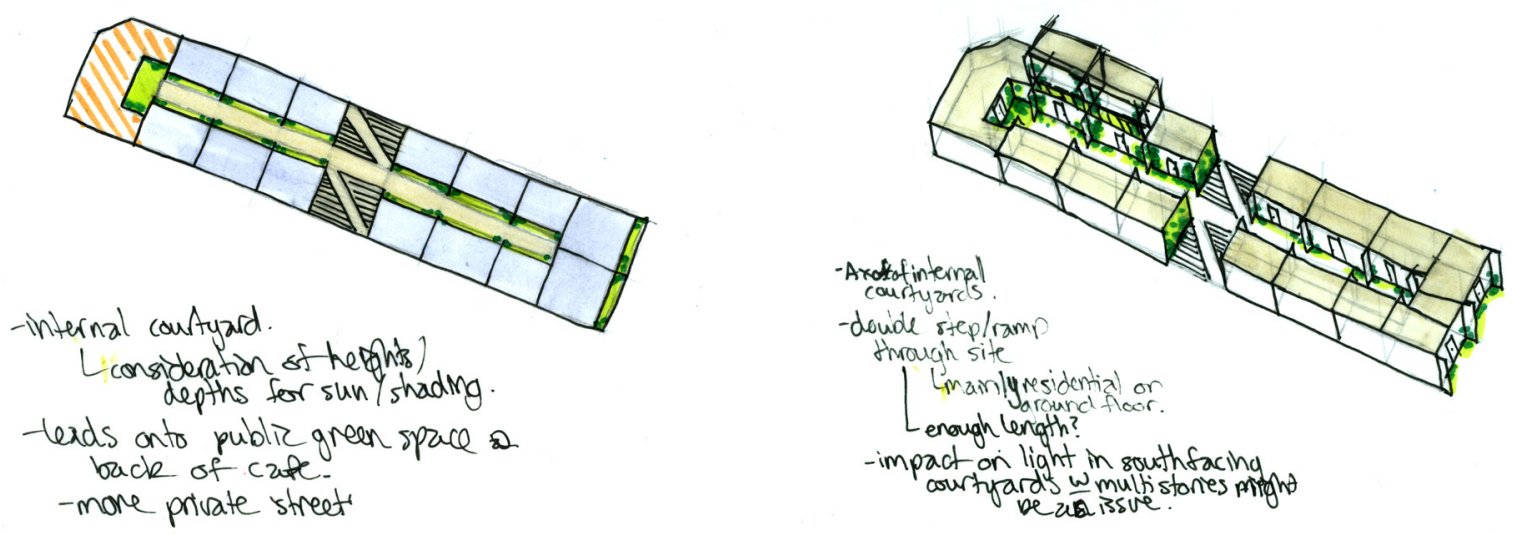

An initial form was derived from the plan iterations that created the best access through the site, and opportunity to explore the vertical circulation. The selected social street design cuts through diagonally as that allows enough distance to ramp up the $3.1 \mathrm{~m}$ and activate more of the ground floor edges. The form deriving from this meant a split into two buildings (structurally and seismically) but with the intention of common circulation and shared spaces around a shared central core. The form had some awkward shapes that the circulation did not compliment or soften. This was one of the critical reflections, the separation of the social street ground floor spaces, which were working well, and the vertical circulation seemed split from one another because there was too much of a threshold between residential and public. This focus on circulation became a key design tactic as the resolution of different circulation elements can benefit social interactions, accessibility and public engagement. 
Older person/ couple - Independent

Elderly/ couple - Dependent

Tertiary Student (couple)

Young Professional (couple)

\section{Young Family}

Middle Age Family/ couple

Elderly-High dependency

Three user groups were established; elderly/ older persons (intended for smaller units), young families (which will grow/ age and adapt within units that the building offers) and tertiary students (with the intention of flats of students as well as studio apartments for on-site student nurses). This was decided by this series of matching residents which ensured there was an intergenerational mix between potential groups.

The groups are selected for their benefits to the elderly when engaging in intergenerational interactions. Tertiary students are being employed in rest homes around the world to support and encourage elderly in their use of technology (Harris, Johanna. Here's Why Some Dutch University Students), young families mean children are interacting with the older persons and elderly and offers a potential for adult children to live close to their ageing parents.
Pairing and grouping all of the different potential resident types with elderly/ older persons revealed that young families, older persons and tertiary students created a good mix of generations and capabilities to house together. 


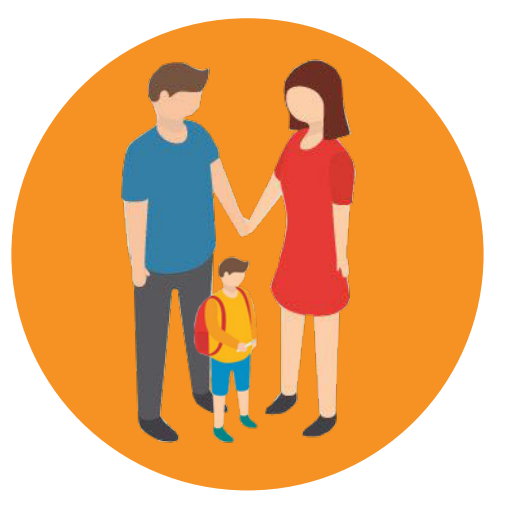

Young Families

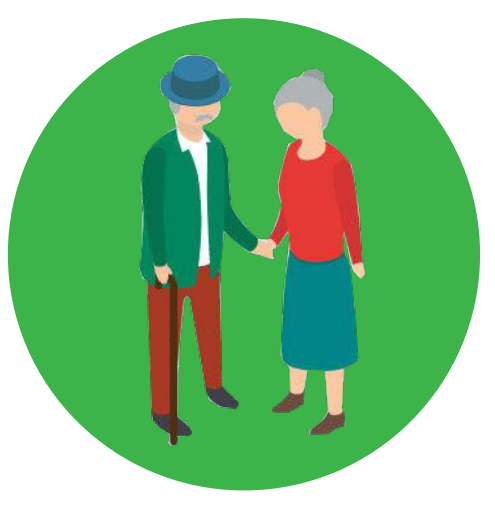

Older Persons

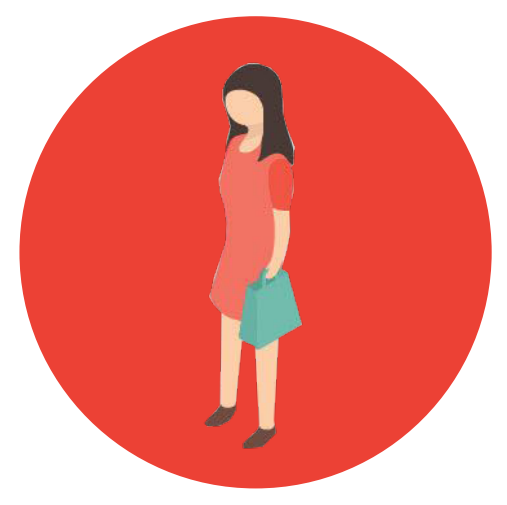

Tertiary Student

\section{Justifications for resident pairing/groups}

Noise/ movement

Benefit of relationships (babysitting, house sitting)

Proximity to building services 


\section{Massing Models}

These coloured groups were used in the massing of apartments on the site. For basic planning of the arrangement of residential apartments, massing iterations were made with blocks representing older persons/ elderly, young families and tertiary students. A bridge between the representation of apartment planning, similar to the SAANA example (Lenk, James), and adding in the context of this site to visualise how many apartments might fit and what configurations would be reasonable. These massing tests revealed that all apartments would need to be double aspect apartments to allow enough ventilation and sunlight into the space. These studies resulted in a diagrammatic way of planning and cold way of grouping residents, lacking the essence of flexibility and warmth that the spaces need to evoke.

Fig. 3.1

Tests of apartment planning, split into resident groups, helped to realise the scale of the site and determined the development would be medium density.

The different configurations of apartments, one or two storey, two or three aspect, initiated the consideration of how the users would occupy the building, what needs would change over time and how the apartments could cater to different needs.
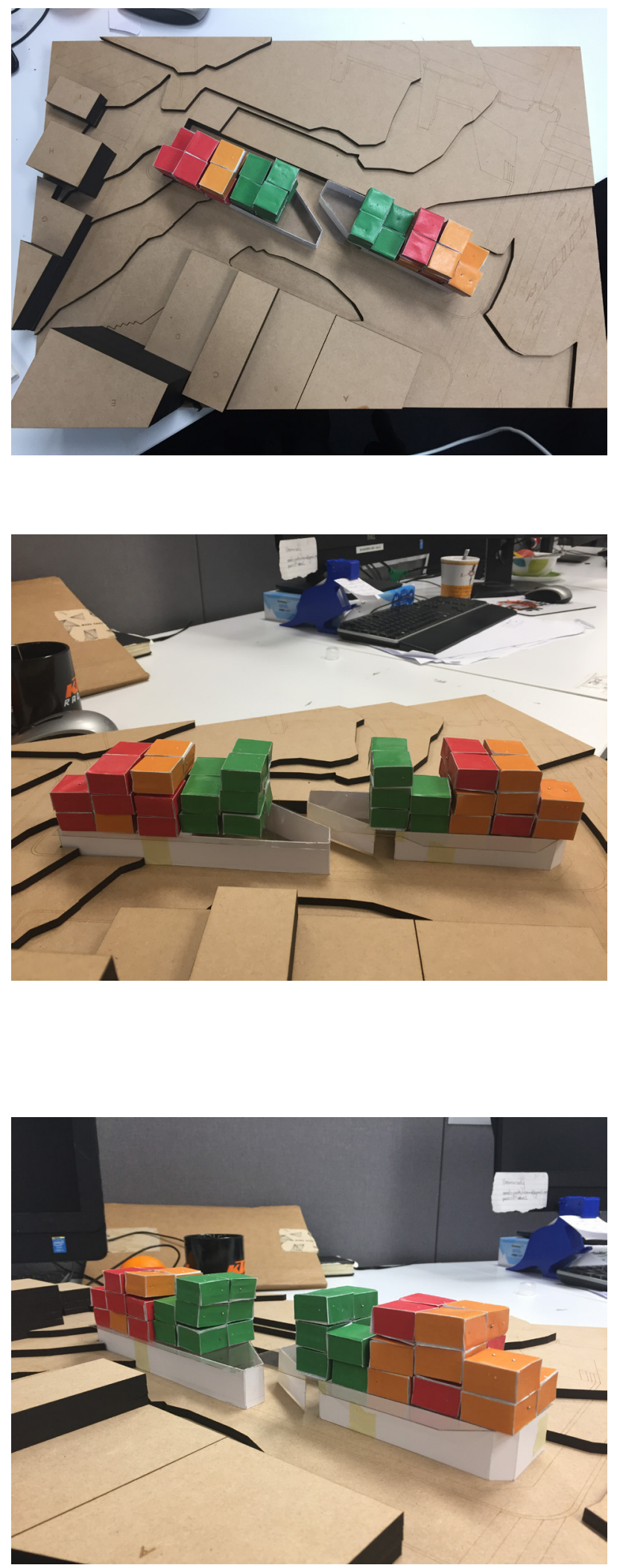

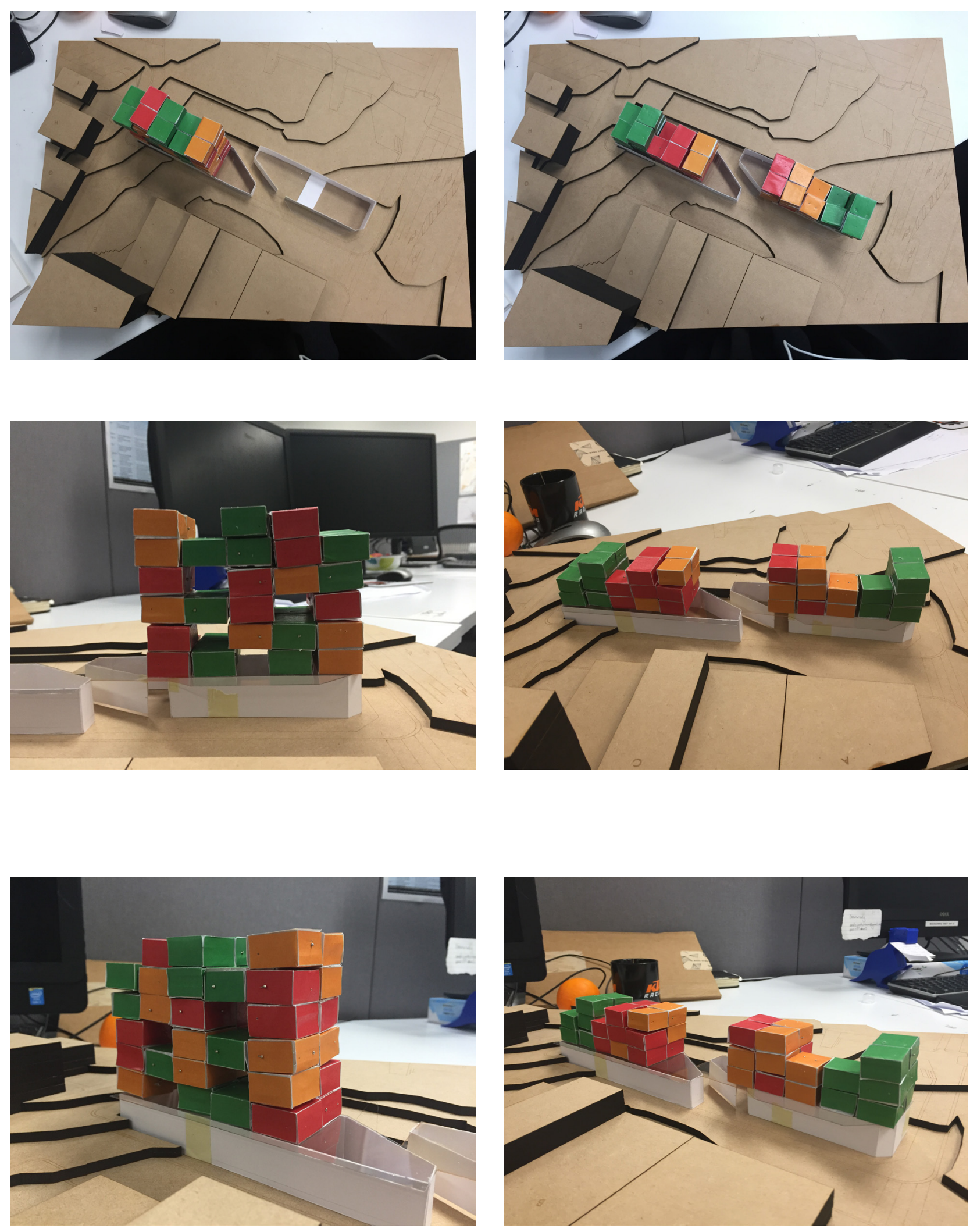


\section{Circulation}
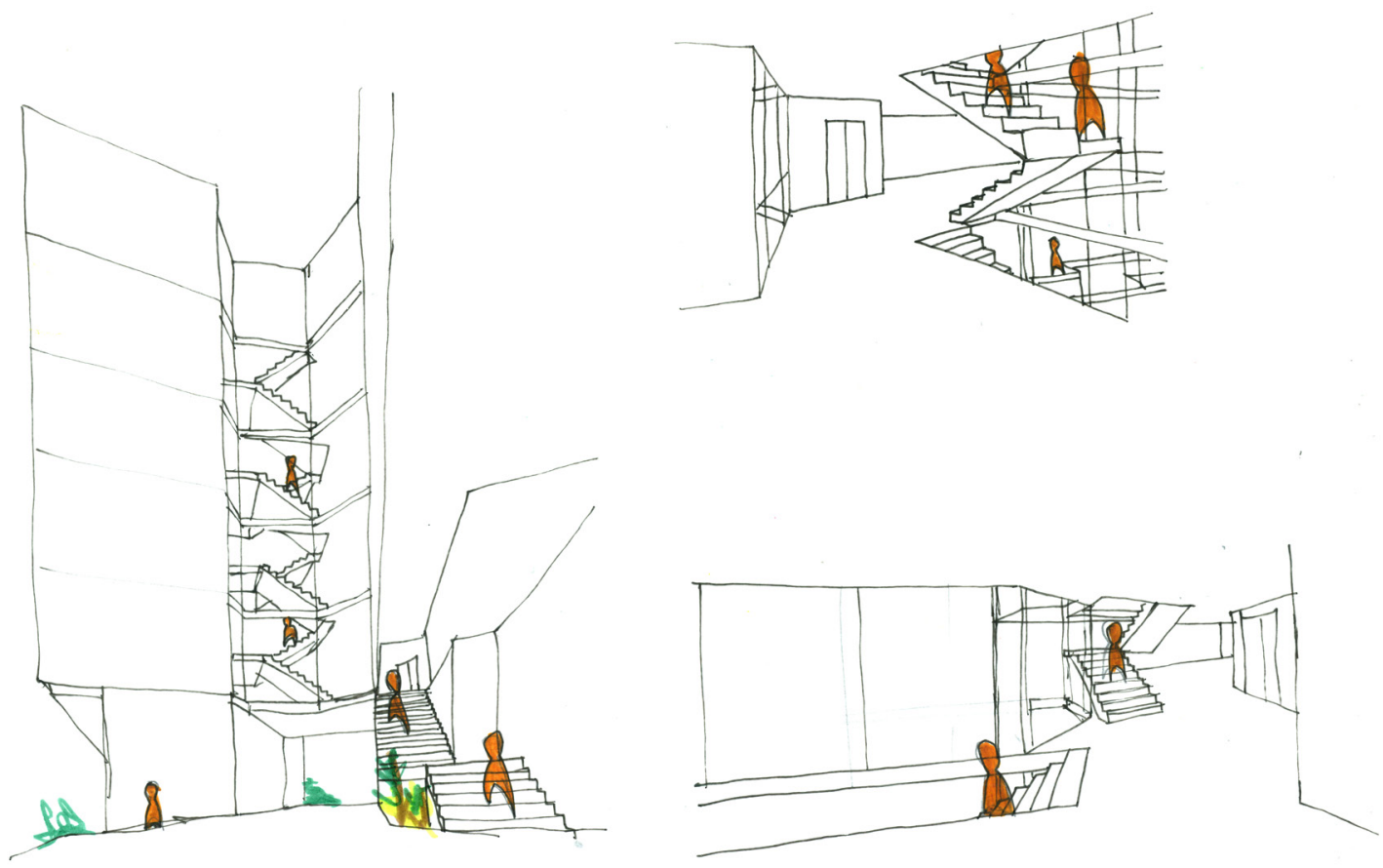

From the drawing iterations and massing model the design was digitised. This arose a lot of issues and intricacies with how the core circulation would work, getting residents to both sides of the building with a generous stair width and tread.

Each 'wing' of the building was extruded up from the plans, remaining block forms for the time being.

This iterations are sketches imagining what the interactions could be within different circulation configurations. People passing by one another when catching the lift, how the stairs could incorporate seating and areas to dwell. This was important for determining the vertical circulation core as a key area for facilitating interaction and placing common spaces. 

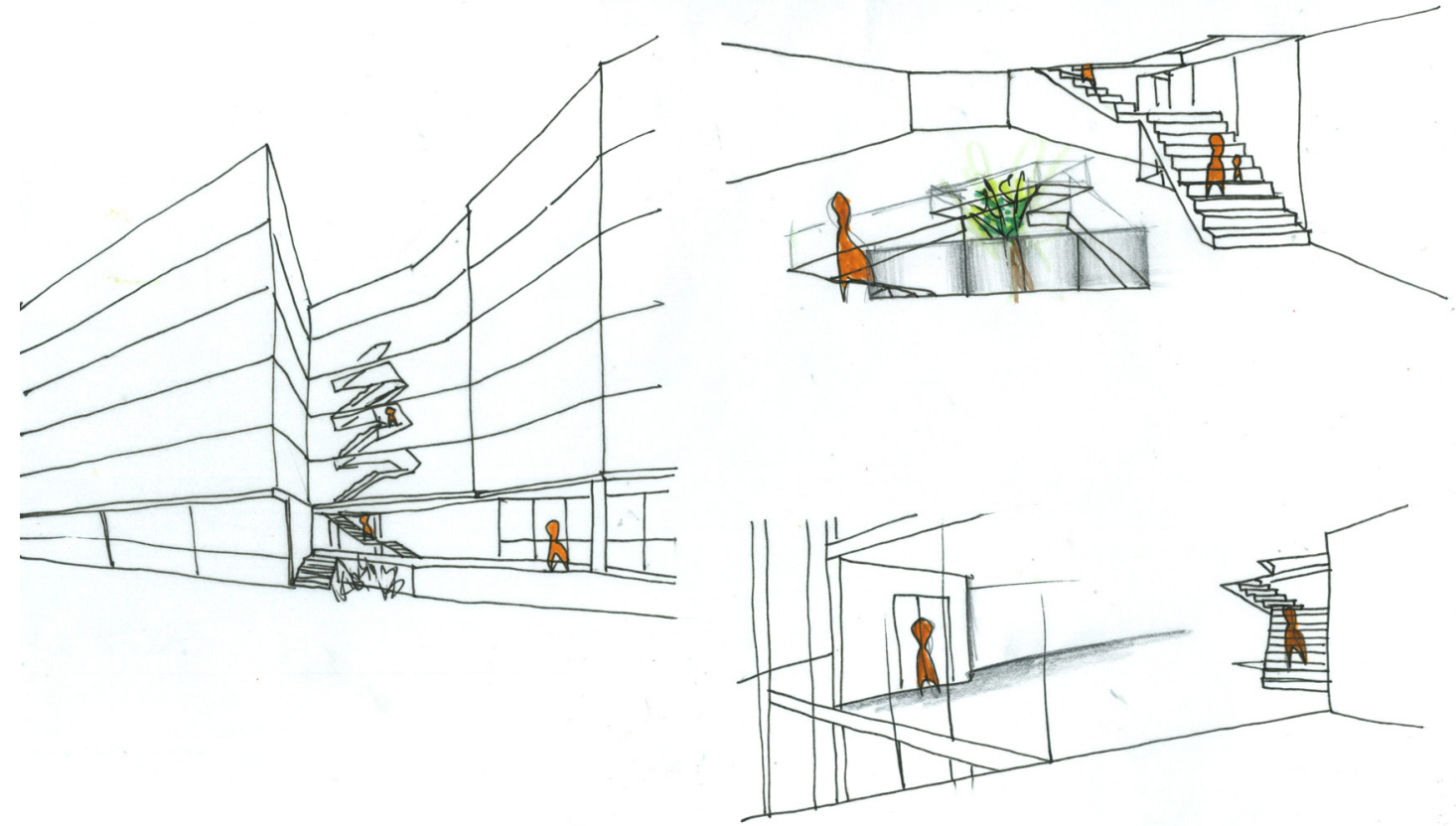

Circulation iteration of stairs core running vertically between the buildings allowing a void for vegetation to intersect the buildings interior.
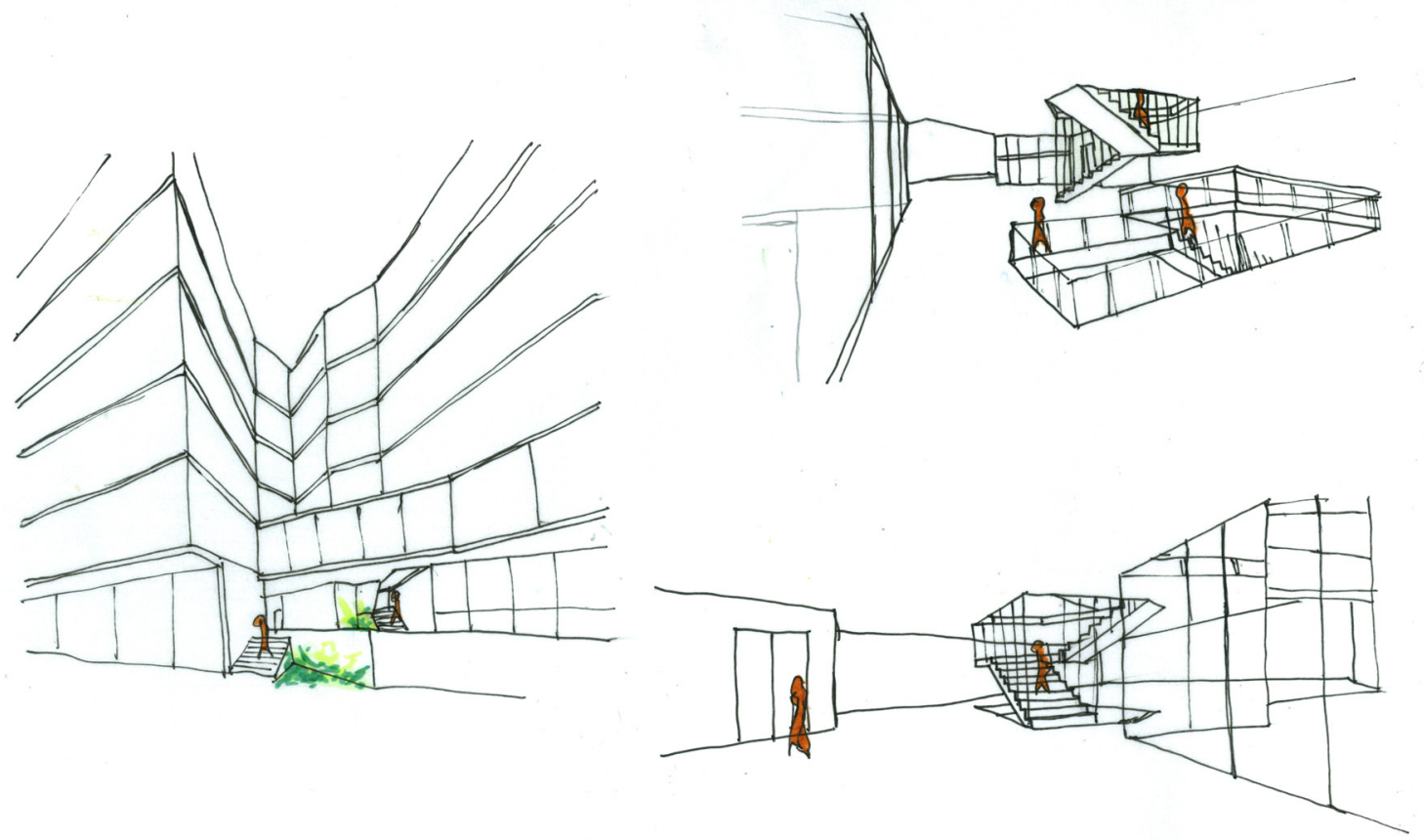

Circulation iteration looking at the proximity of the stairs and lift and residents interacting while using both. 
Walk through

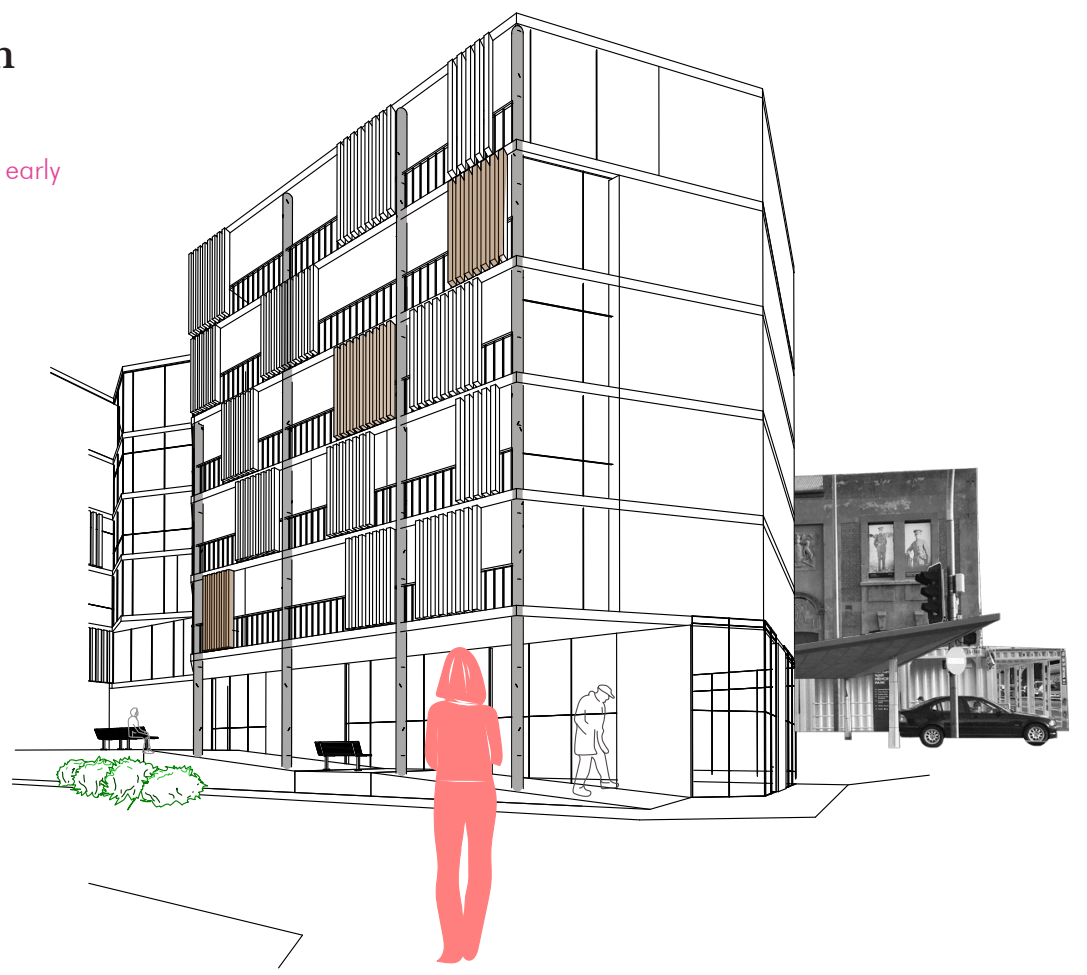

Leslie has arrived back at the apartments after her walk.

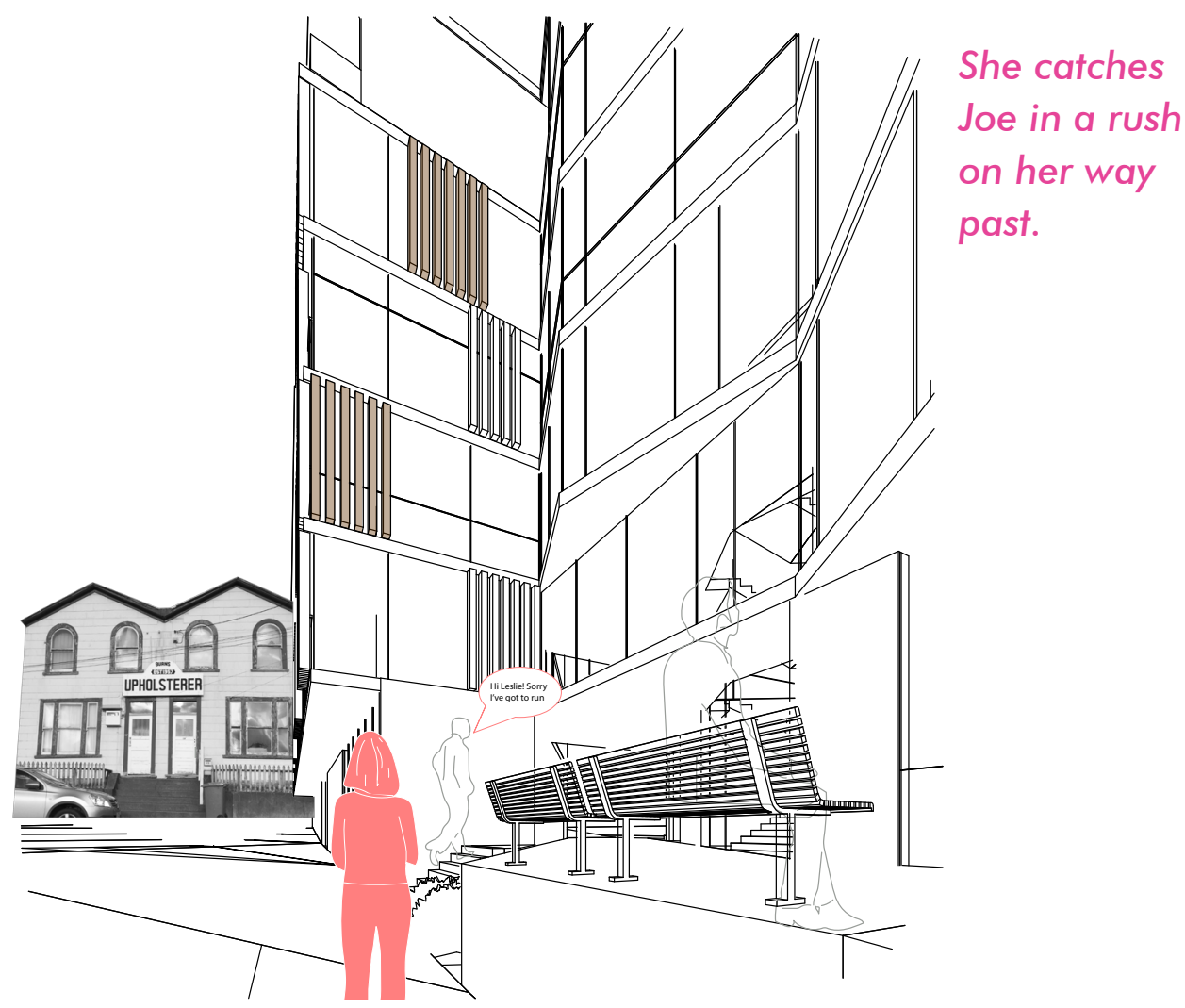


Leslie is just in time for her yoga class.
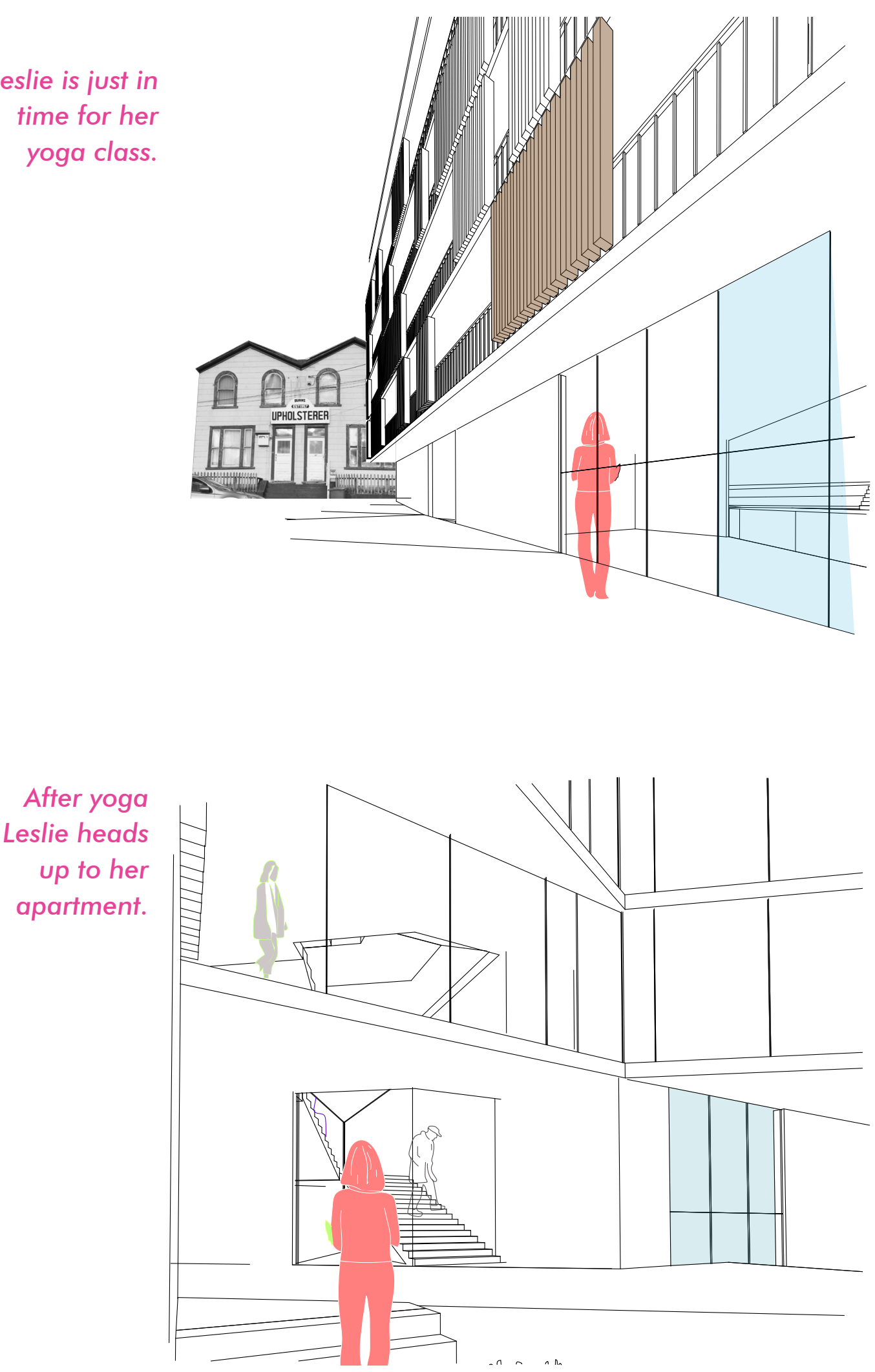

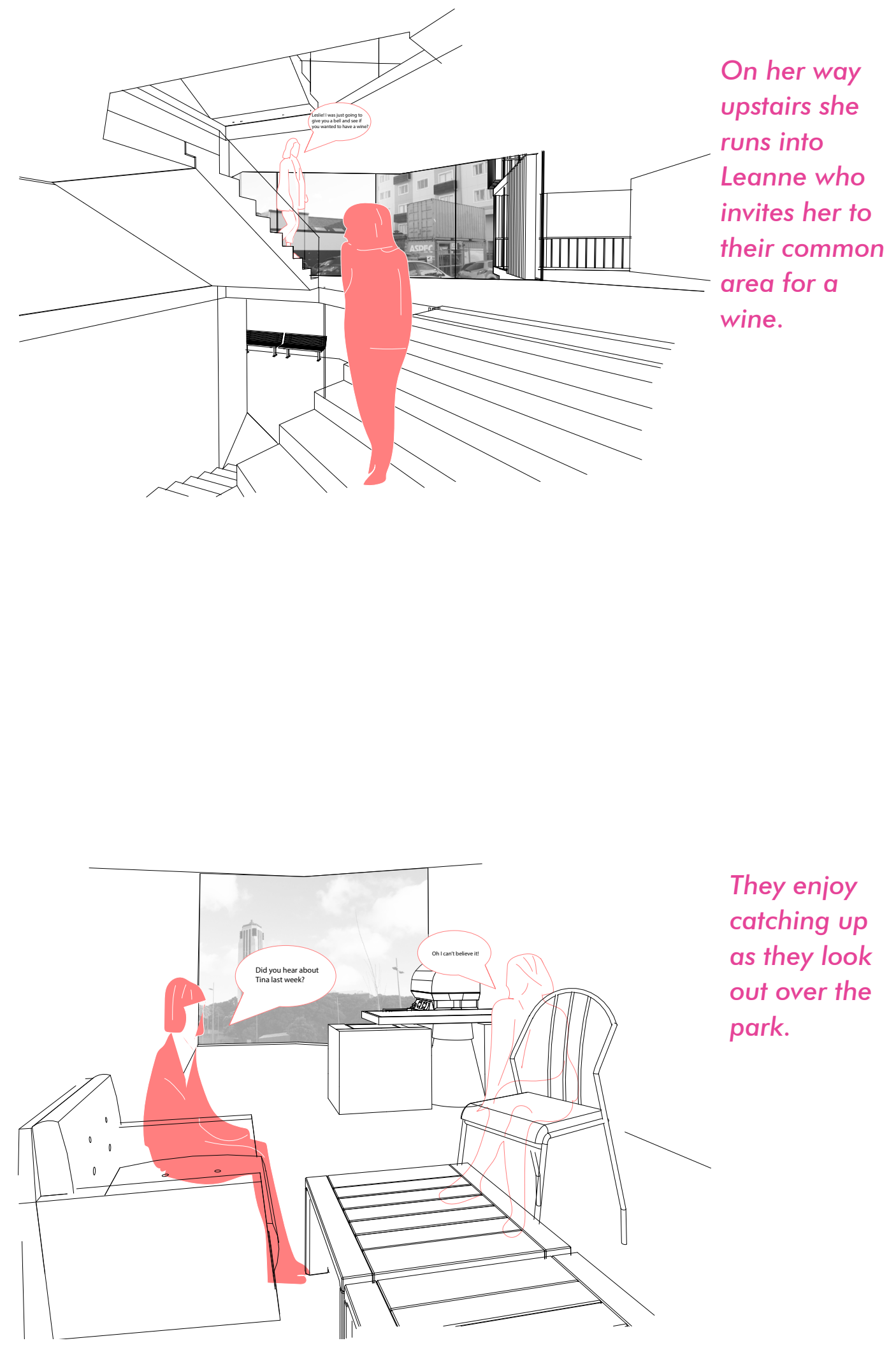

They enjoy catching up as they look out over the park. 


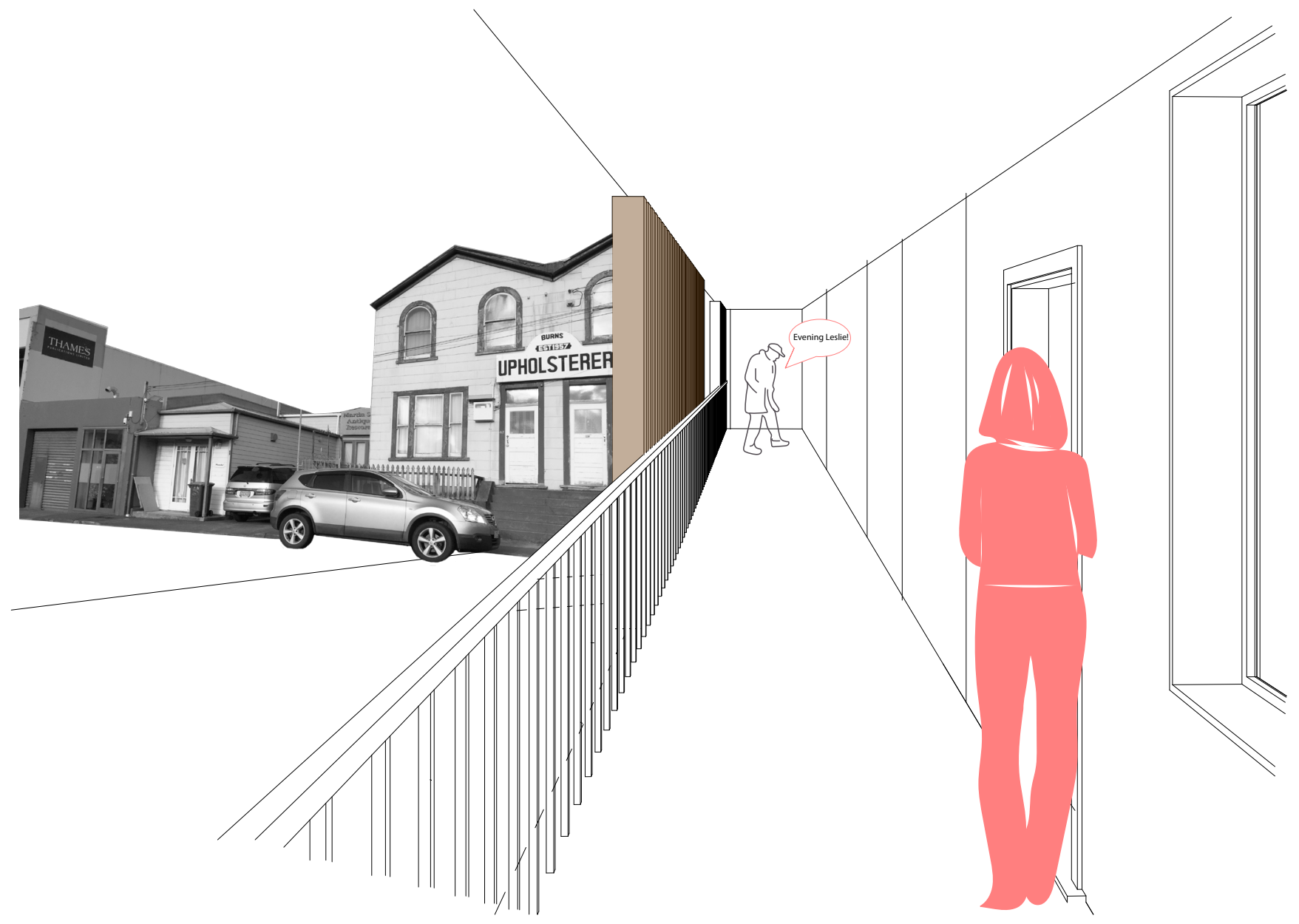

Leslie then heads back to her apartment after a busy day. 


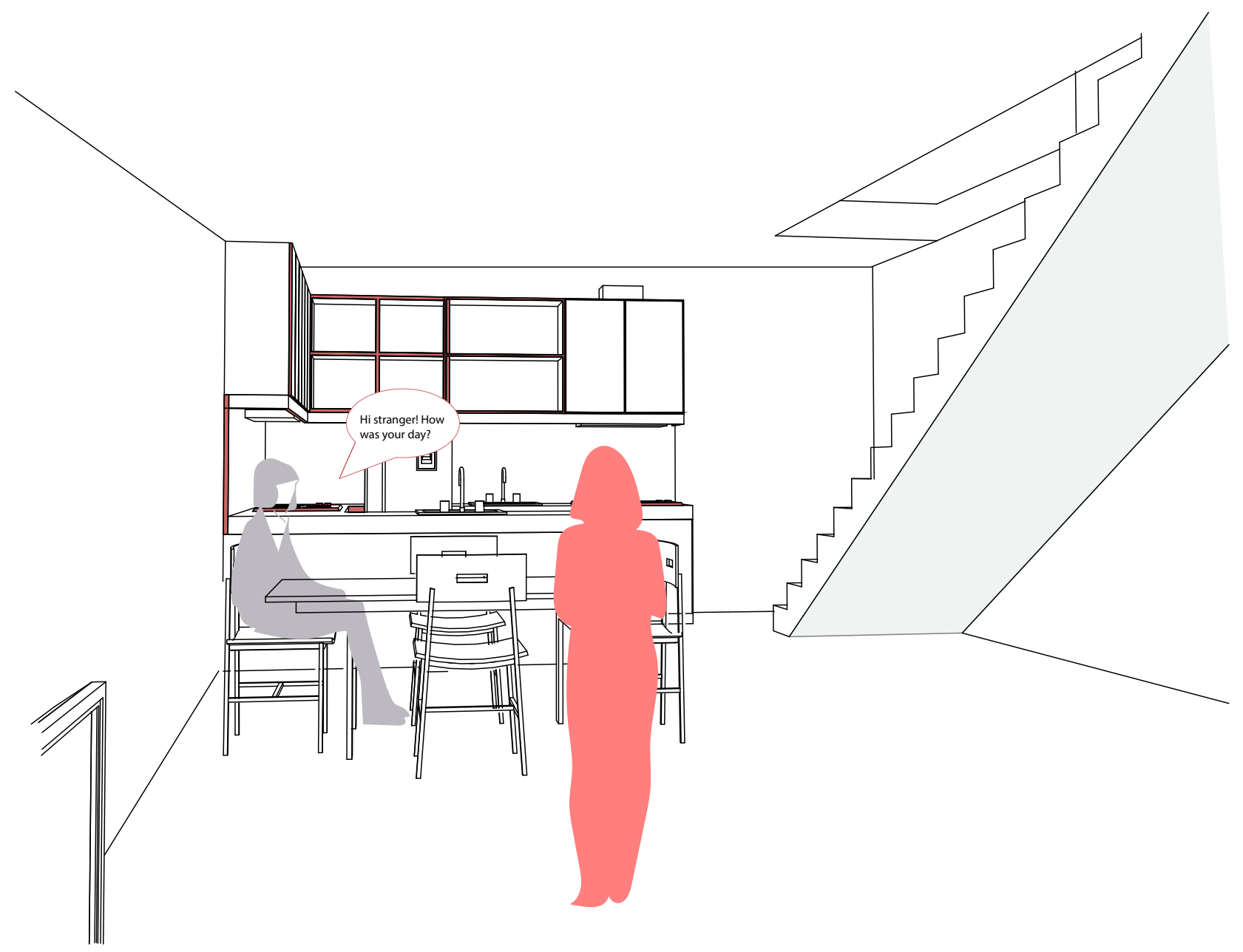

Leslie's wife has dinner

prepared for her when she arrives, they eat and relax for the rest of the evening. 


\section{Strategy:}

To grasp the scope of this project the four main areas of investigation were selected based on what was emerging as primary focuses for achieving the aims and objectives. These four areas, called the four tactics, are 1. Urban Location- looking at the opportunities of the selected site and context and ensuring the development compliments the landscape, 2. Social Circulationproviding different types of circulation through the building, facilitating interactions between residents and the public, 3. Mixed Housing- fully accessible apartments, which cater toward any resident and will allow growth and change in needs of its residents, 4. Shared Amenities- providing health and support services for the residents and public. Going forward into more design refinement and development, areas of experimentation were highlighted from the four tactics. The first two tactics and overall form were made into broader concepts to look at the design as a whole again and what it is missing. Discussed in the next chapter is the implementation of these design experiments to the overall design refinement. 


\section{The Four Tactics}

Early Strategic Diagram outlines four main tactics and their initial representation in the first design response.

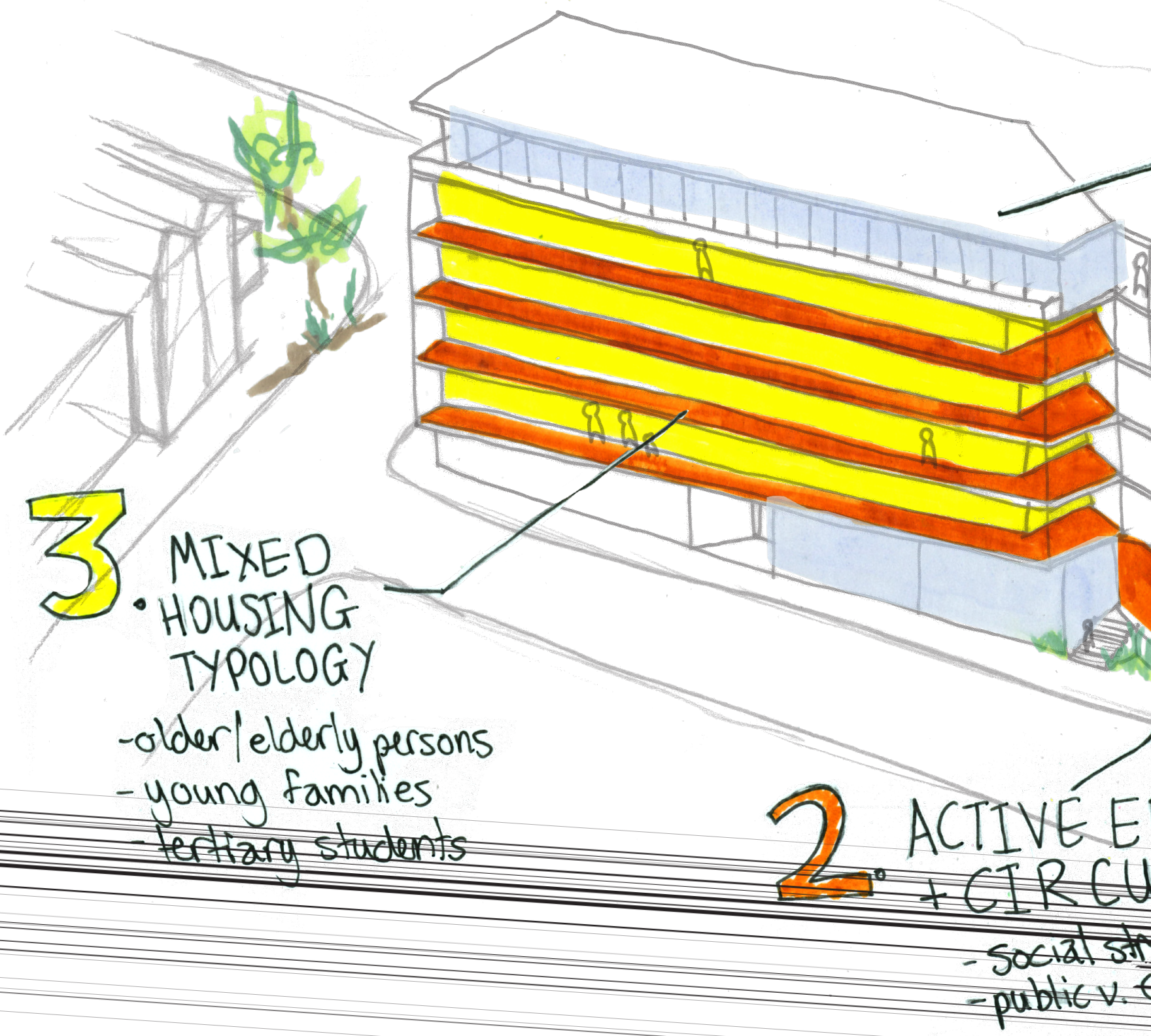






\section{Chapter 4:}

Form, Materials and the

Three Concepts 


\section{Expansion of ideas}

This stage of the project happened because of the issues that arose with the schematic design. A different approach, particularly for the circulation, needed to be explored to better resolve the projects aims of providing incidental interaction and exploring intergenerational programming. The aims of this stage were to broaden the way I was thinking about the circulation and the building function to see other opportunities in the use of ramps and potential materials 


\section{Form}

Removing constraints of site dimensions, materials, apartment types and just allowing a freer concept development process which was purely driven by the conceptual framework which helped establish the four tactics from the initial design response. This process consisted of word derivation of things associated with tactics and a design experiment task which transforms different combinations of these words into formal concepts. Some looked at how people could walk between spaces vs manoeuvre a wheelchair between spaces or drive between spaces. Some looked at the relationship between activity specific common spaces and floor of different residences. Each concept worked with colour and basic geometry to convey the zones and each ideas key elements. From here became an establishment of what was working well and what was not. The ramp as a formal element was taken forward as well as playing with the boundaries between vertical and horizontal circulation. The idea of separate common space was left, as it seemed to cater toward 'same' user groups and would not encourage as much intergenerational interaction.

Physical modelling was used to explore these ideas. Colour and surface texture and scale were played with to explore the potential of 'safe' and 'unsafe' spaces for elderly and children as well as how recognition for simplicity in way-finding around the building could be achieved through these means. The models mostly looked at internal and external circulation spaces, to see how the apartments could support these spaces as design and structural elements.
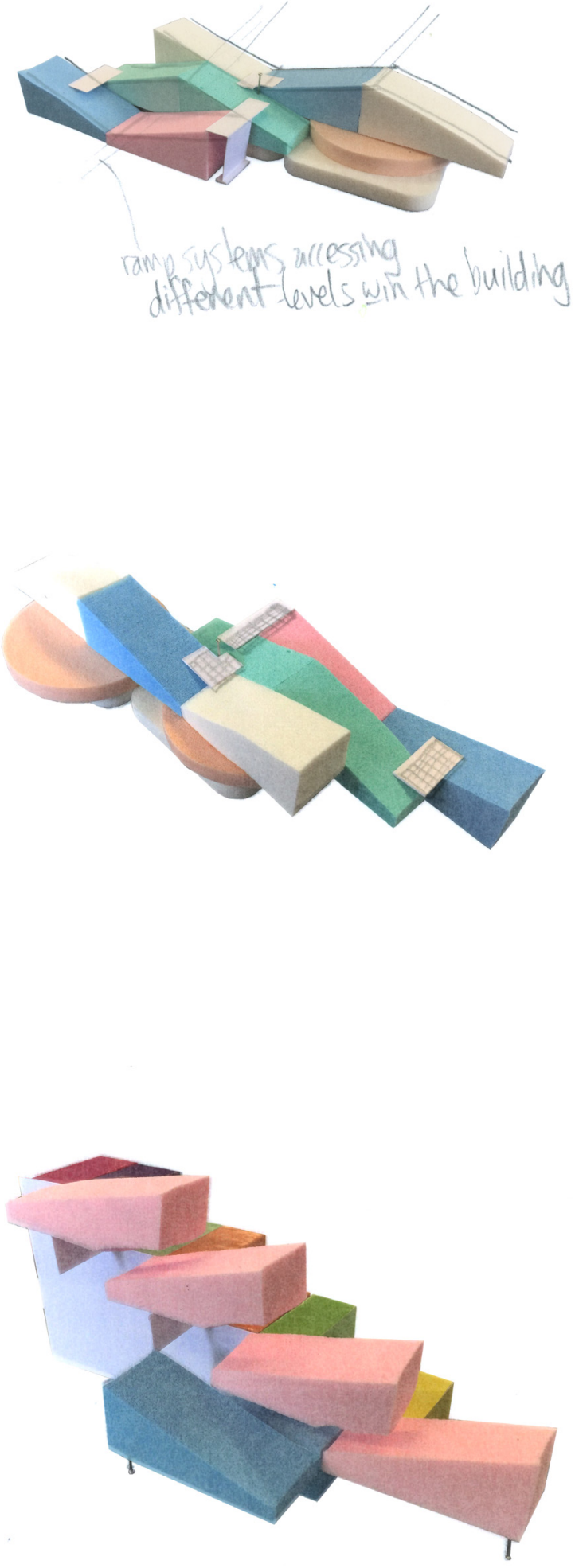


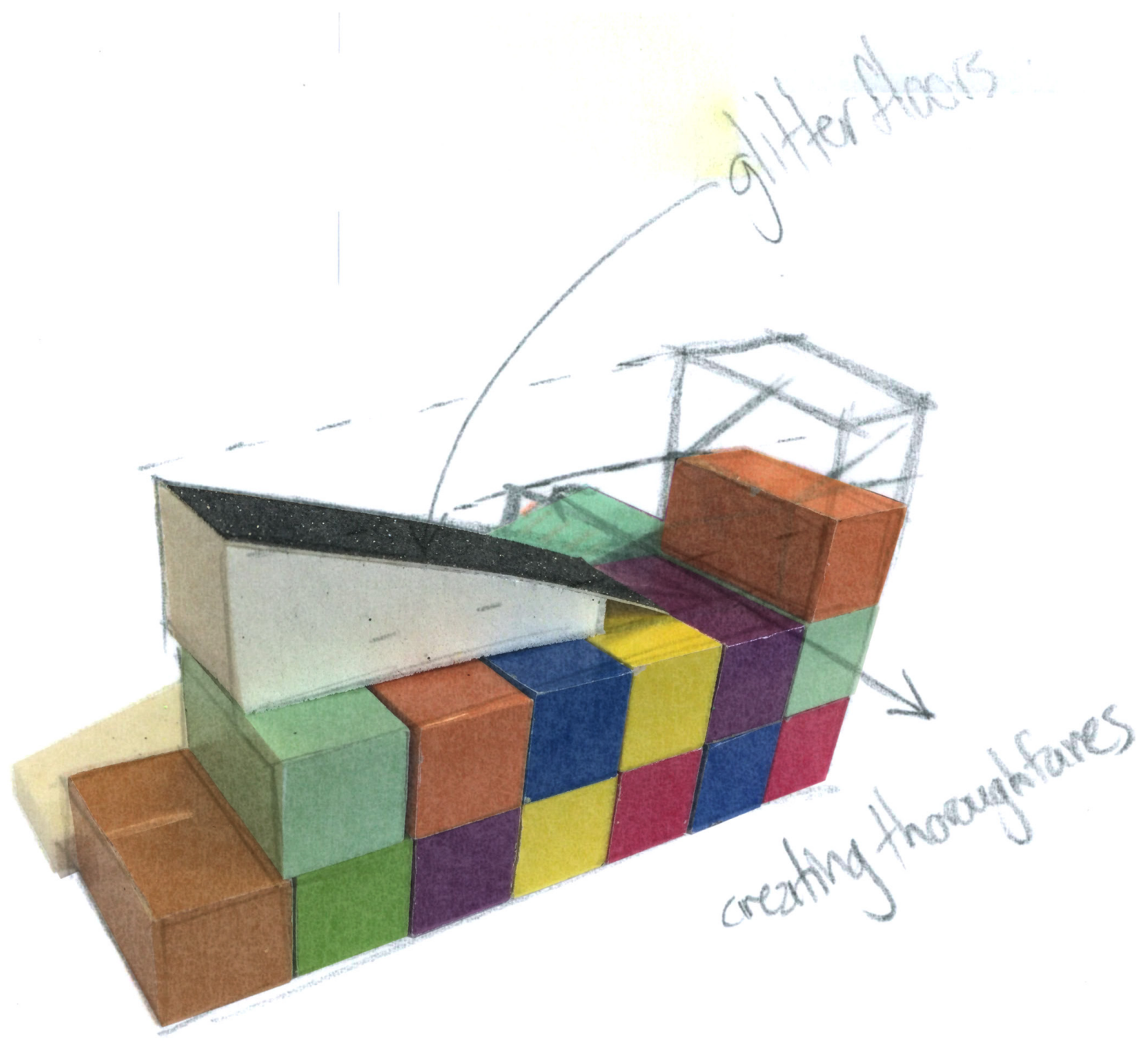

Blocks representing the apartments merge with the

ramp forms to create circulation on all sides of the building. 


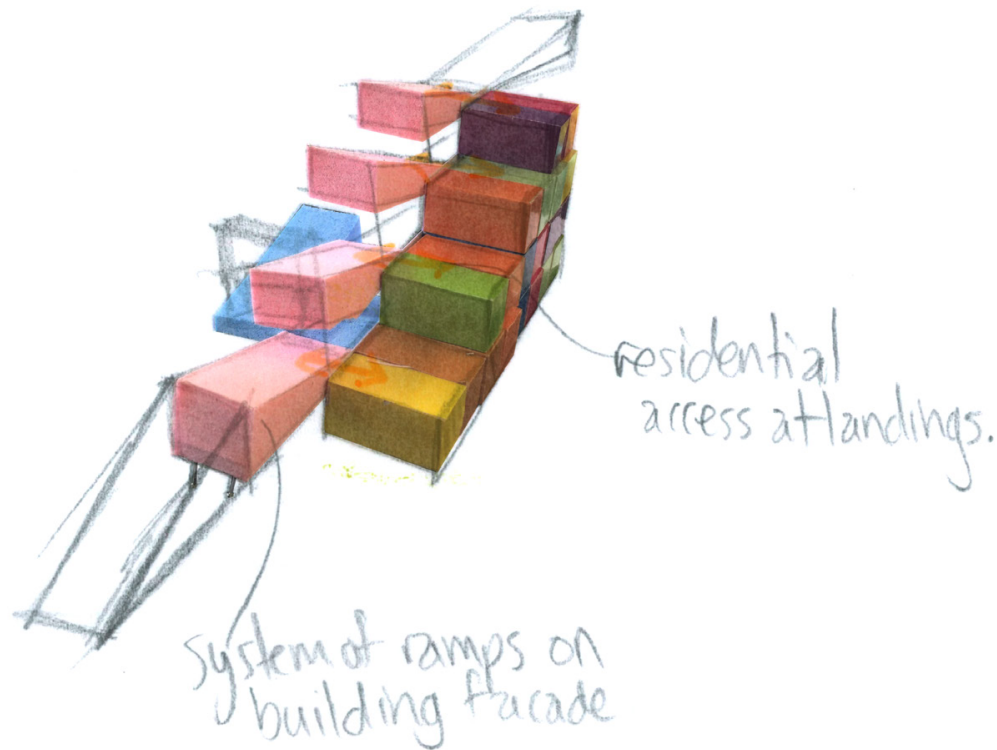

Ramps along one building edge and apartments along the other, could obstruct the view/ light into apartments but would create dynamic circulation spaces along apartment access.

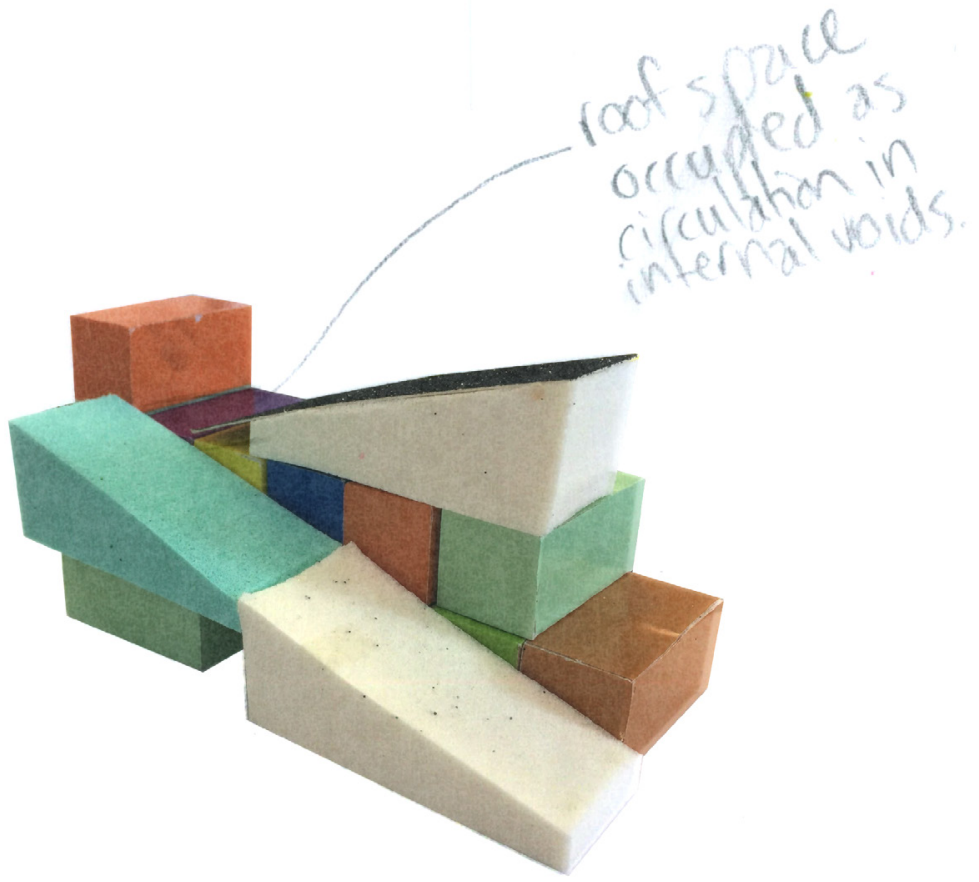

Looking at connections between ramps, breakout space for seating and differentiation through ground floor texture. 


\section{Critical Reflections:}

The key critical reflections from this exercise were the importance of using the transition spaces whether it be between types of circulation or between circulation and an amenity, plus how these spaces can be used for creating areas to dwell instead of just movement around the social street for incidental and planned interactions. The simplicity of how the circulation runs vertically with changing directions and slopes needs to be highly considered in ease of use by elderly, simpler the better. Creating a loop pattern gives a sense of not being able to get lost if you can just keep following the path and also a means of exercising, walking the loop in the colder months to keep the older people active. Another aspect of the ramp which affirmed its importance on the interior of the building is the ability to children to use it as a play feature, for when they cannot go to the park they can scooter/ run/ skateboard down the ramps and entertain themselves.

From these model experiments three concepts were developed which would be analysed and adapted back into the initial design to address the critical issues with it. The three concepts were titles 1. Soft Form, 2. Urban Design up and 3. The Ramp.
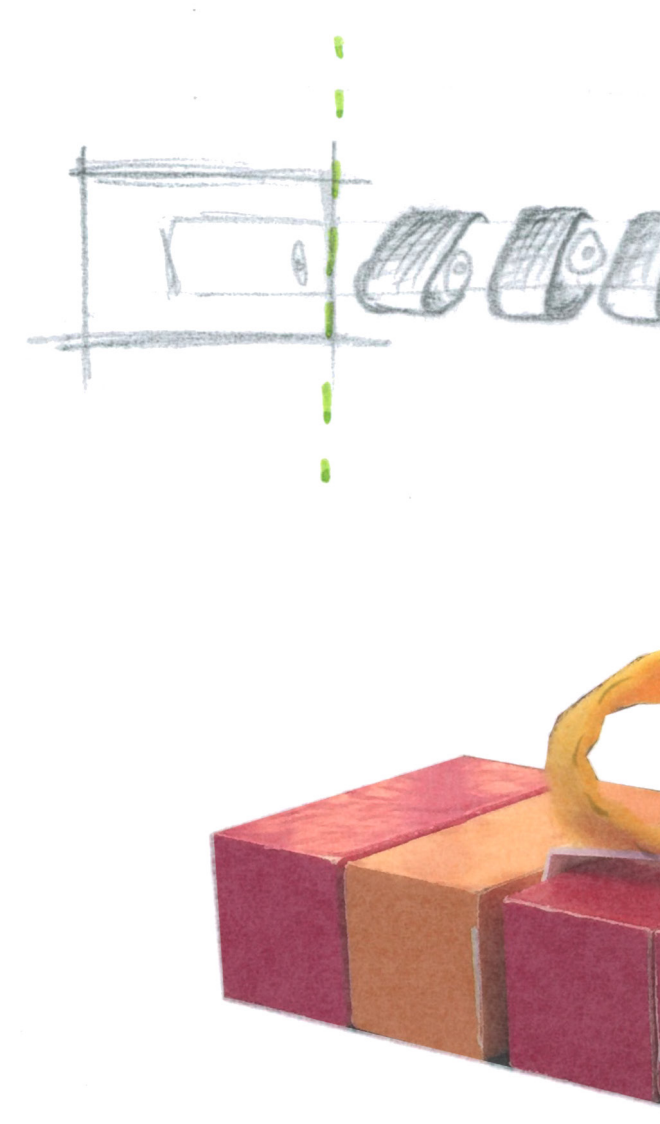


\section{The Three Concepts}

\section{Concept One: Soft Form}

Mainly focused on the how harsh, in terms of its treatment to the street and park edge as well as formal decisions, the initial design came across. This derived from the shape laid out by the social street in initial iterations. Firstly softening the form in a literal sense by keeping the basic parameters but curving the edges, creating pockets of natural entry to the ground floor spaces through these curves and using them as a gesture to the park in which it could inhabit some of this and vice versa. The softening worked in plan but did not translate very well to the verticality of the building. Approaching soft in a different interpretation meant trying to soften the threshold between the public space and residential space, making it more of an implied boundary where people feel like they should not cross it, rather than a physical boundary/wall. Also in softening the park edge, as mentioned previously but with the use of bridges and materials which would create a pathway along the park on that south edge which integrated with the park design and encouraged people into the public entry ways. Ultimately, this concept was unsuccessful as the issue of threshold between public and residential had issues of security and was more heavily a circulation issue. Softening the form did not necessarily translate into softening the relationship between building occupants and site.
Elevation and $3 \mathrm{D}$ sketches were used to imagine how different façades could work on curved walls, as well as how entry points into the building could be differentiated.
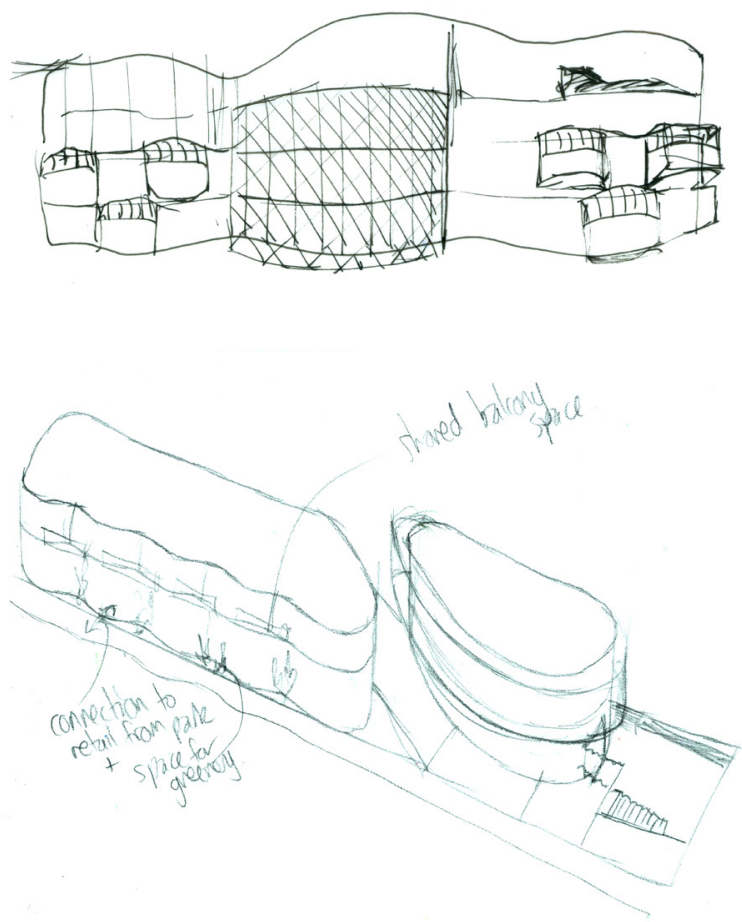


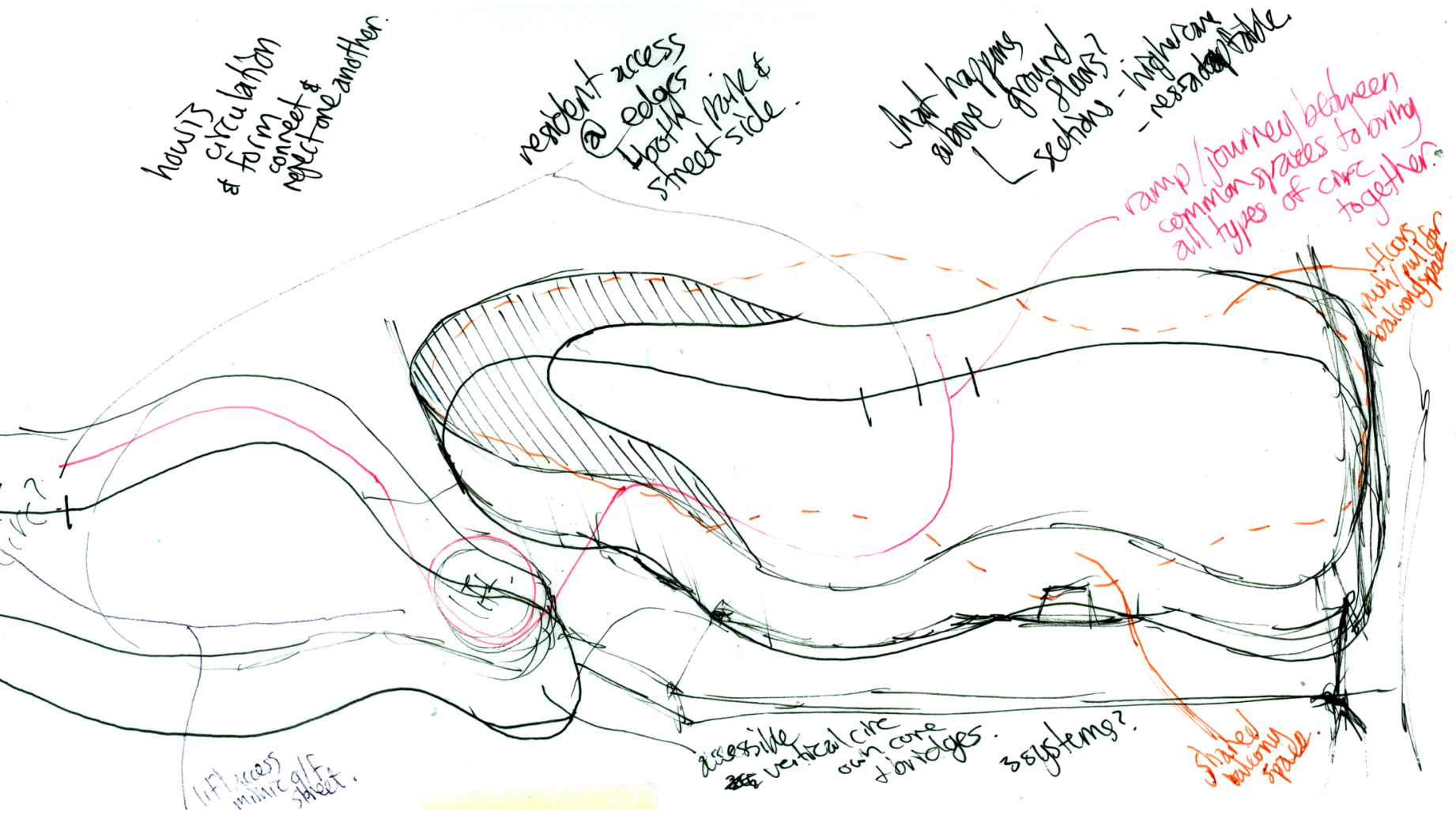

Imagining what 'soft' form could look like based on interpreting the initial design concept. Curving the walls in plan to see how the two buildings could react to each other and create pockets around their perimeter.

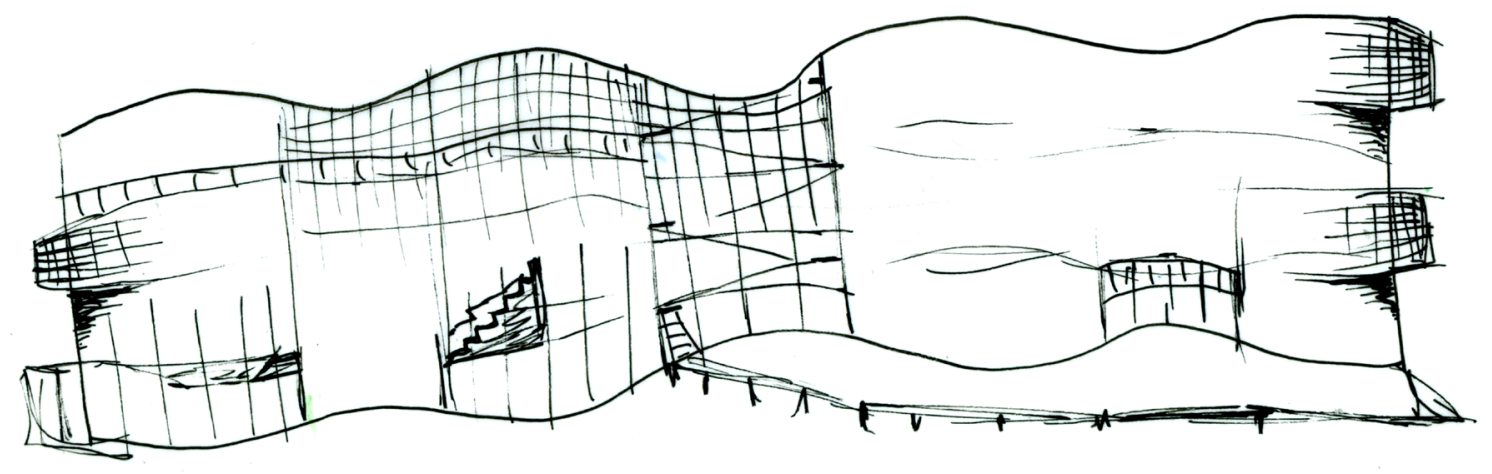




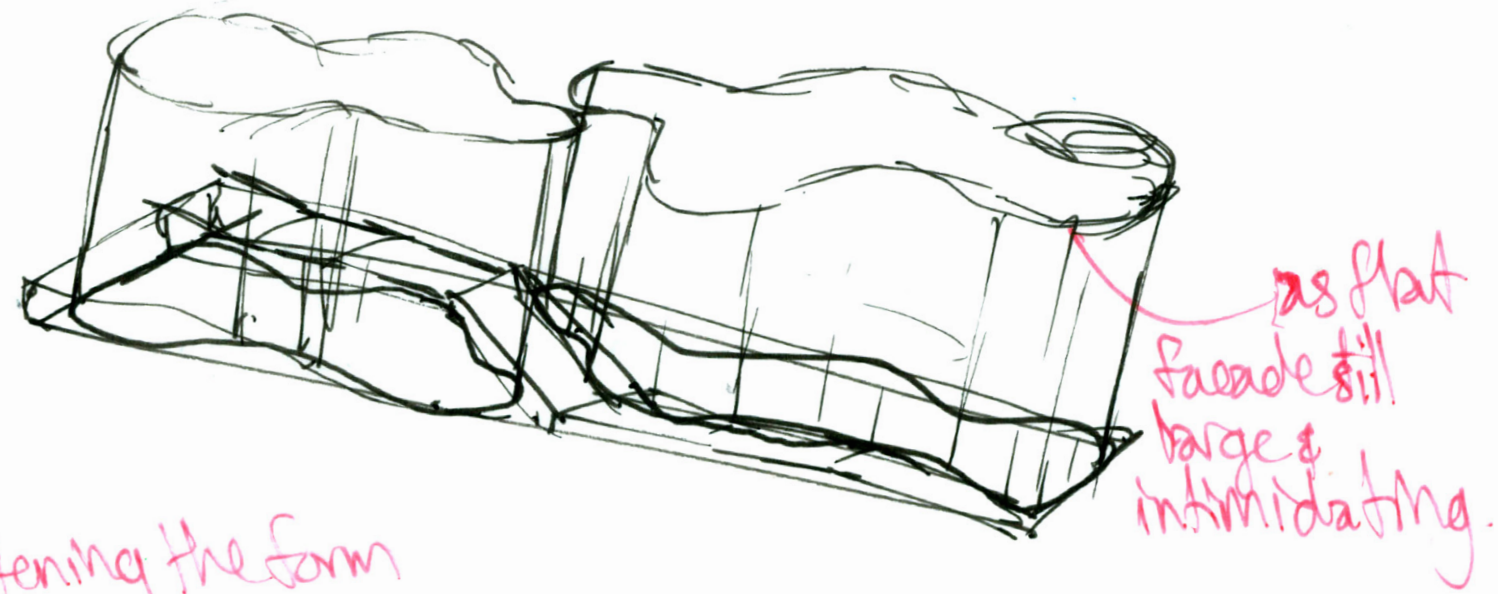

sotening the forw

Lencouradena dwelling

active-activities tseating
along edges - internal texternal

interactive - structure? sensory expentence $\rightarrow$ arculation changes in

Extruding the curved plan vertically. 


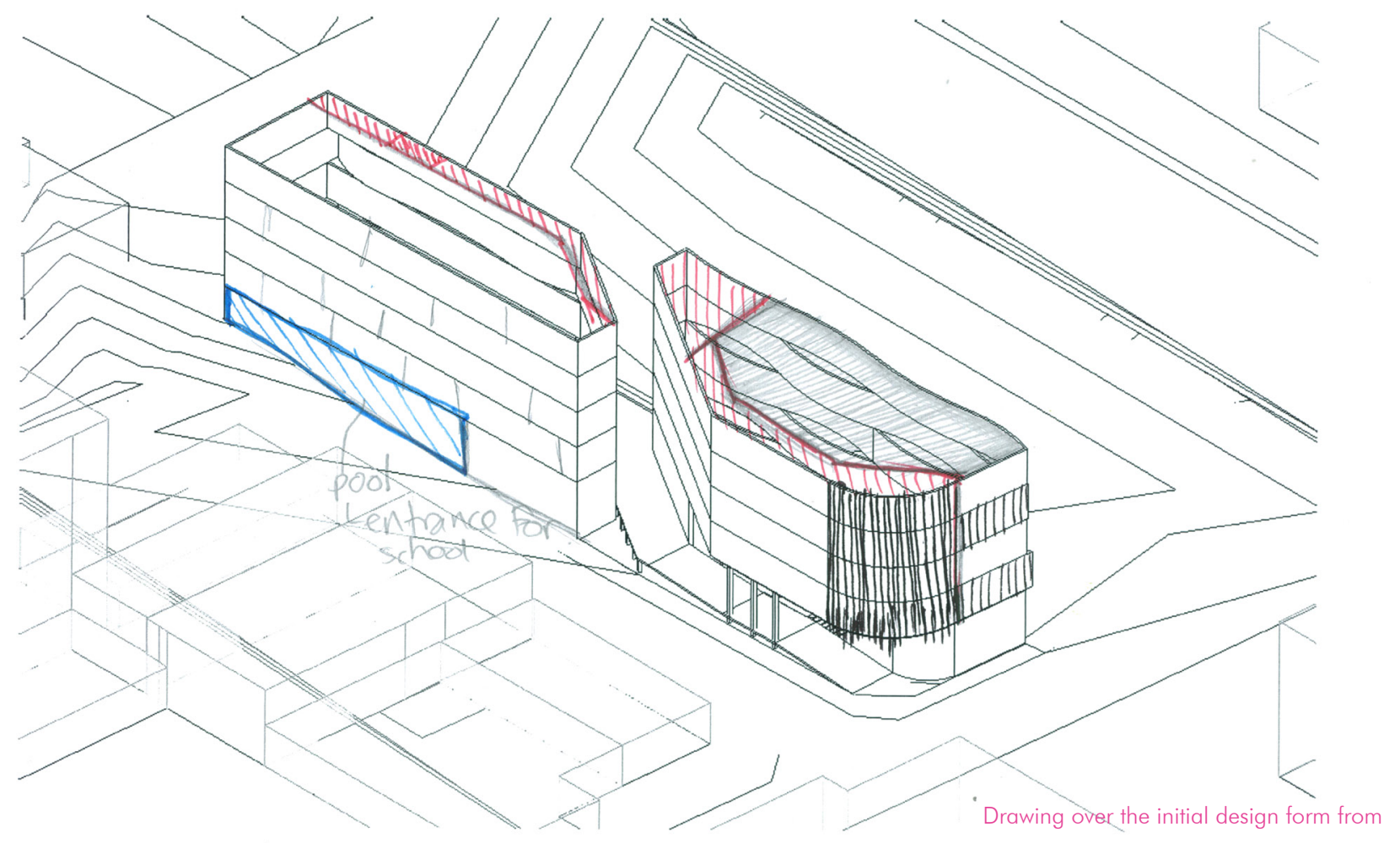

schematic design, softening the park edge.

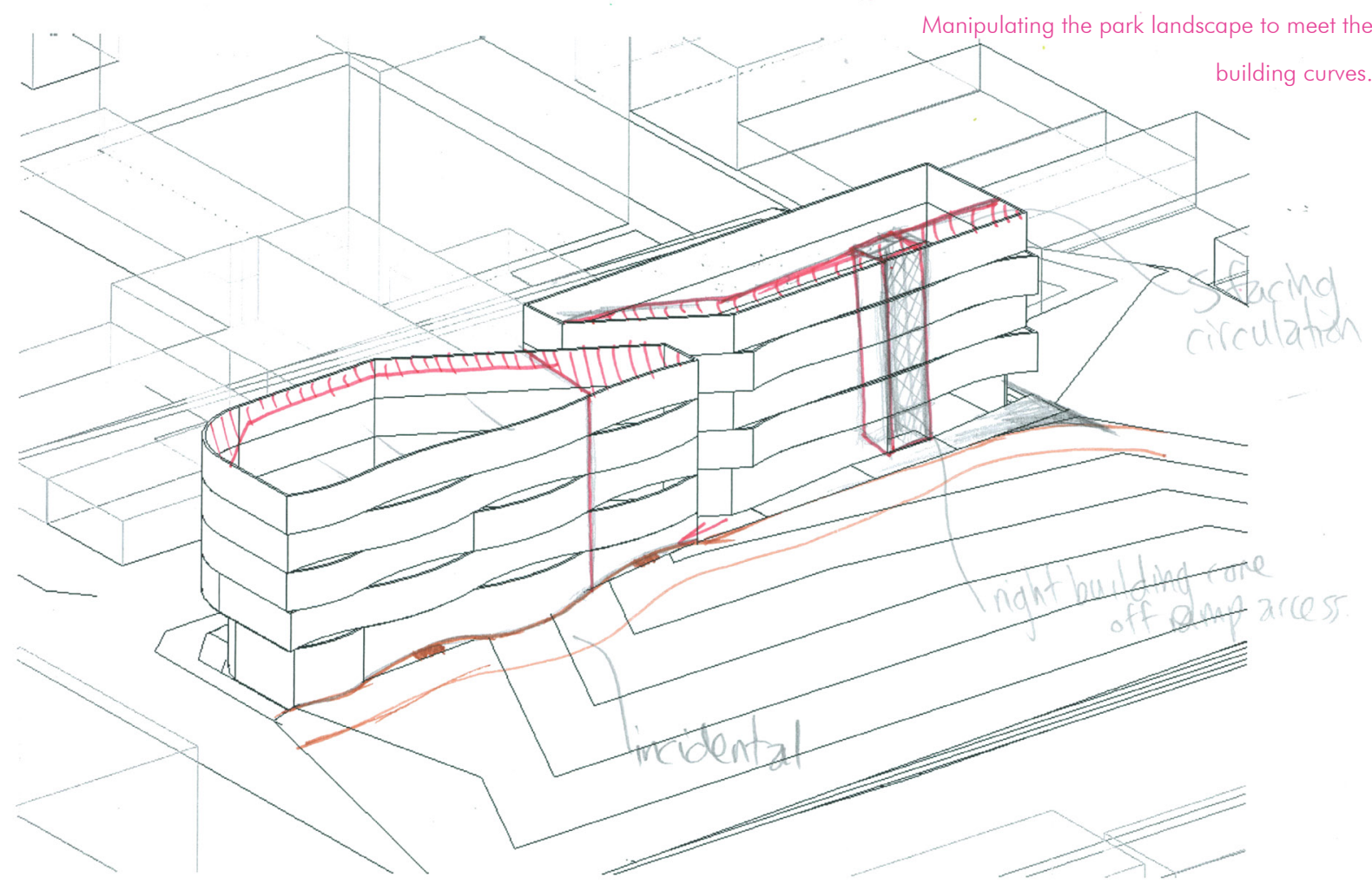




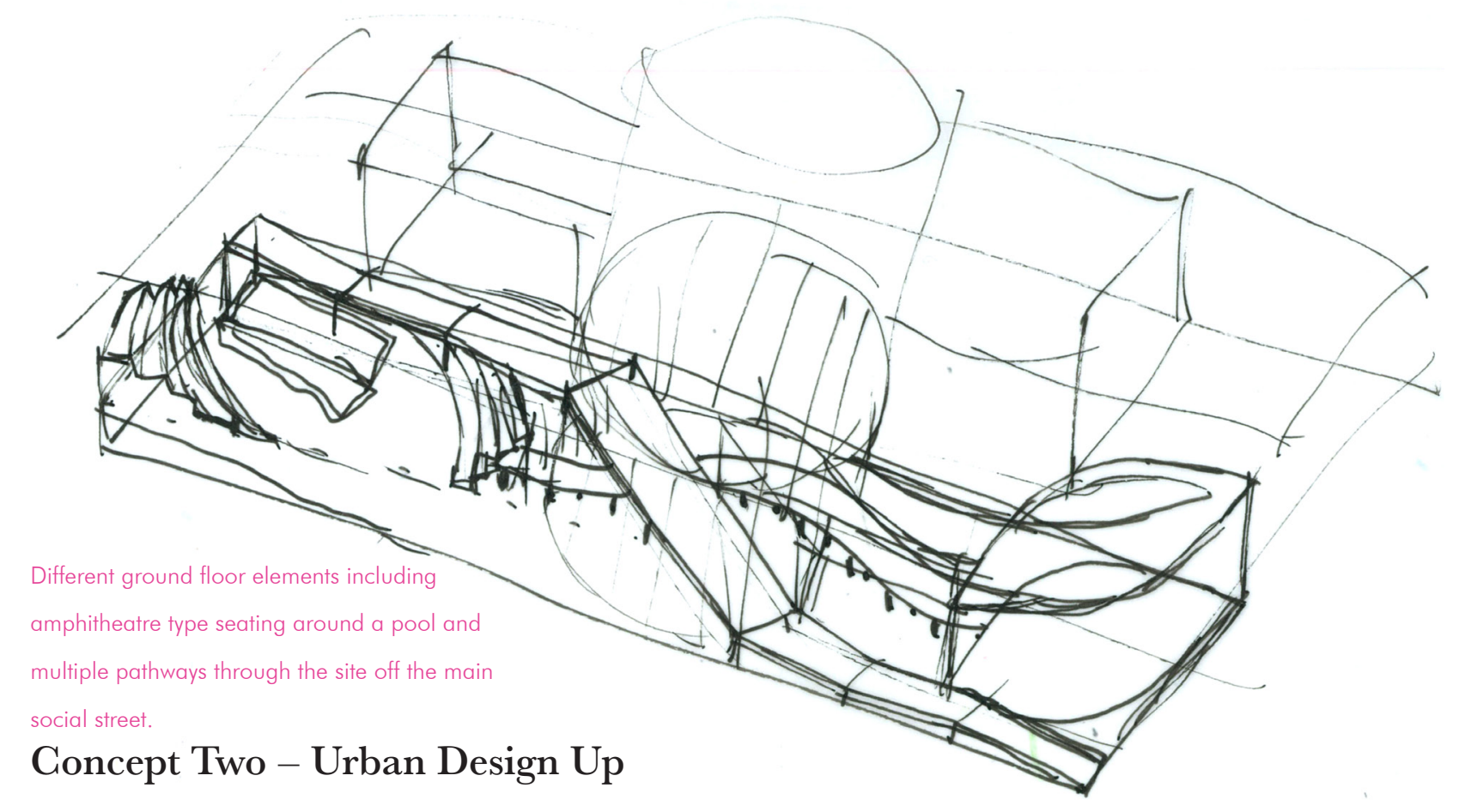

This was derived from the missing component of encompassing key urban design elements into the approach taken with the initial design. The site sits beside a highly designed piece of public landscape and offers a merge between commercial and public/ memorial areas. Beyond just looking at the attributes of amenities in the area such as the school and using that to inform design decisions, this concept is approached as designing the ground floor/ $1^{\text {st }}$ floor to became an extension of the park. Looking at the threshold between the park and site, how the building can allow the uses and nature of the park to influence the ground floors design with materials, pathways and public space.

The concept was first developed through floor plan sketches, mapping the materials and how they relate to the park edge and would be pulled into ground floor. However, this made it difficult to understand the ground level shift and what that meant for circulation between park and site. 3D sketches accompanied these plans and explored ideas such as having a network of streets, each leading to different amenities on ground floor. Some of these sketches resulted in intricate webs of internal and external spaces on ground and first floor and a large mass above indicating apartments, which became quite grand and overbearing. Therefore, the idea needed to expand further than just urban design spilling horizontally into the site; it needed to influence the verticality of the building particularly in circulation. Looking at under-croft spaces and getting people up into the building it became clear that the space needed to utilise external areas and look at how green areas could be incorporated through the building (either dictating form or complimenting and working with an existing form). 


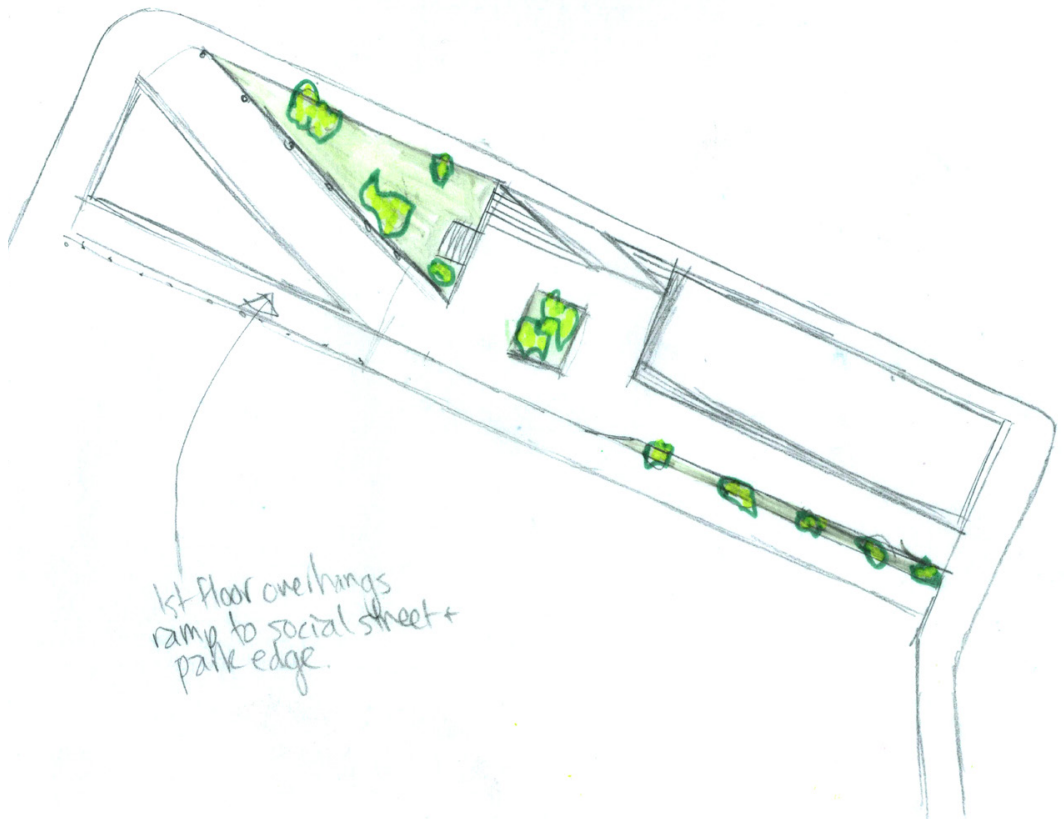

This concept development went back to plan iterations with a main focus on green spaces and how they could take up more of the ground floor.

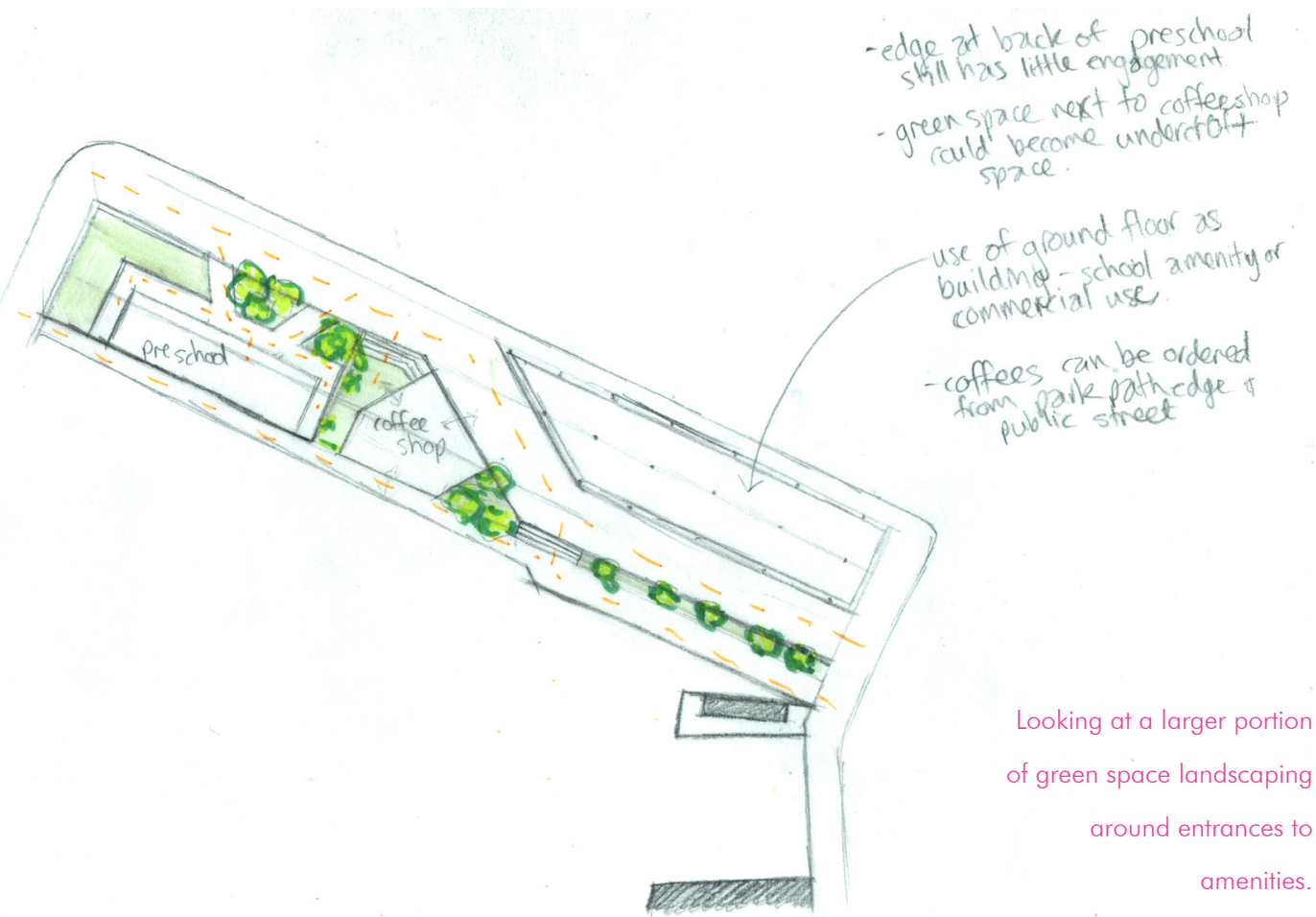




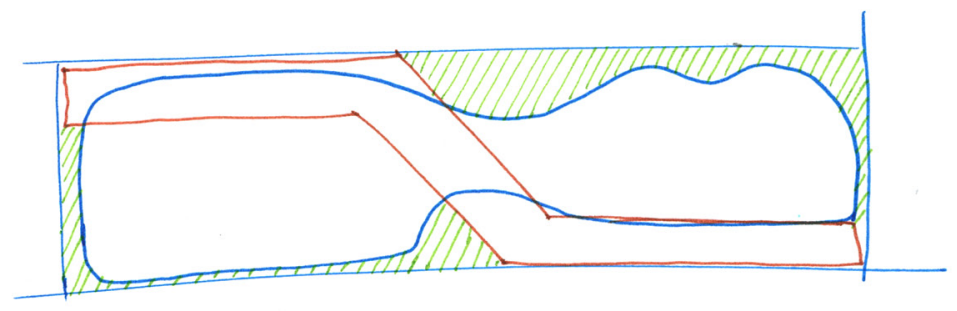

-ramp+ form opposing elements.

- softedges

gesturino towards

the parke.

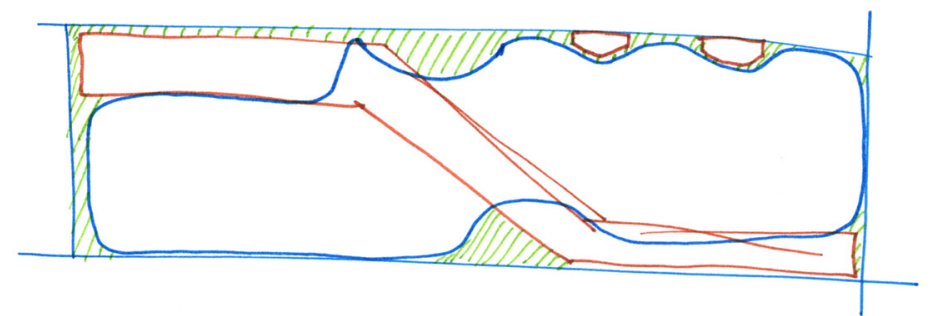

$$
\begin{aligned}
& \text {-bridge connetions } \\
& \text { to pan-form } \\
& \text { dictates internal } \\
& \text { commercial spaces }
\end{aligned}
$$
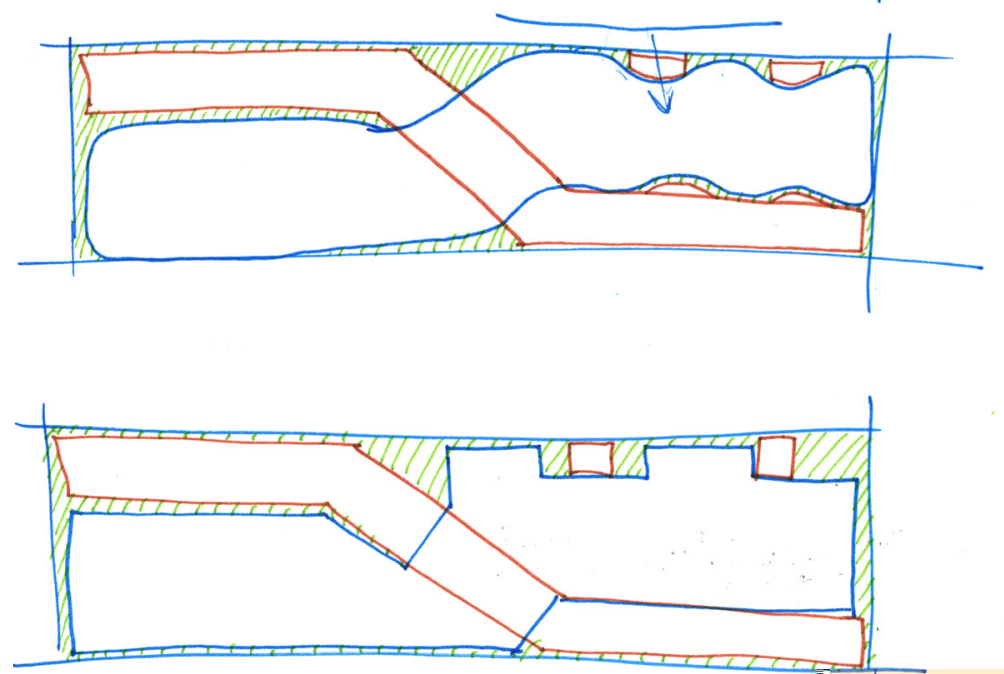

- same gesture to

the parte w

sharper

iseftective of

reftective of

ariadseraring?
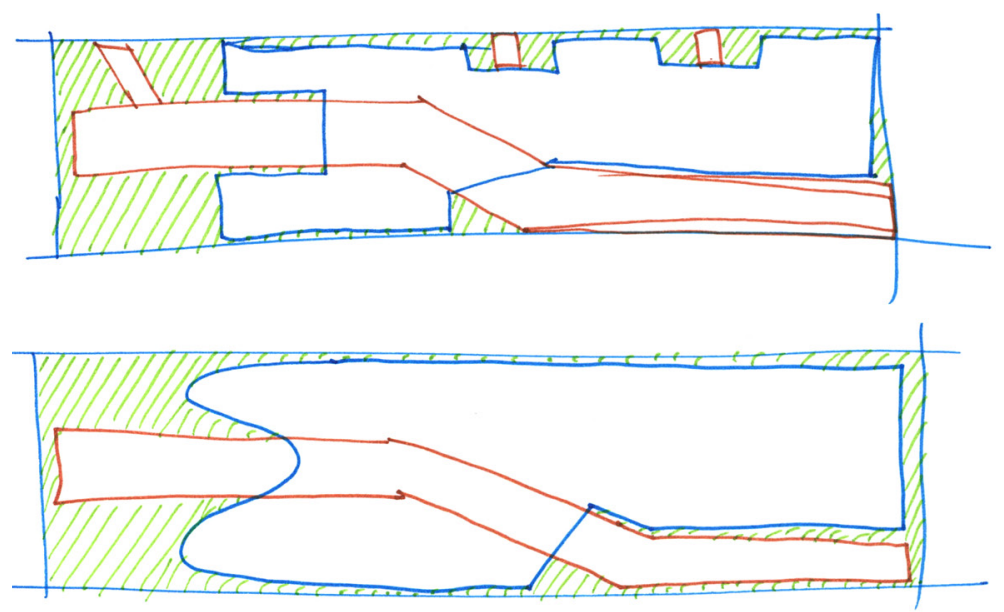

This series looked at building form (blue), social street (brown) and green space (green) and their overlaps in plan. Keeping a similar social street form, how could the building form be manipulated to allow push the green space into the site. 


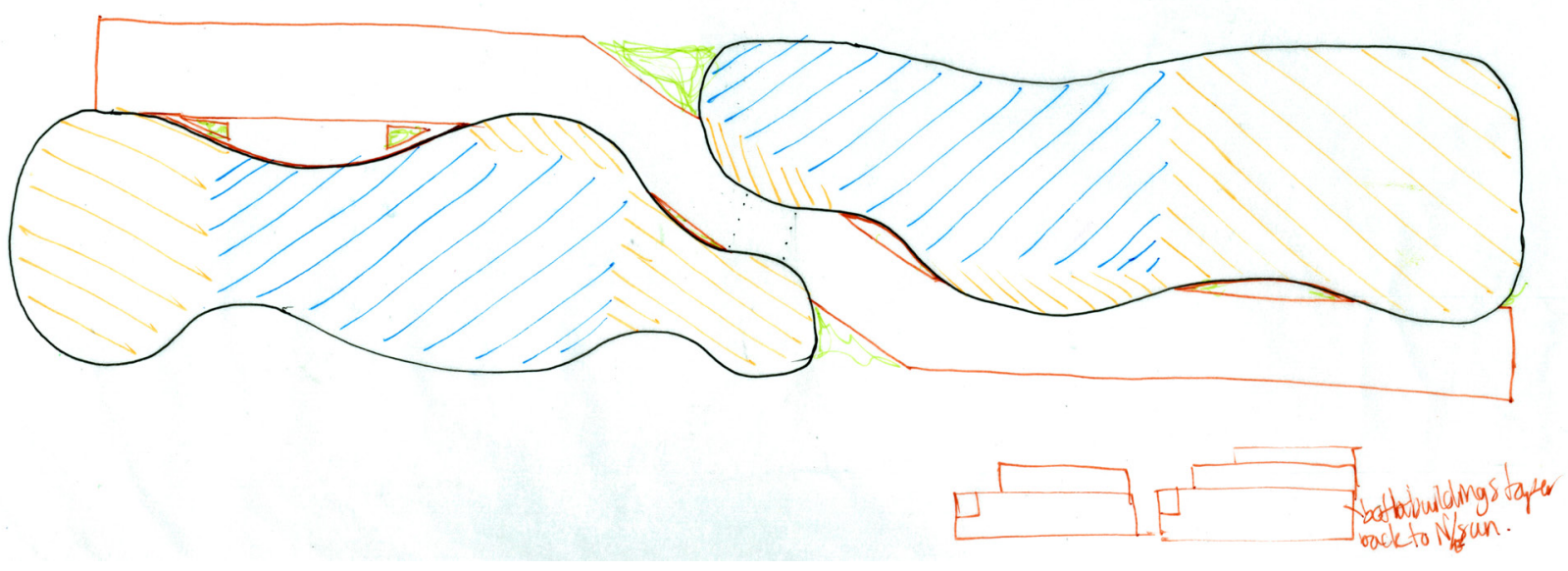

Keeping the 'softer' form from concept one and pushing it into the social street creating more pathways and potential under-croft spaces.

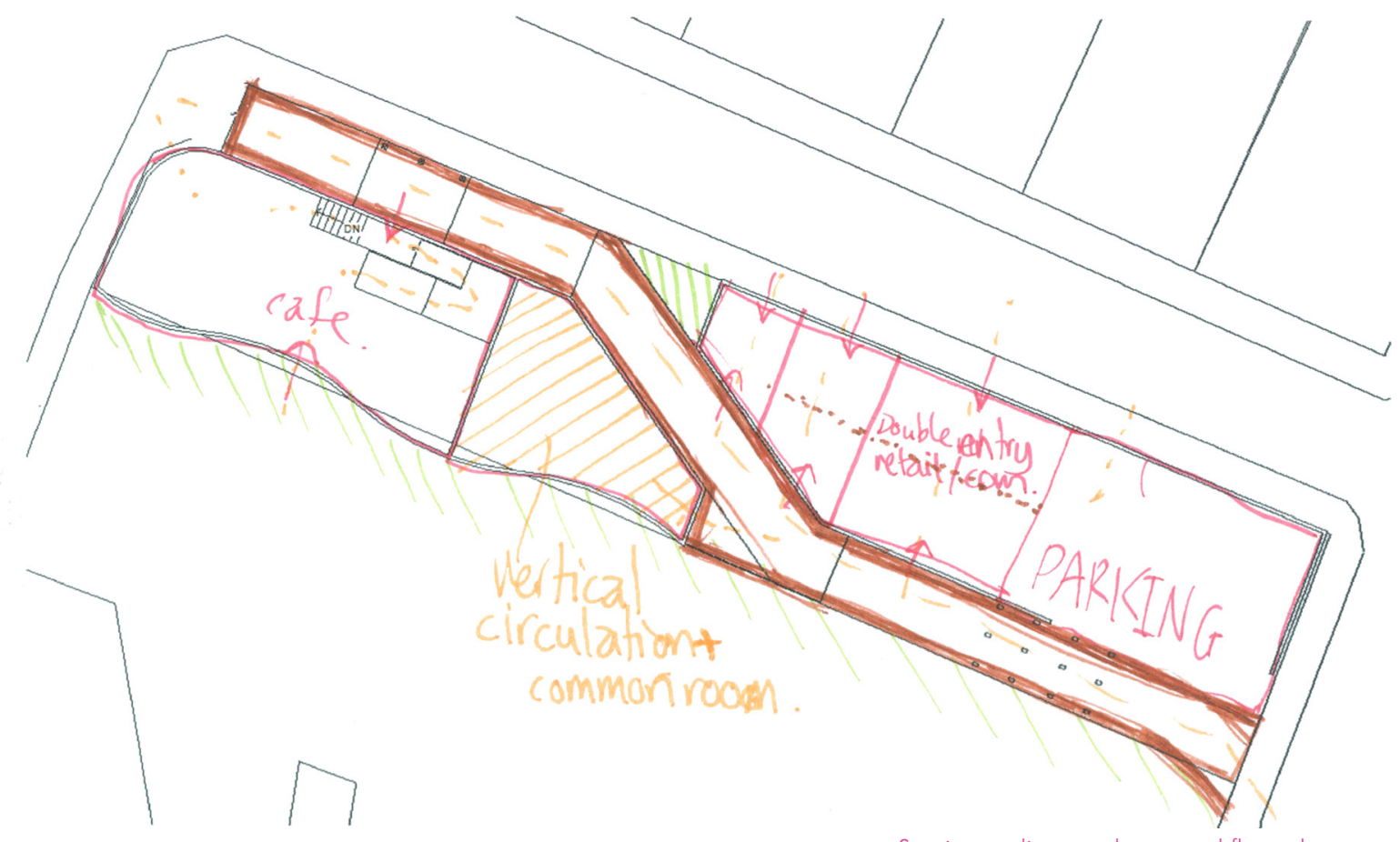

Starting to diagram the ground floor plan areas are massed out in a combination of this concepts ideas and the initial design form. 


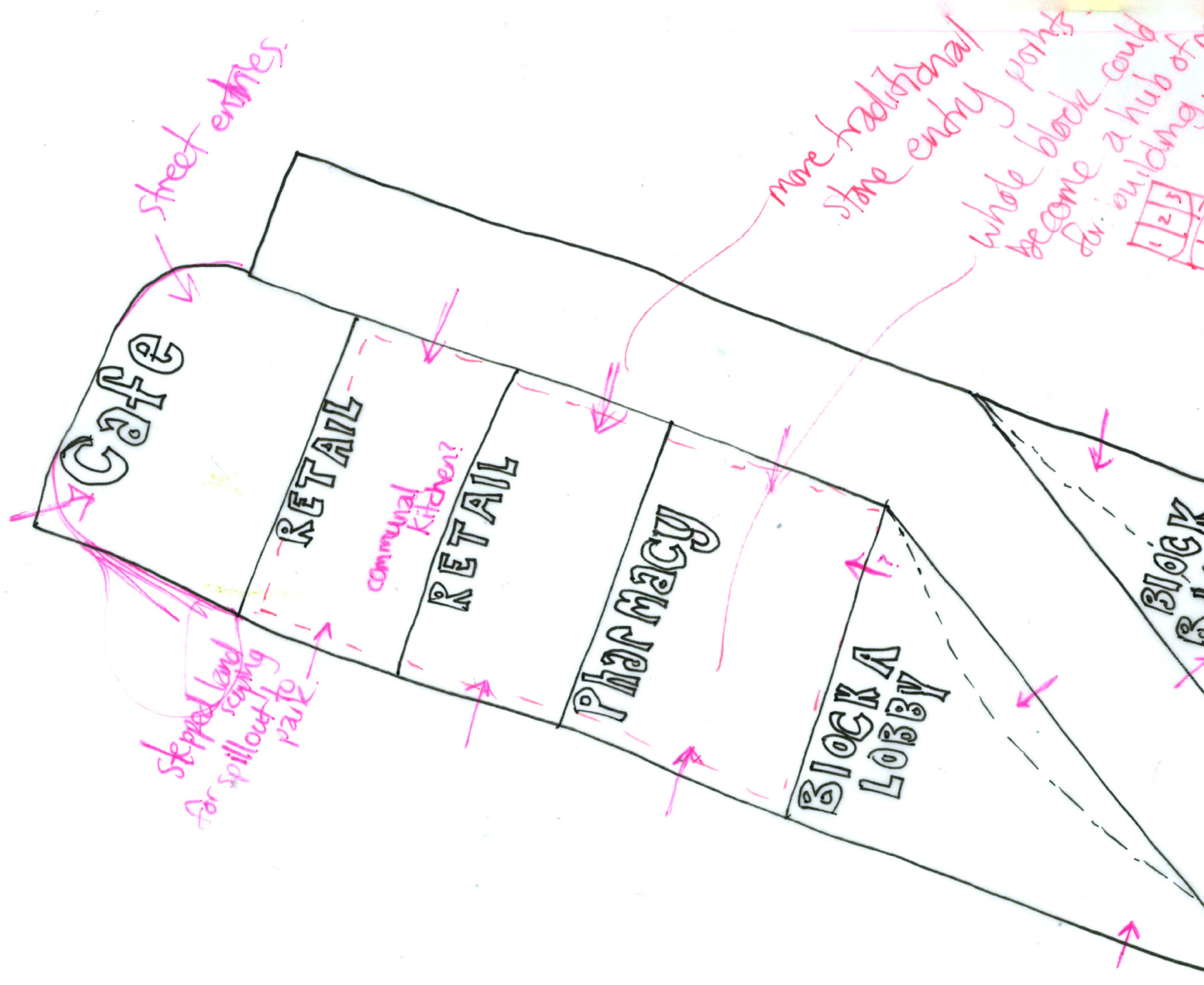

This plan iteration maps out which tenants would occupy ground floor and looks at the interface between the pool and the park/ school entrance.

Multiple entry points with the left block having clear divisions of space and the right block a more open flexible ground floor space. 


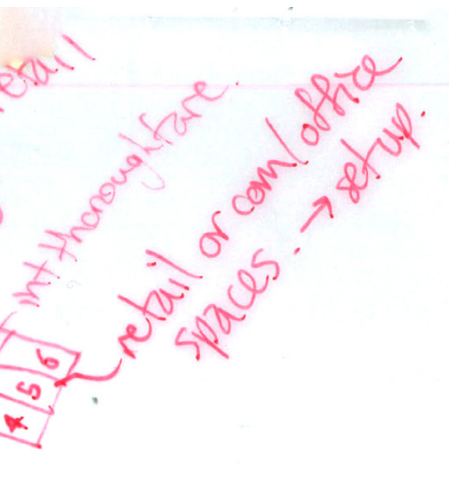




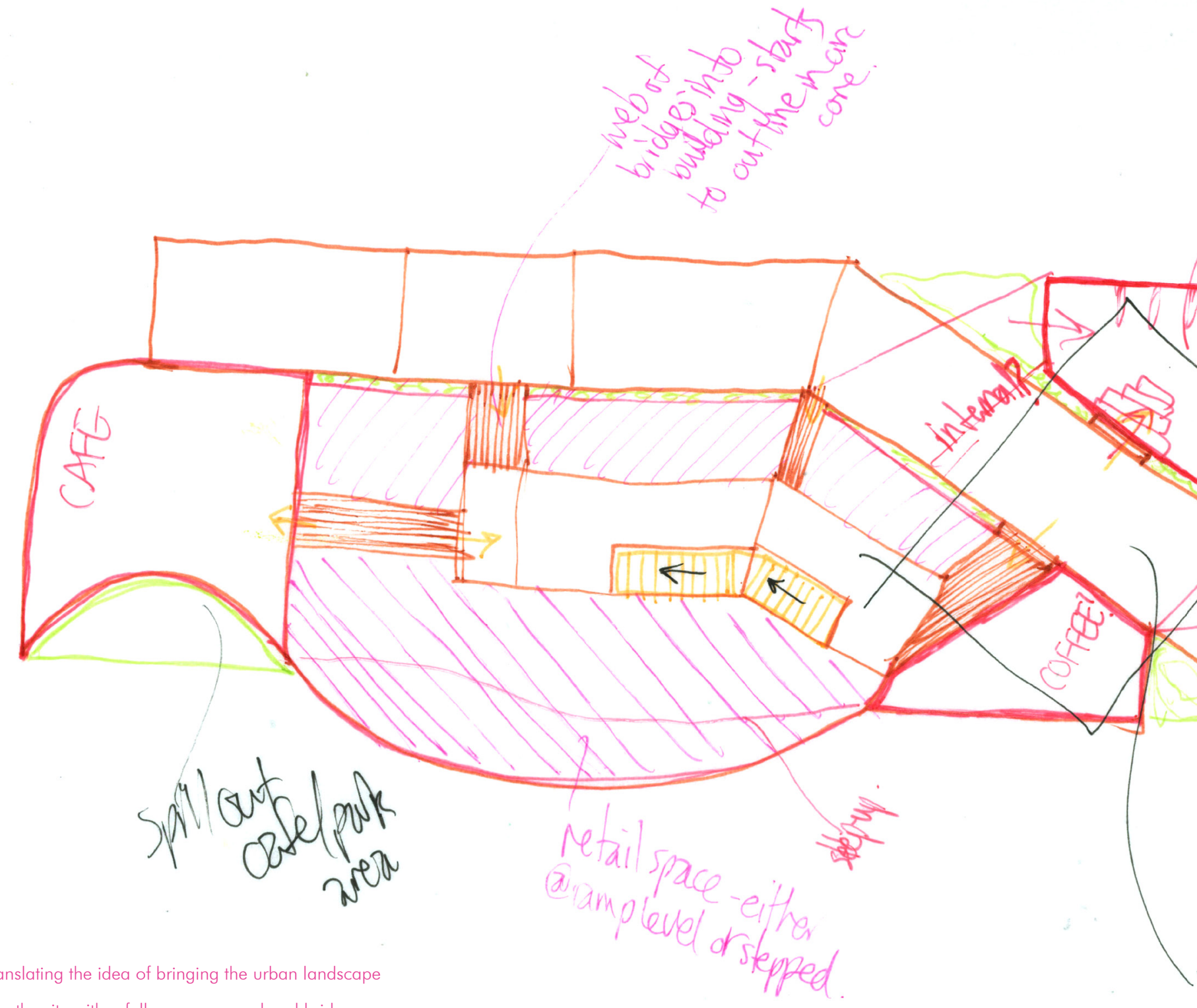

into the site with a fully green ground and bridge

type construction for the social street. Looking at how

circulation could come off this type of social street. Some

of the geometry does not lend toward the street and

building connections flowing. 


\section{Concept 3: The Ramp}

Looked at the social street ramp and how that could be further integrated into the building and encourage the same use and interaction up the building vertically. The tests within this concept were different iterations around how the ramp could become the building form where it functions as internal and external circulation. It formed an internal courtyard or ran up one façade of the building, similarly to the works of SAANA in Japan with their Kitagata apartment building (Lenk, James). This approach may over do the social and interactive element of the design with everything being put on display and constant circulation around apartments. The elements of the ramp being pull further into the form through layered vertically ramps was taken forward but ultimately the idea was dismissed because of the impracticality and integration with the surrounding environment. -There was not a need for too many entry points or the level of circulation this would provide and making all of it accessible was unrealistic for such a small site. This idea would also reduce the amount of floor space available for apartments, and although this design argues for prioritising more space for circulation, this would make the scheme not viable or affordable.

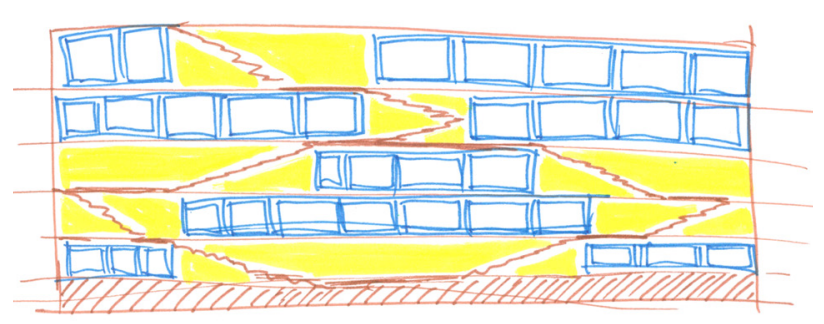

In section, seeing how ramps could flow between floors internally, trying to interpret some of the experimentation models.

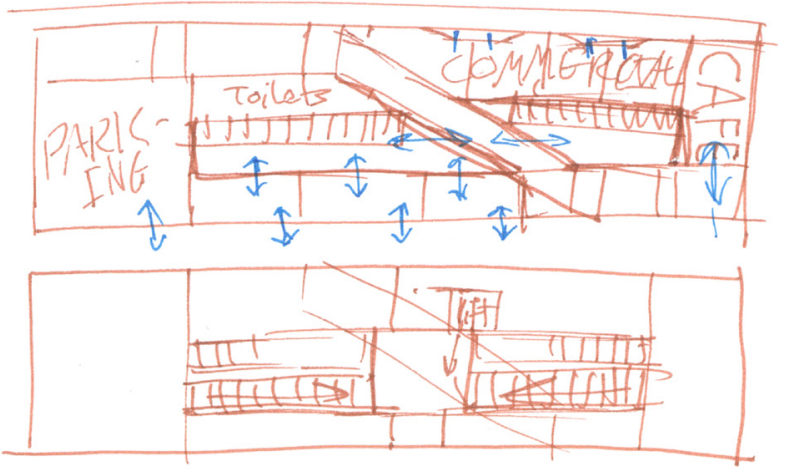

Looking at the above sketch in plan, creating a circulation core which acknowledges but shifts the geometry set out by the social street. 


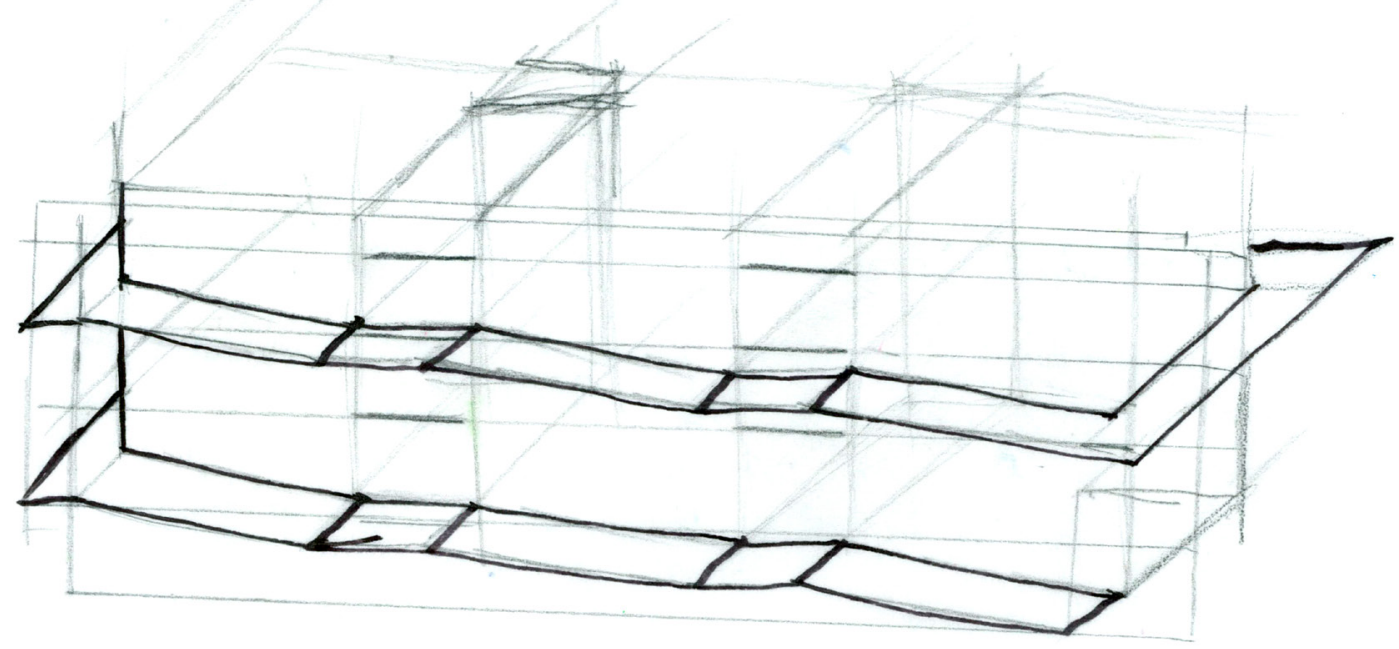

Looking at a ramp form wrapping around the whole building, with platforms to enter at different floors.

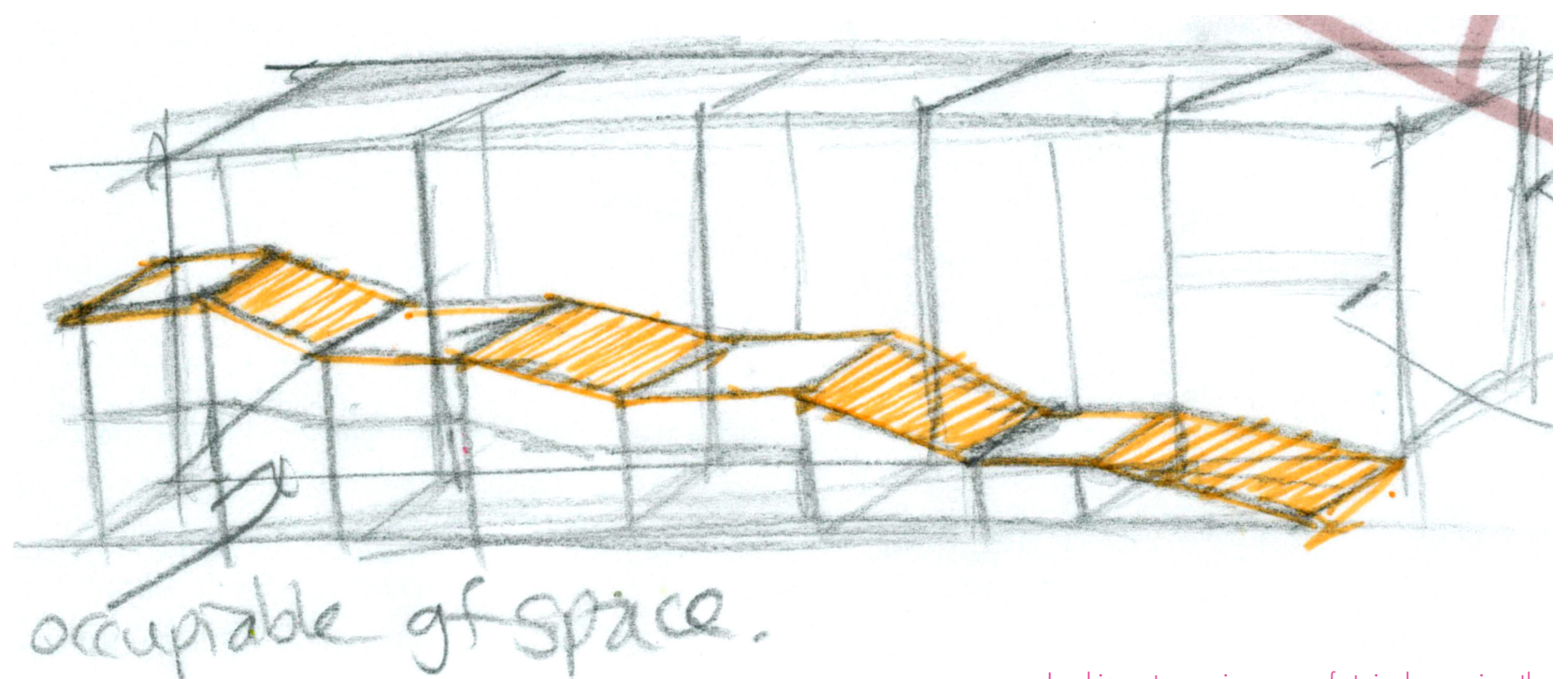

Looking at a main ramp of stairs becoming the facade of one side of the building, creating a shelter for the ground floor amenity entrances. 

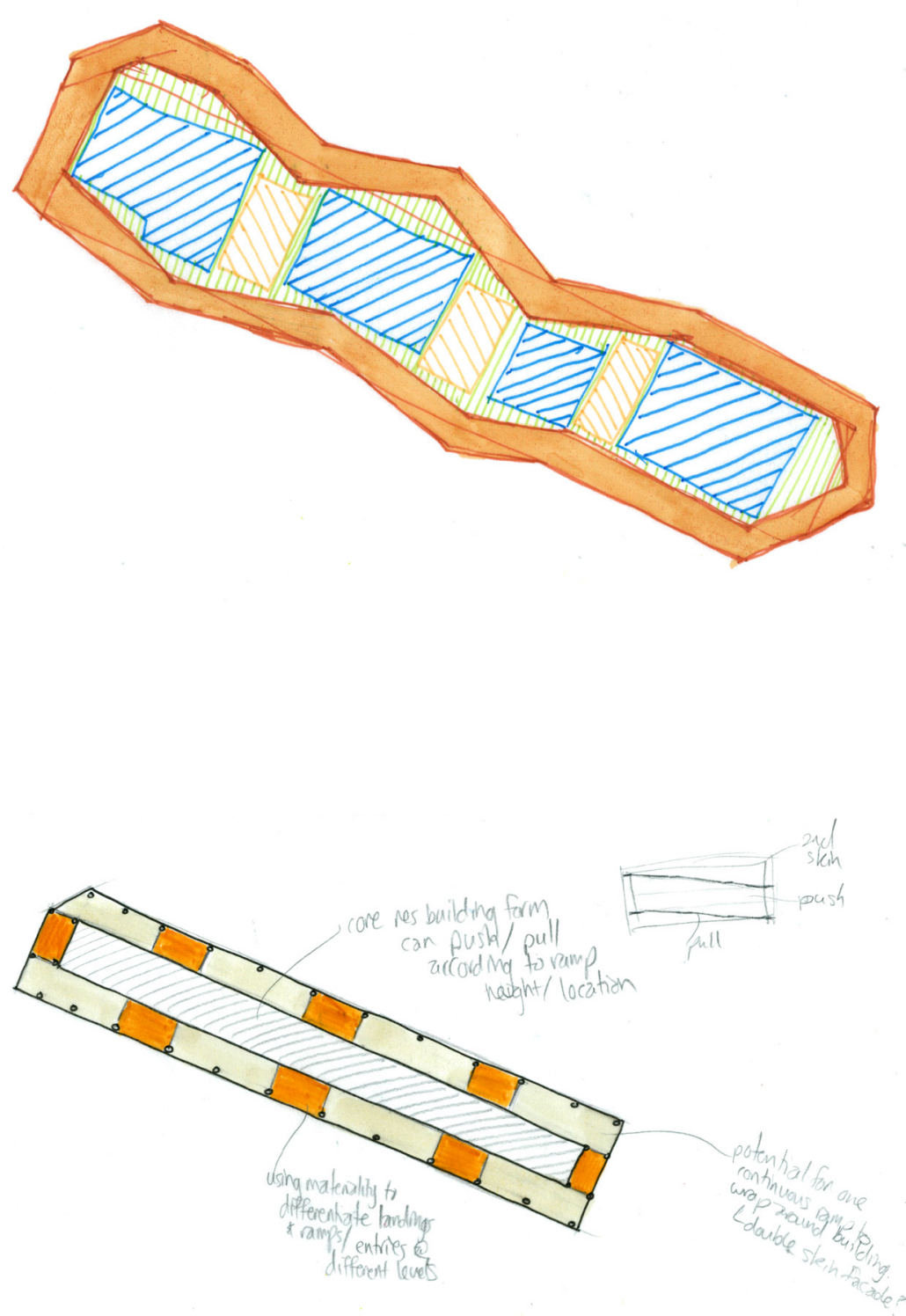

Two plan examples of ramps around the entire building/ site perimeter, where landings could go and how horizontal circulation work intertwine. 

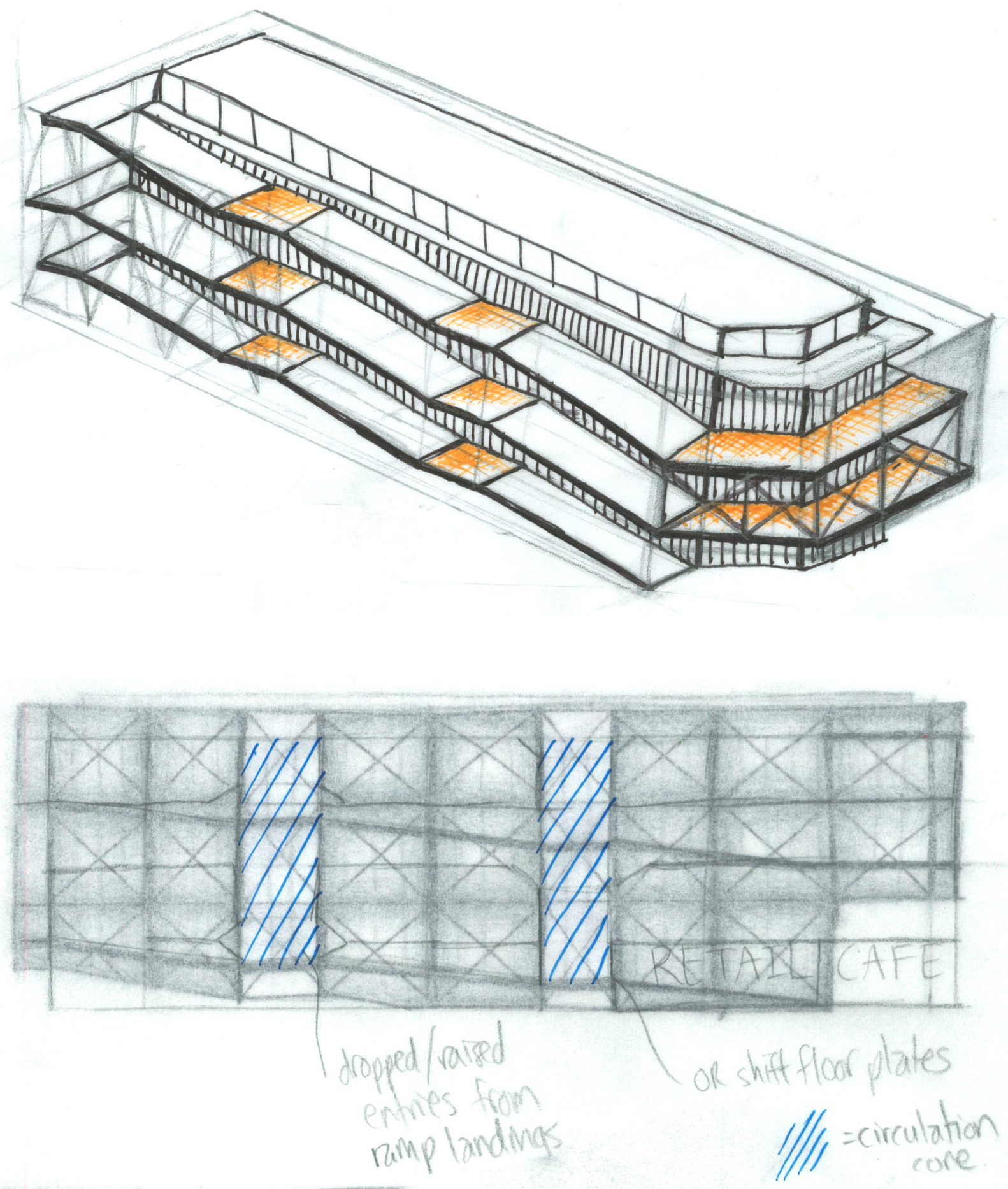

The ramp circulation around the building with structural considerations and mesh or screening if external. 
Concept Two- Urban Design Up was chosen because it provided the most successful resolution in how the transition from surrounding site, to public circulation, to resident's circulation could be configured in the building to encourage use and facilitate interactions.

As this concept developed it implemented some of the most successful elements from concepts one and three, looking at a softer form, however the geometry of the softness in form, particularly in plan did not compliment the angular designs in the Pukeahu Park design. This concept reinforced the importance of the public nature of the ground floor space, and with the ground level shift encouraging that type of activity up to first floor from Taranaki street side. A main emphasis was on how access to the pool, being placed specifically for the ease of access and use by the school. This amenity provides an activity for residents and schoolchildren to interact, as well as creating a visual link, with glazed façades, between Martin Square and the Park to create a more approachable environment. 


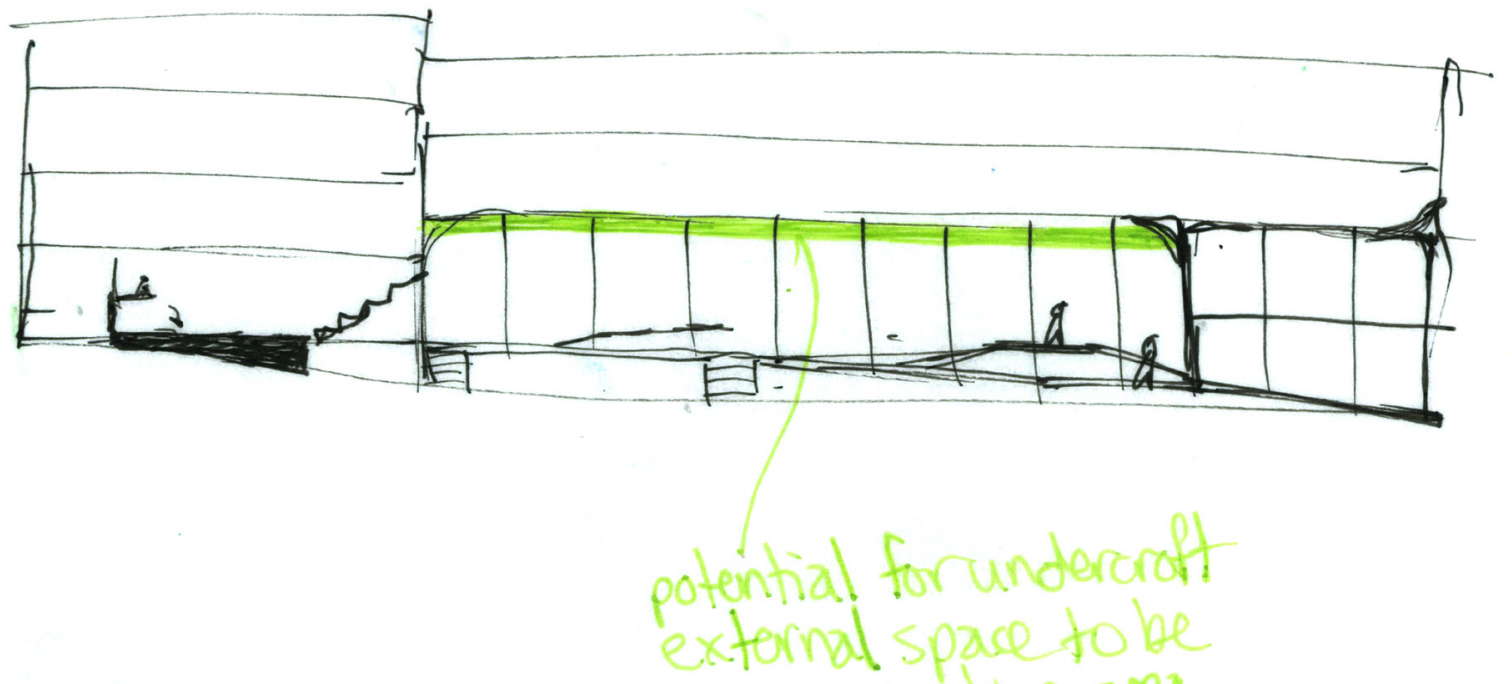

Section looking at an under-croft space on ground floor if the building was lifted. Allowing flow through the park in multiple directions.
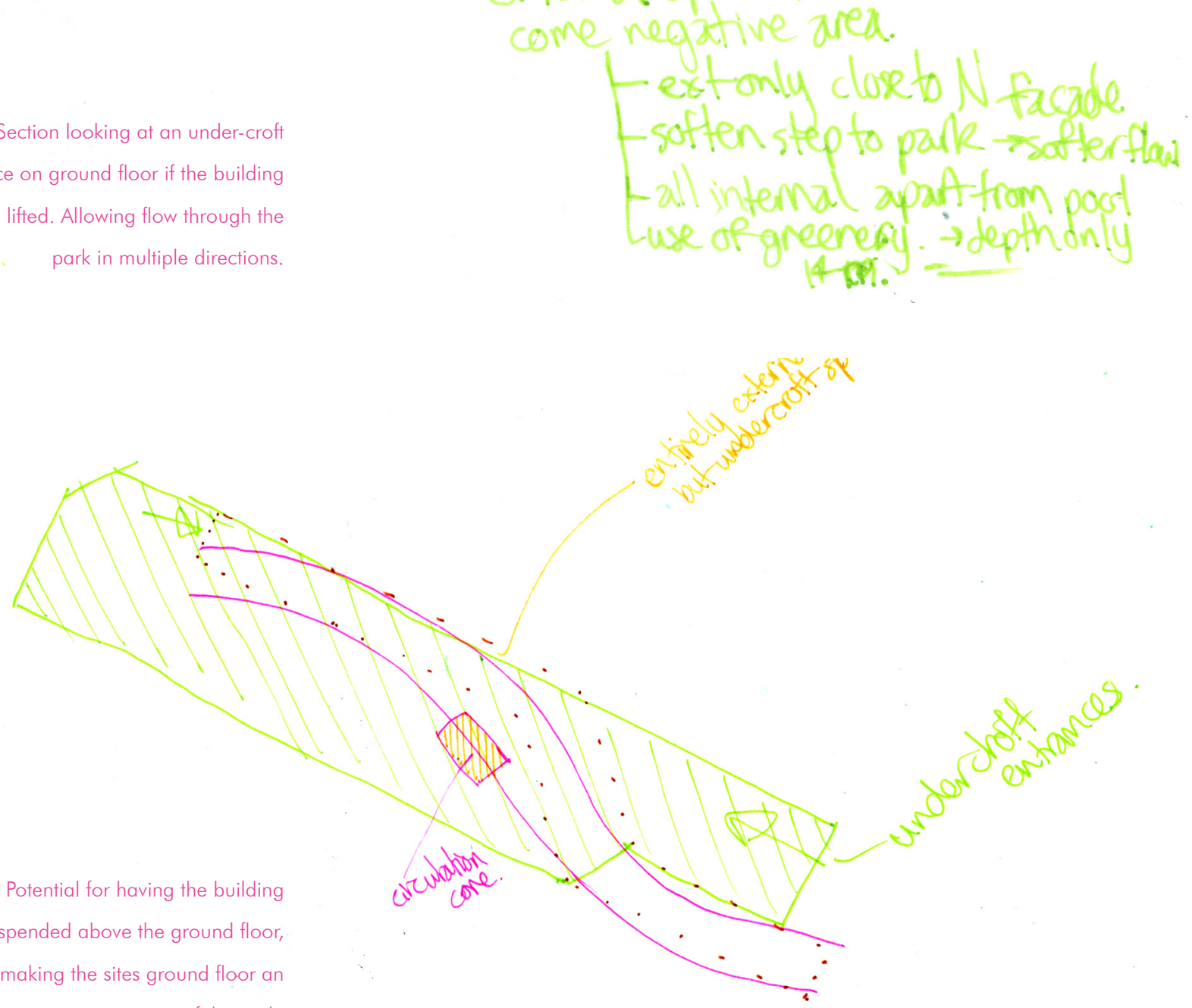

extension of the park. 


\section{Material Palette}

The last area of investigation in this experimentation section of the design was gathering research around materials and establishing a material palette for the building.

This investigation looked at the issue of stigma and how aged care housing is portrayed and contributes to this through its materials. A comparison study of a number of aged care facilities in the Wellington region revealed a common pattern in materials and signage which was specific to aged care typologies and attempted to give these larger complexes a more residential scale, playing into the idea of these places becoming 'home.' In traditional aged care, brick façades and large signage were two main things that made these places stand out from the communities in which they sit. The similarity of different buildings within a complex, regardless of material type, gives a repetitive look creating a recognition as aged care to a place and increasing the stigma associated. Some examples which worked well in integrating their facilities with the communities, in which they sat and in appearing more modern and less stigmatised were Sprott House in Karori and Te Hopai Home and Hospital in Newtown. Each of these used a mixture of materials in particularly their entrance façades, with wood, glass reflecting different colours and tones of light, varying heights and materials in rooves, landscaping toward the entrance. All of which work together to create a vibrancy and welcoming aesthetic which does not immediately stand out as aged care housing.

Looking at the interior spaces of the aged care there is an absence of people, large areas with tables and chairs are set up to (interior analysis more depth/ explanation) facilitate people and activities but when they are not used they look like dreary and depressing spaces.

This analysis could have been push further by looking at specific types of aged care in isolation, particularly more independent examples and expanding the comparison pool to a wider New Zealand context as this is not a Wellington specific issue. This might have resulted in more conclusive evidence of specific architectural decisions used to de-stigmatise in New Zealand instead of selecting positive elements from a smaller source pool.

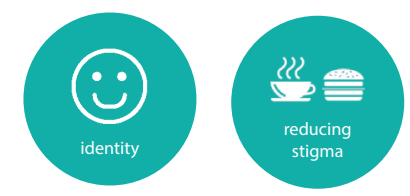




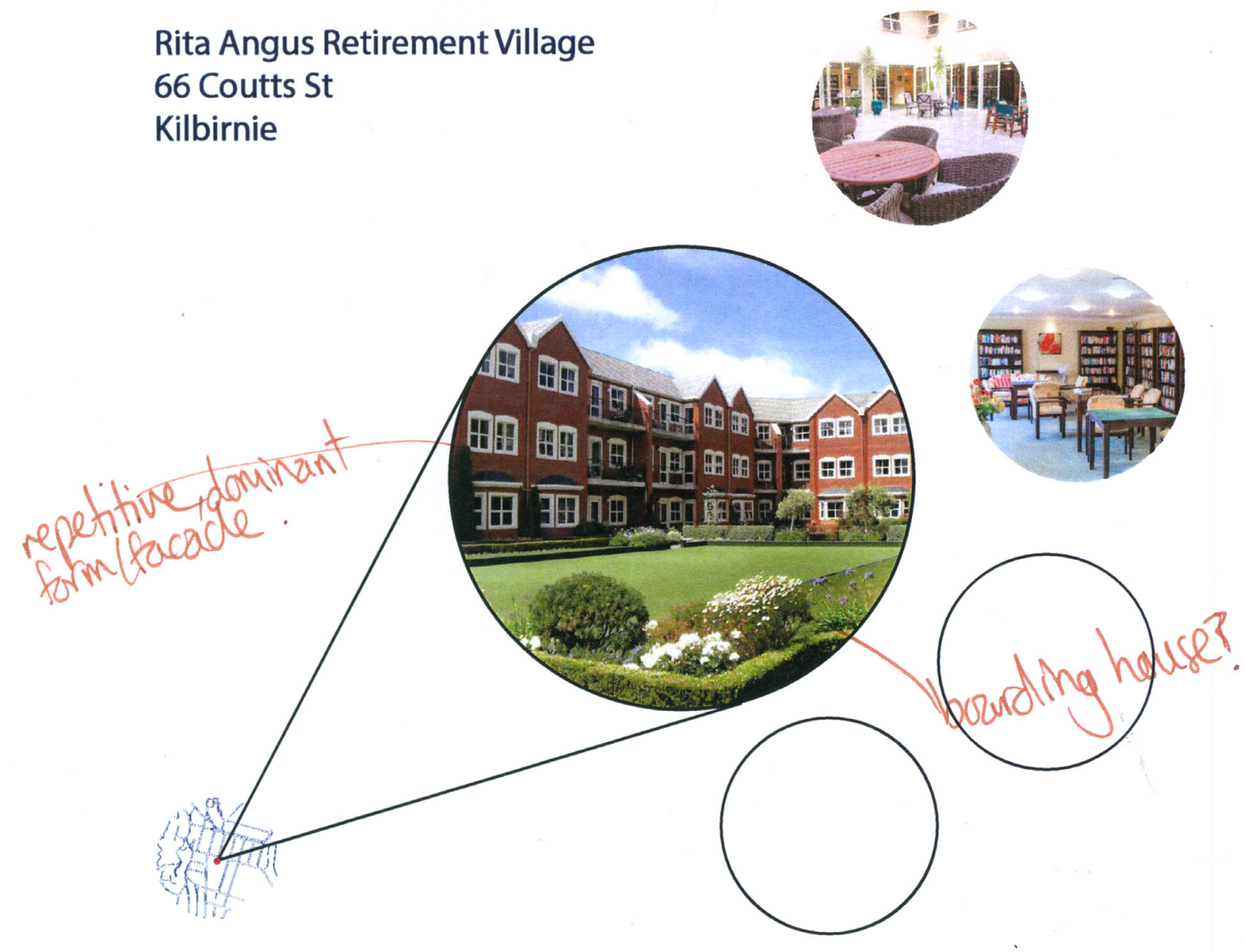

Fig. 4.1

A negative/ stigmatised example of aged care housing aesthetic and materials 


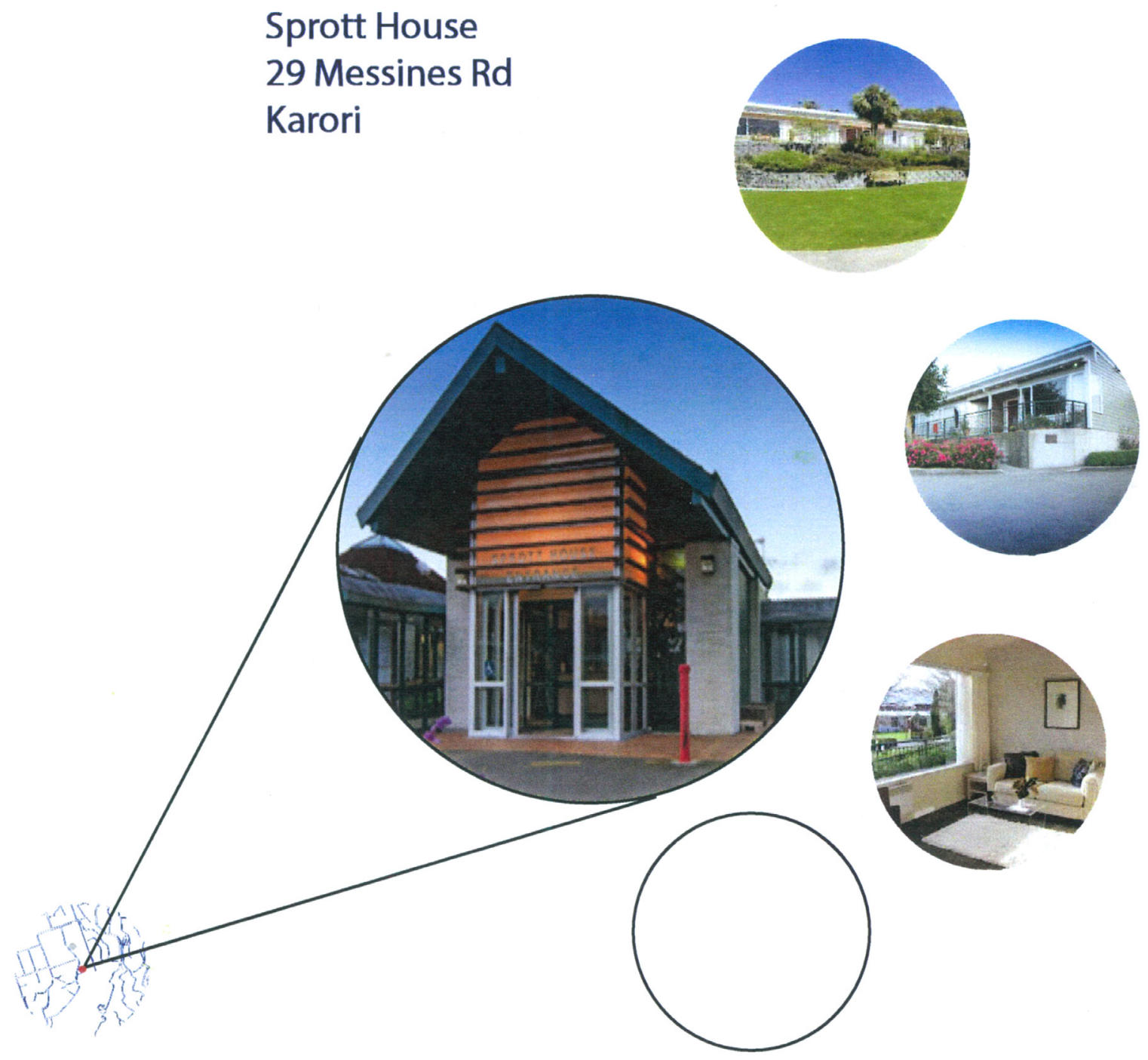

Fig. 4.2

A positive example of aged care

housing aesthetic and materials in

Wellington 


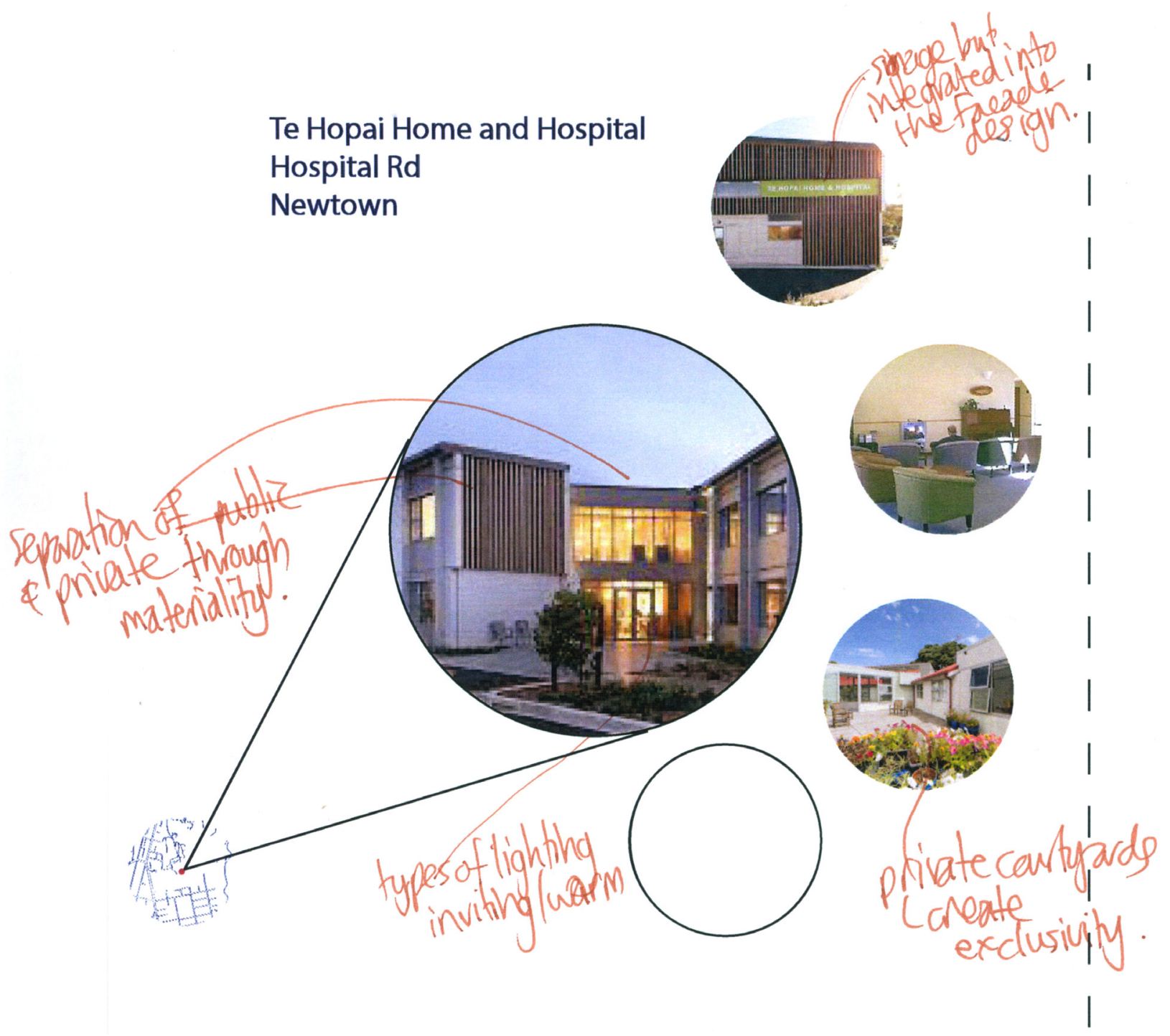

Fig. 4.3

A positive example of aged care housing aesthetic and materials in 


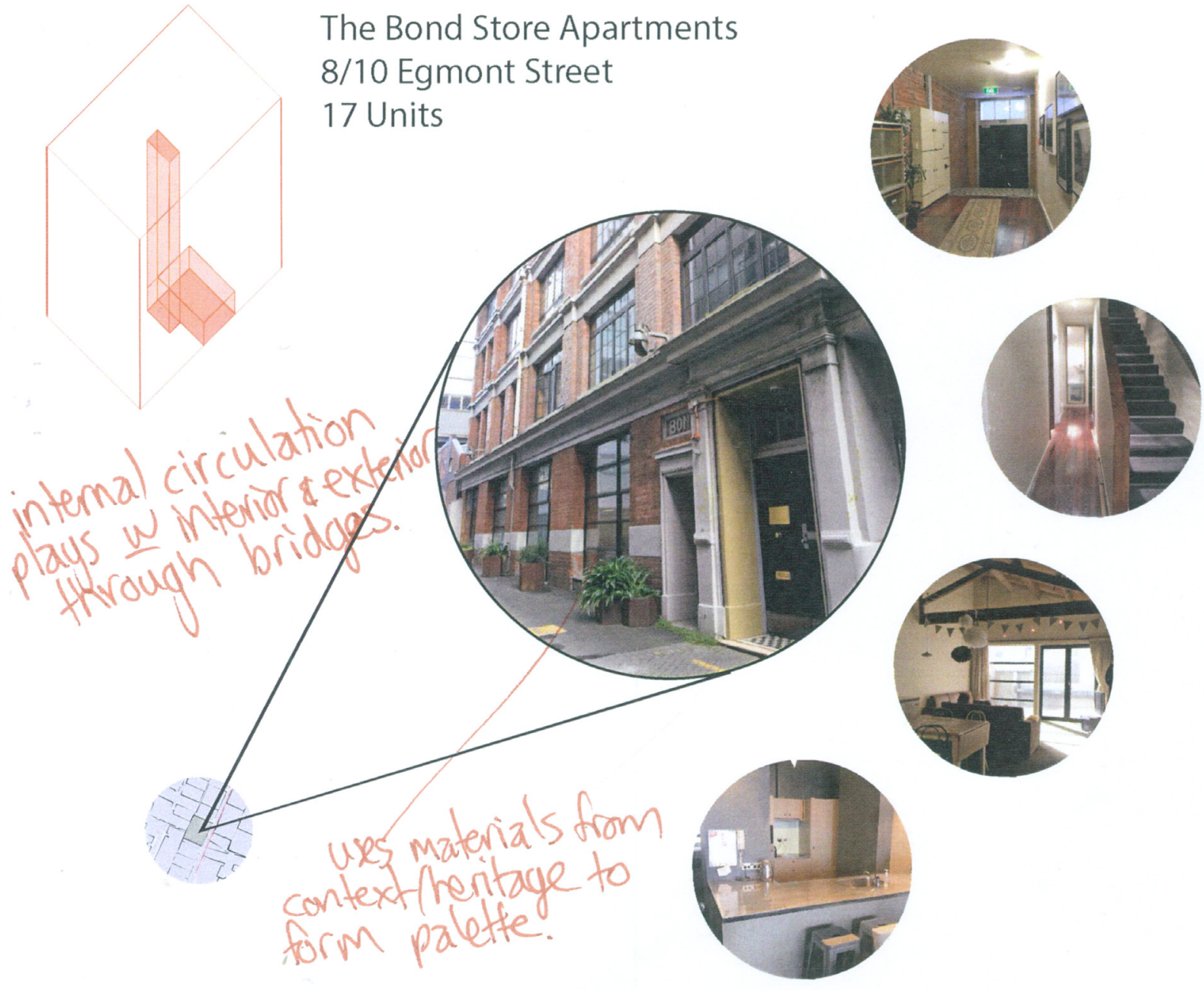

Fig. 4.4

A positive example of Urban

housing aesthetic and materials in

Wellington 
A further comparison study was done on urban housing models in Wellington City to produce some results into their aesthetic approaches and whether they came across as less stigmatised as models which do not typically house older persons. Looking again closely at the entrances, because they are the first thing you see and that initial experience is where the stigma first presents itself. The more successful designs use colour and texture to make their entrances stand out, although in some cases blending in can be a benefit of security, the character that having an entrance that stands out gives is important in reducing stigma. The interior spaces were mostly kept as clean and simple as possible, however ones such as the tattoo apartments, which use mood and metal to break up the interior palette, create a much more modern and home like feel to the spaces.
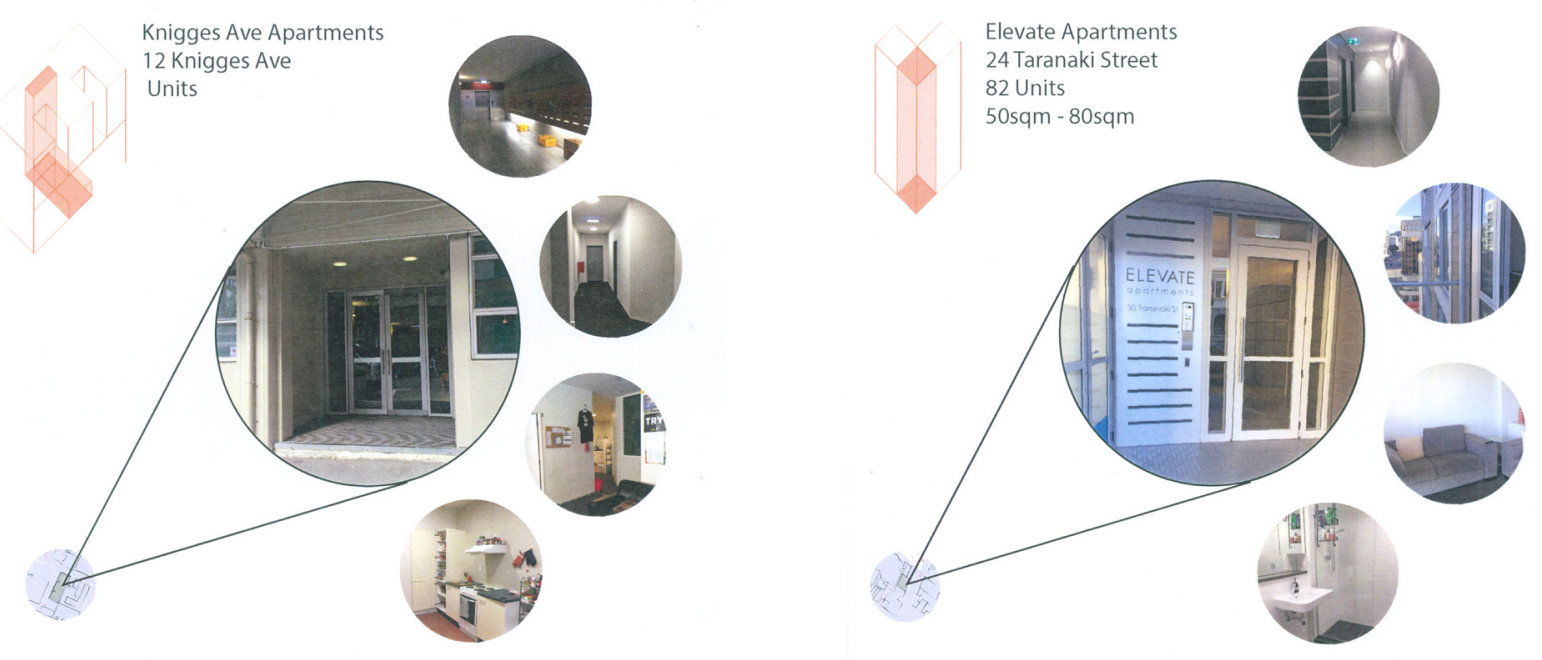

Fig. 4.5 and Fig. 4.6

A negative/ stigmatised example of Urban housing aesthetic and materials in Wellington For full material palettes see Appendix A. 
This phase of experimentation was an important step in determining how each of the design tactics would develop in working towards the aims and objectives. The treatment of entryways and the buildings presence in context are what I believe are to be attributed to stigma and by experimenting with materials that add vibrancy, lightness and evoke an interest in the environment a reducing in stigma could be achieved. 
Model Iteration

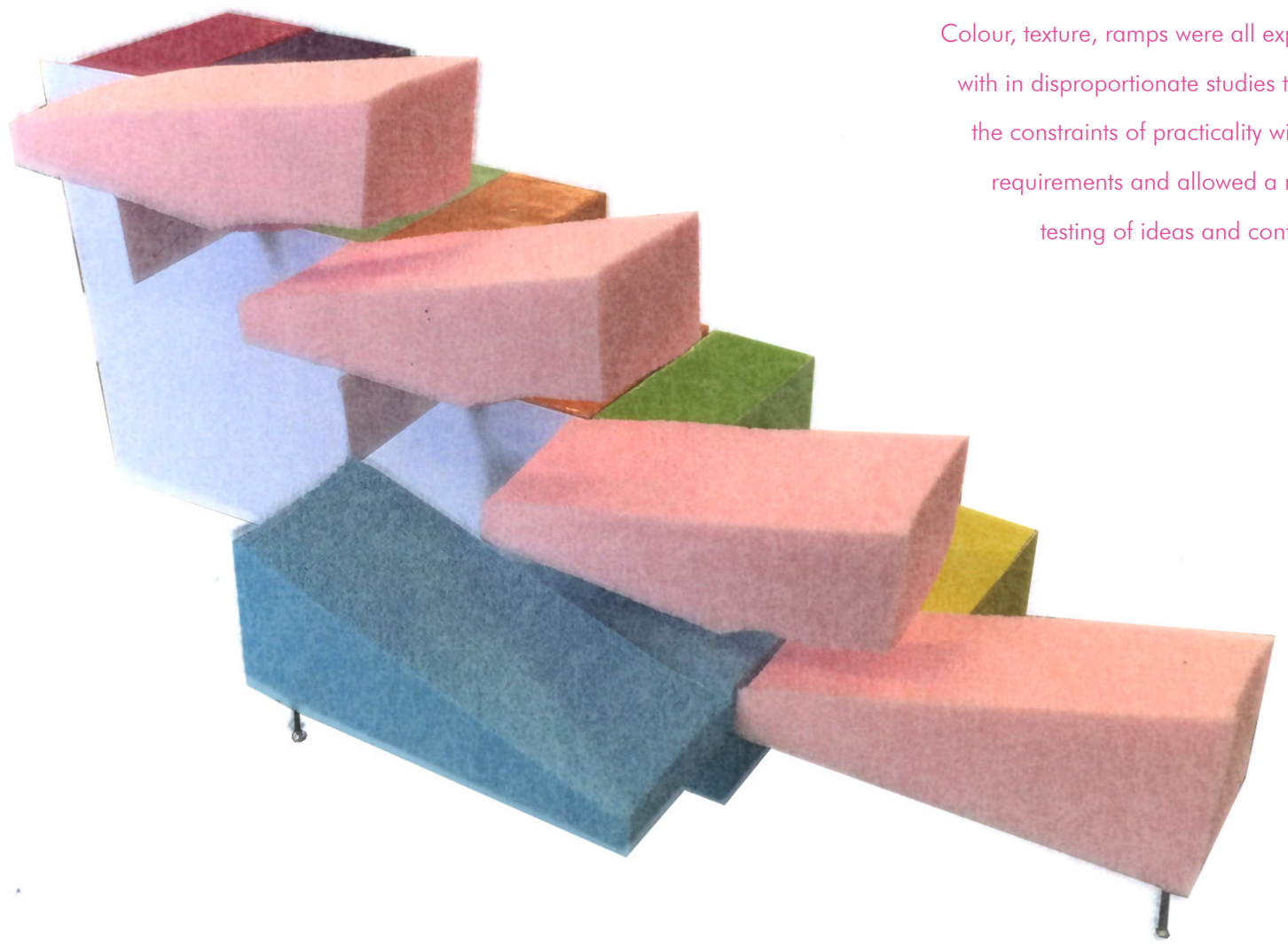





\section{Chapter 5:}
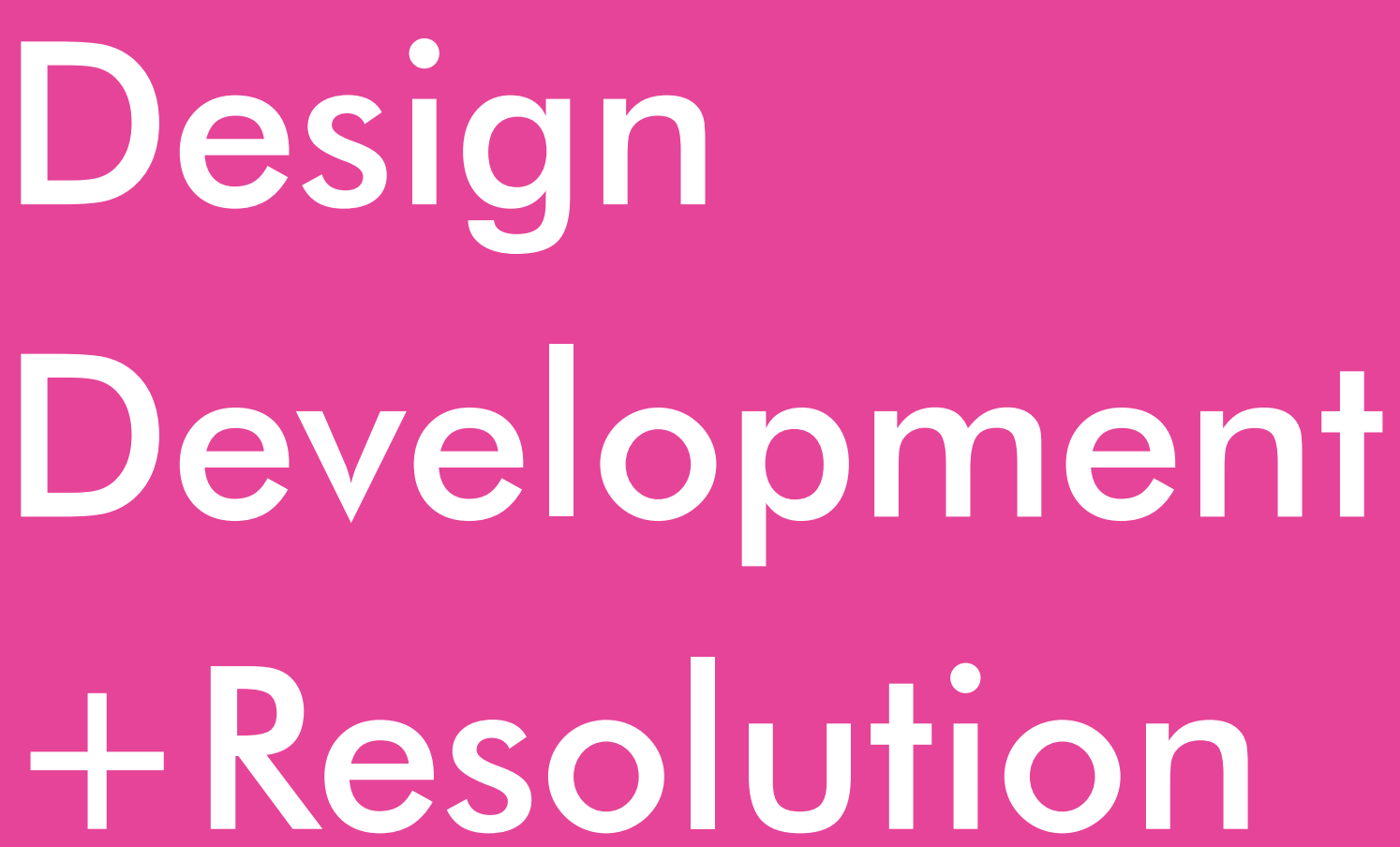

\section{Developing Concept Two with the Four Tactics}




\section{Refining}

This design development resolution began with the refinement of the experimentation results, narrowing down on the design of each of the tactics area as well as the materiality and construction considerations. 


\section{Residents Timeline}

The design development section of this research investigation focuses on how the iterations and testing, through the experimentation phase, can be used to better the design outcome with focus on the four established tactics of urban location, social circulation, mixed housing and shared amenities.

Firstly establishing a more in depth residents' timeline, this is mapping hypothetical resident's lives as they grow and adapt within the building, imagining what their apartment requirements and changes would be in order to establish an approach to apartment design which covers the needs of all residents in a simplified design response. The focus was experimenting with the addition or subtraction of an additional room to units, particularly for older persons and elderly needing a career on site. The flexibility of these spaces was in key how they could adapt to many different resident types. Two story apartments became less feasible as they would allow easy access for a separate unit to a house with its own private entry but accessibility through a multi-story apartment starts to separate who can live where and people maybe having to move if declining mobility impacts their use of their spaces. The apartment design approach focused on threshold between private common space to external circulation/ social space- becoming the basis of wheelchair accessible plans.

\section{Older Person/ Elderly Demographics}

Looking at groups of older persons and elderly

and what their experience and timeline in

this development could look like, based on

spouses, children and increasing needs.
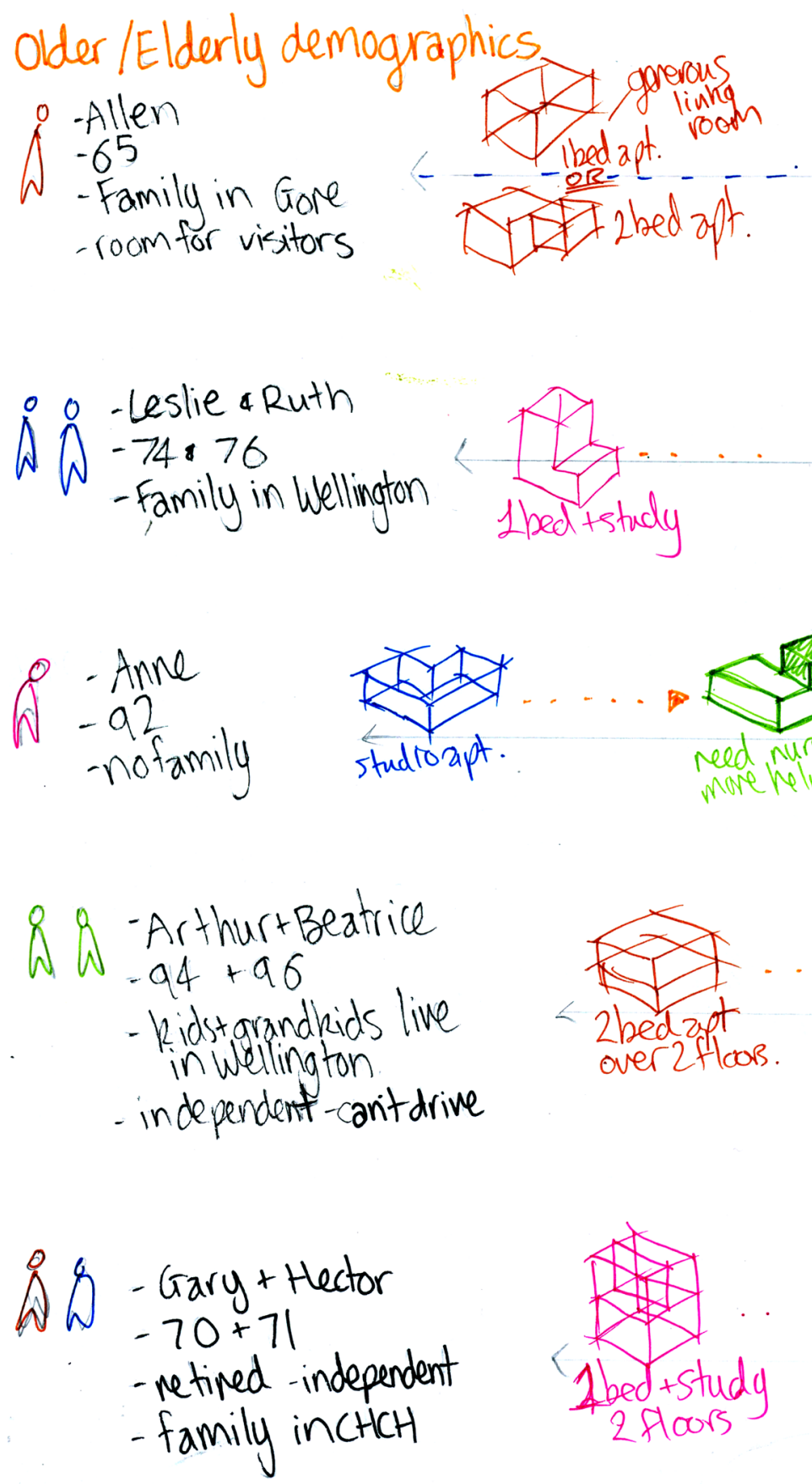
young persan demographics
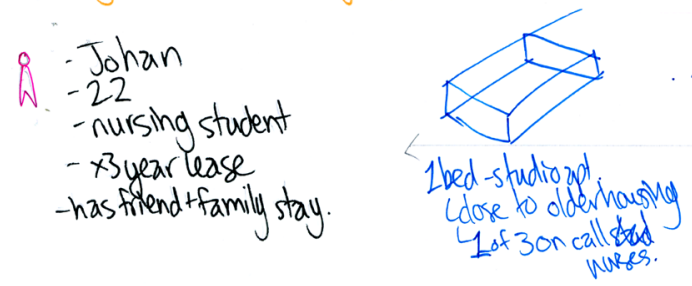

\section{8 - Priya, Tama, Drew, Chorbtte \\ $-18-24$ \\ - Massey Unistudents \\ - social + only stay during \\ term time.}

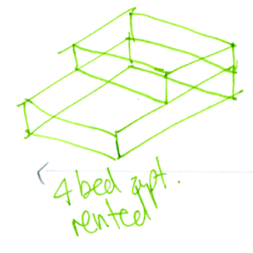

$$
\begin{aligned}
& \text { Wh } \\
& \text { - George + Ihaia } \\
& \text { - } 23+24 \\
& \text { - unistudentstyopro } \\
& \text { - potential longer termstay } \\
& \text { - here year round }
\end{aligned}
$$

$$
\begin{gathered}
\text { QRA - Mia, Renee, Hayley } \\
\text { - } 23 \\
\text { - postgrad studentst } \\
\text { yo pros. }
\end{gathered}
$$

$$
\begin{aligned}
& \text { - olive } \\
& -22 \\
& \text { - Vicuni student. }
\end{aligned}
$$
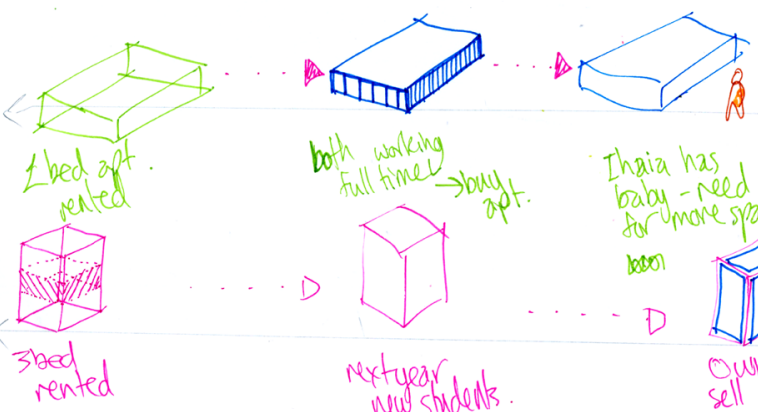

$$
\begin{aligned}
& \text { rextyear } \\
& \text { new sidents }
\end{aligned}
$$
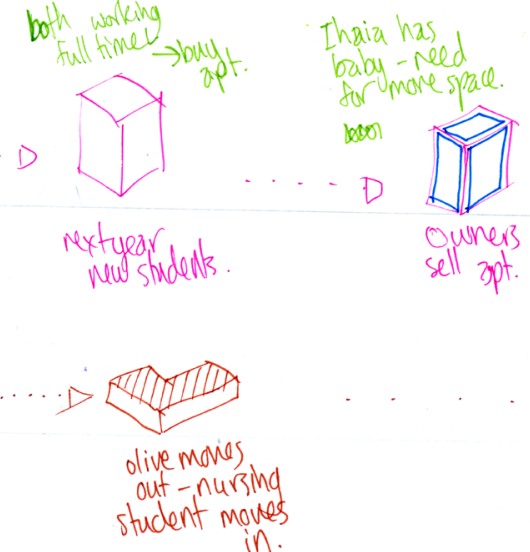
johan stays for the rewnuging sesica lengthothis study shatent woves in
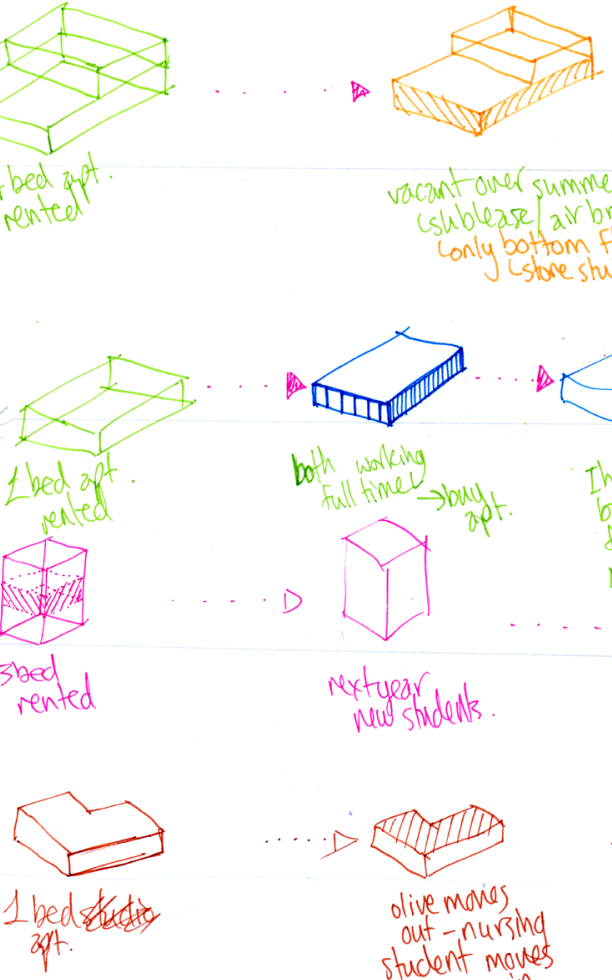

\section{TYPOLOGIES}

- lbed studio

-1 -4bed apt

adapted to family leldenly ap.
wion sale.

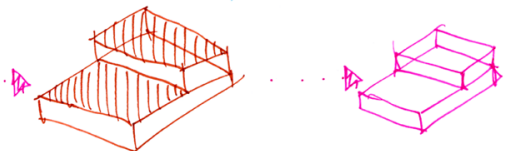

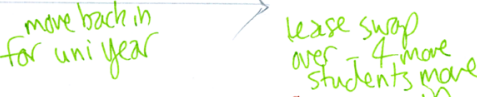

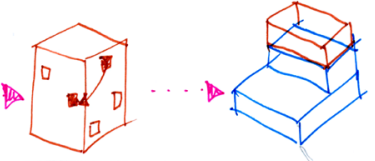

move win black to bidoel

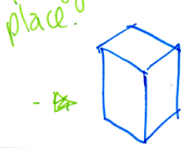

new oumers move in acupy
celdenty comples

\section{Young Person Demographics}

Looking at groups of younger persons, flatting or living

by themselves. Apartments that would be rented out with fast resident turnovers. 
Family Demographics
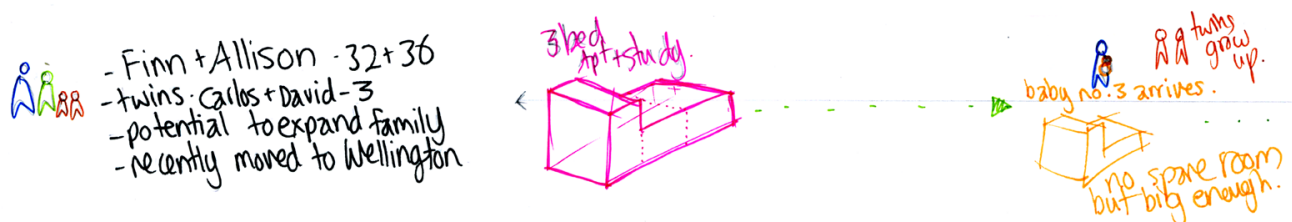

The twins want to go flatting-apt gets convered intrances 2 - seperate entrances

8\%-Ardie + Martin 28+30 - baby sage - not having any more children - family in Hutt valley

$$
\begin{aligned}
& \text {-kirk }-39 \\
& \text { - } 22 k=7 \\
& \text { - single parent } \\
& \text { - Family in Whangarei }
\end{aligned}
$$

AQR
- Manu + Melissa $40+42$
- caitlin -16
- Marcie - 3
- rew towellington
Lnew jobs

Q
- Robyn -38
- Alex -14
- single parent

TYPOLOGIES

-2.4 had a n - need to mavelexiand

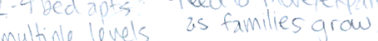

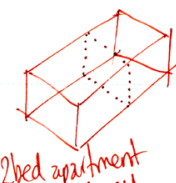

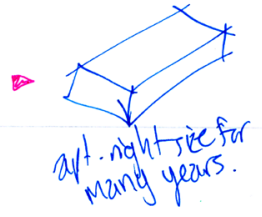

趾
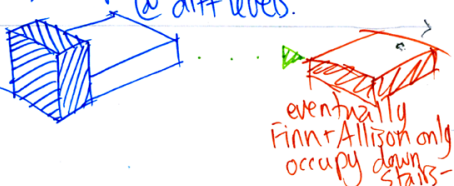

5

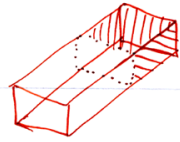

occupy down

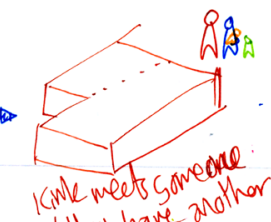

Lhey have chid.
reed for brges home

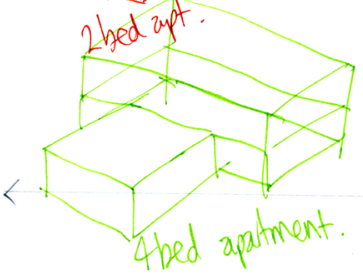

-

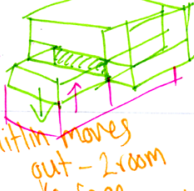

凶
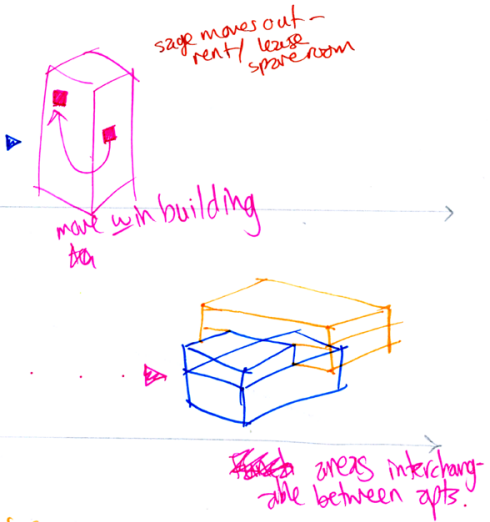
whe between zpts.

to frel

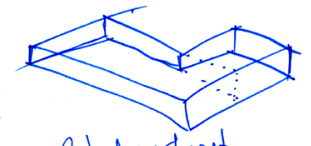

3 bed aprotment. ederly couple below family

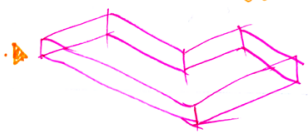

Robyn meets somearet \& $a$ chas another

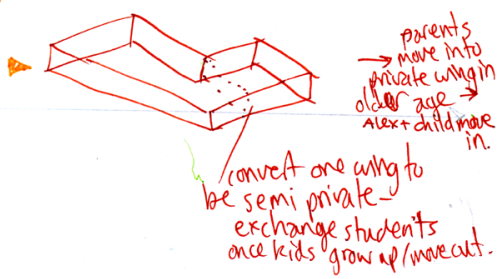

Family Demographics children moving out, parents moving in. Moving from a family home to a home to retire in. 


\section{Concept Two: Urban Design Up}

A massing model of the building form was made after creating multiple iterations of a push pull effect on the residential floors, giving them each a unique character but still following a similar plan layout across each. The model images were then sketched over to explore different façade treatments, particularly how they shift up the residential floors. Playing with glass and wood to create different external patterns and internal shadows, looking at how the circulation walkways along the north façade, given priority over direct north facing window apartments, could become glass tunnels, or be quite closed off or have movable wood slated panels which the residents could share autonomy over. These iterations resulted in a need for distinction between floors and greenery throughout the building to liven the spaces.

The development in this stage of the research focused again on the four design tactics. Refinement in these areas ensured I was focusing on the elements of the design which would achieve the research aims.

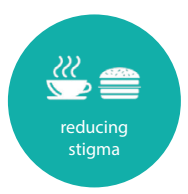

\author{
Facade Iterations \\ Looking at materiality of the façades which \\ reflect the positive, stigma reducing qualities \\ discovered in the material palette.
}
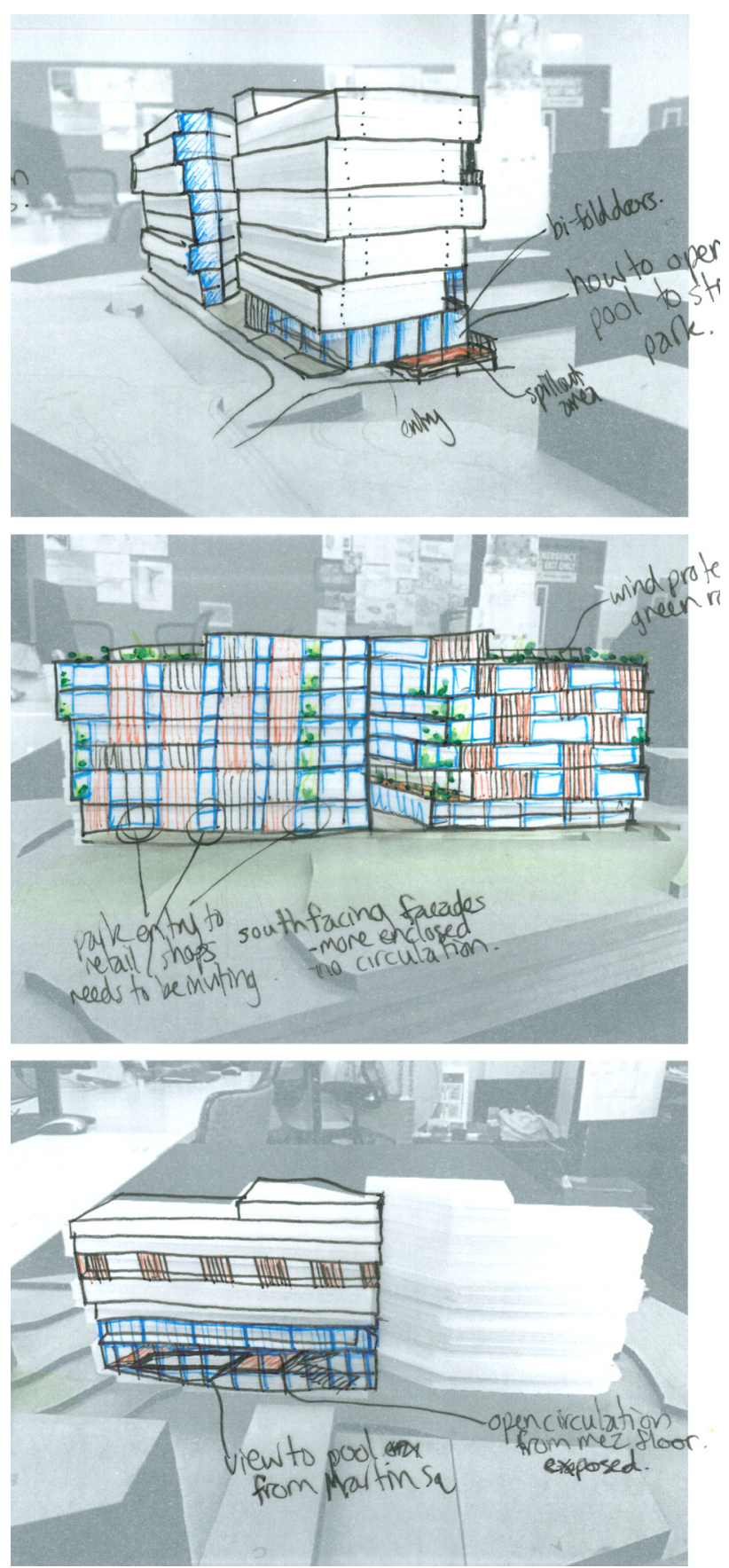

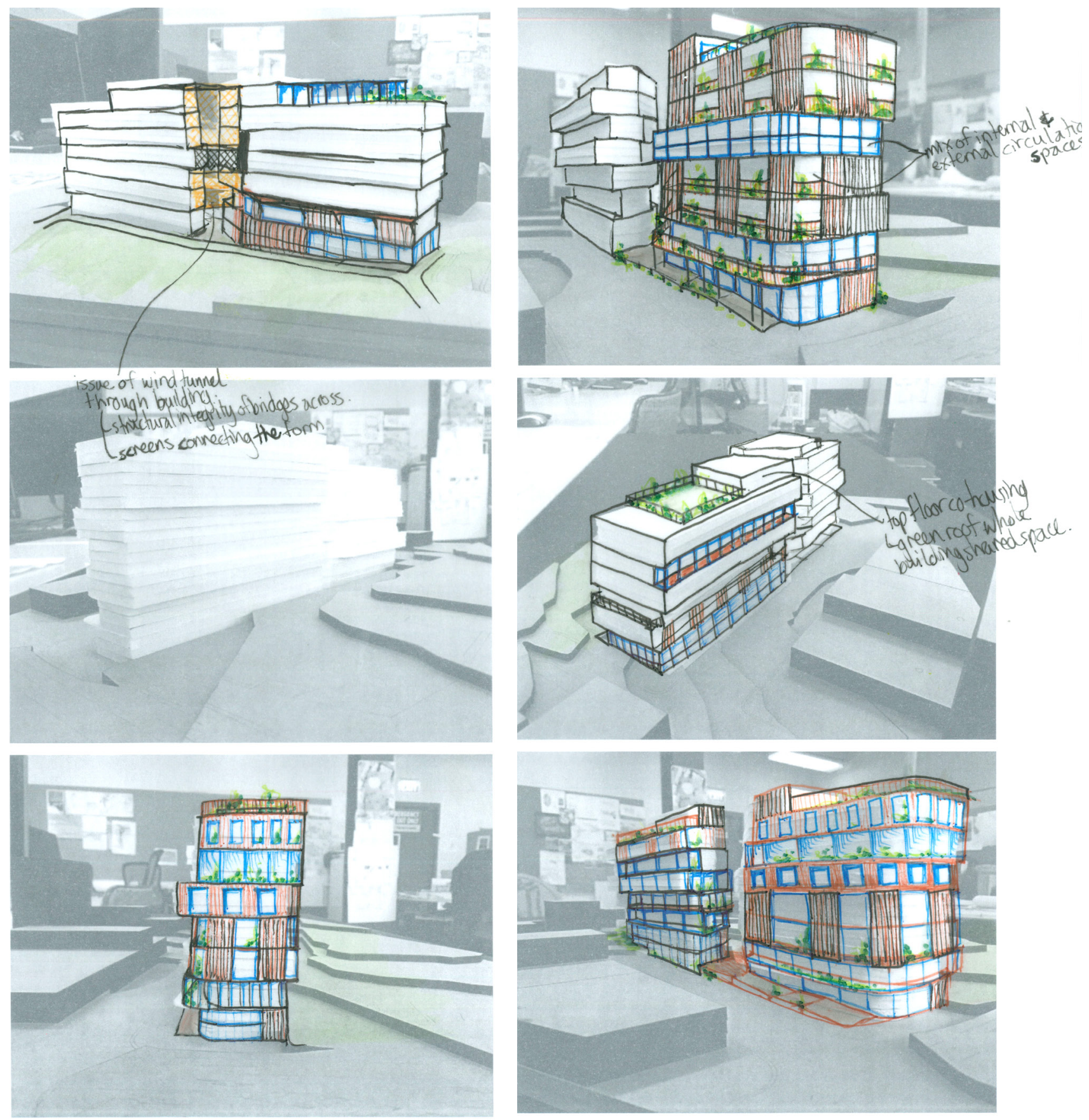

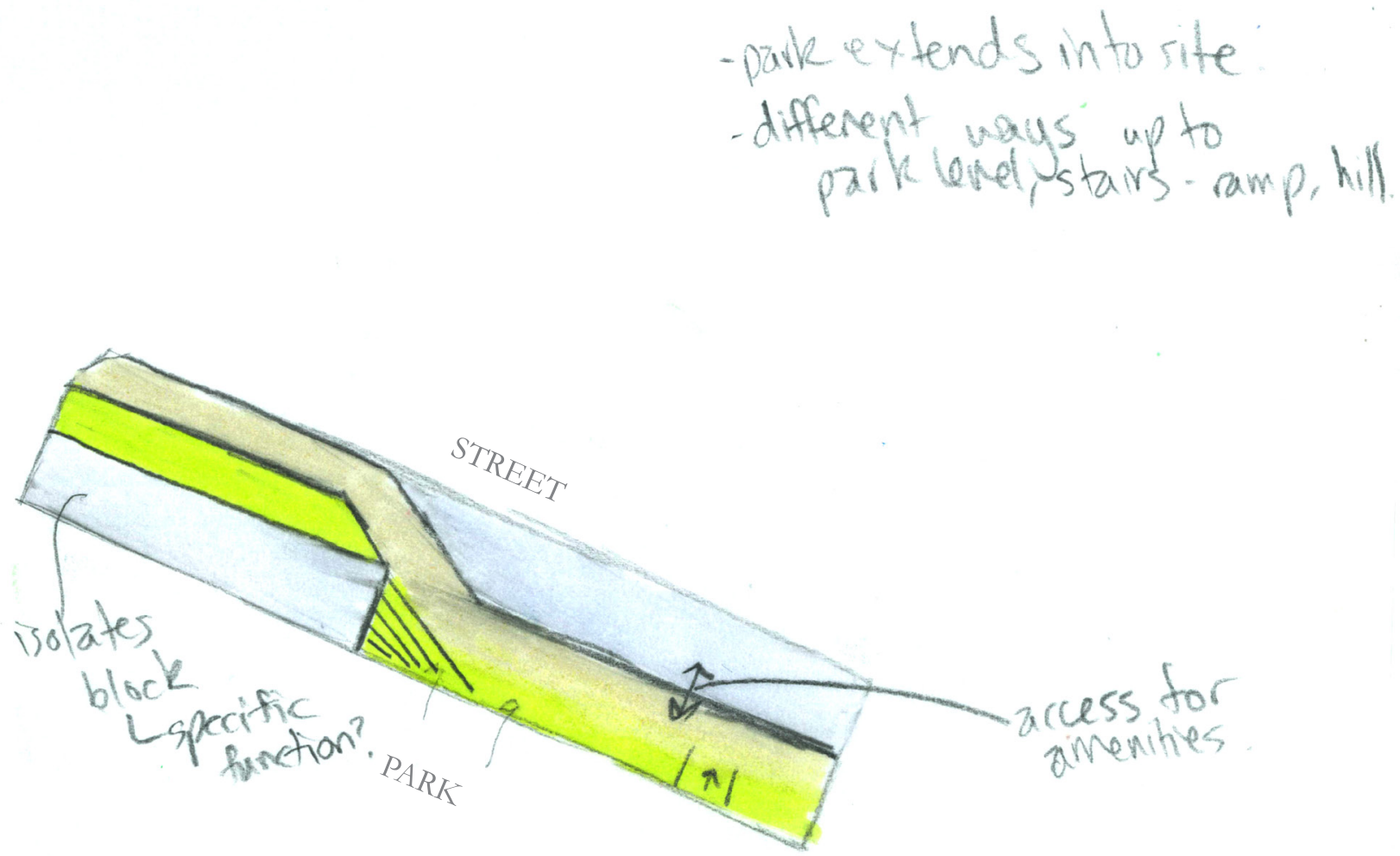

This drawing condensed what concept two- urban design up, would mean for its interpretation on this site. Having lots of entry points along the social street to the park and to the road. Creating visual connections through the building from park to street. Lots of smaller gestures which see the same plants and trees from the park to grow on the site, in circulation areas. Within this design decision more explorations were explored. 


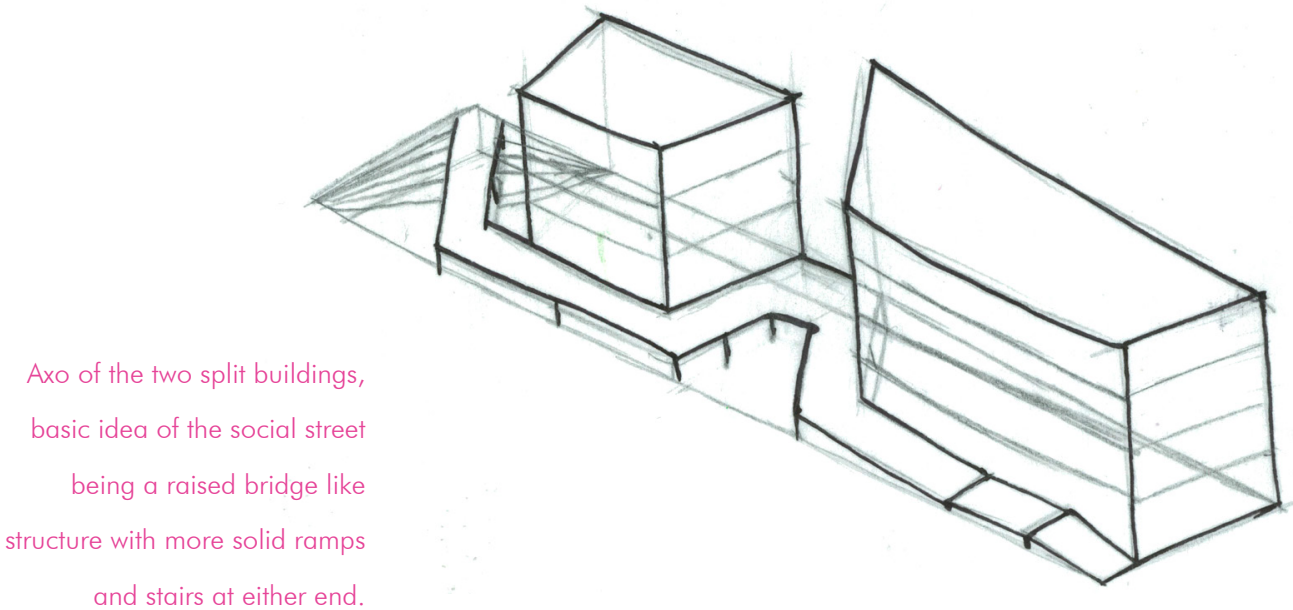

and stairs at either end.
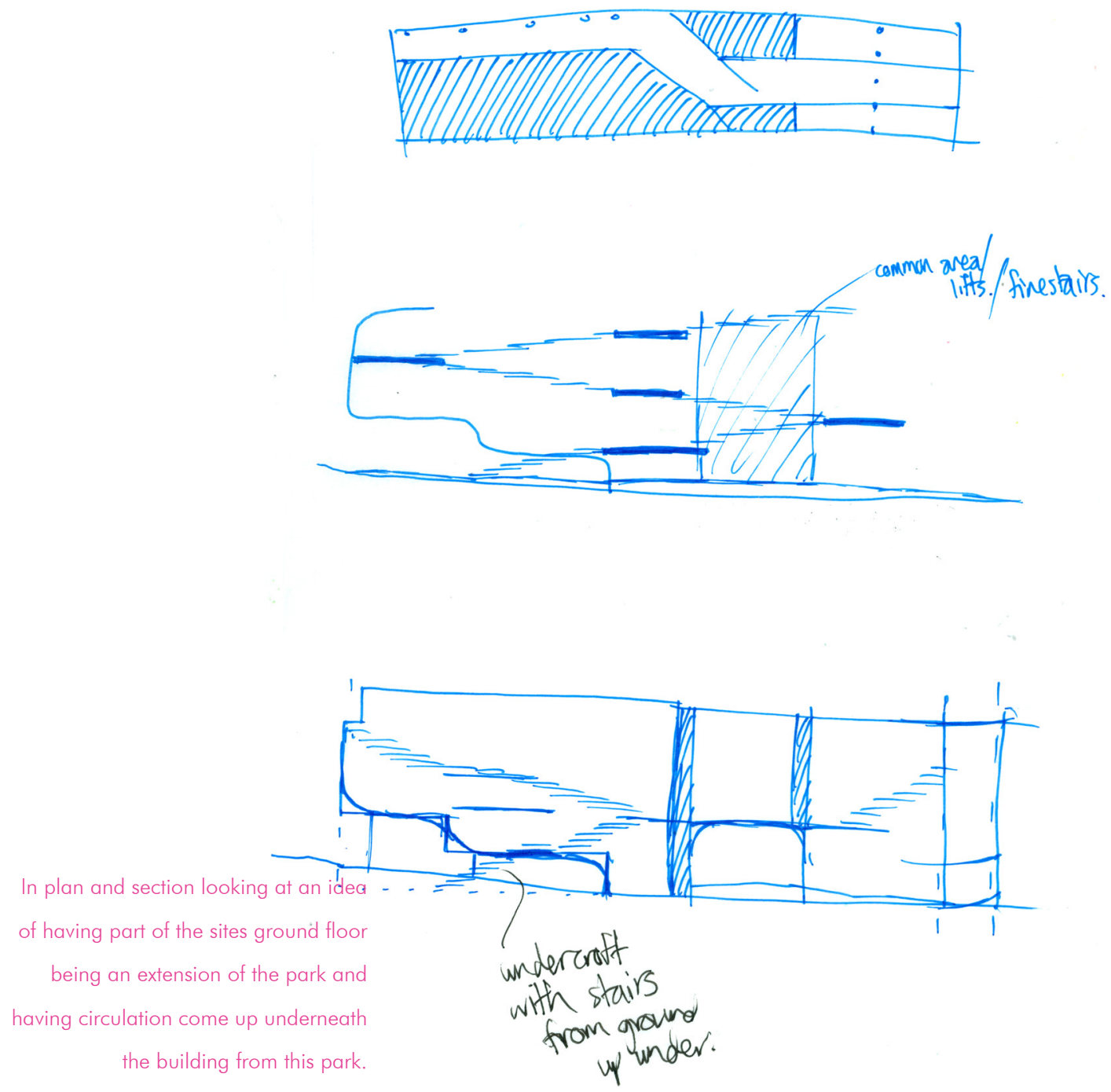

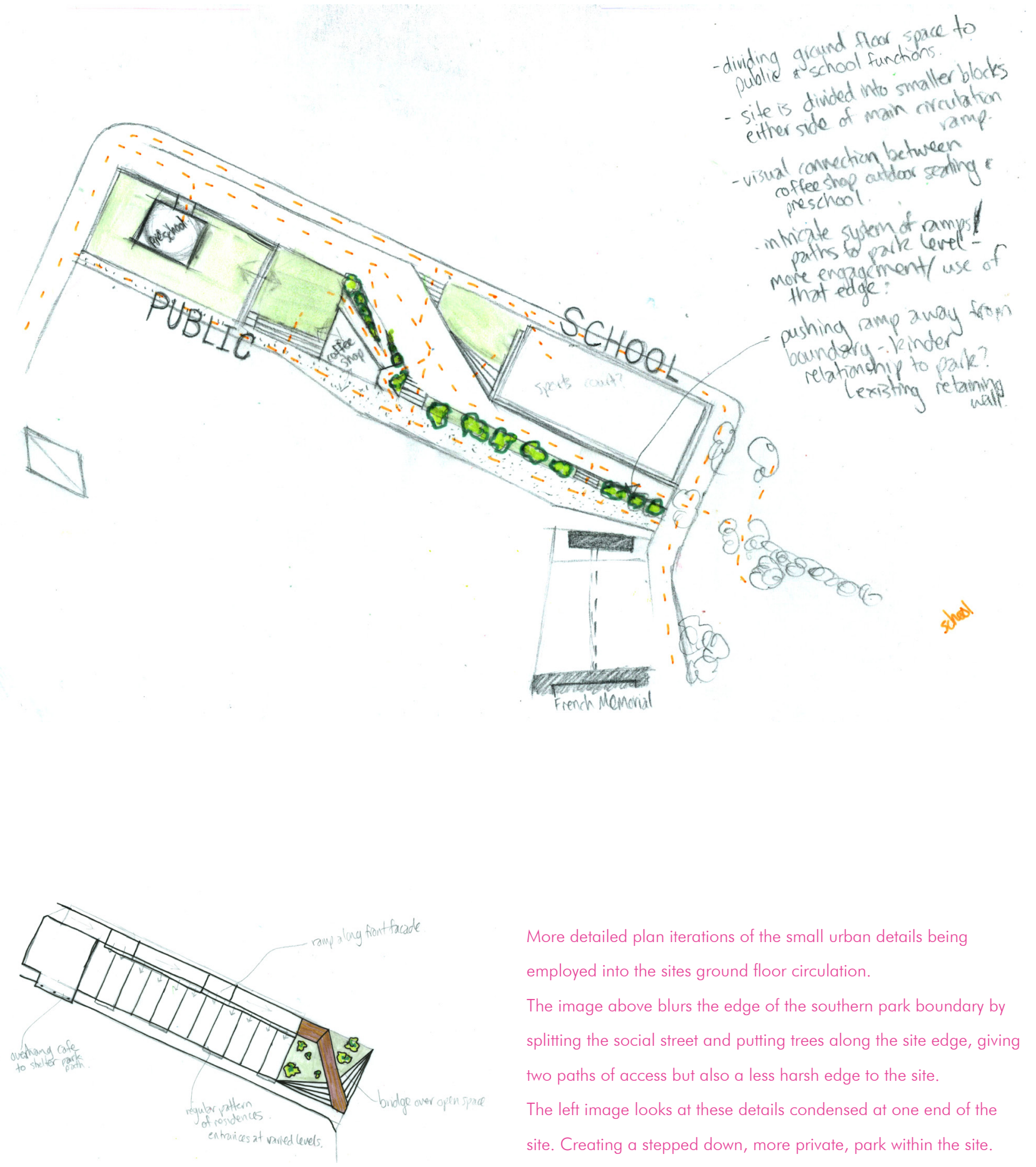

More detailed plan iterations of the small urban details being employed into the sites ground floor circulation.

The image above blurs the edge of the southern park boundary by splitting the social street and putting trees along the site edge, giving two paths of access but also a less harsh edge to the site.

The left image looks at these details condensed at one end of the site. Creating a stepped down, more private, park within the site. 


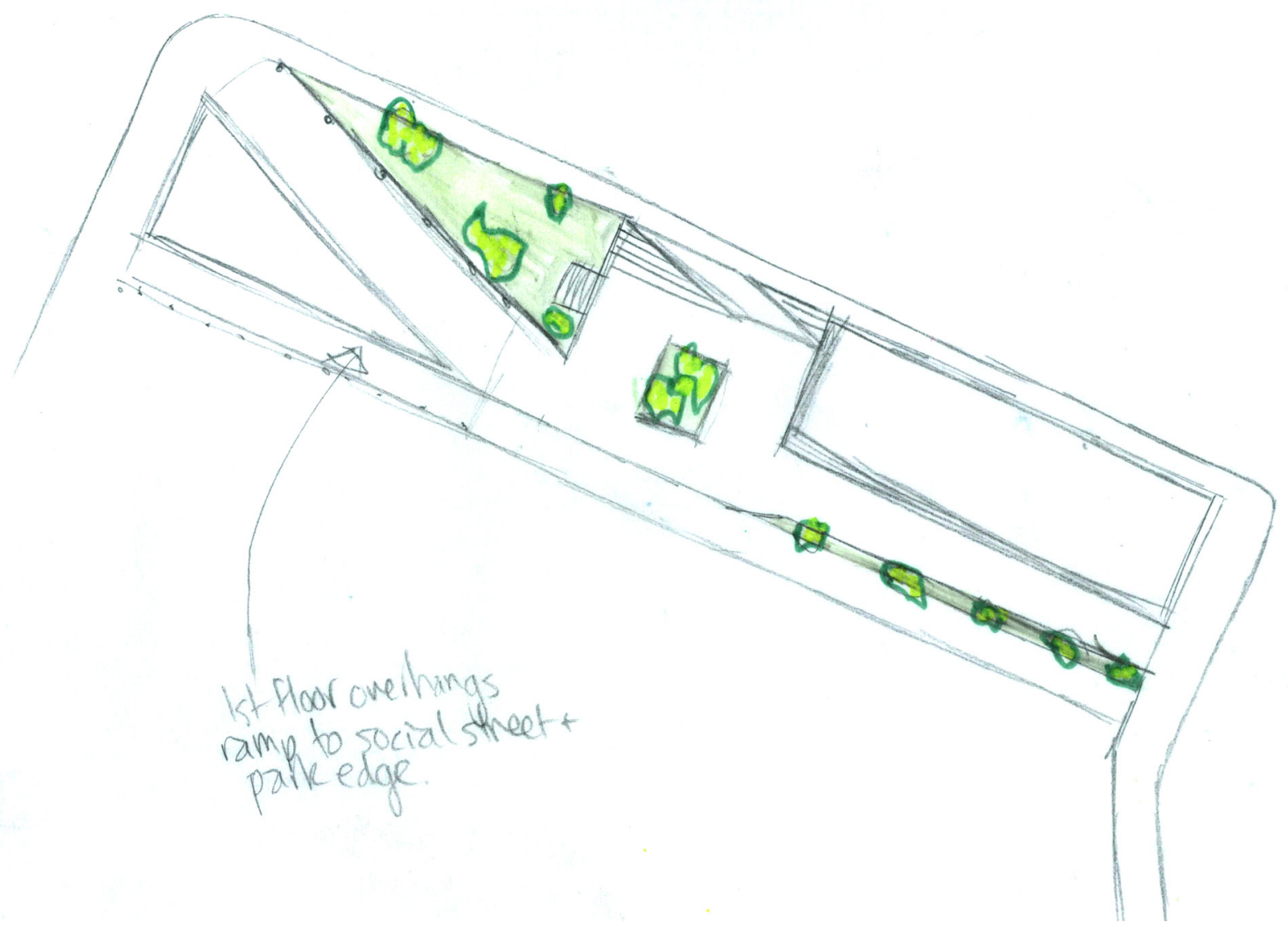

The top iteration has park dedicated spaces throughout the site, some intersecting with potential internal spaces and some softening the street edge.

The right iteration splits the ground floor building footprints into three, with the consideration of floors above needing to take up majority of the site, many of these green spaces would become under-crofts and potentially less utilised for interactions because of this.

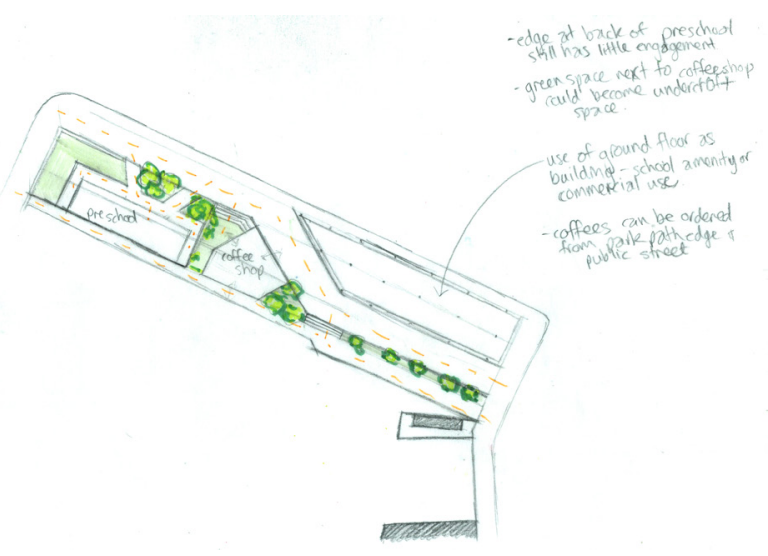




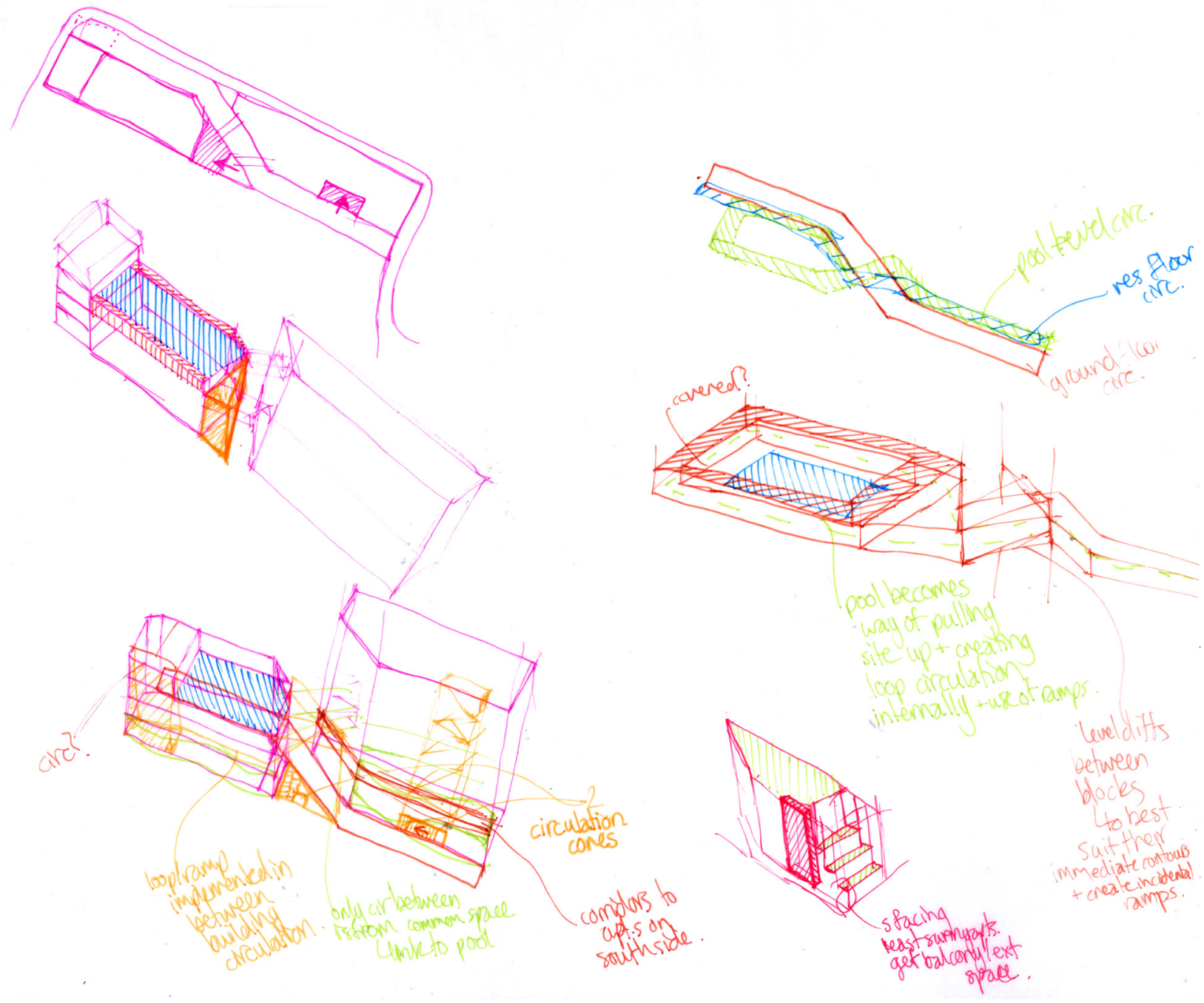

Looking at pulling these ideas of urban details vertically up the building through the pool placement. Looking at staggering the building block heights and having a rooftop pool. This would mean more circulation within the buildings to ensure everyone could access the pool and would make it less of an accessible public amenity. 


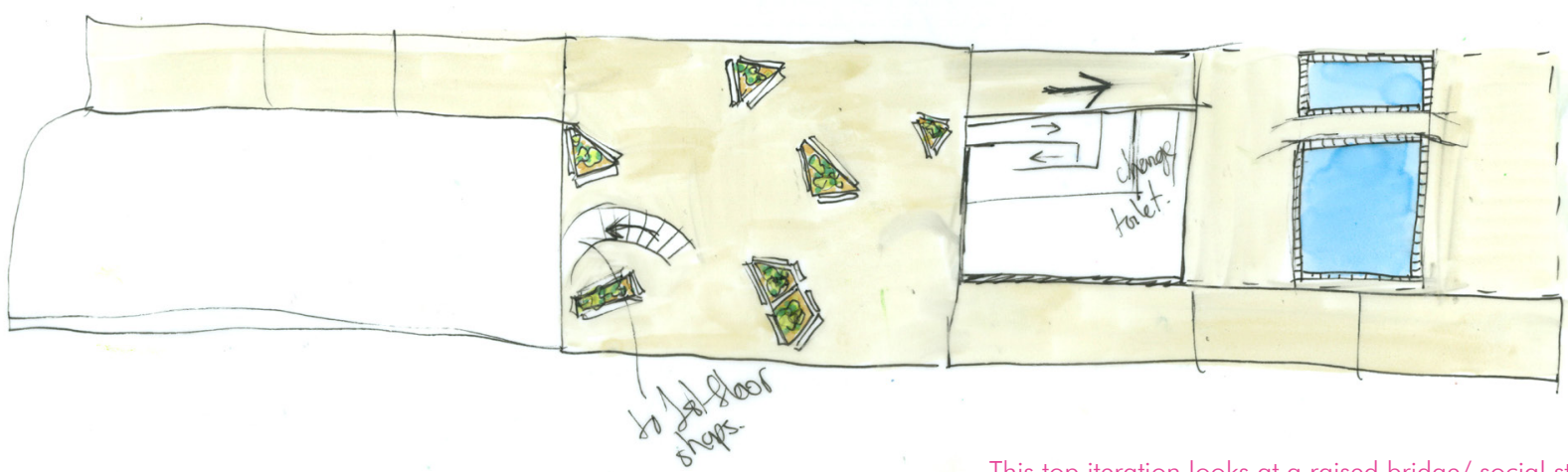

This top iteration looks at a raised bridge/ social street across most of the site. This allows the pool to sit at ground level from the $3.1 \mathrm{~m}$ high park edge. Pockets of vegetation can come up from underneath through seating planters.

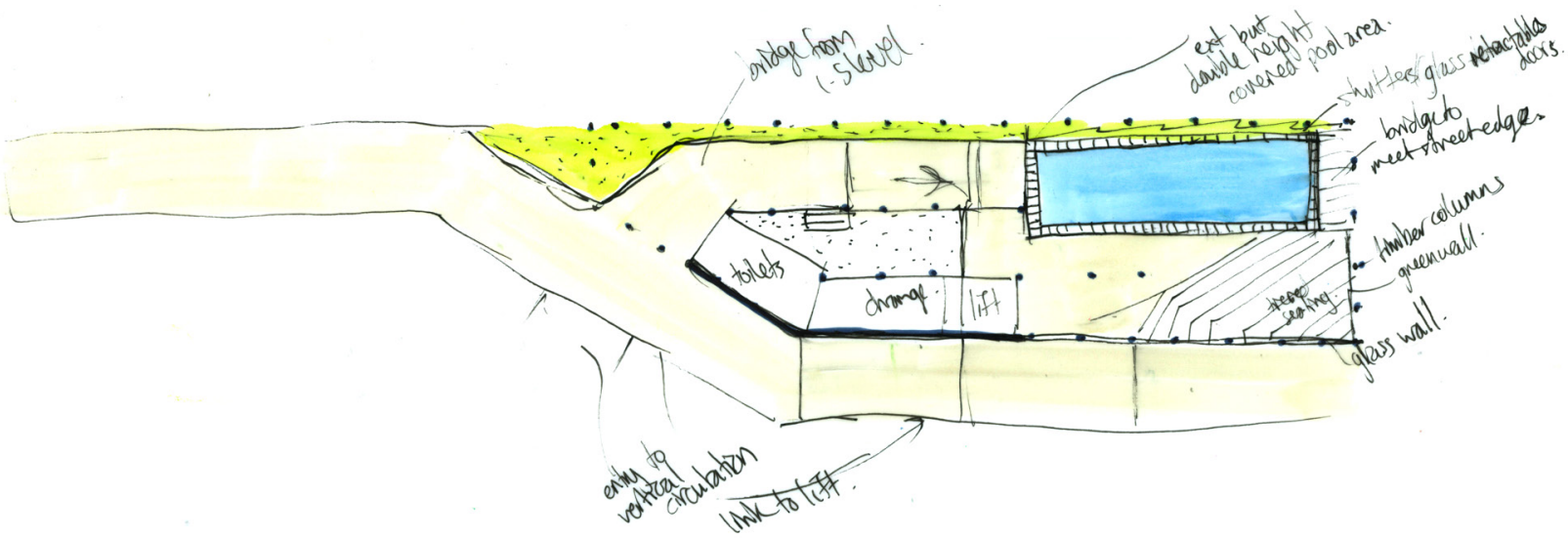

Looking at the accessibility between the pool entrances and getting to bathrooms and changing rooms with both stairs and ramps. 

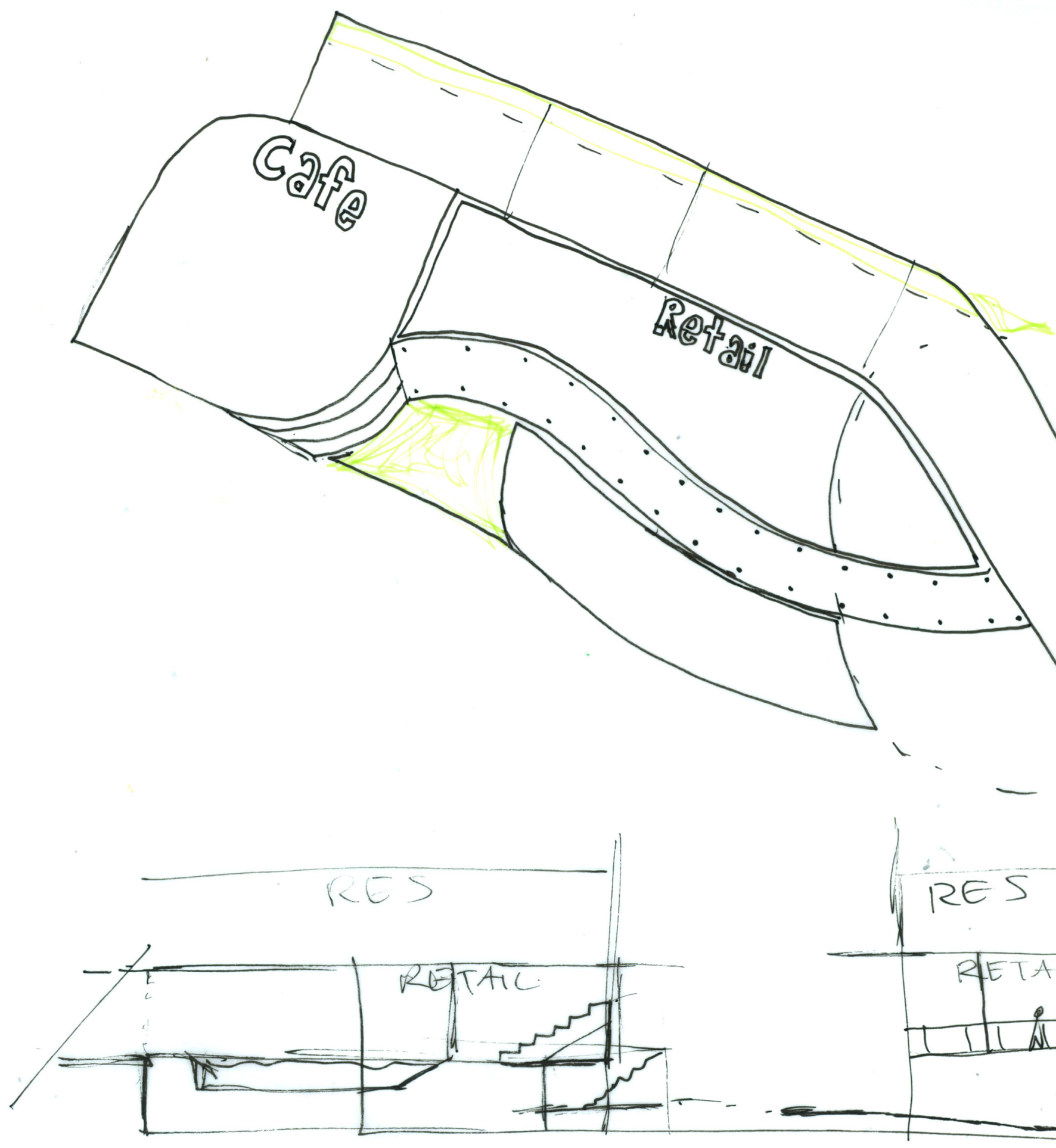
Looking at having the original social street as concrete ramp system but with some bridge like pathways between amenities on ground floor. Curving the corners to the pool and cafe to soften the edge and create seating in the entry areas. Because of the height difference in lower and upper ground being $3.1 \mathrm{~m}$ this iterations section looks at having retail over two floors, giving more space to public amenities.

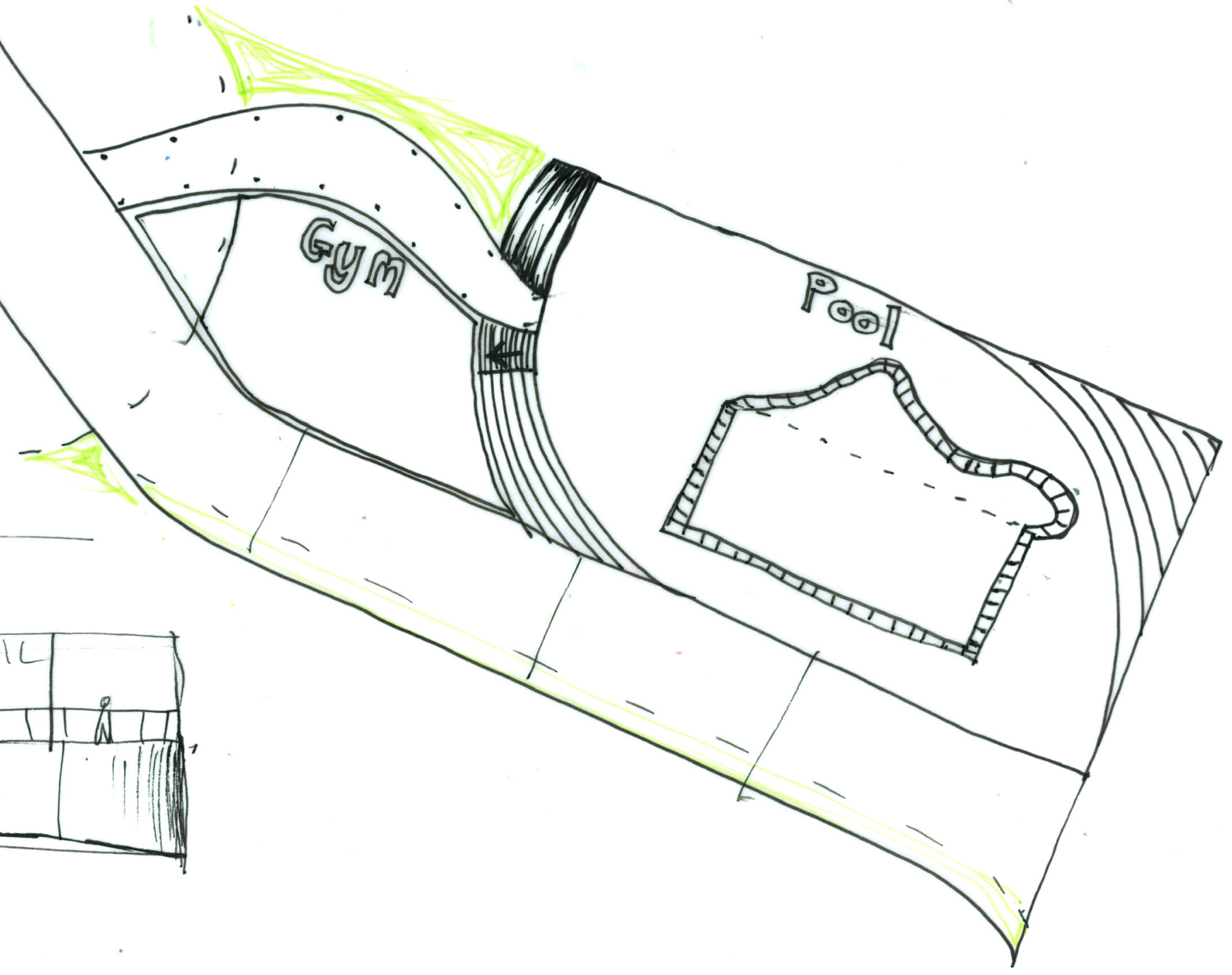




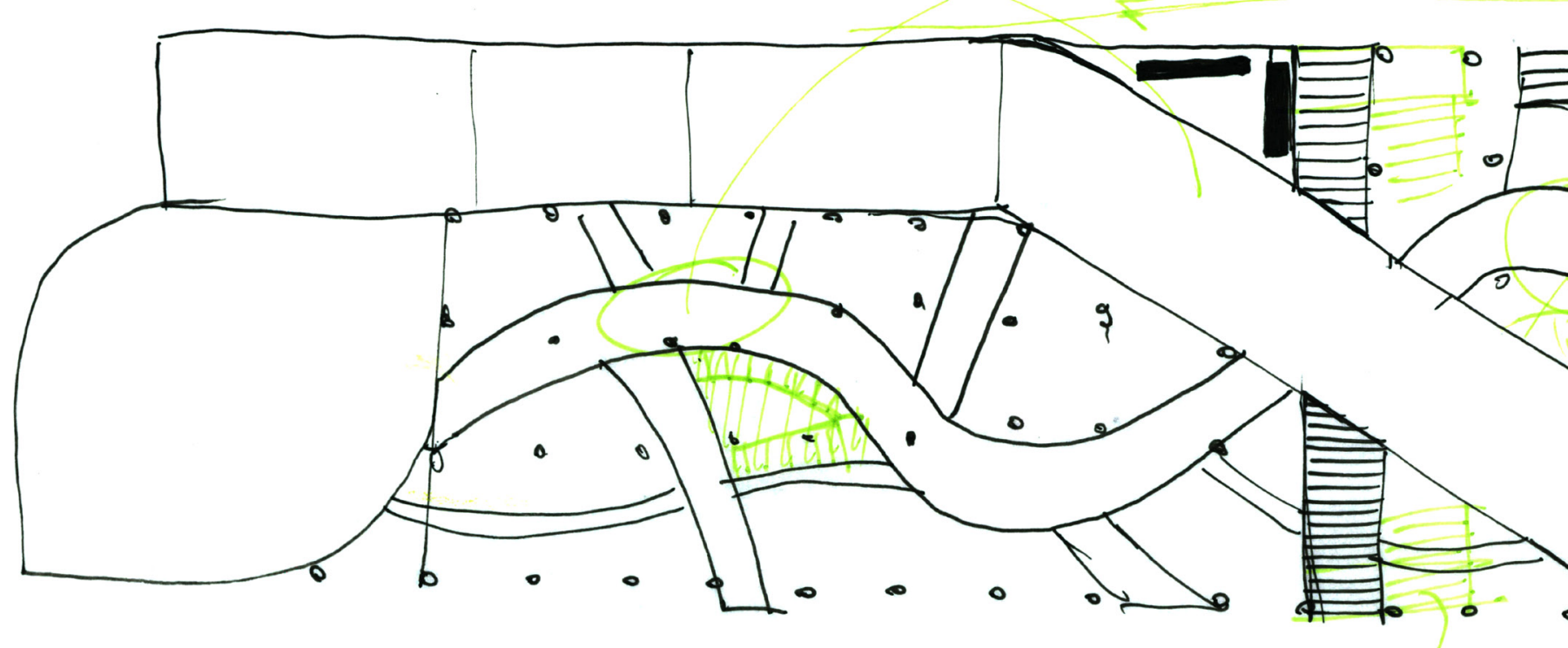

A more complex version of the previous iteration, focusing only on circulation. It becomes quite busy and hectic with this many pathways, although allows an opportunity for many different colours and materials to be used. A consideration of how a structural grid, support the above structure, could dictate the circulation placement decisions. 


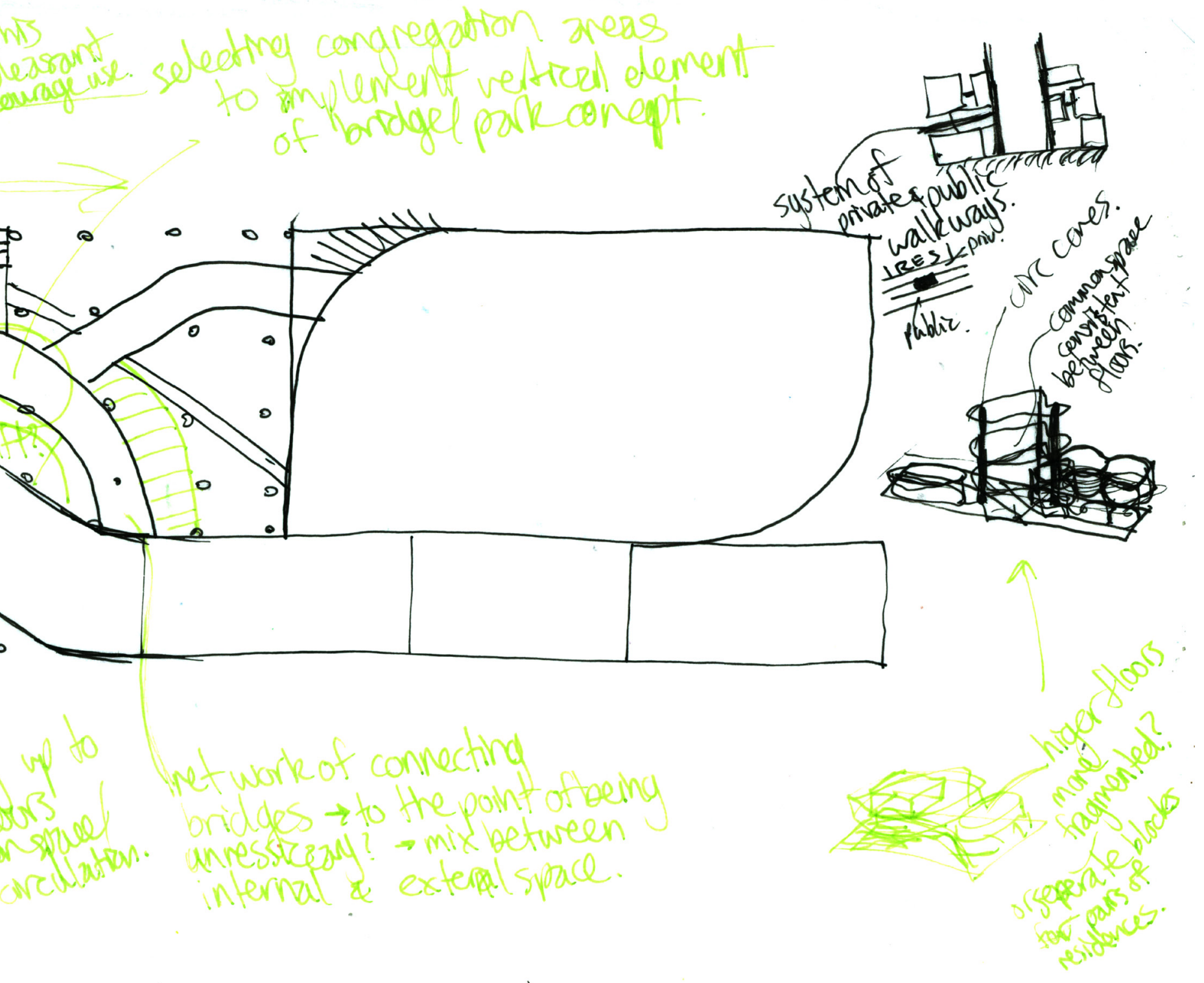




\section{Tactic One: Urban Location}

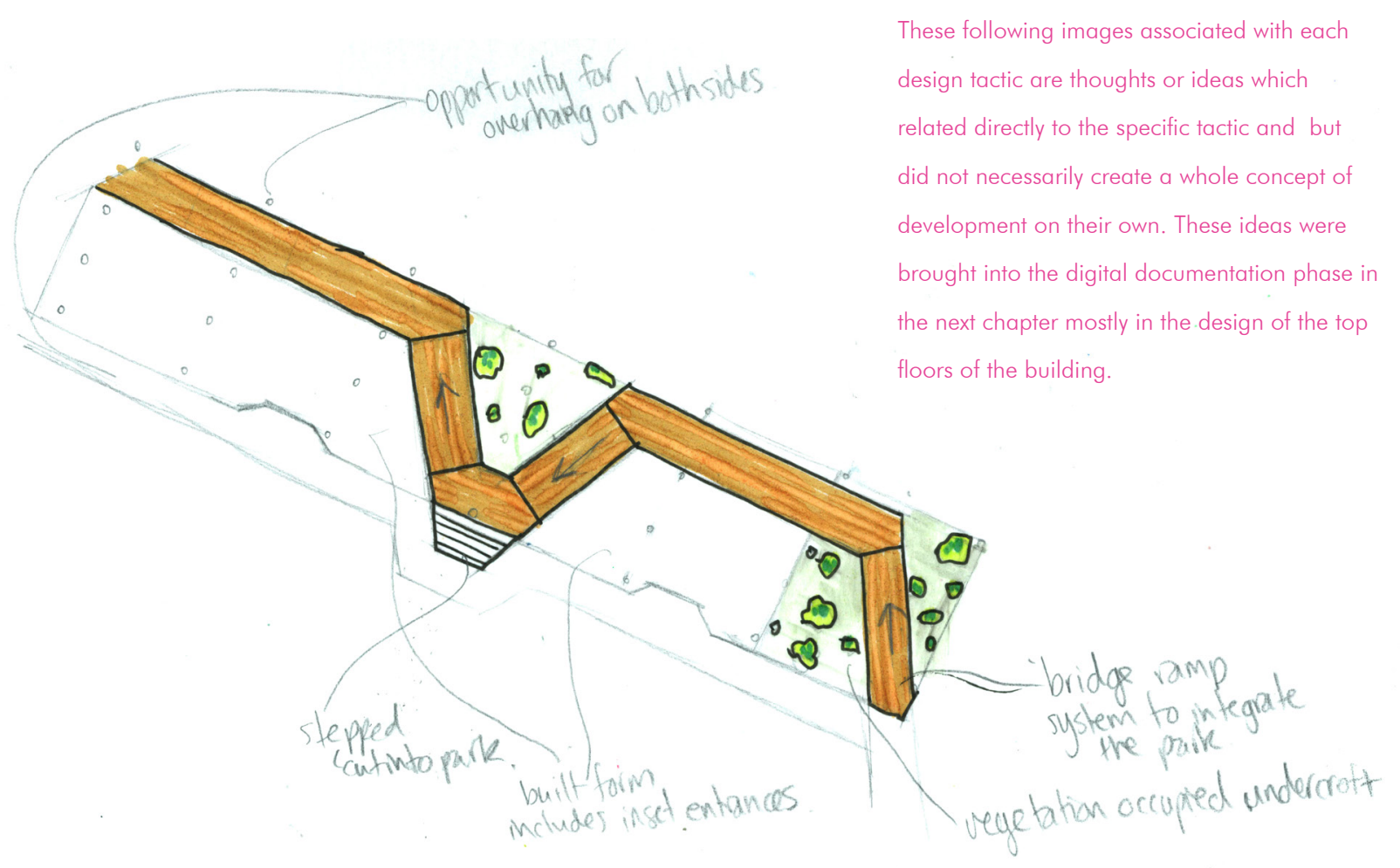

Bringing the greenery of the site up through the vertical

circulation creates a clear link to the ground floors

inclusiveness of the surrounding park context.

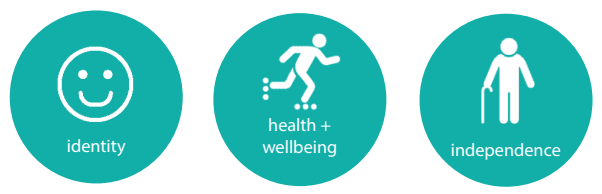

This tactic is to engage the surrounding context and utilise that in the design investigation. Gesturing toward the park, the school entry, the social street and the Taranaki Street entrance. The entrance to the pool was pushed back to allow dwell space for the school students gathering in the area, done through by steps and a flat plane off the social street for accessibility. The space is sheltered for dwelling upon arrival and exit.

The café, with entrance off Taranaki Street, spills out into the park with inset seated areas, which provides seating along its edge for park users and a start point

for an implied pathway along that edge of the site. In addition, the use of greenery along these park edges is consistent with that used in the park design, to create a cohesion and meet requirements of the Te Aro corridor design guideline.

These design elements aim to create both incidental and programmed interaction, their placement and consideration of entry allows places to stop and sit or chat. The engagement along street edge and park edge are unique to this chosen site along Taranaki Street, there is an activation of these spaces with seating and amenity entrances. 


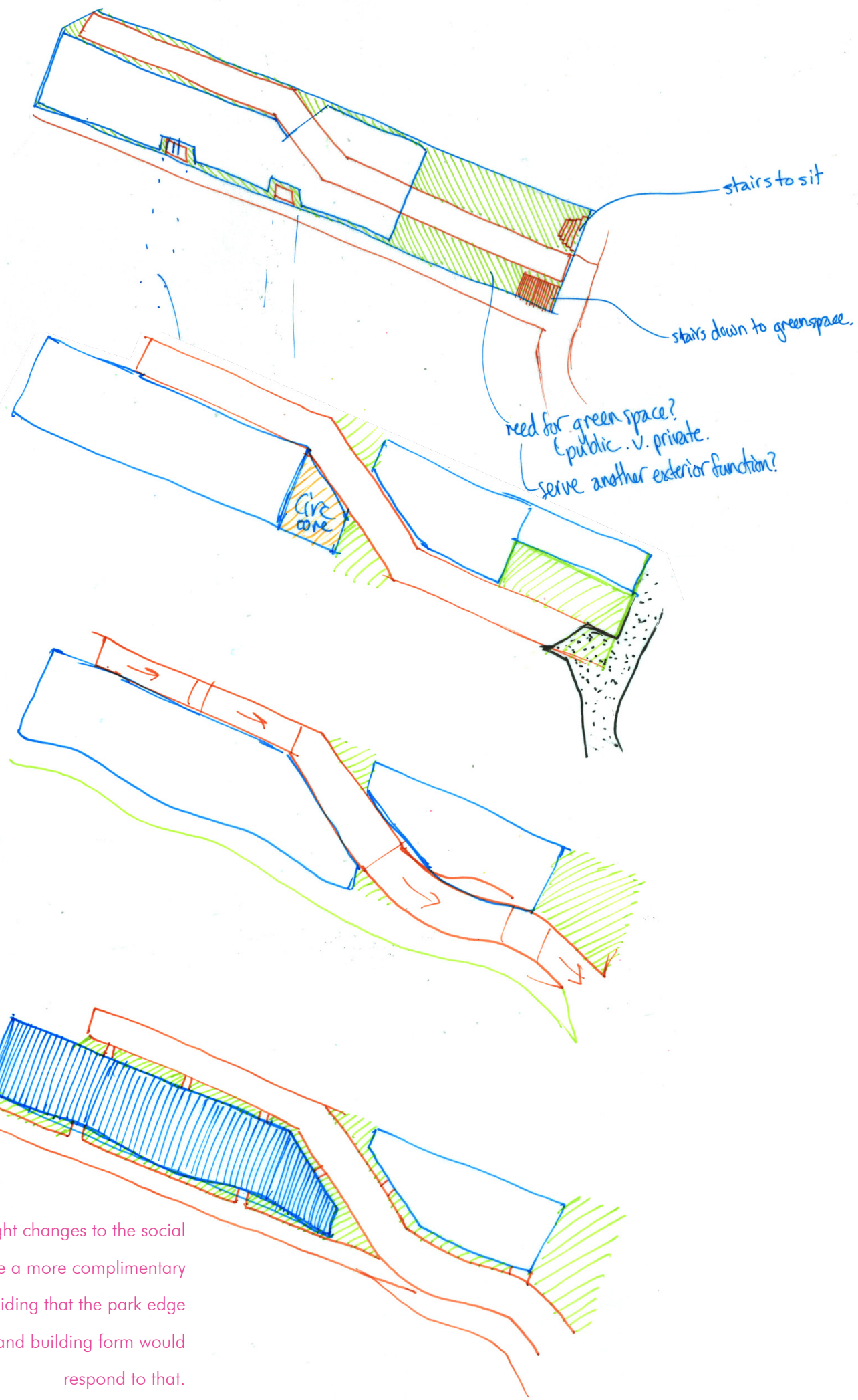




\section{Tactic Two: Social Circulation}

This tactic developed as central to the design and experimentation process to respond to the research aims of creating incidental and planned interactions as well as reducing the stigma of accessible circulation. It became an integral part in how the research works toward de-stigmatisation and better urban aged care/ housing by providing health and well being amenities the residents can maintain independence.

This tactic is broken down into three parts; the social street- which is the public circulation on ground floors; and Common circulation- which is the shared vertical circulation stairs and lift, as well as the common social spaces on each floor, and the access to the apartments.

The social street aims to provide a fully accessible path, for users with walking aids to wheelchair and mobility scooter users, through the site to engage in the amenities provided on lower levels and provide spaces for incidental interaction and to dwell. For this, precedents of apartment buildings providing healthy circulation, which was celebrated and encouraged use were looked at, such as this apartment building in Brazil by Gruposp architects. It uses colour to highlight and differentiate the circulation systems from the rest of the architecture. Also Kitagata apartments in Japan by SAANA, uses circulation as a façade feature and encourages use of many different paths. The design response looks at how this street could cut through the site in different directions, ultimately deciding upon this configuration which allows enough ramp length to cover the $3.1 \mathrm{~m}$ height and creates a view port through the building to the Carillion.

Used often in the co-housing precedents outlined earlier, common spaces allow residents more room for group activities such as barbecues and celebrations and encourage social interaction. They are a way of engaging people to interact and build a sense of community in the building. Grace Kim common house establishes a positive environment in common spaces by implementing things, which require people to work together, such as gardening planter beds (Kim, Grace).

The third element of circulation is the access to residences. This looks at the importance of common spaces and having patio space at the front of apartments which poses this idea of ownership but still allows incidental interaction as people pass by. The space intends to become a shared with pieces of individual ownership, such as these precedents, Murray Barkers backyard bungalow (Papers, Assemble, Backyard Bungalows) which opens up to a back street and creates an interface between his dwelling and the street, allowing people to stop for a chat or say hi when they pass by. Similarly in Cat Alley in Sydney residents on the street have worked together to create this green street, which not only attracts attention but becomes a nice place to occupy and allows communal gardening sessions, encouraging residents to take autonomy over their space on the street (Reid, Georgina). 


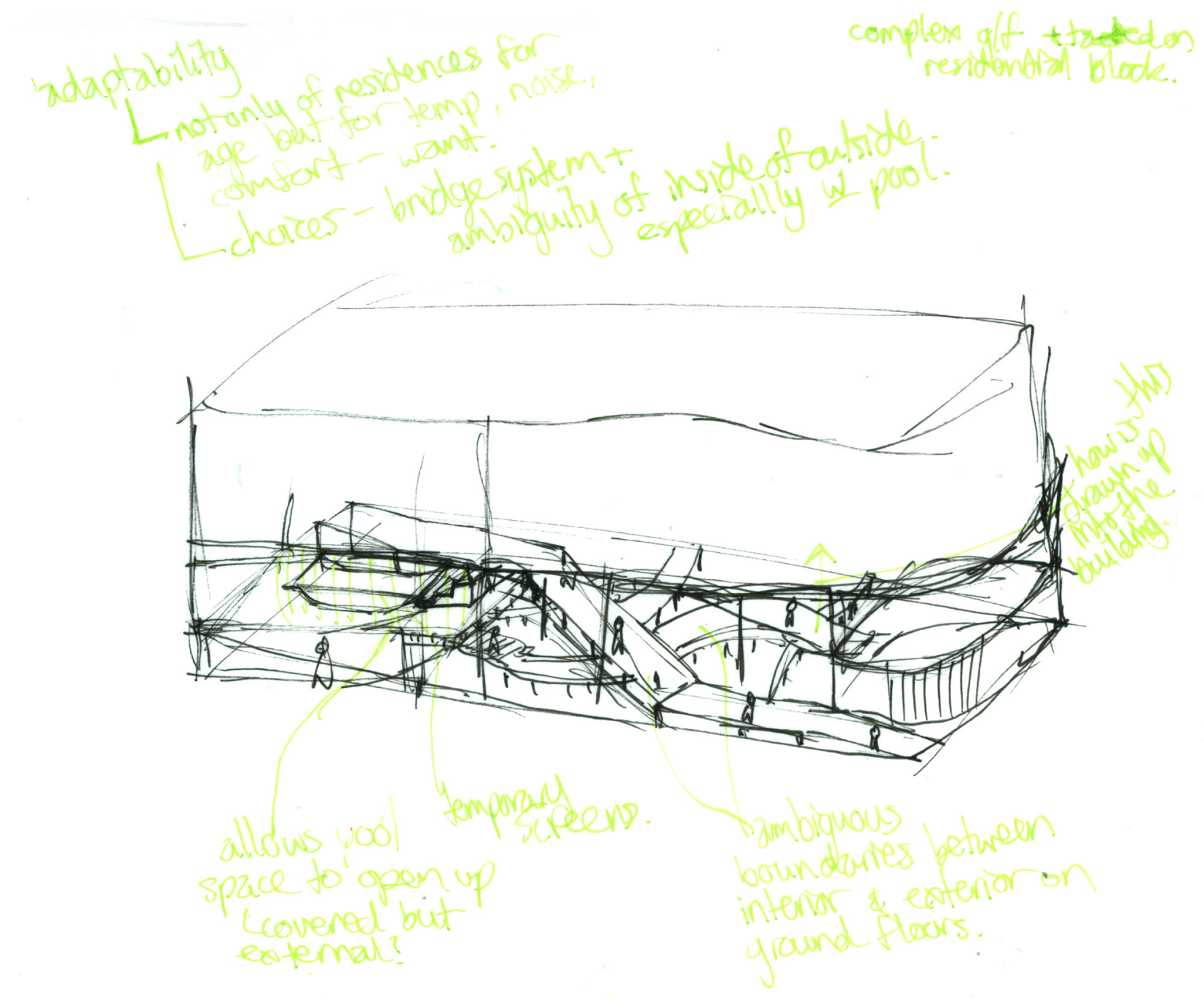

(14.) 용웅 호

The first drawing of the 'hectic' ground floor circulation, bridge and ramp, system. Imagined with a building mass above it. Proving the importance of bringing some greenery and complexity into the circulation systems up the building to avoid a mass sitting above a complex and detailed ground floor. 


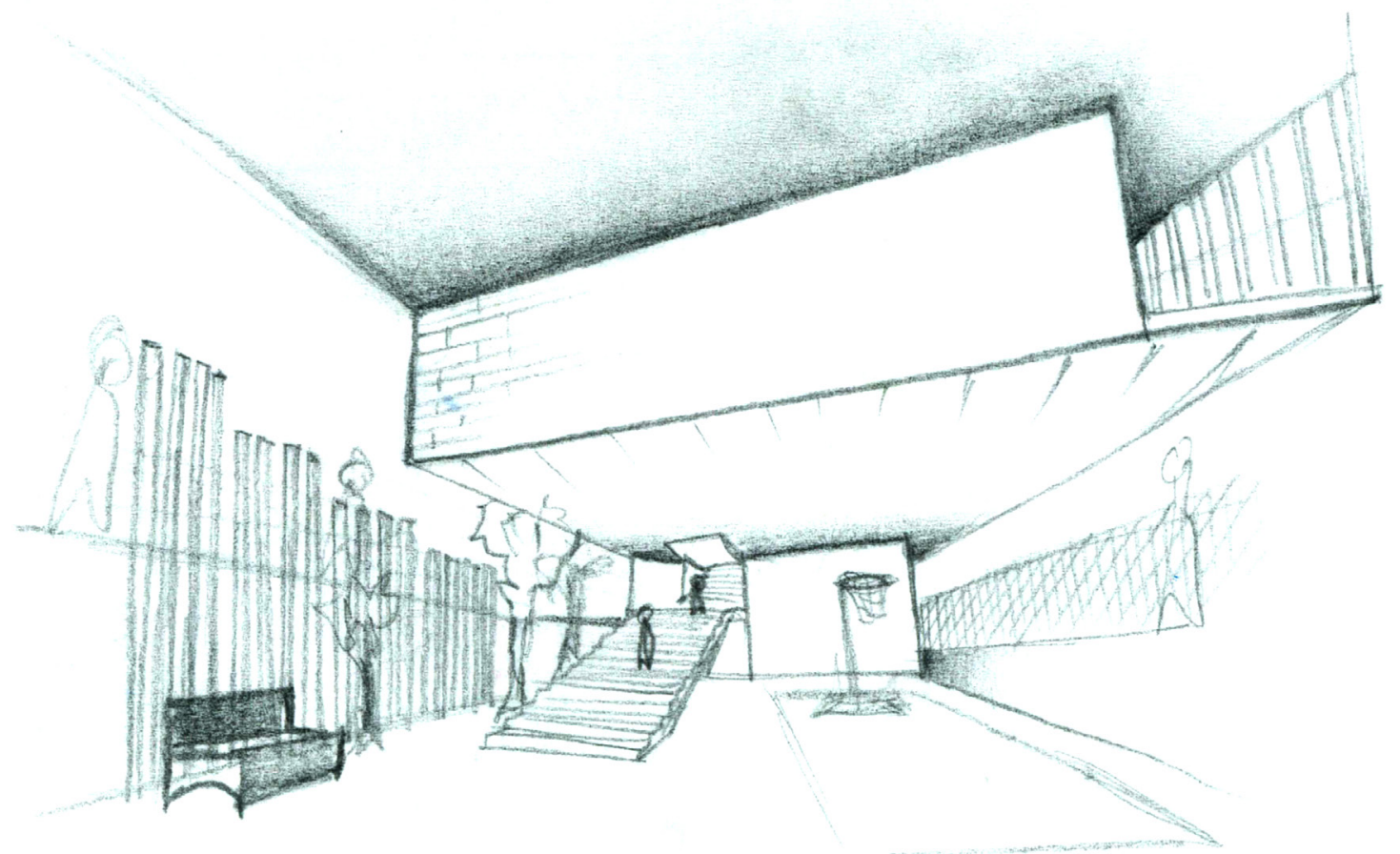

Considerations of how any under-croft spaces could remain occupyable. Having first floor apartment access over looking the ground floor 'park' space. Trees and plants along the left ramp edge, with wood barriers and seating. Ground surfaces for playing ball sports. 

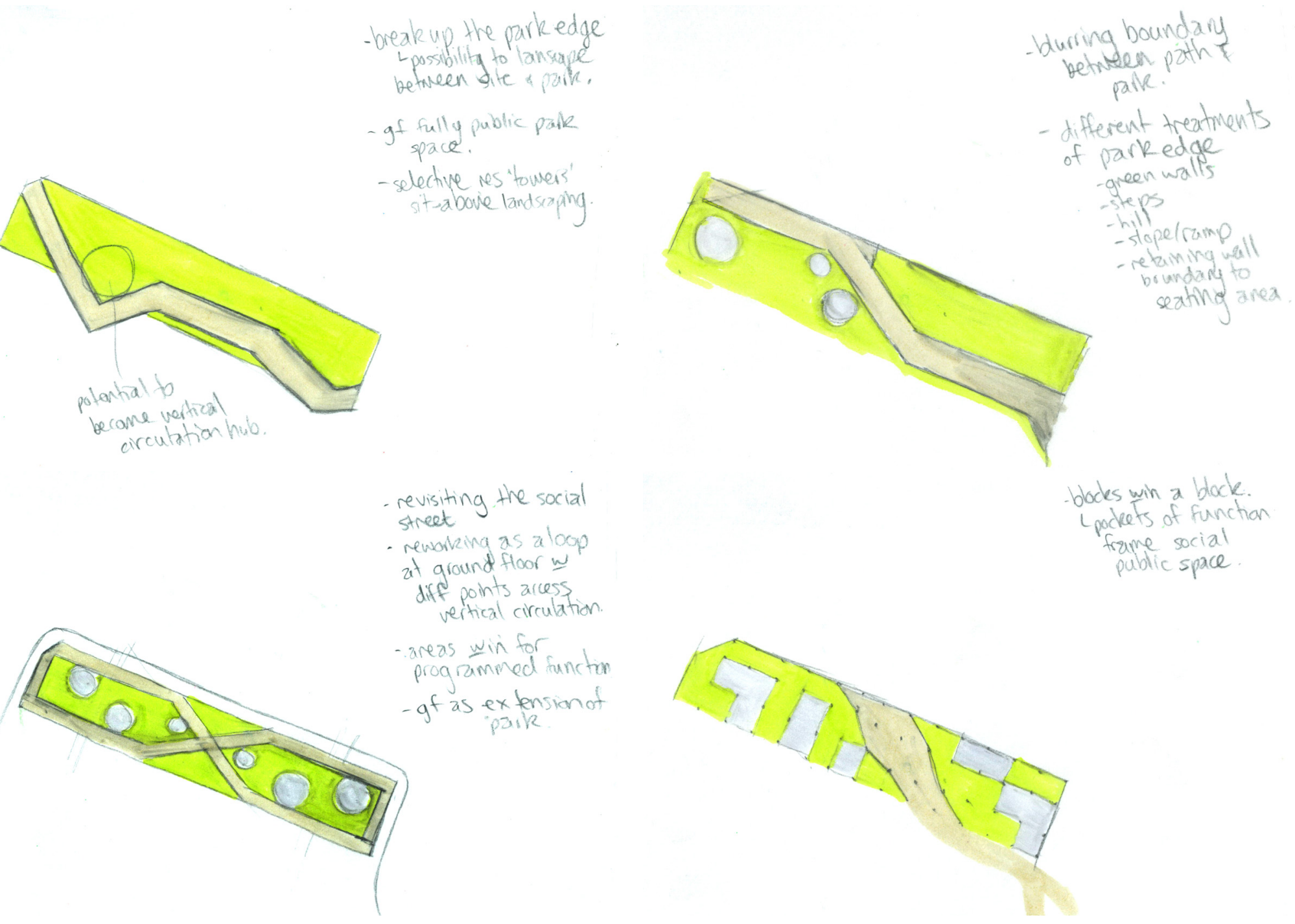

Looking at the direction of movement through the site, as to be translated into how internal circulation in the floors above could be replicated.

Utilising both the north and south façades was deemed unnecessary due to the amount of circulation needed, north facing pathways would be sufficient. 


\section{Tactic Three: Mixed Housing}

The development of the mixed housing was pushed using the resident's timeline which helped to understand the abilities of older persons and what the building could cater for. There is four different apartment sizes and all are intended to serve residents with accessible requirements with single floor dwellings. This came as a reflection on a two story apartment that began developing as a way of having an addition above or below for family or carers to stay in, however the complexity of this with accessible design led me back to single story dwellings. The precedent for the owner ship and renting model is intended to be like nightingale housing and other models which allow rent to buy schemes as well as individually owner or rented apartments within the building. (HOUSING, NIGHTINGALE)

The outdoor area in the access circulation, which was touched on in tactic two, also adds value to the mixed housing as it creates a sense of ownerships for residents, being able to decorate and treat the space how they chose.
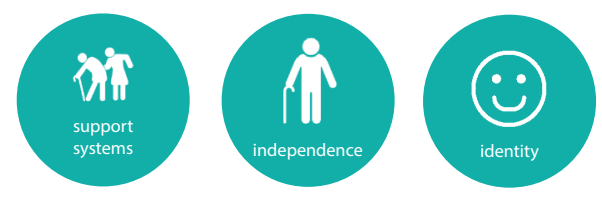

\footnotetext{
Apartment planning looked at how many apartments could fit on each floor of the building. 1 bed studios - 4 bed apartments were decided upon as best suited to the residents profiled earlier, with more 1 and beds to ensure availability for older persons. This tactic started to detail the design of the circulation outside of the apartments. Determining shutters or a move able facade would be beneficial in an exterior space. The entryways to apartments are iterated to test for privacy and accessibility with wheelchairs.
} 

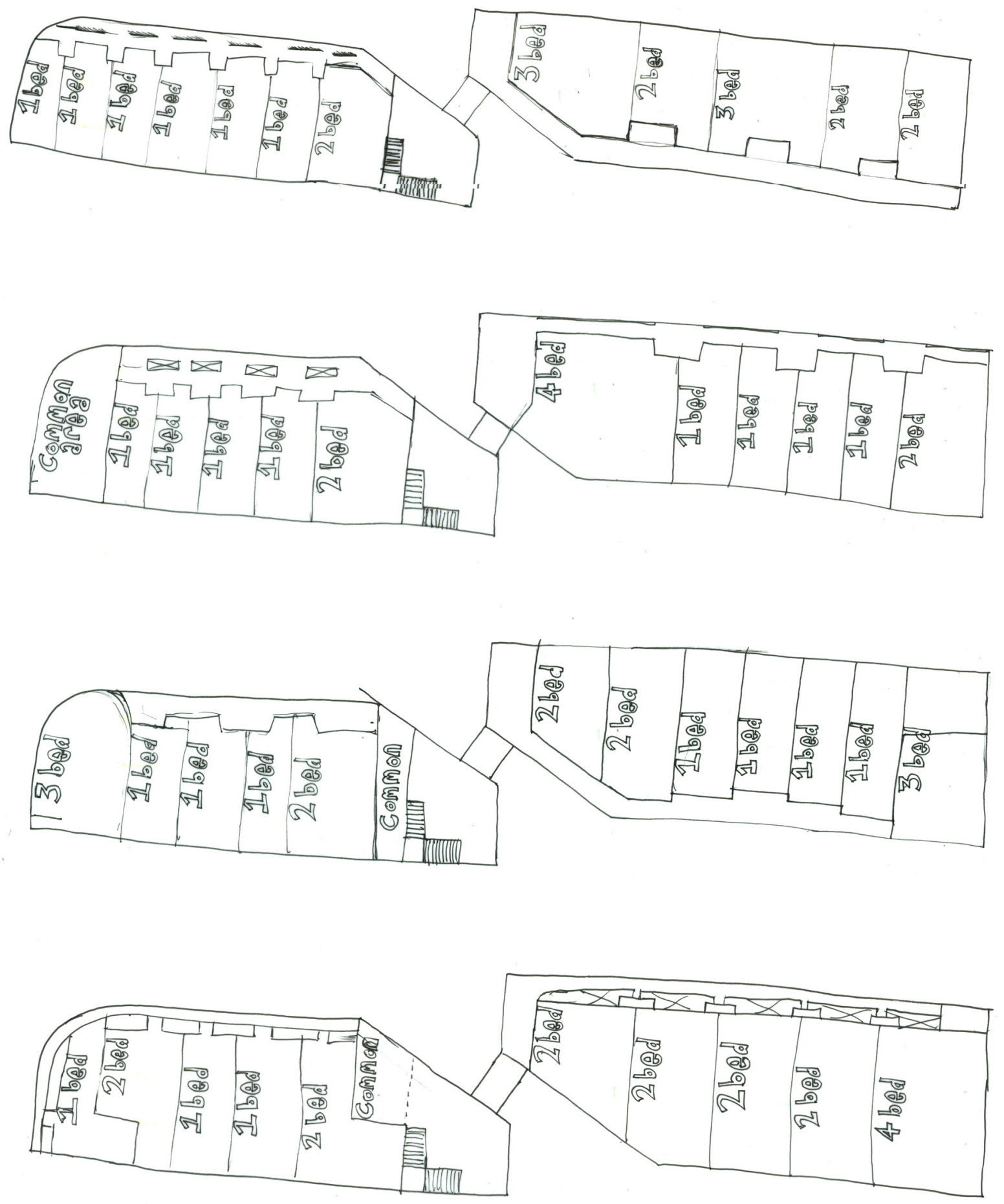


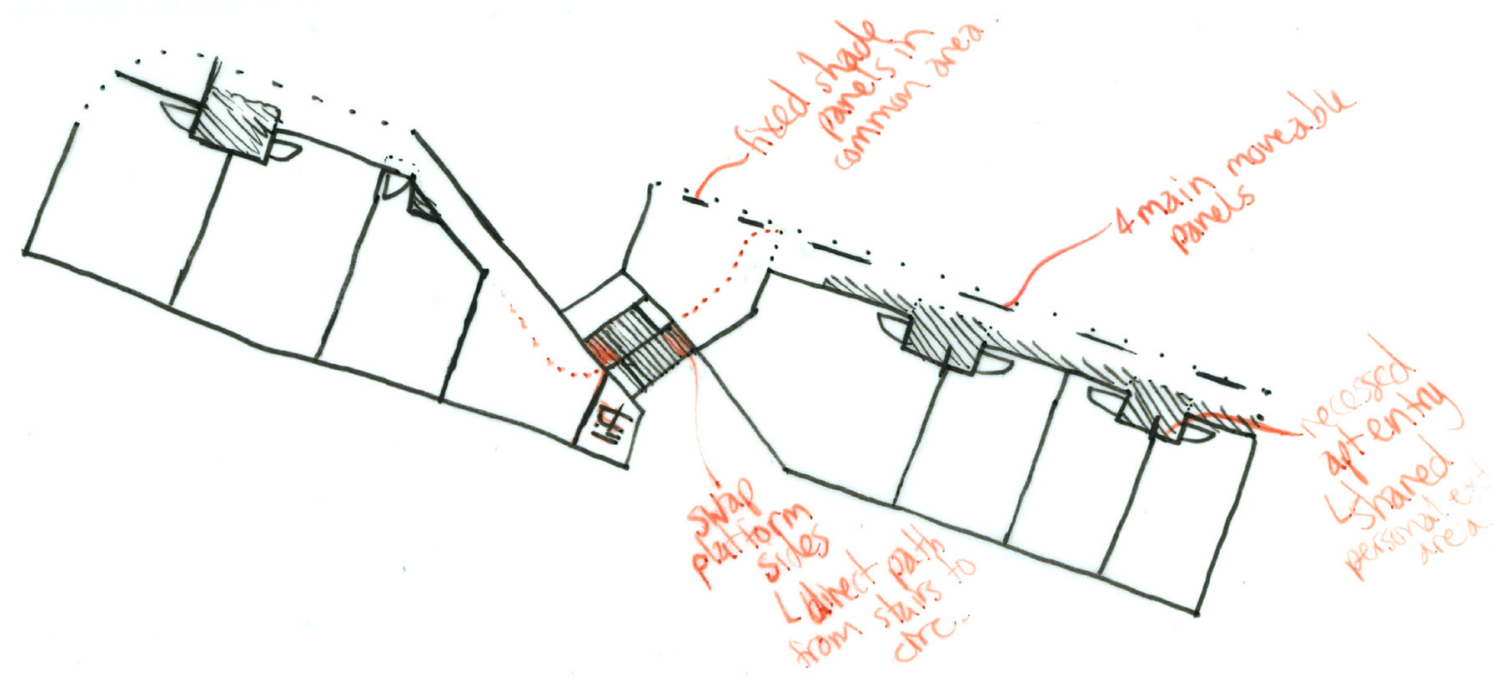

This iteration series maps the ownership over spaces in front of apartments.

How the apartment entries design can create more or less space for seating and interacting. This also looks at how the moveable timber panels can be placed to allow light into apartments and create more exposed spaces.

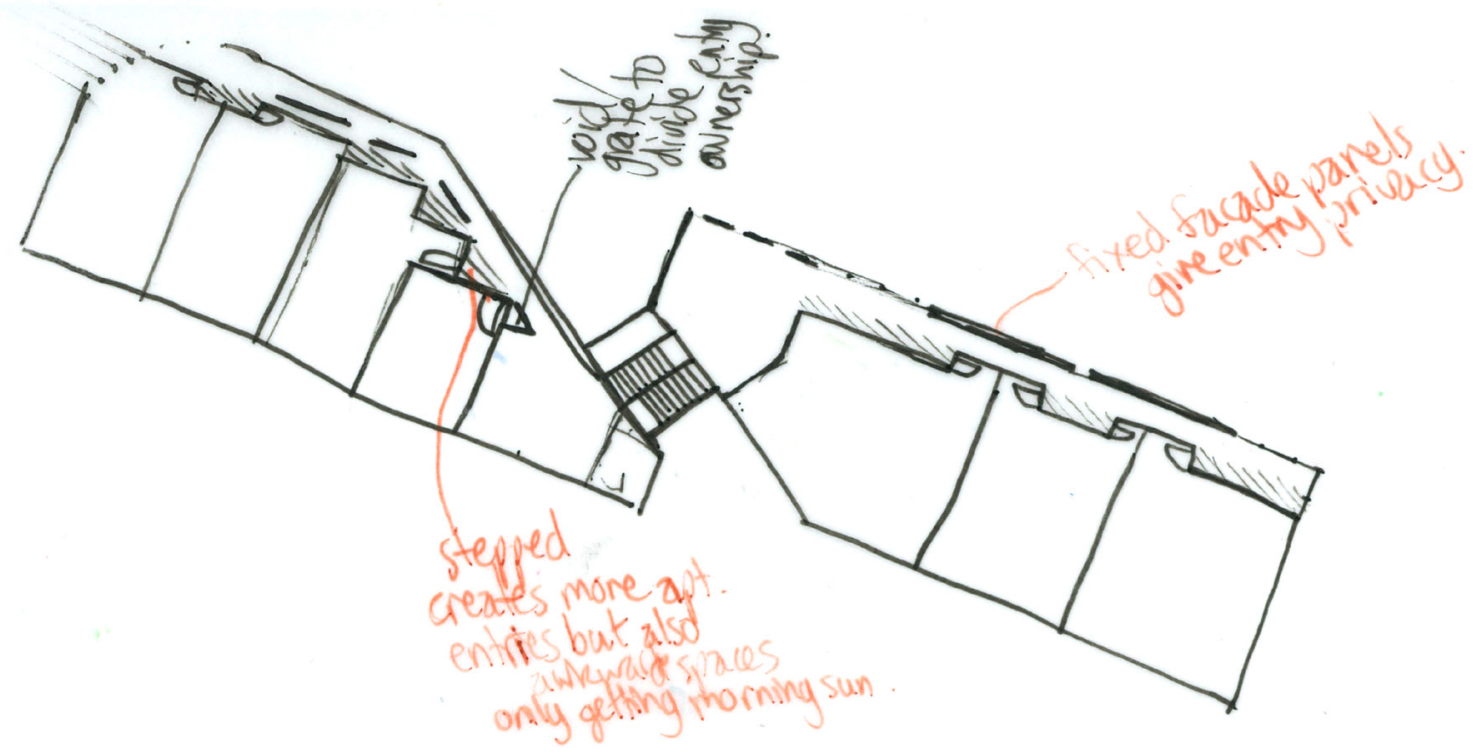



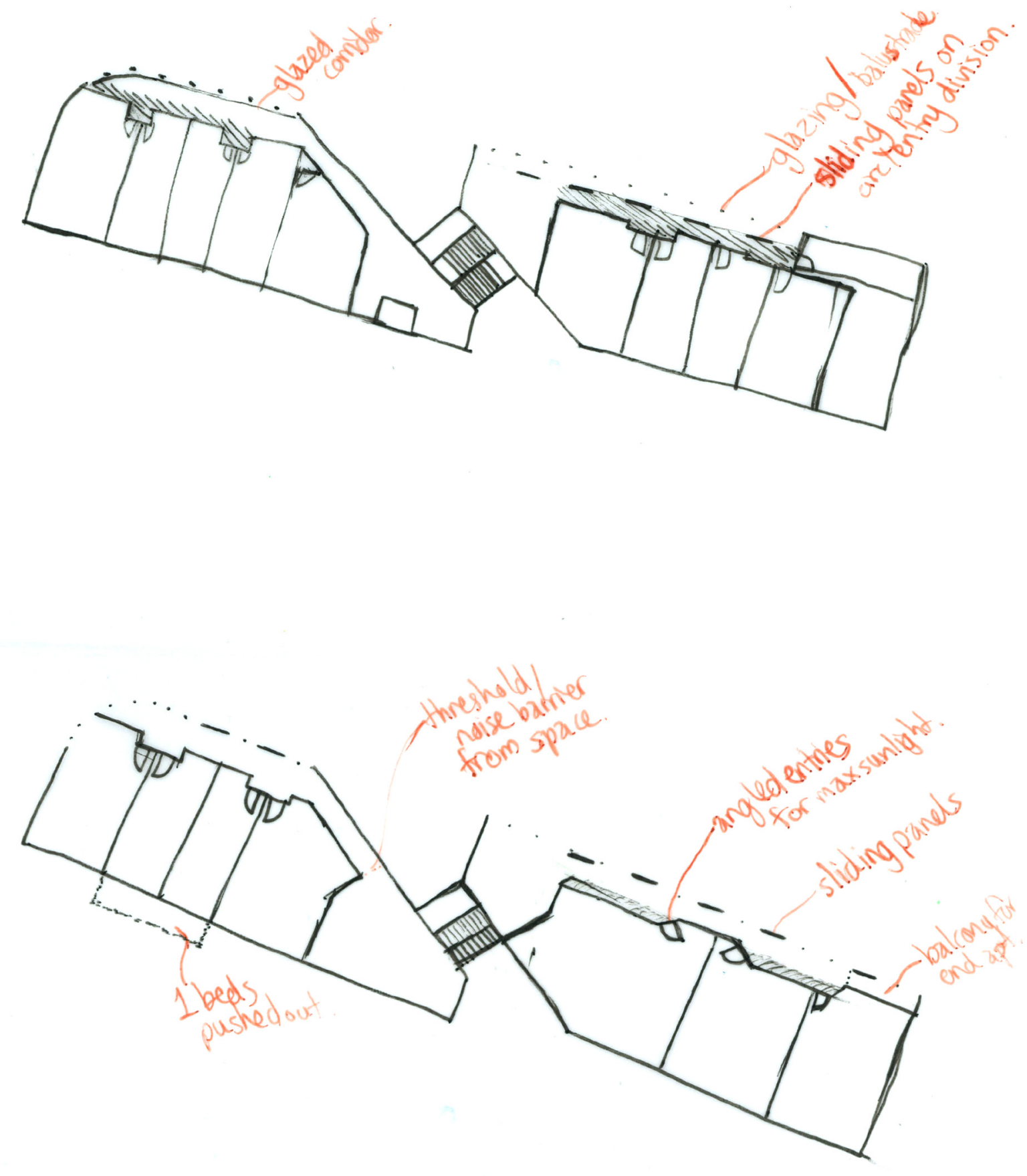


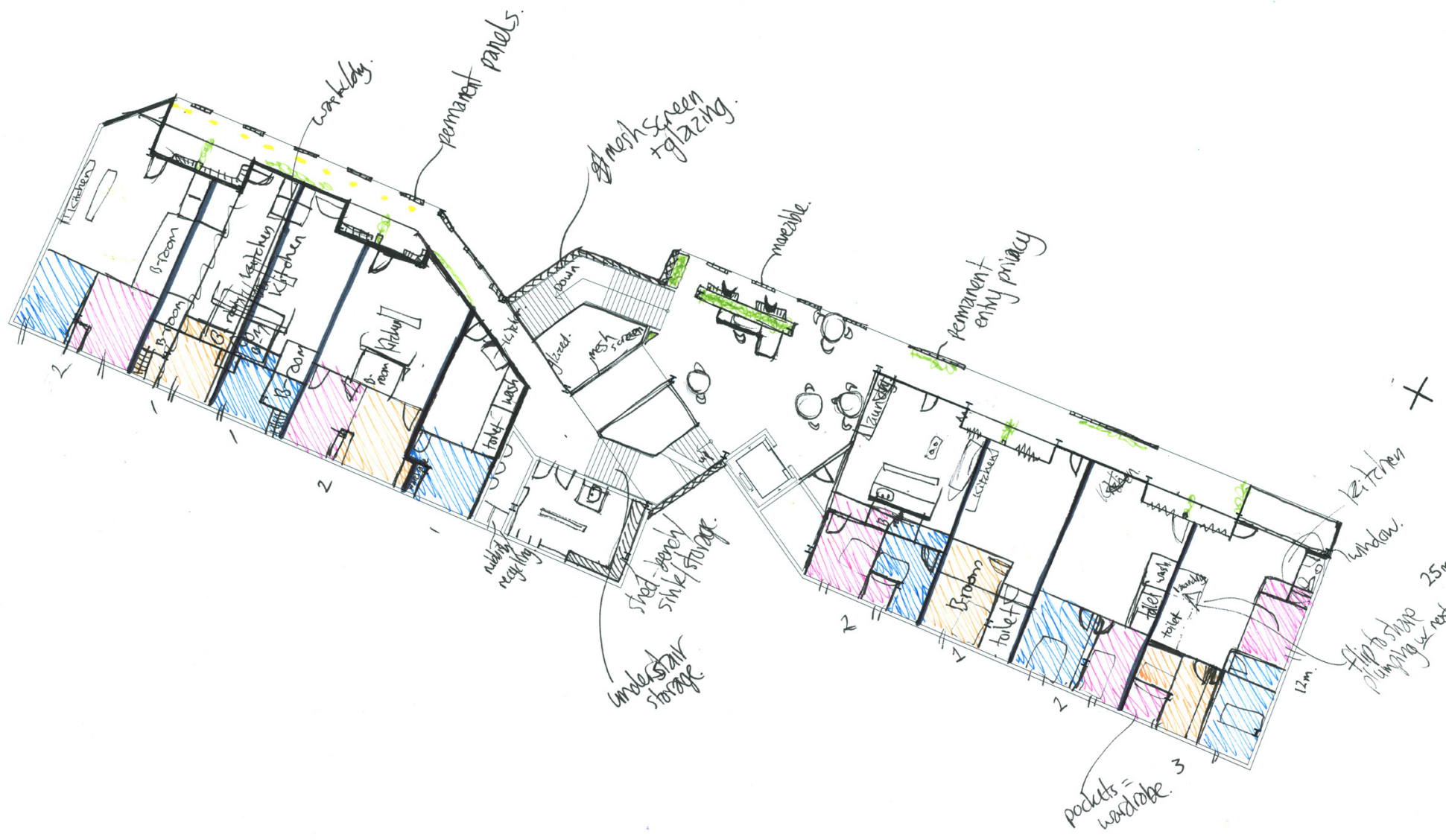

This series of drawings is apartment planning sketched over the base digital model. Looking at the internal layout of the building, the apartments are planned with common areas facing the circulation and bedrooms facing the park. 


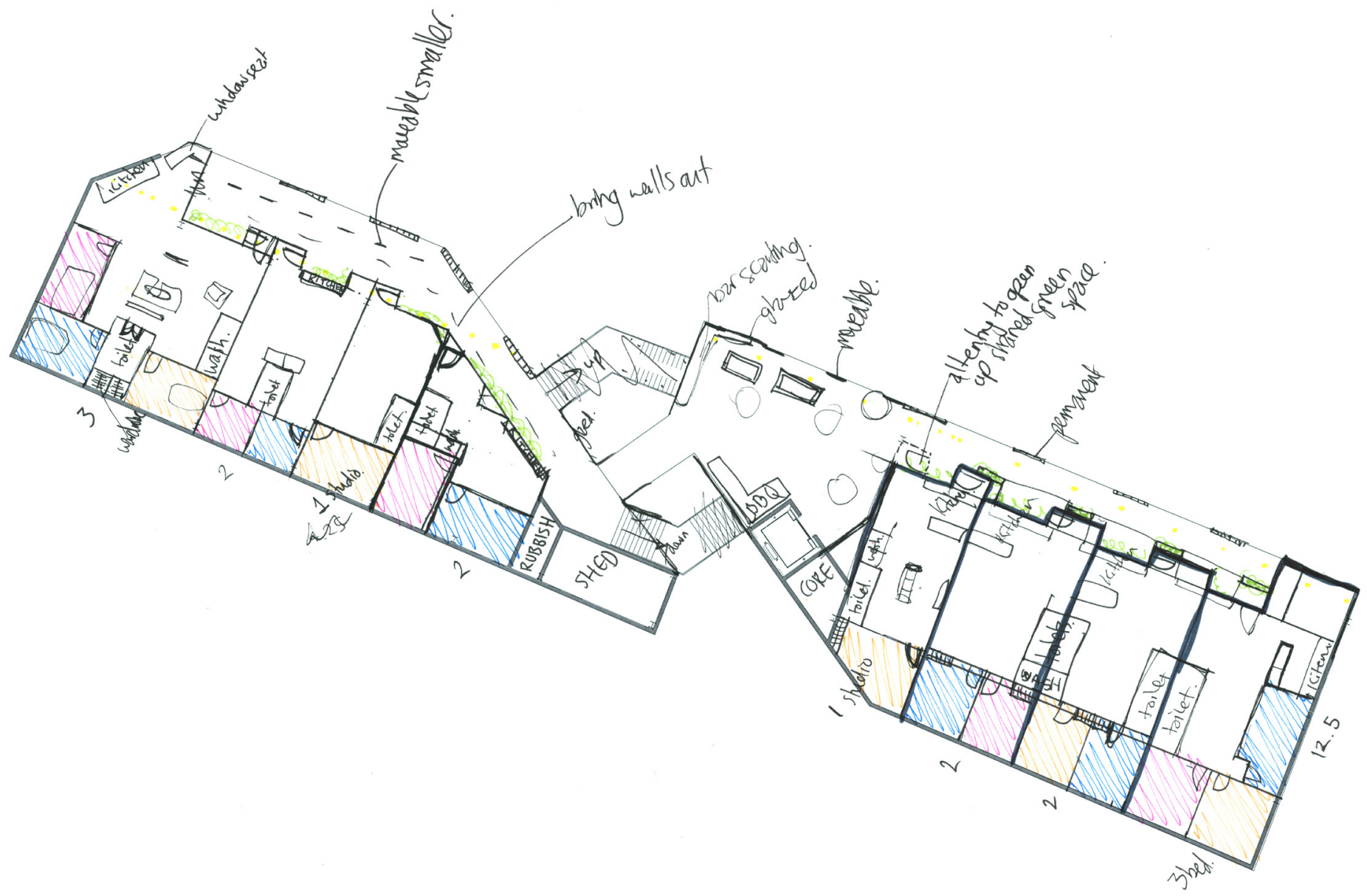

Where plants and seating occupy the common areas is important in encouraging residents to interact and use the spaces. 


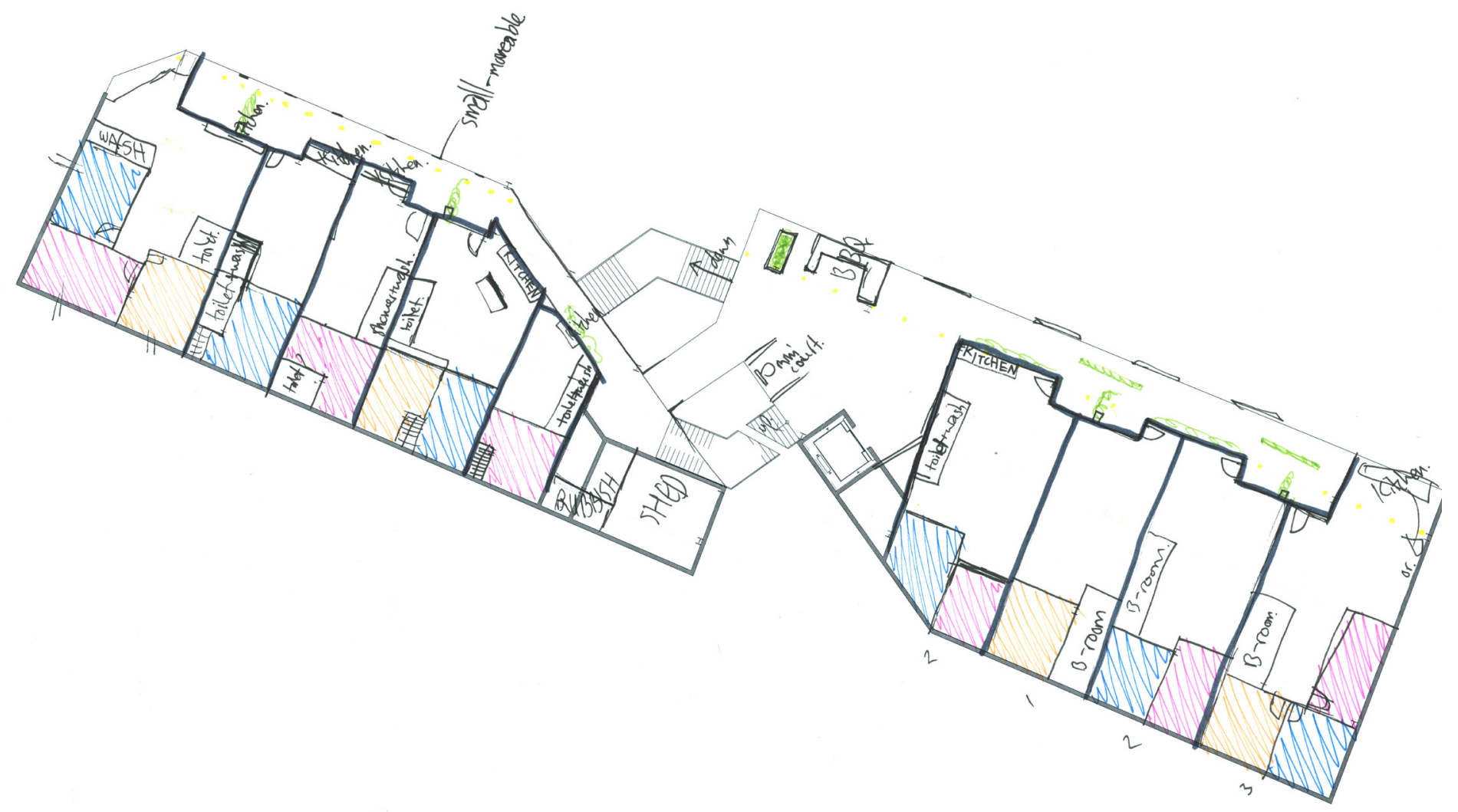

Having one common room on each floor encourages all residents to use the same space and its placement means people living on both sides of the building pass through it. 


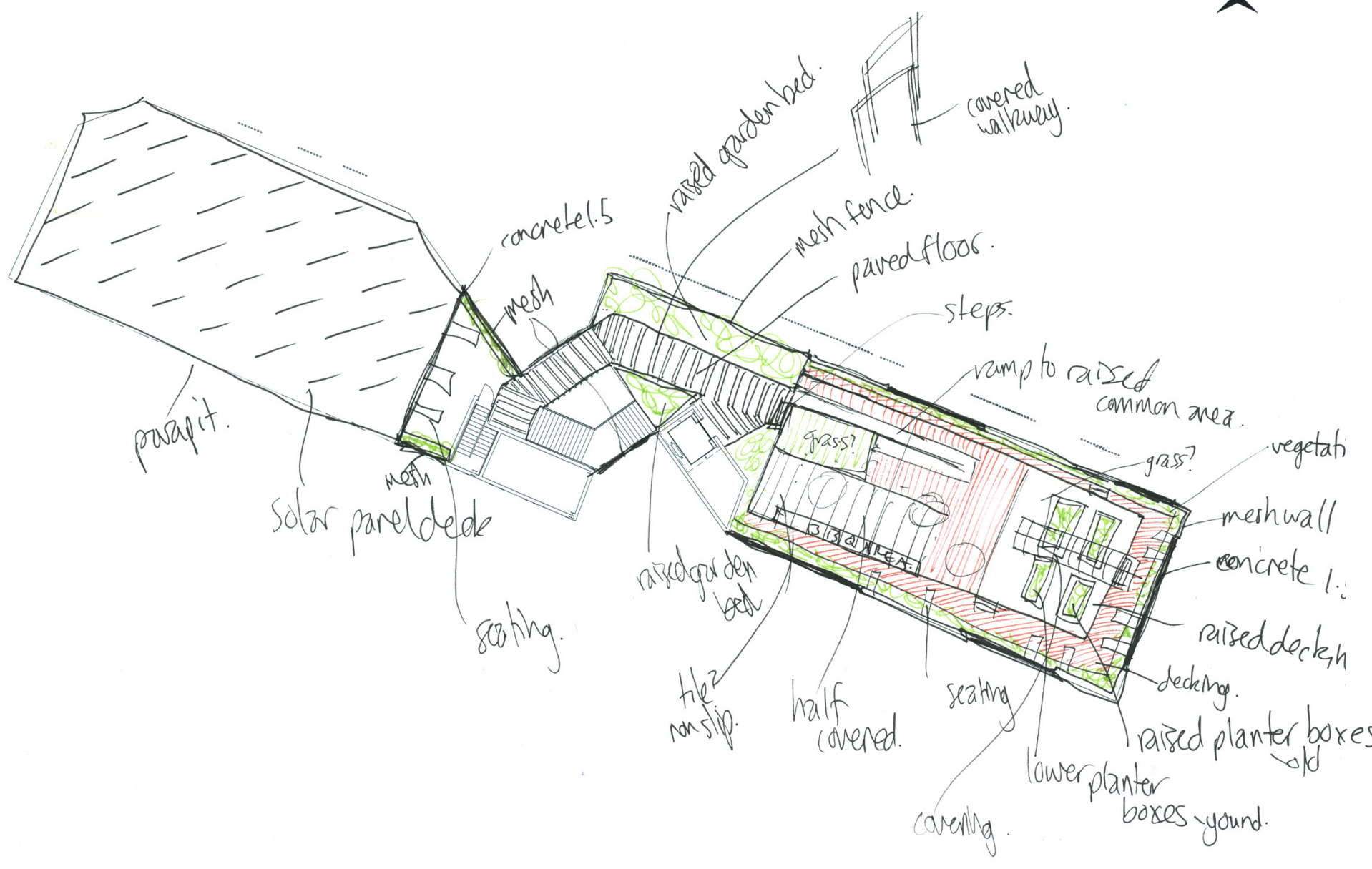

This iteration focused on the design of the common

garden and barbecue area, with raised decking, perimeter gardens and shading. The idea of solar panels arose as the left block gets the most sun. 


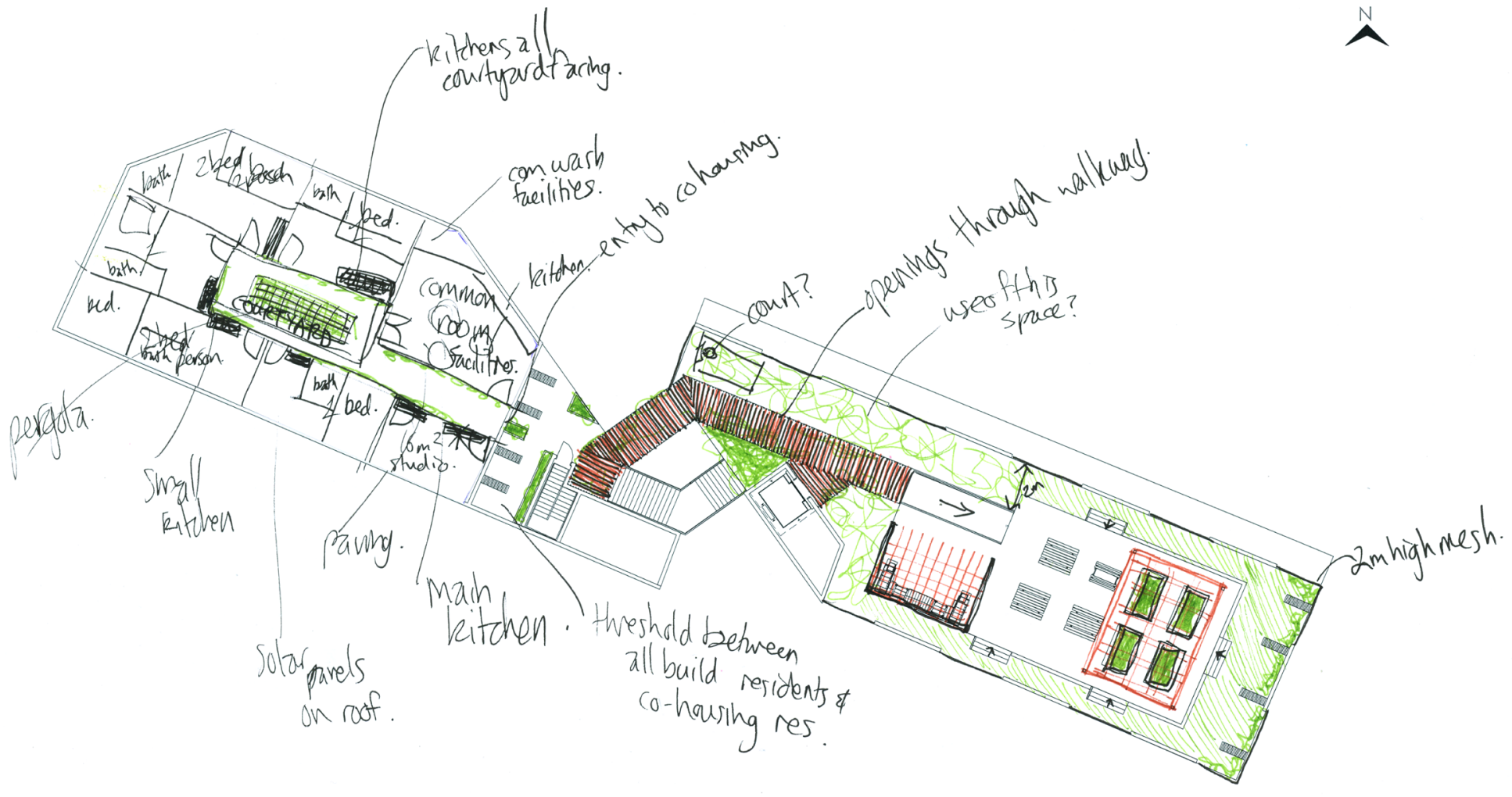

This iteration, swapped the co-housing onto the left block roof for optimal sun and privacy from the core circulation. 


\section{Tactic Four: Shared Amenities}

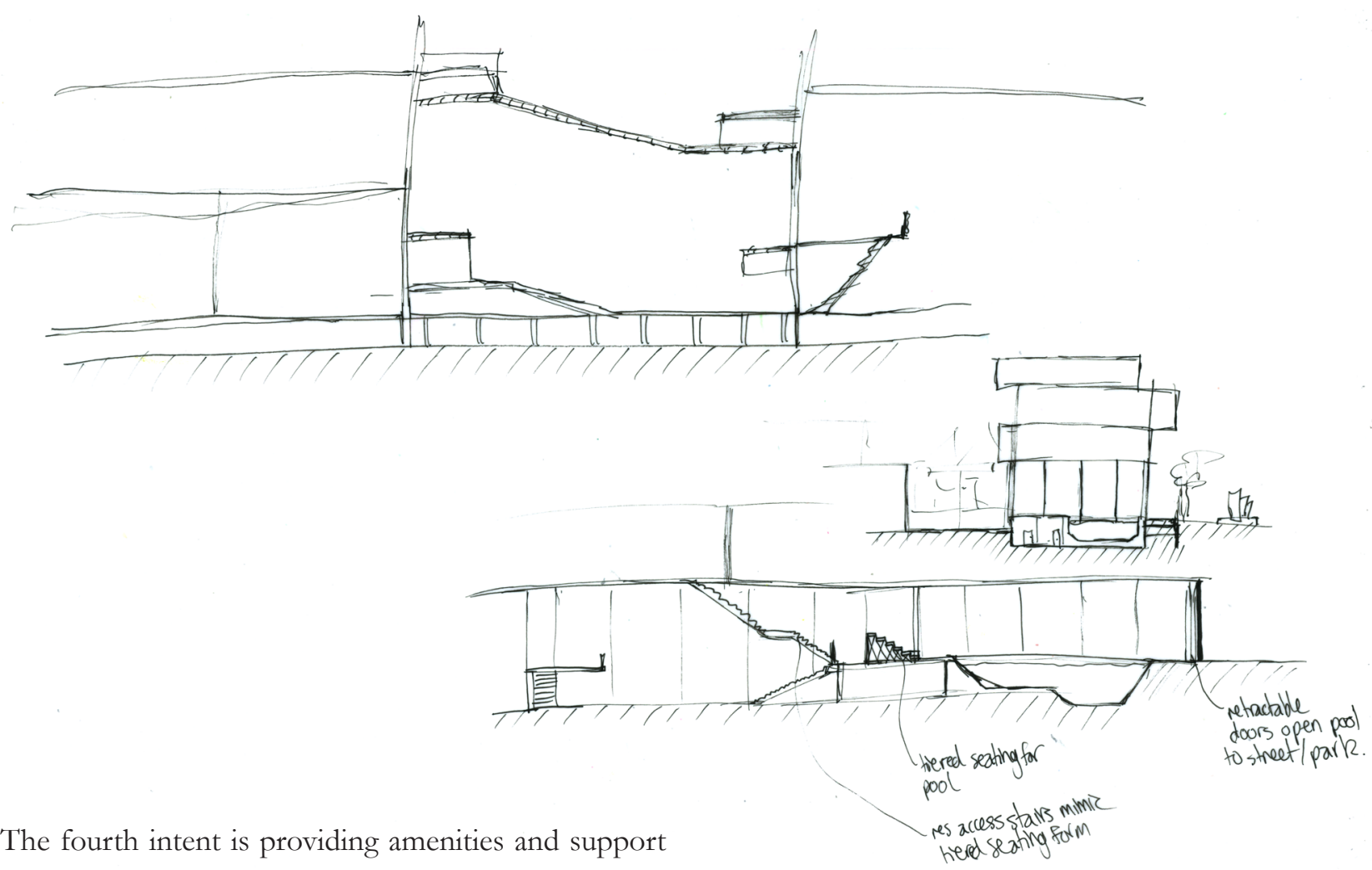

services, the importance of being able to serve the community and the residents was integral in encouraging a relationship between the building and passers-by. The design always had a café at the Taranaki end of the site, a natural way of enticing passers-by. That further developed into a restaurant, being able to cater food for residents allows higher dependency elderly and older persons to remain residents with the support they need. A main move for amenities is in the realm of health care- general practitioners, It became clear that the amenities needed to occupy more space, for the lower ground and upper ground circulation, but also to make this more of a destination space.

This section looks at internal circulation from the pool up to or down to other amenities.

Circulation between buildings is key in that the health care amenities can be easily accessed moved between.

physiotherapy facilities, a small gym and accessible pool. All of these serve both the residents and public and encourage an importance being places on being active.

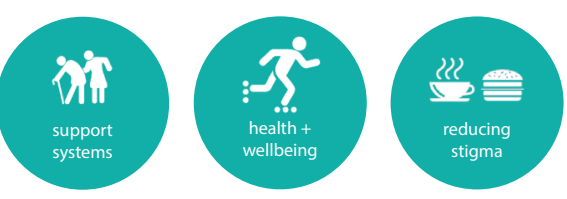




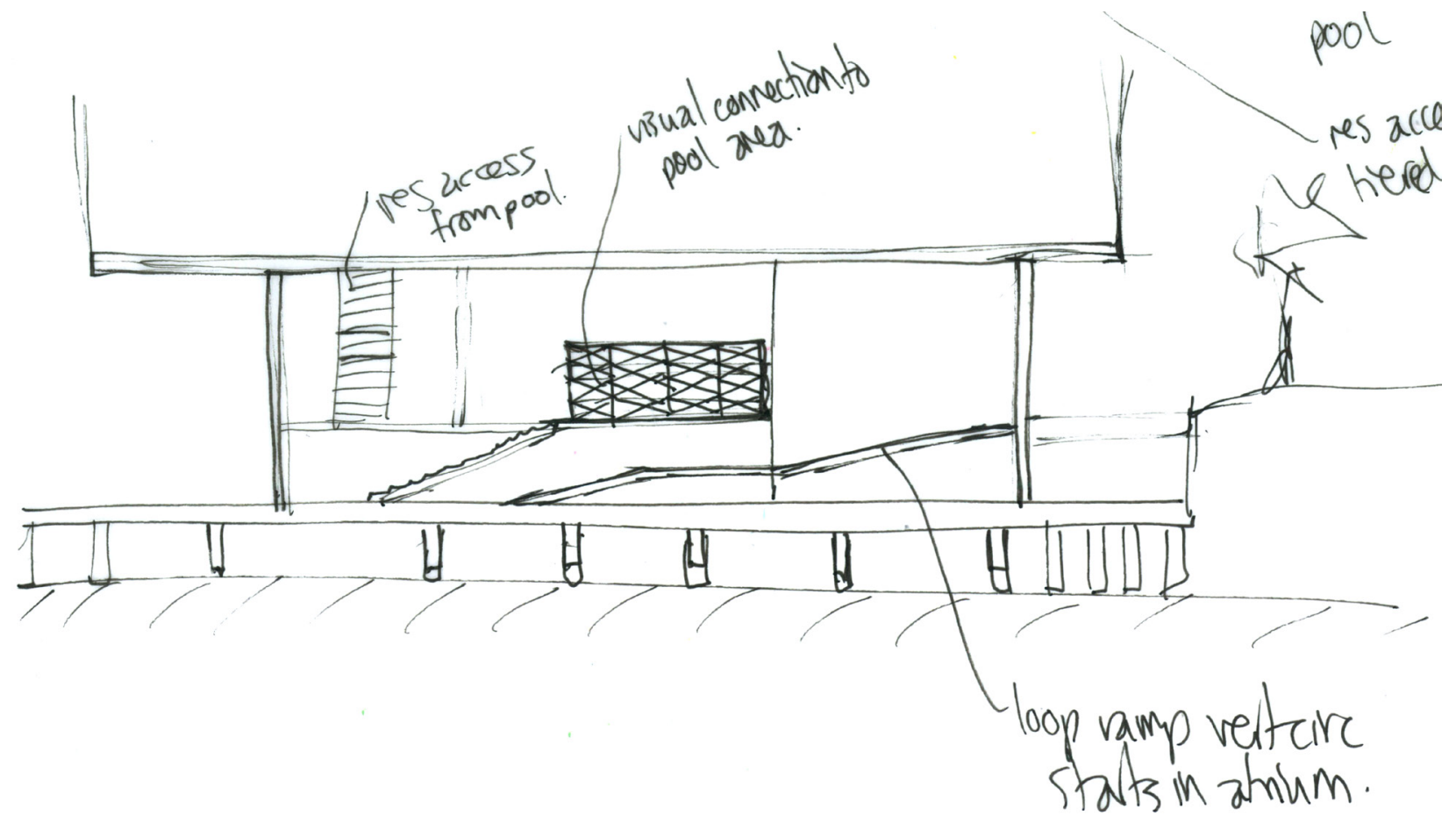

This section looks at coming off the social street into the pool area. The pool design had a lot factors, including after hours access

for residents, safety in accessibility and facilitating multiple groups at the same time. 
The way these four tactics developed, and in turn the overall building design, was a result of iterative testing of ideas. These chosen solutions are a result of the direction of the research investigation but could be improved and modified with further research. The design of the internal spaces of these amenities could have replicated the nature of the Social Street and circulation spaces, supporting interactions and engagement. In the final chapter, these four tactics will be shown in a wider scheme working together and highlighting the key areas in which the building has design for achieving the research aims and objectives. 


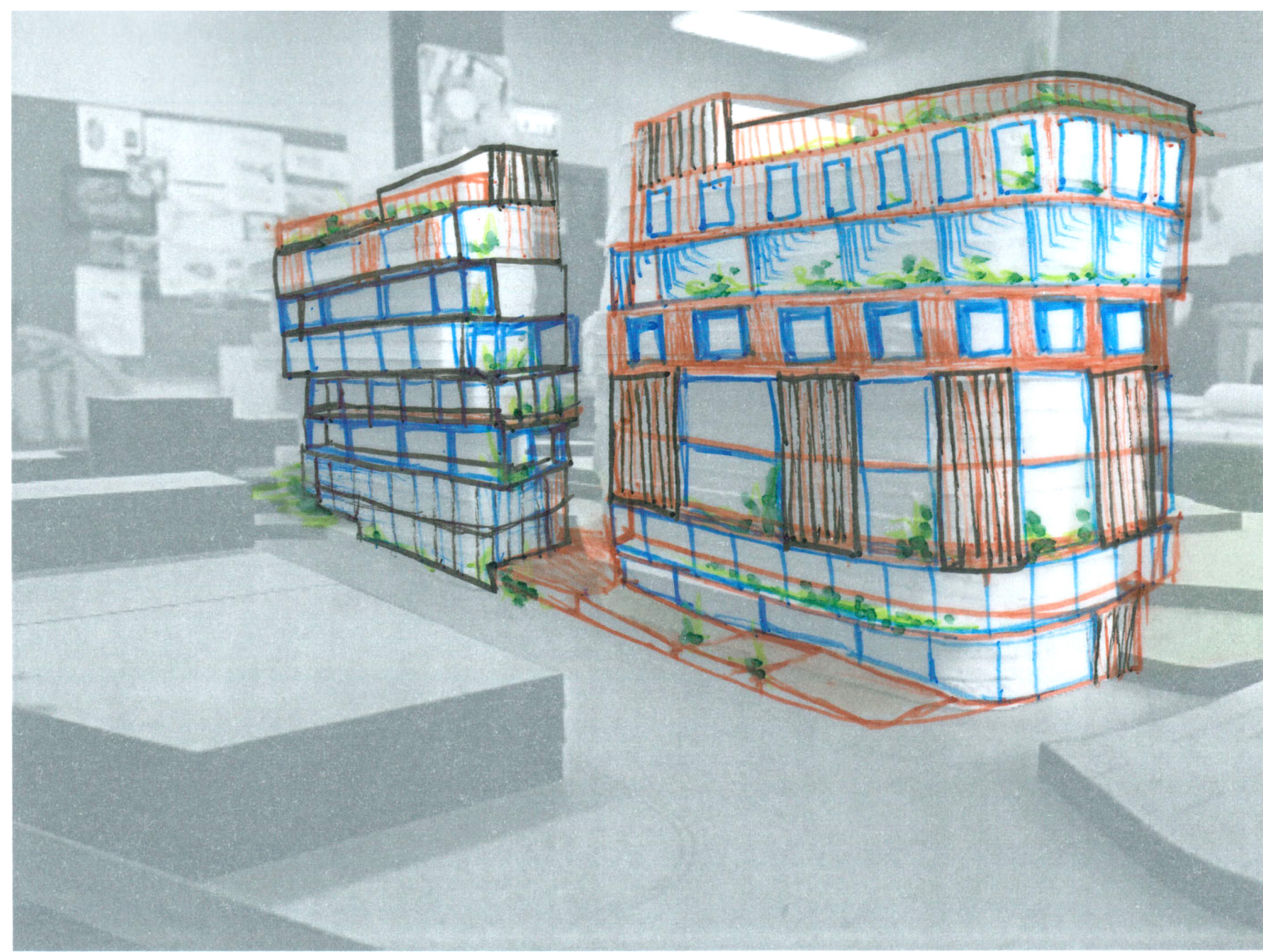

Overlaying facade iterations onto the physical mass model. 



\section{Chapter 6:}
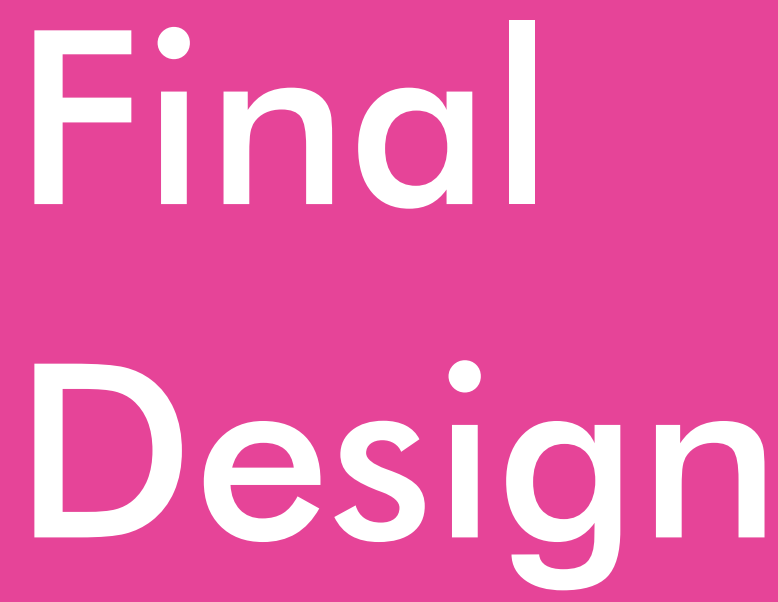

Strategic Diagram + Final Drawings 


\section{Age and the City: An Intergenerational, Urban Housing Scheme}

Final design presents the urban housing scheme in annotated drawings bringing together the ideas within the four tactics and their relation to the research aims and objectives 


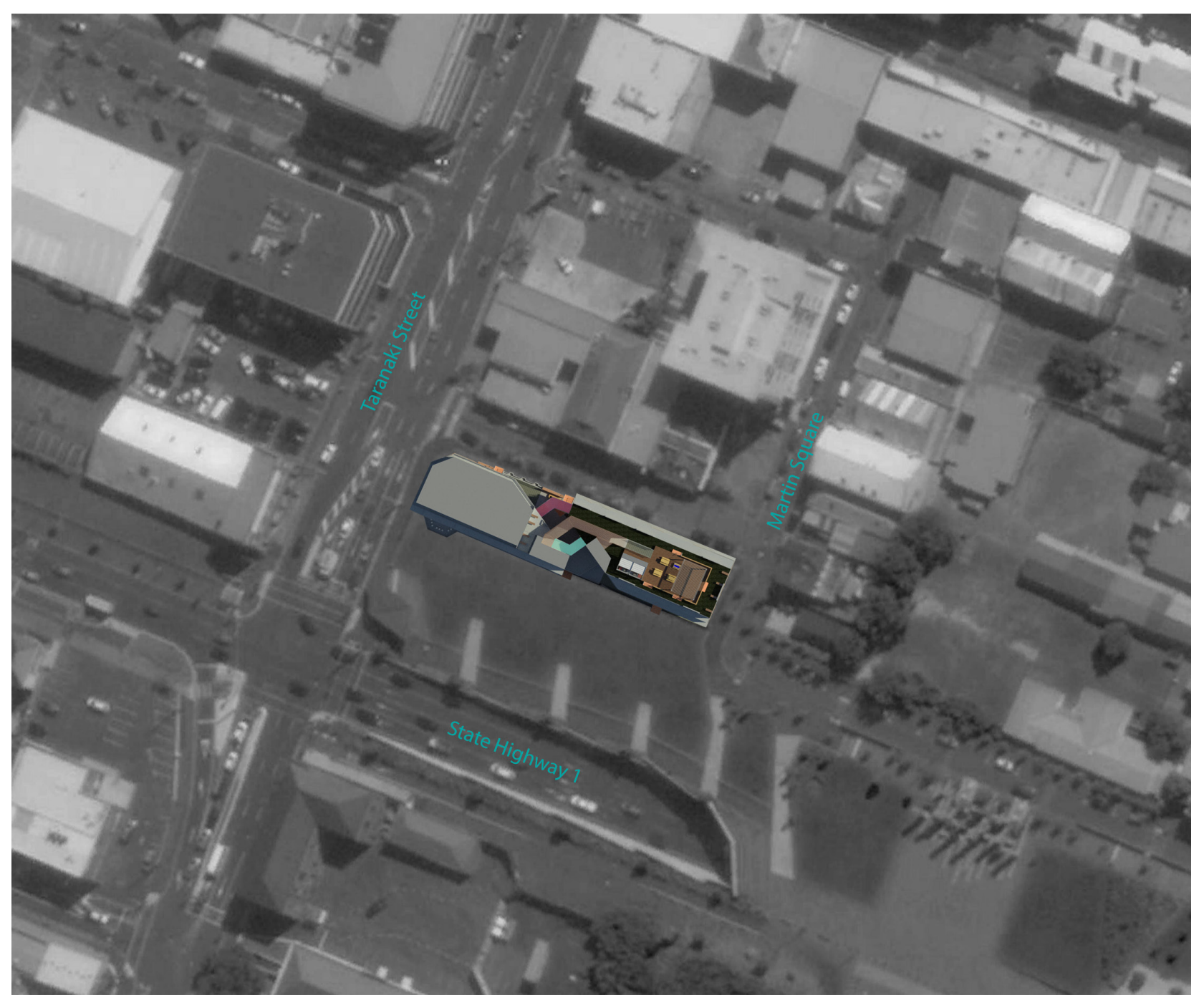




\section{Strategic Diagram}

\section{Tactic One: Urban Location}

This tactic addresses independence, health and well being and identity in the key positive ageing attributes.

This is done through locating the building in an area with lots of activity and near amenities which residents can easily access

\section{Tactic Two: Social Circulation}

This tactic addresses accessibility, meaningful interactions, autonomy and reducing stigma in the key positive ageing attributes.

This is done through prioritising the circulation space. Celebrating accessibility with the inclusion of safe ramps, colour indicators between floors and dedicated common space.

\section{Tactic Three: Mixed Housing}

This tactic addresses independence, identity and support systems in the key positive ageing attributes.

This is done through intergenerational interactions being facilitated in the mixed apartments and access porch space which residents can make their own.

\section{Tactic Four: Shared Amenities}

This tactic addresses support systems, health and well being and reducing stigma in the key positive ageing attributes.

This is done through providing amenities most beneficial to older persons and elderly as well as amenities that can facilitate and encourage intergenerational interactions. 


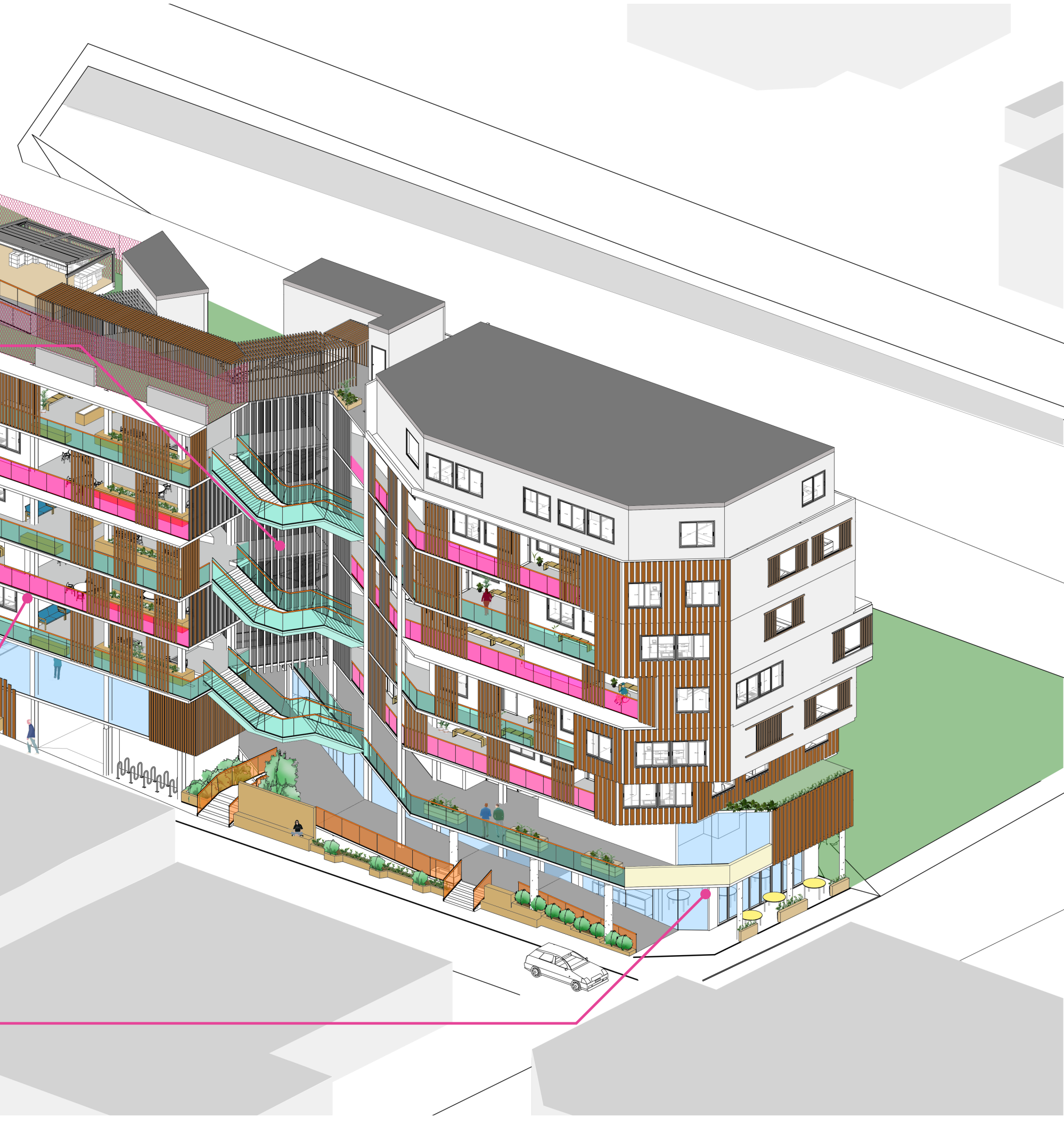




\section{Floor Plans}

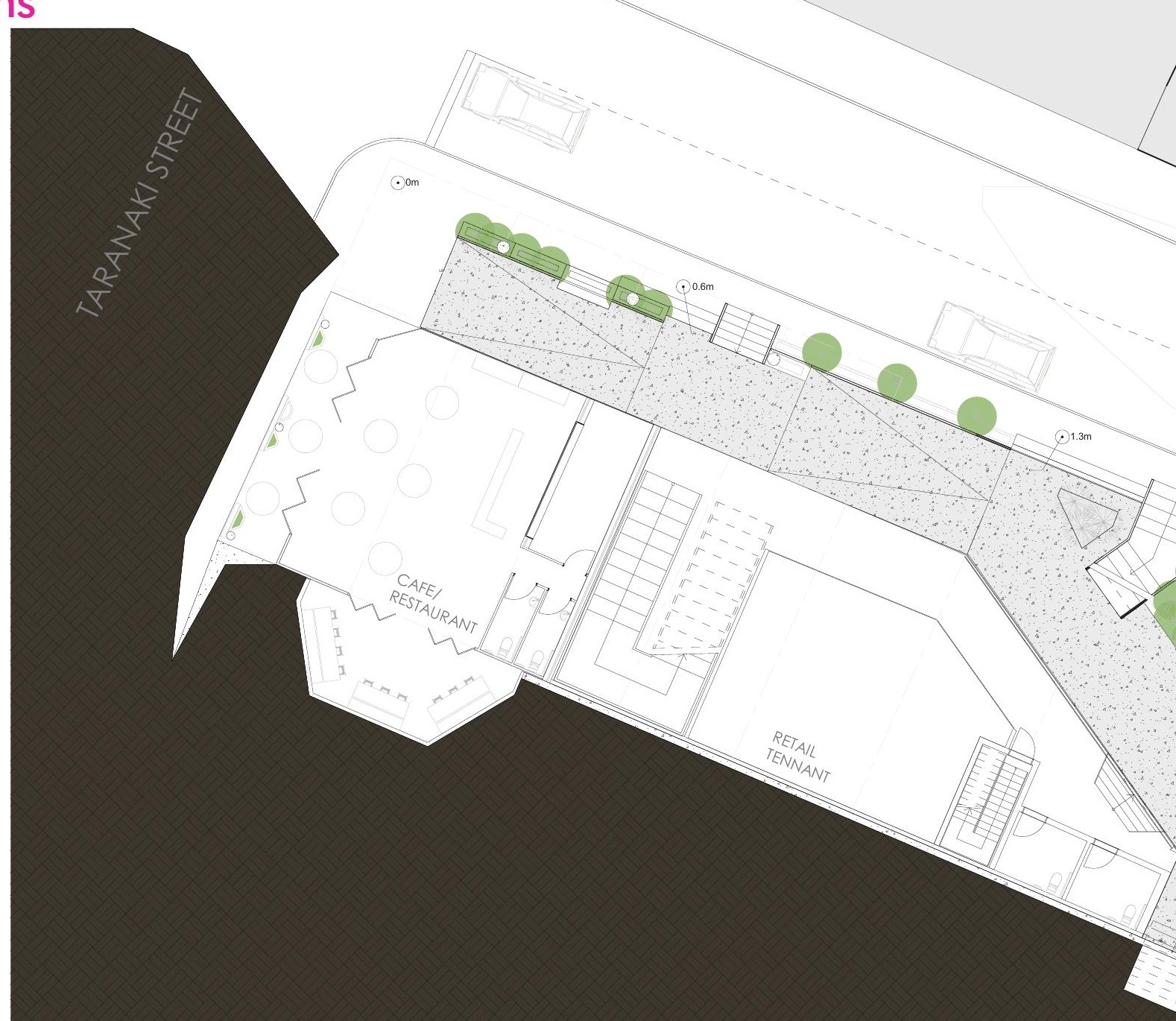

The Lower Ground Floor holds the cafe/ restaurant and retail tenants. These amenities are easily accessed by pedestrians down Taranaki Street and residents walk past both when leaving and

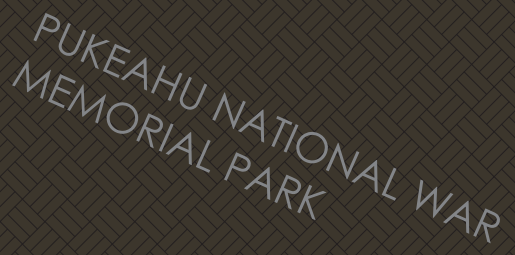
returning home. 


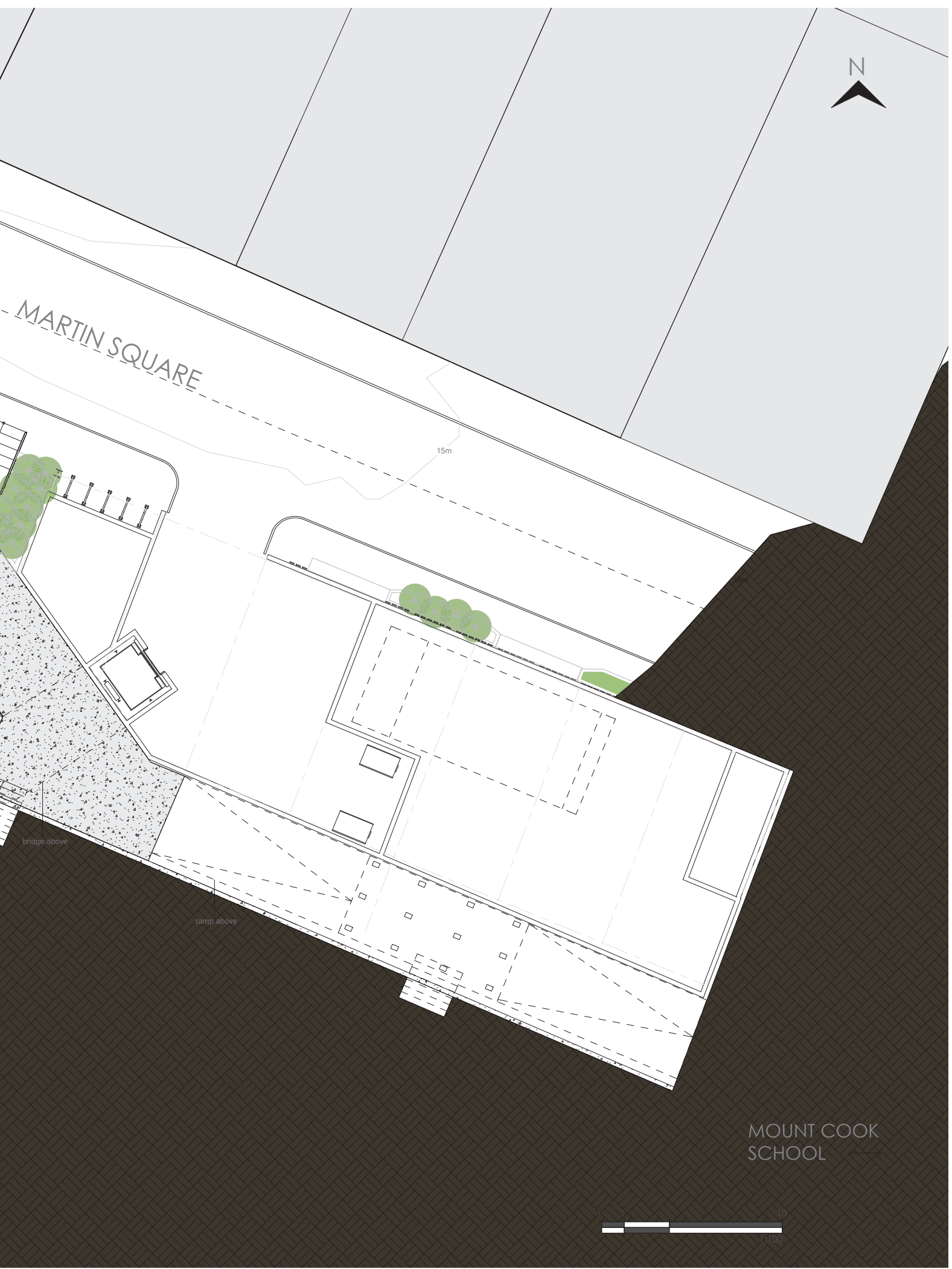




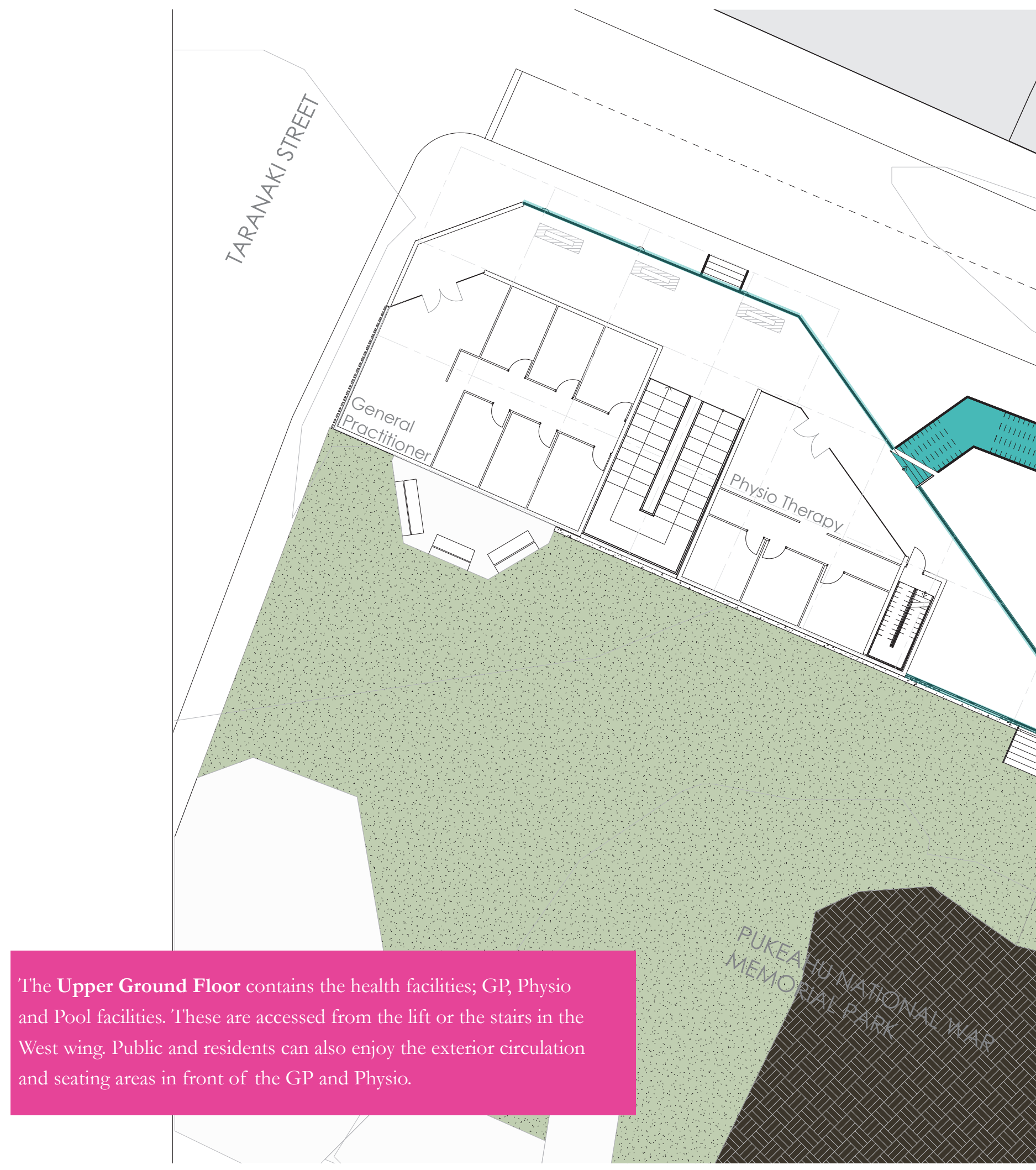




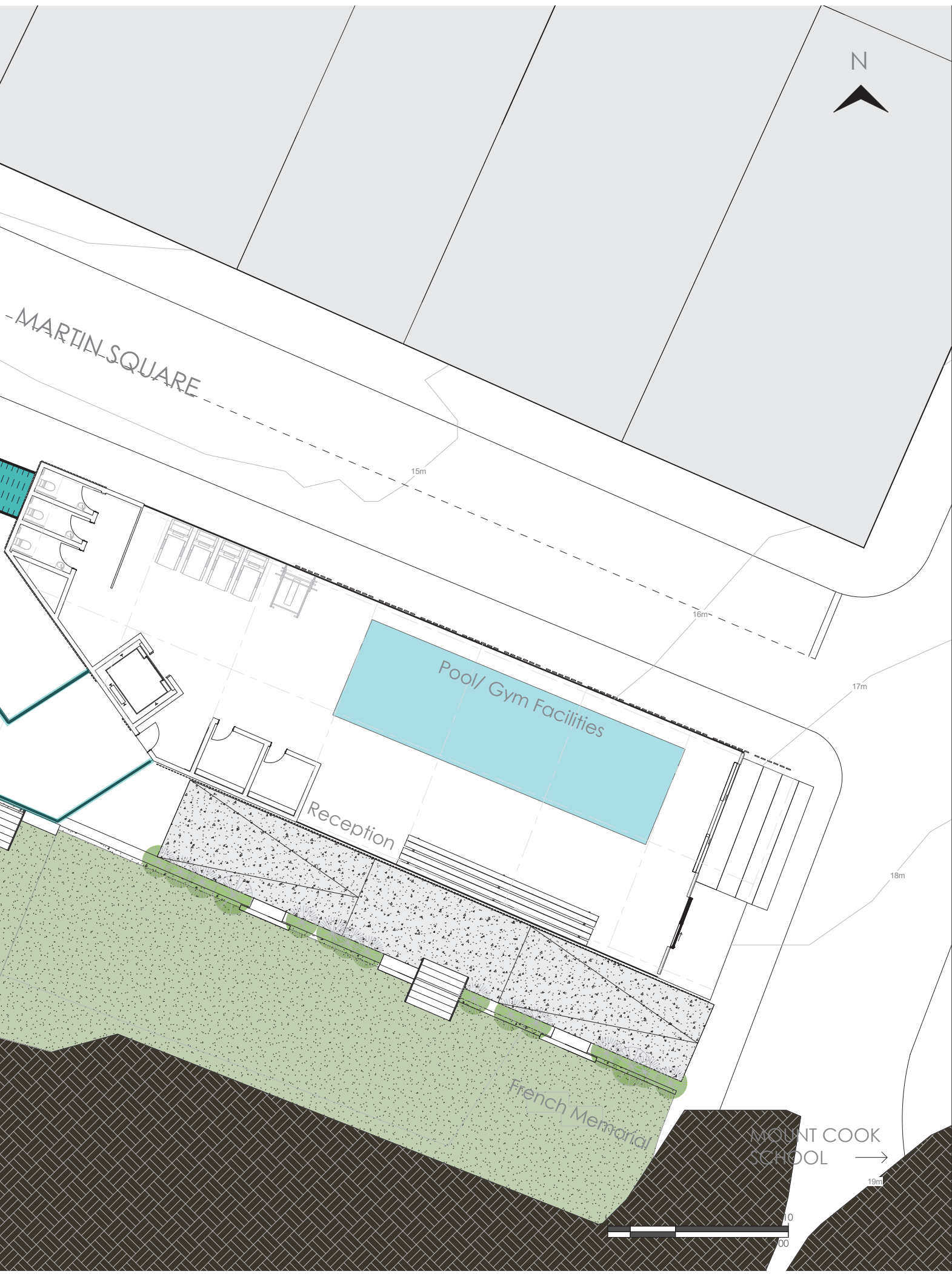




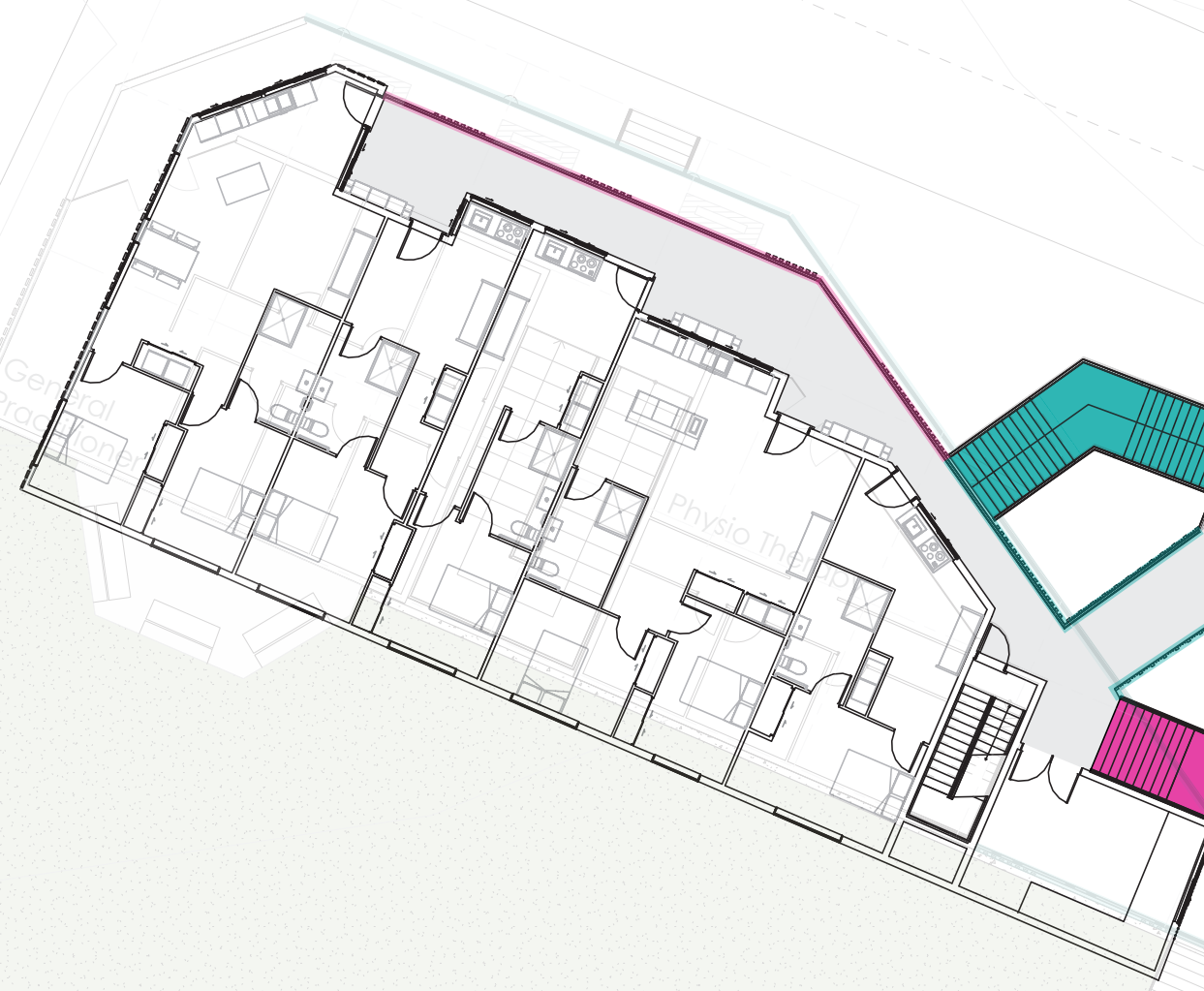

First Floor 


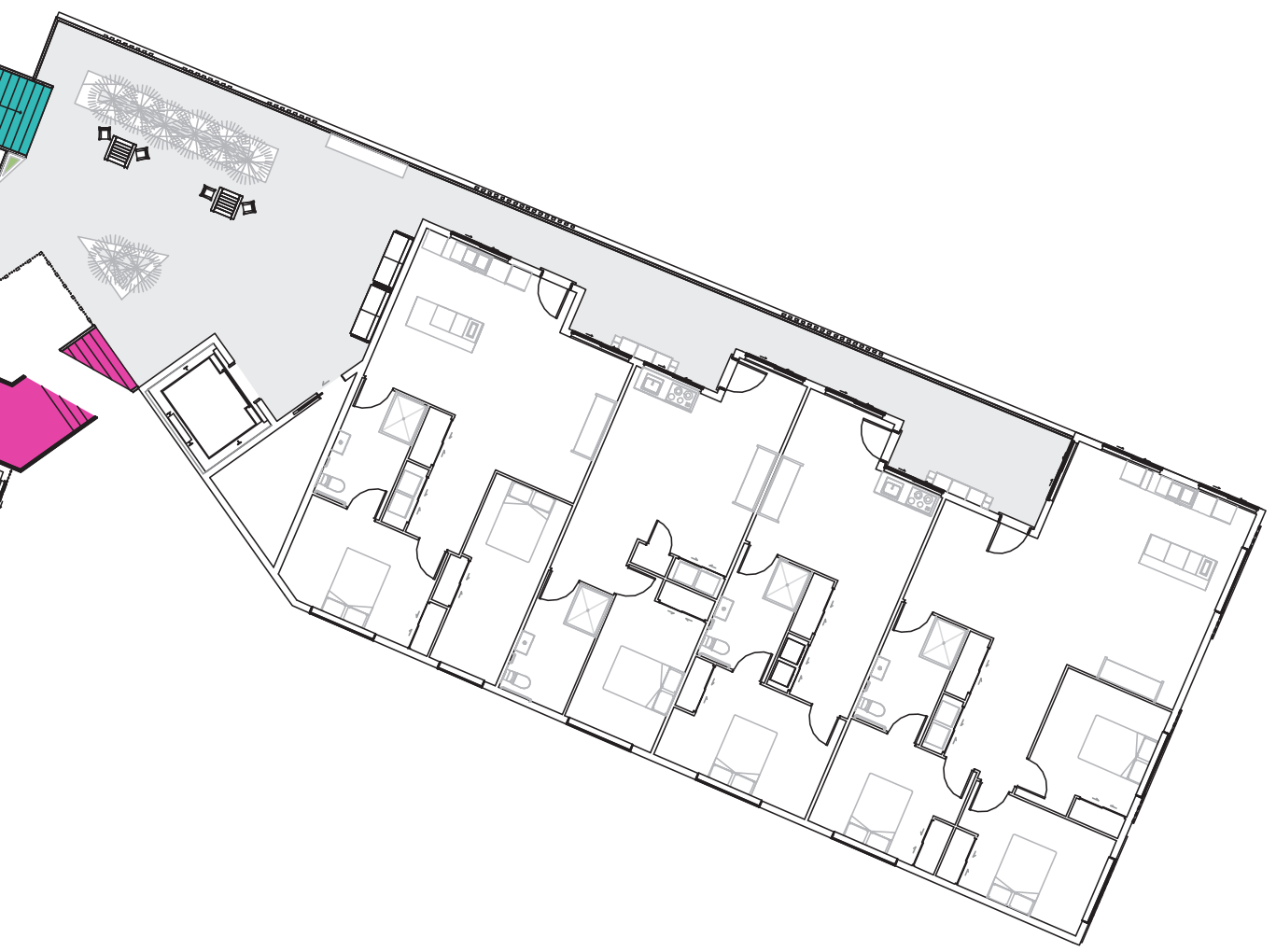




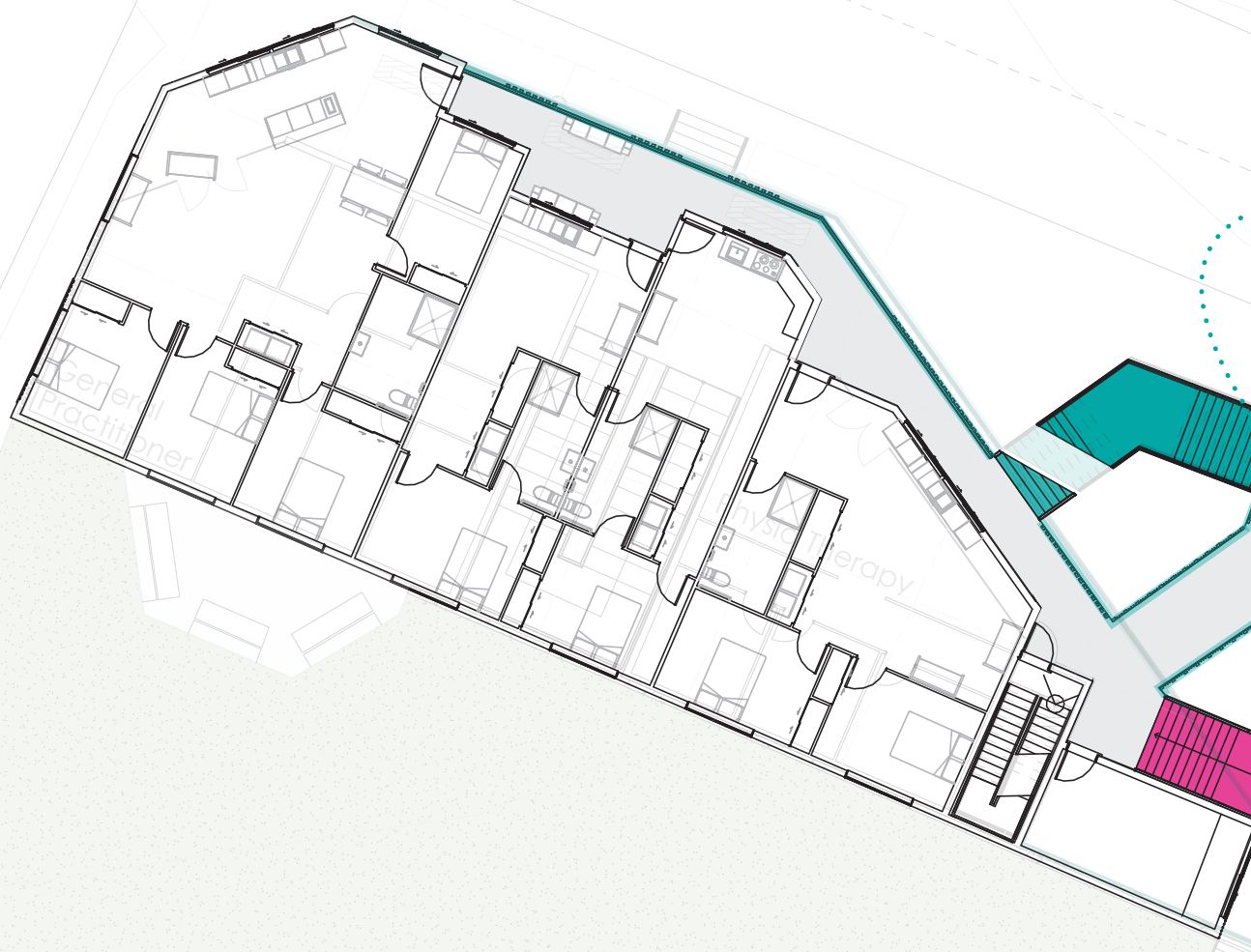

Second Floor 

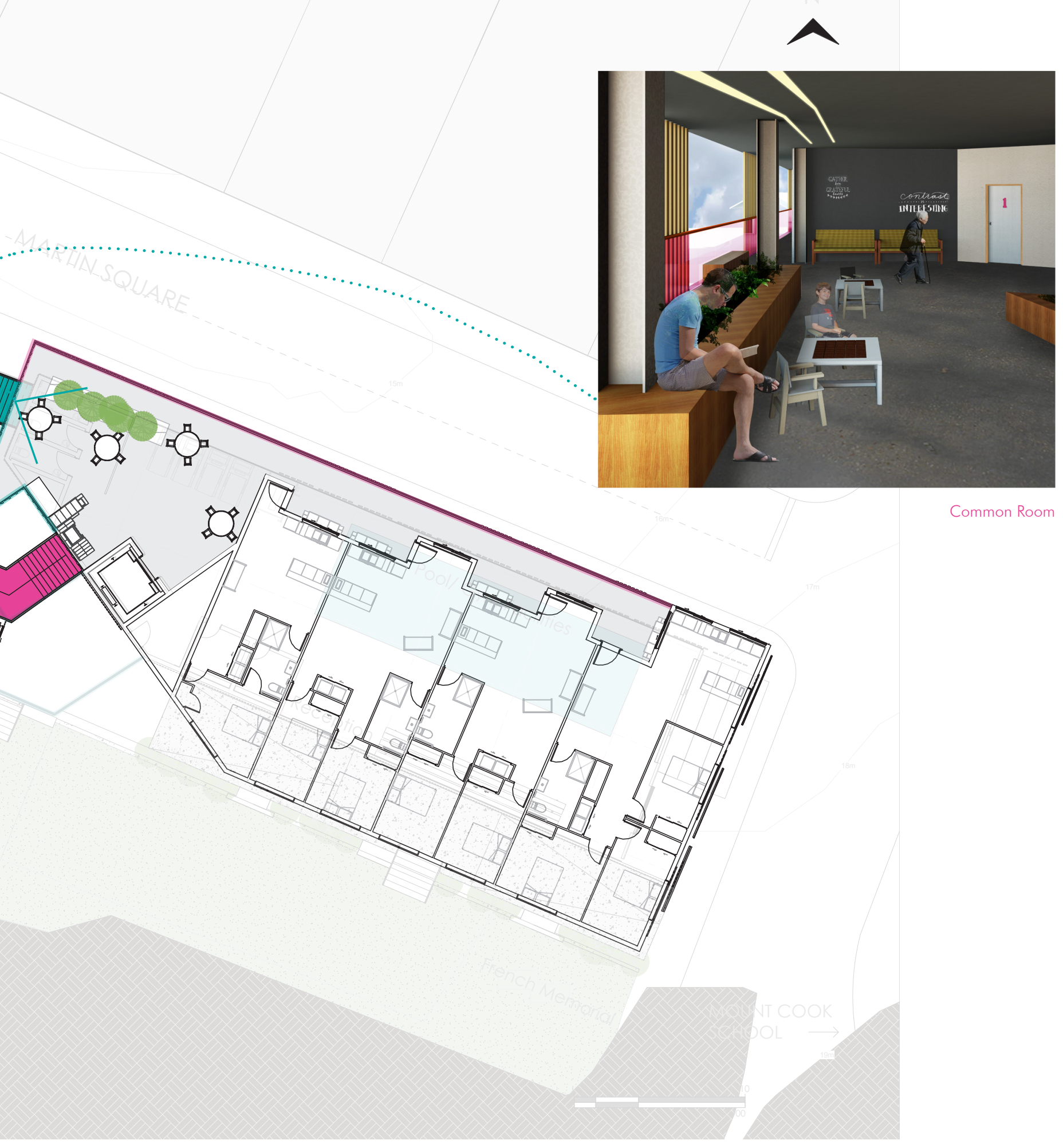


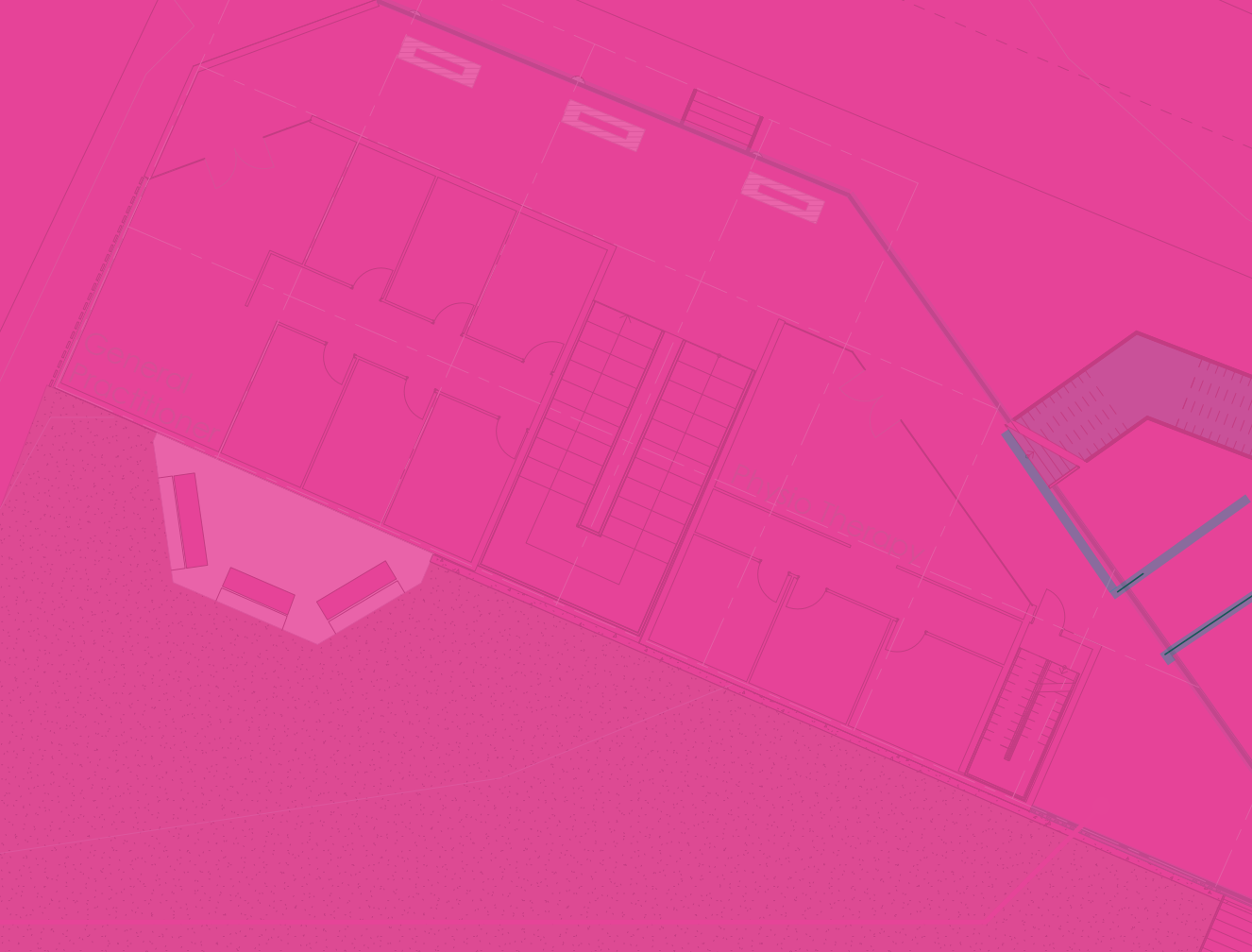

Each floor contains a 'shed'. This is intended

as a messy work space and can be used by any

residents on the floor. This space can also be

used for storage, such as bikes and tools.

\section{Third Floor}

Fourth and Fifth floors replicate the plans

already shown and can be found in Appendix B 


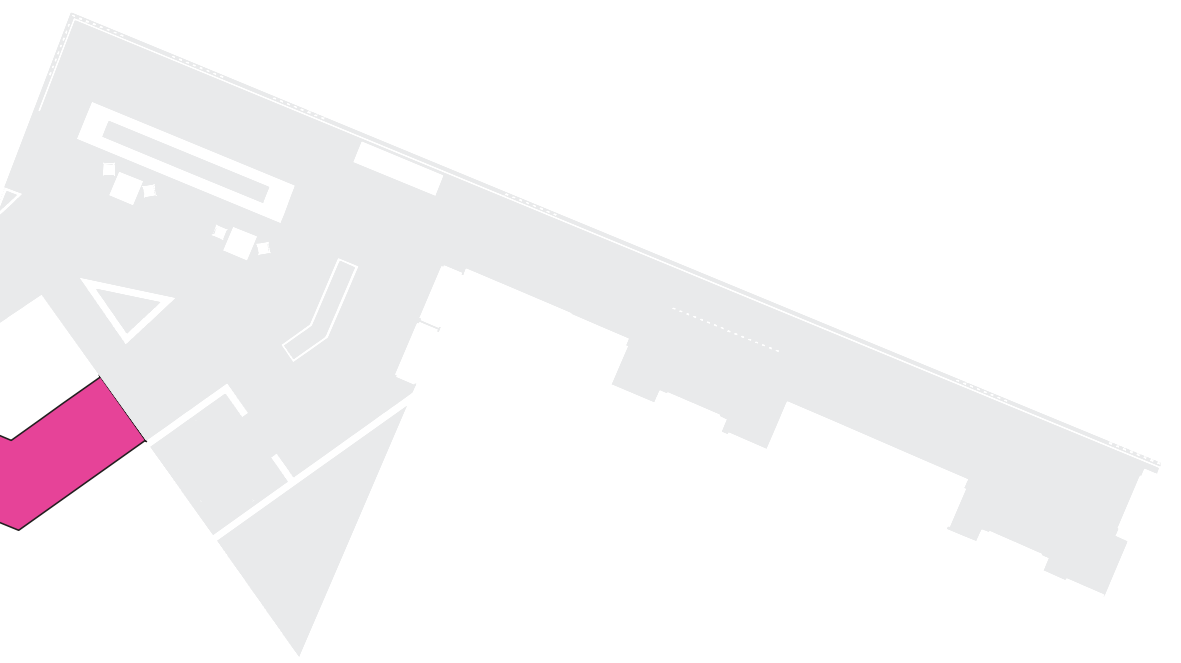




\section{Co-Housing}

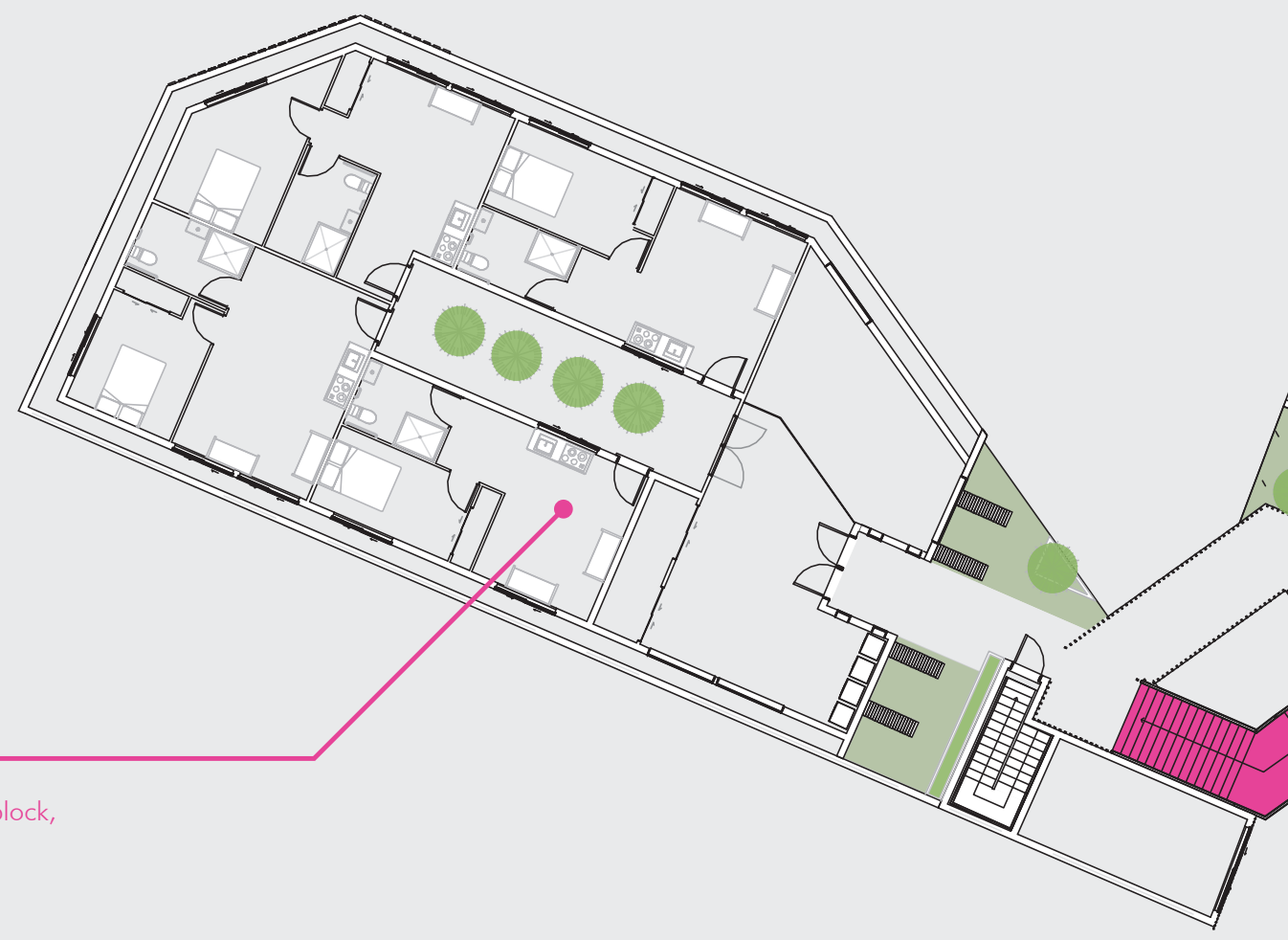

Sixth Floor - Rooftop 


\section{Sections}

\section{Rooftop Communal Garden}

The roof top space is utilised as communal barbecue and garden space for all residents. The garden uses native plants species which are also used in the War Memorial Parks landscaping such as tussocks, ferns, hebes and creeping fuchsia.

\section{Apartment Bedrooms}

The orientation of the apartment bedrooms is along the south west facade overlooking the park. This gives privacy from the common areas on the north facade.

\section{Social Street}

The ground floor circulation is a concrete ramp cutting through the site. The ramp has lighting along the edges, steps up to the park and down to the street and seating along the edges to facilitate incidental interactions.

\section{Pool Facility}

The pool has two entries, at the school end and off the central vertical circulation. This space allows interaction between a wide variety of generations and provides a health amenity which older persons can use independently. 


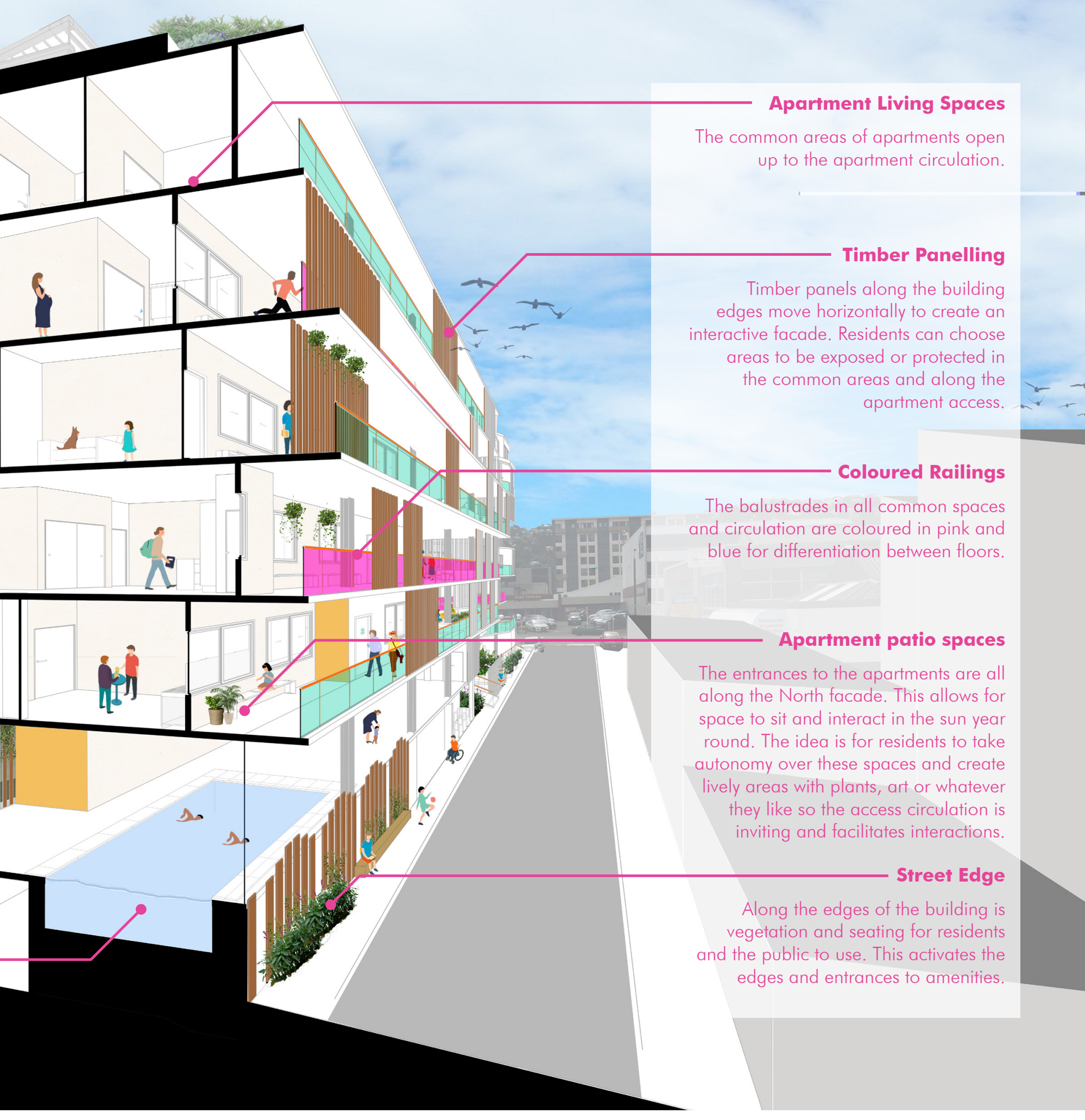




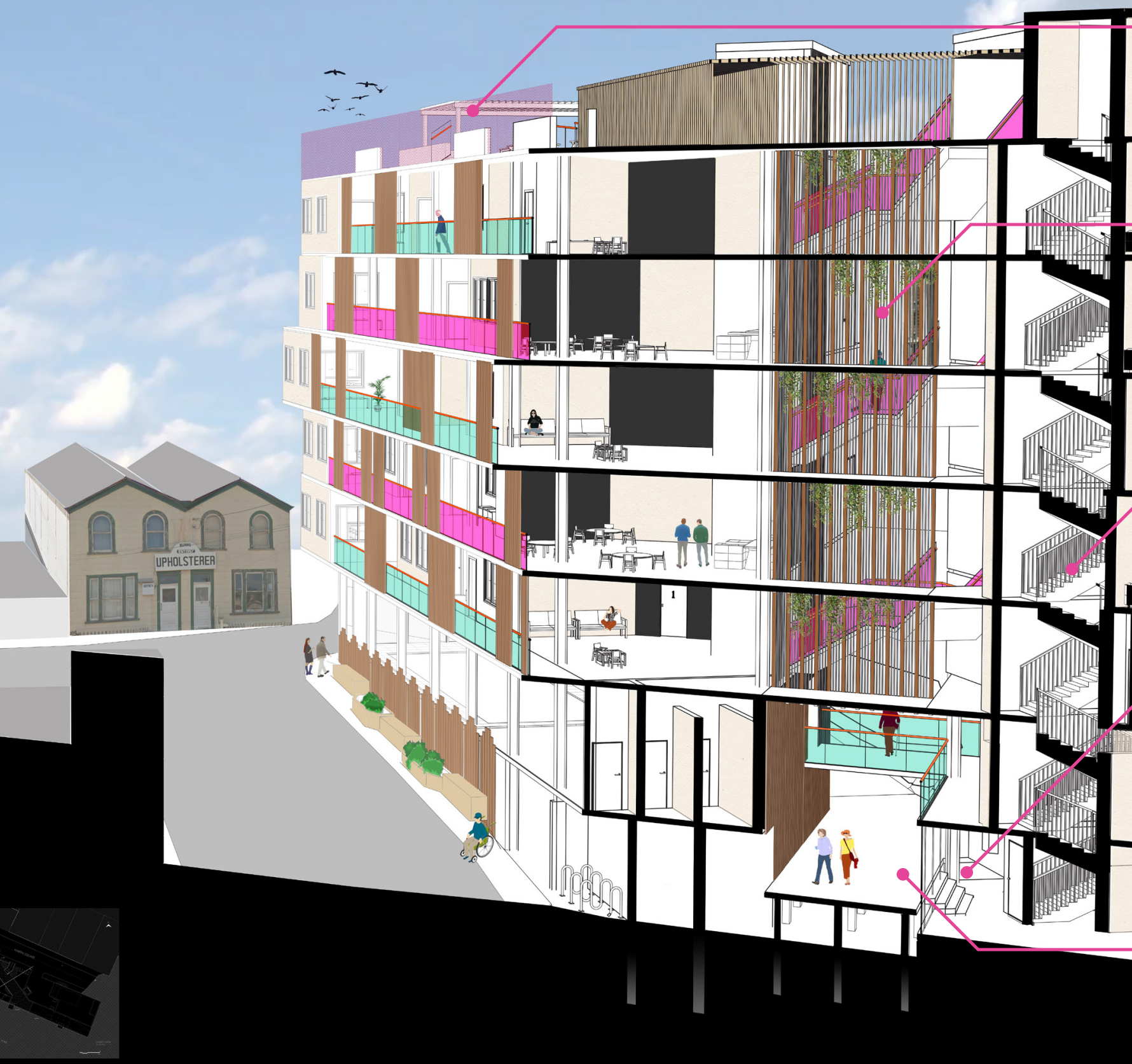




\section{Parking}

Some ground floor covered parks for shared vehicles otherwise roadside parking-encouragement of walking/ public transport

\section{Rooftop}

Covered, stepped up, BBQ area, entrance

\section{Cafe/ Food tenant}

Connection to Taranaki Street and social street, catering for residents that require it

\section{Co-Housing}

Consideration of another type of

housing responsible for the up-keeping

of the communal gardening

\section{GP/ Physio}

Located on the Upper Ground floor, outdoor areas with seating, easy access to pool and down to lower ground

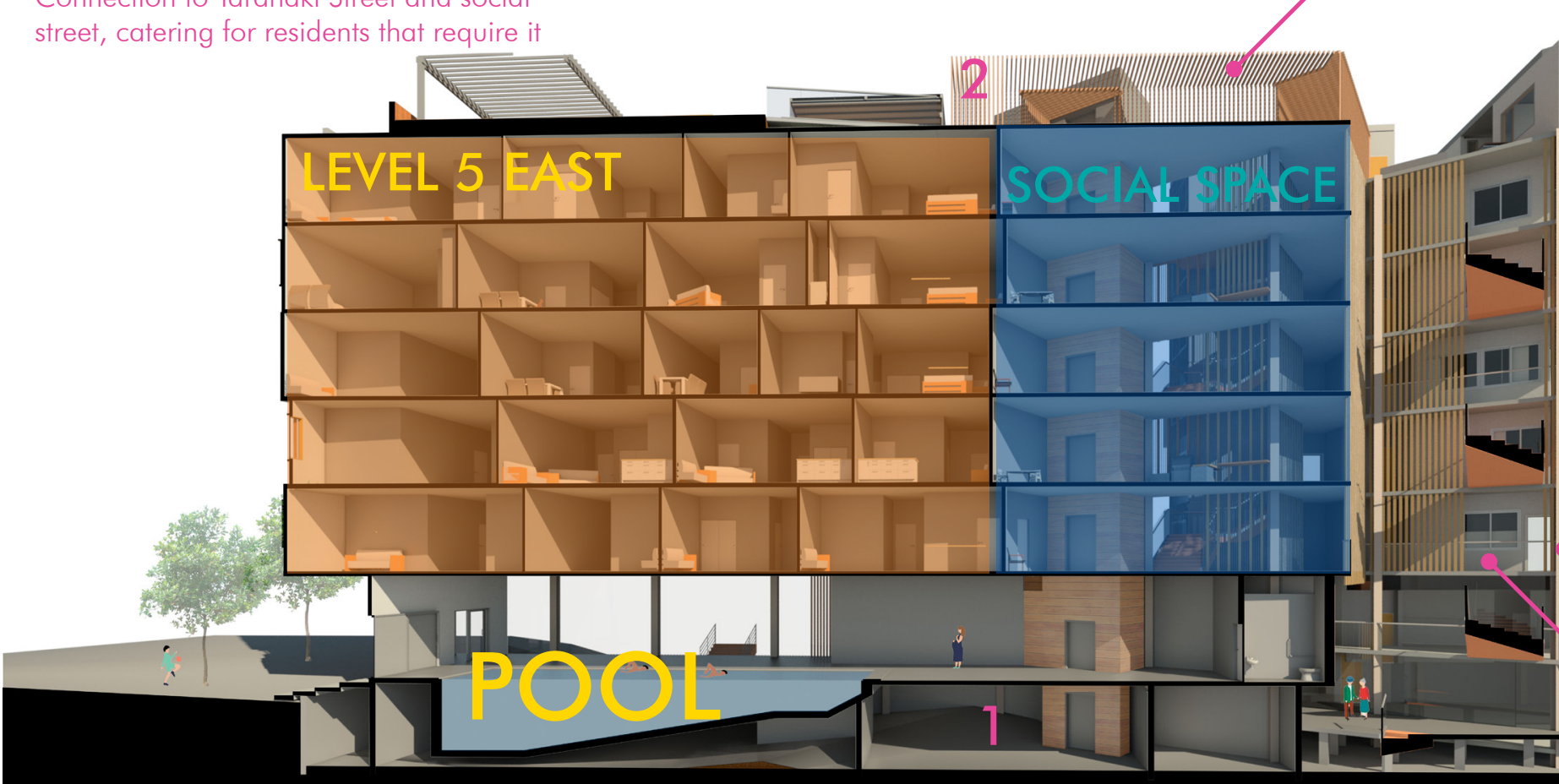




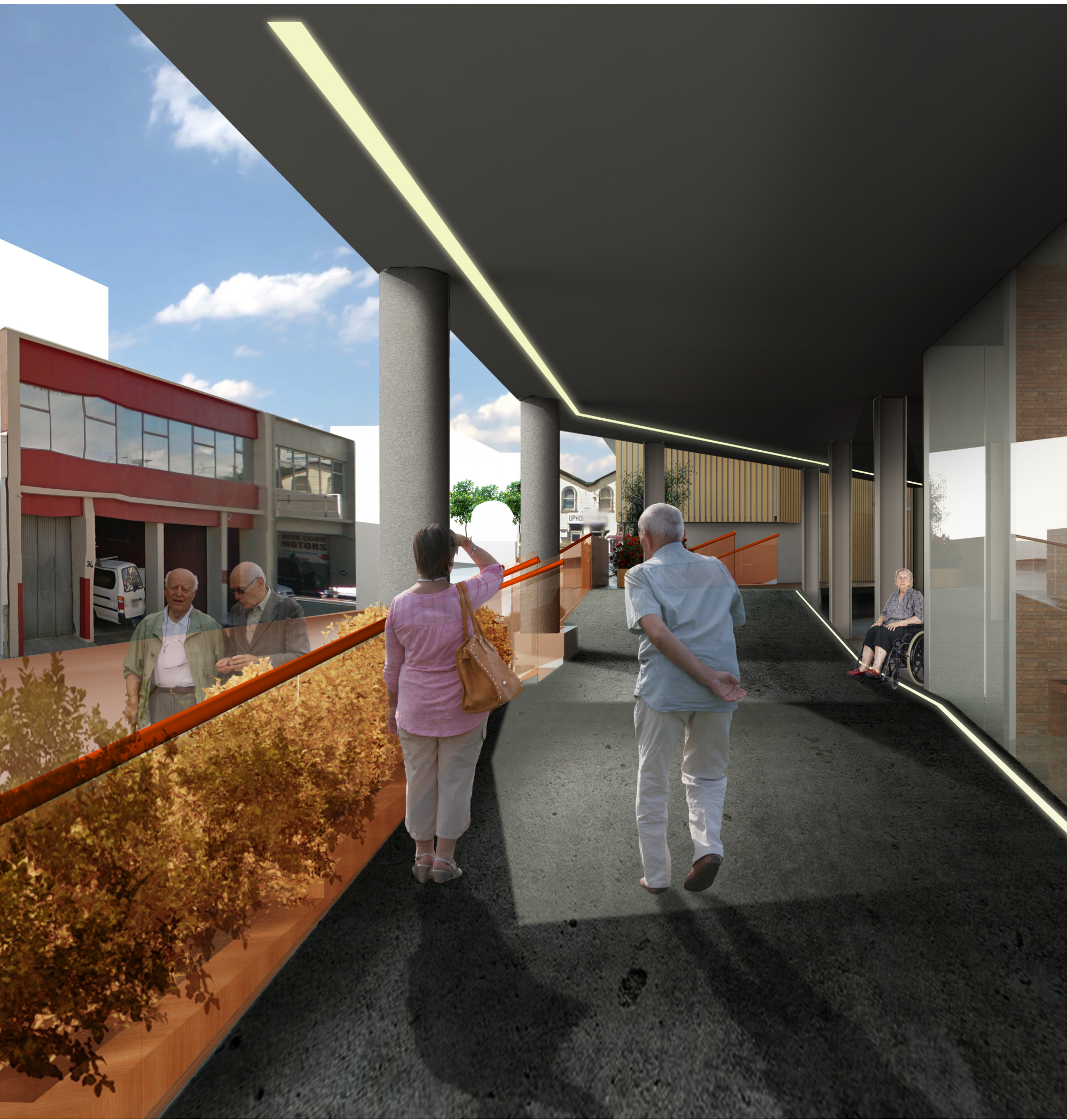




\section{Walk through Views}

Henry and Julia have lived in the building for 3 years, they have just been to see the new exhibition at $\mathrm{Te}$ Papa and now they are returning to attend a residents barbecue on the rooftop. 
Christian and William, two resident who became friends after living on the same floor, are leaving to go for a walk. They run into Mark, the nursing student on their floor, as they walk down the social street.

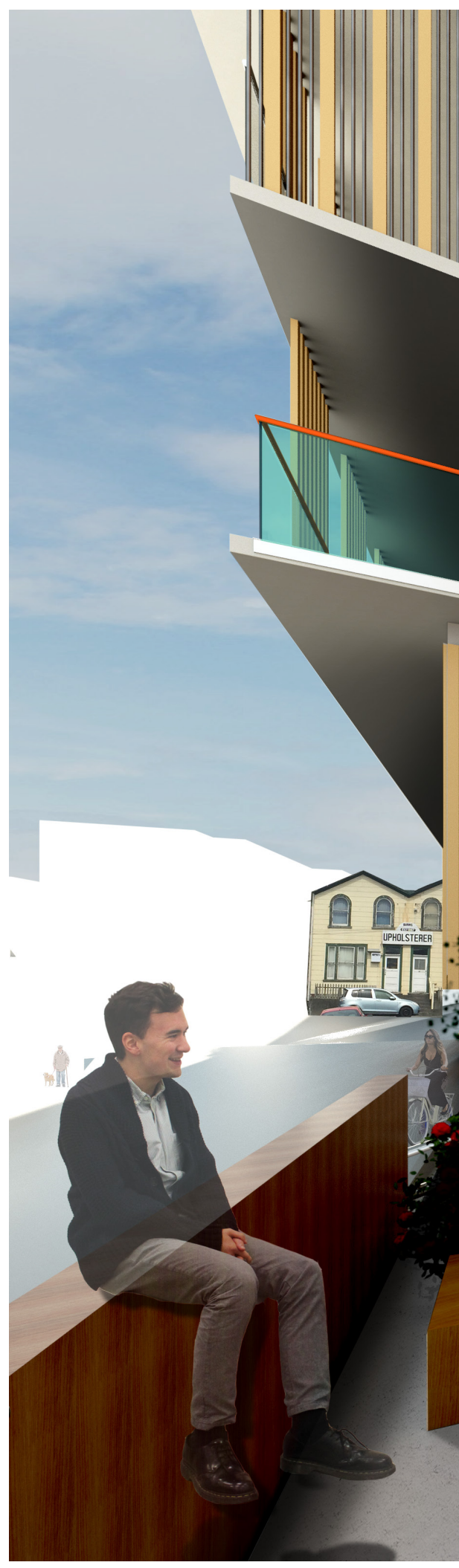




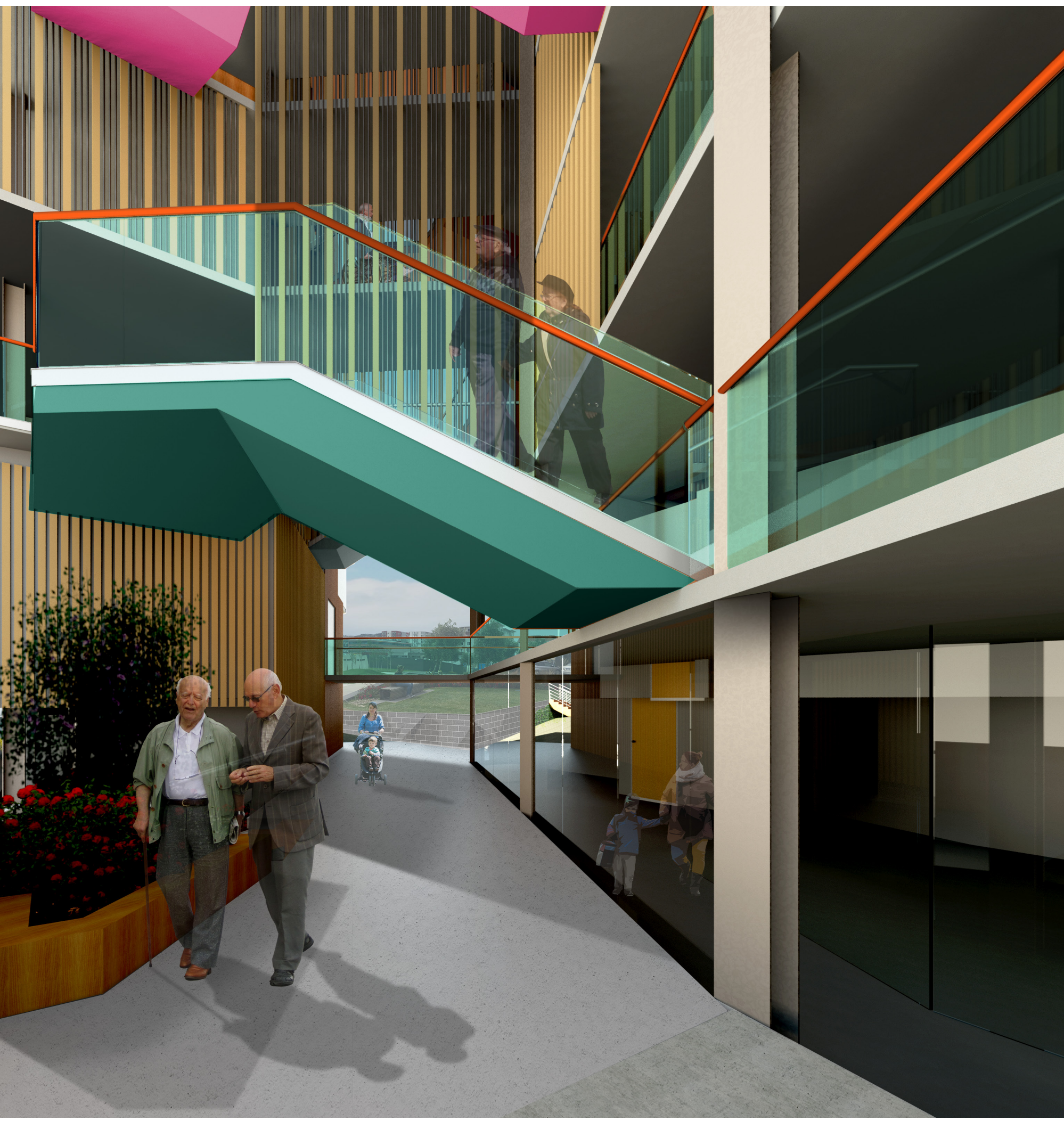




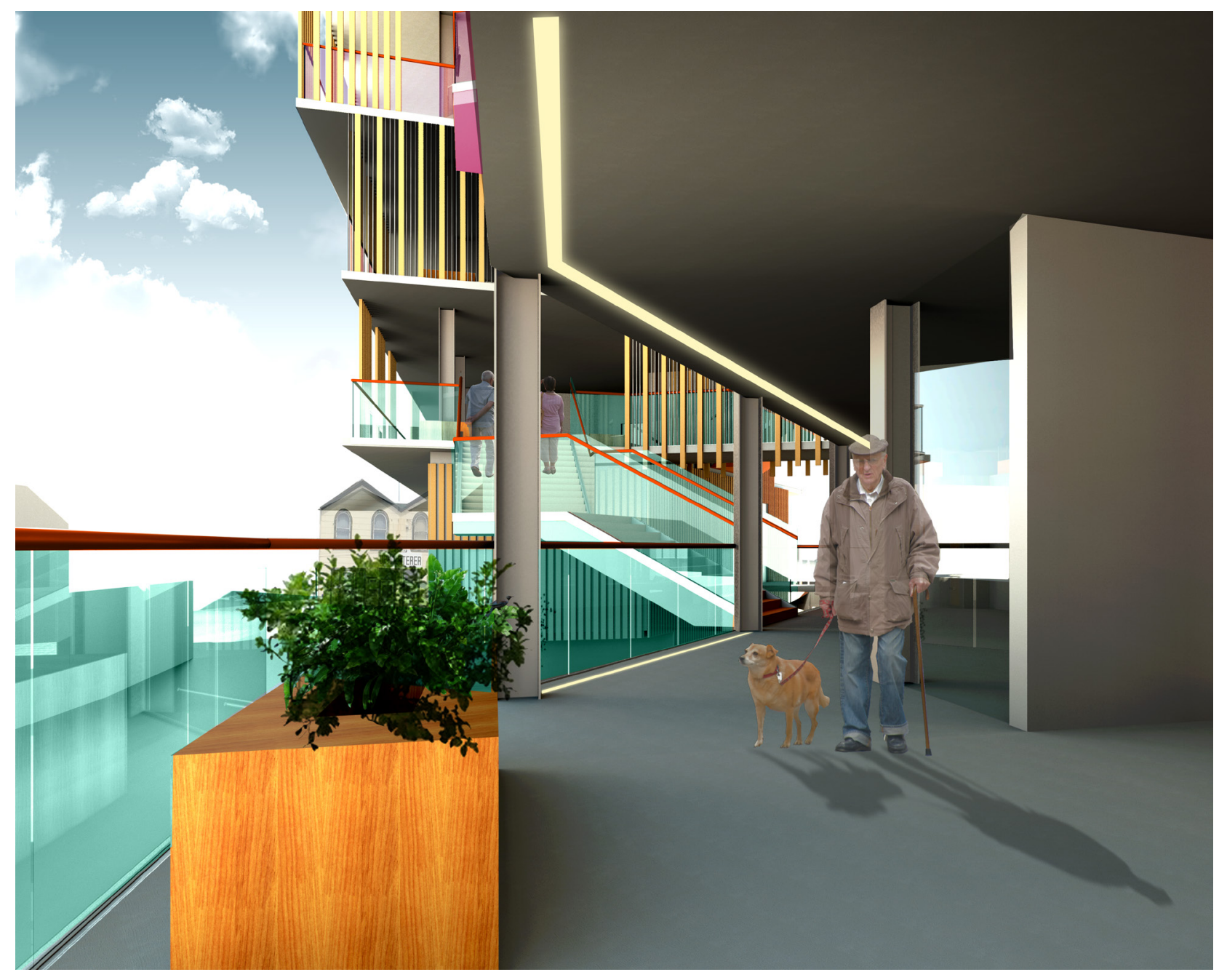

Jack, a Wellington resident, is walking to the GP to collect a script, his dog is distracted by a bird in one of the planter seats along the circulations edge. 


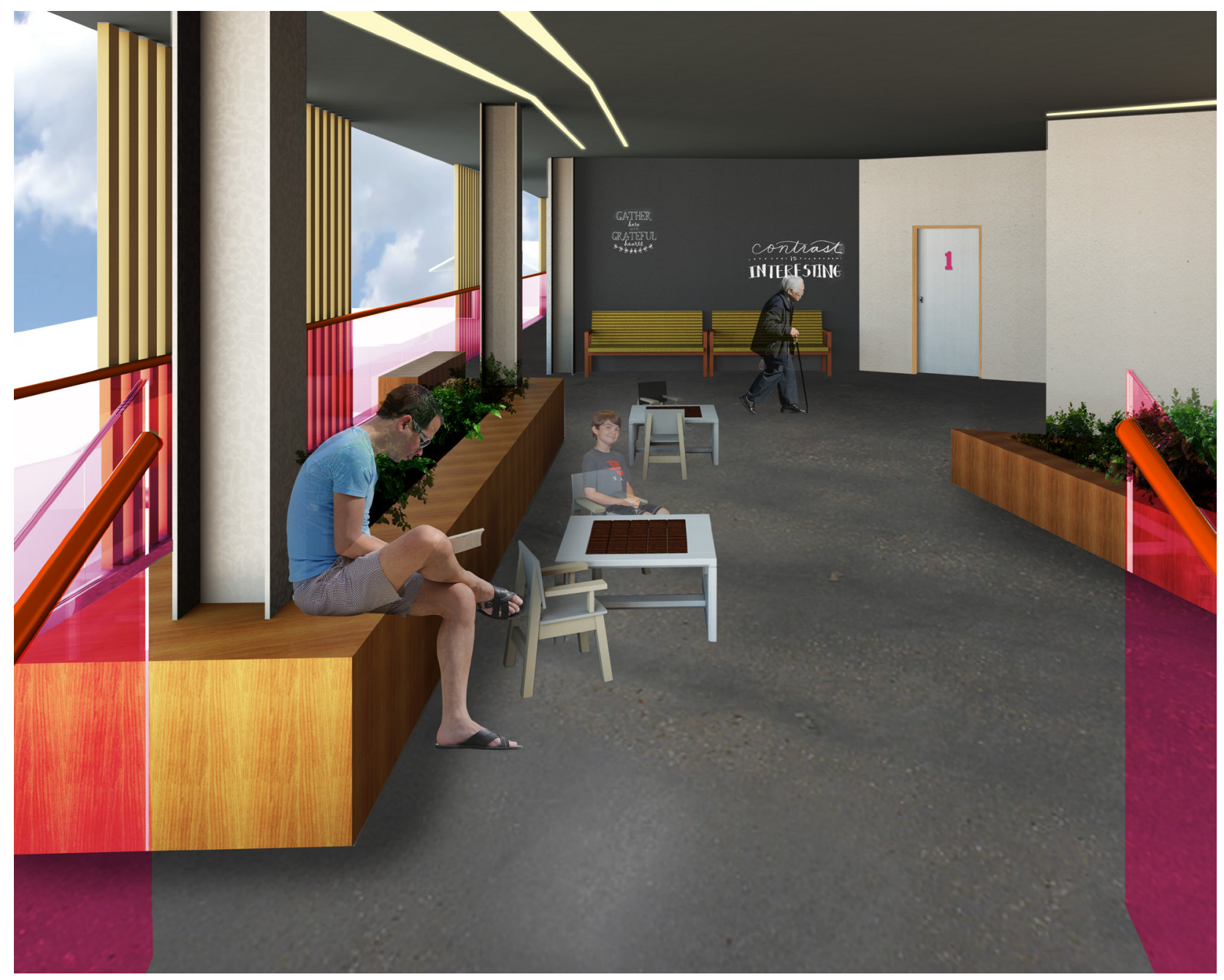

David is waiting in his common space with his son Charlie for some of their neighbours to walk up to the rooftop barbecue together. 


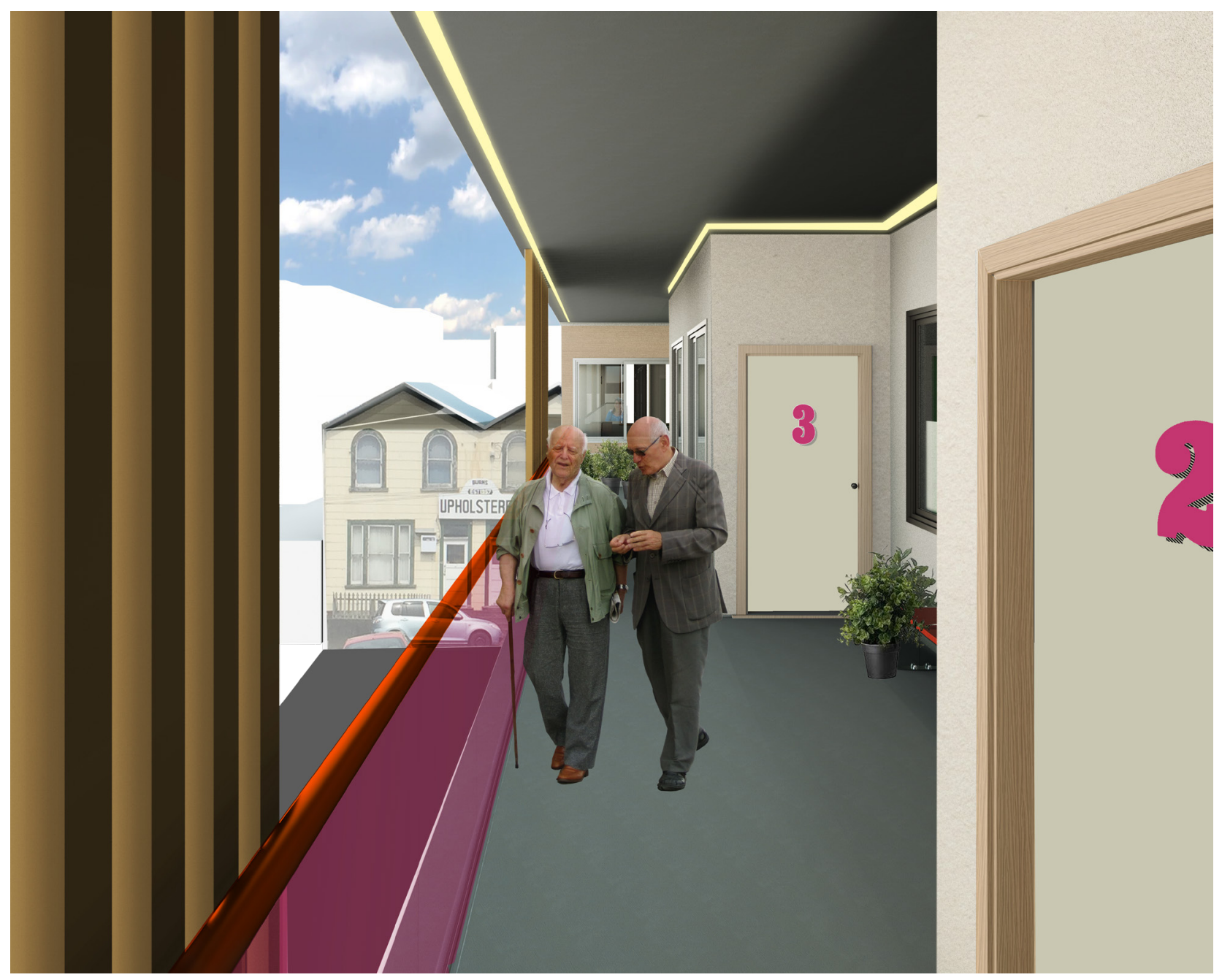

Christian and William leaving apartment 3 after visiting one of their neighbours who is ill and getting a catered meal tonight from the restaurant instead of attending the barbecue. 


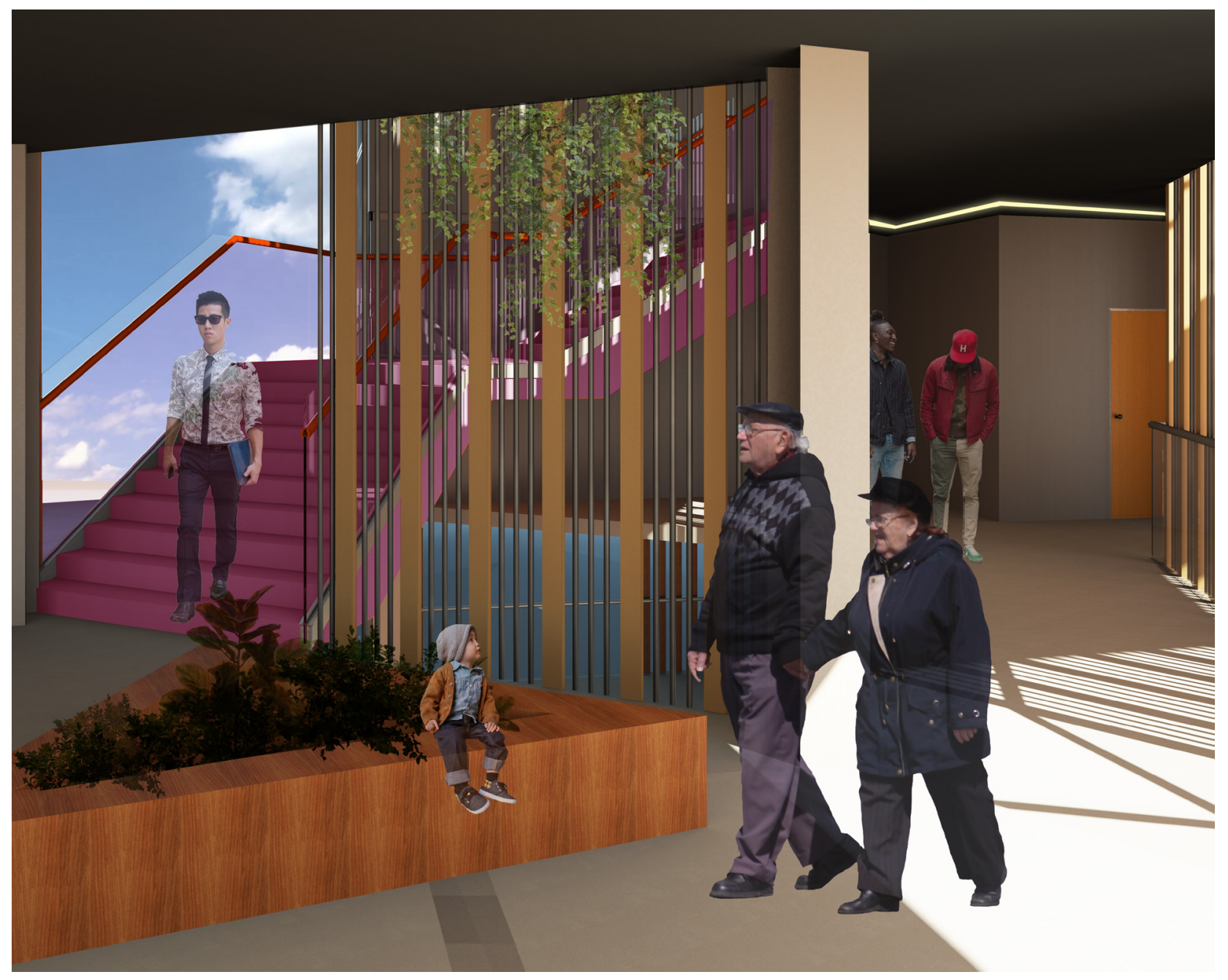

Cynthia and Paul heading to the lift to get up to the rooftop, after catching up with Nathanael and Cameron who aren't far behind them. 
Henry and Julia arrive at the barbecue rooftop area and are greeted by resident who have already arrived, some of which are new to the building and they quickly begin getting acquainted. 
Residents of all ages and walks of life enjoy their evening in the rooftop garden, overlooking the War Memorial Park and soaking up the last of Wellington's' summer sun.

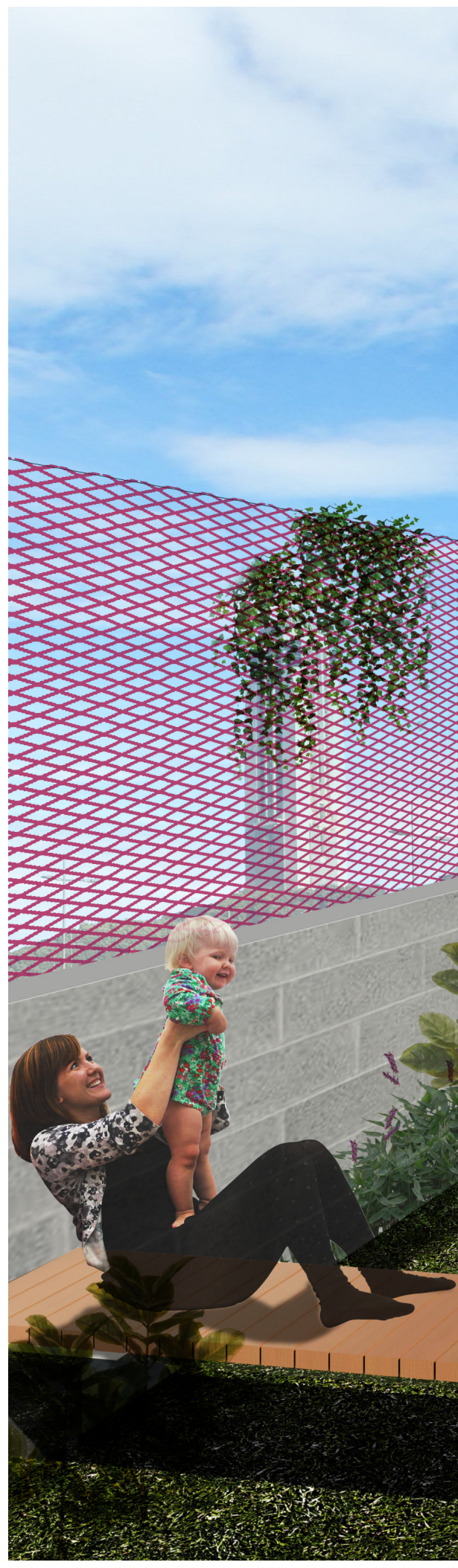




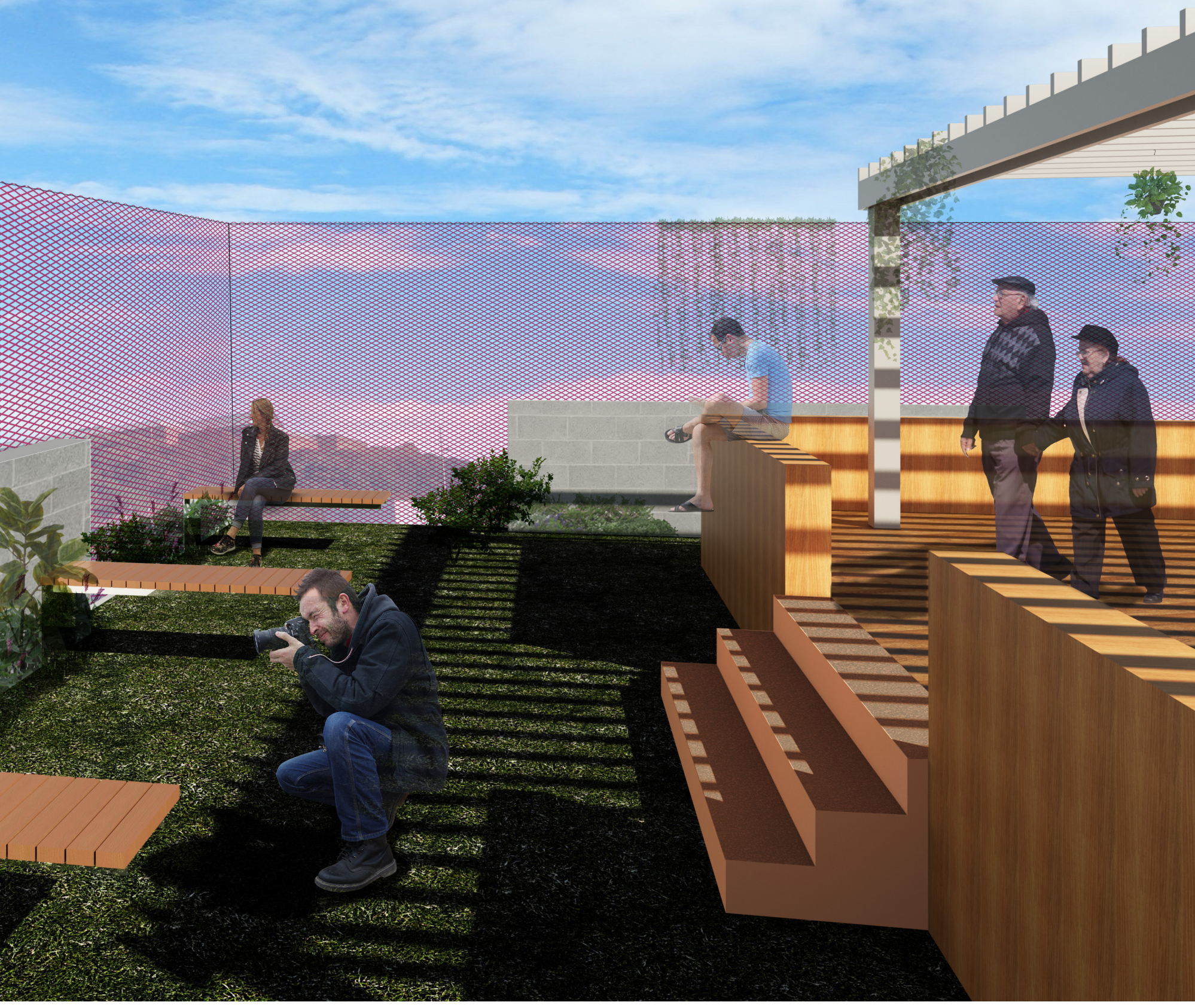


This design embodies the key principles of a better ageing experience through the design of the four key tactics, Urban Location, Social Circulation, Mixed Housing and Shared Amenities.

This building provides older persons with an alternative housing experience which is focused on providing them the autonomy, independence and support they will need 1 as they age and which will ensure the later years of their lives are happy ones. 


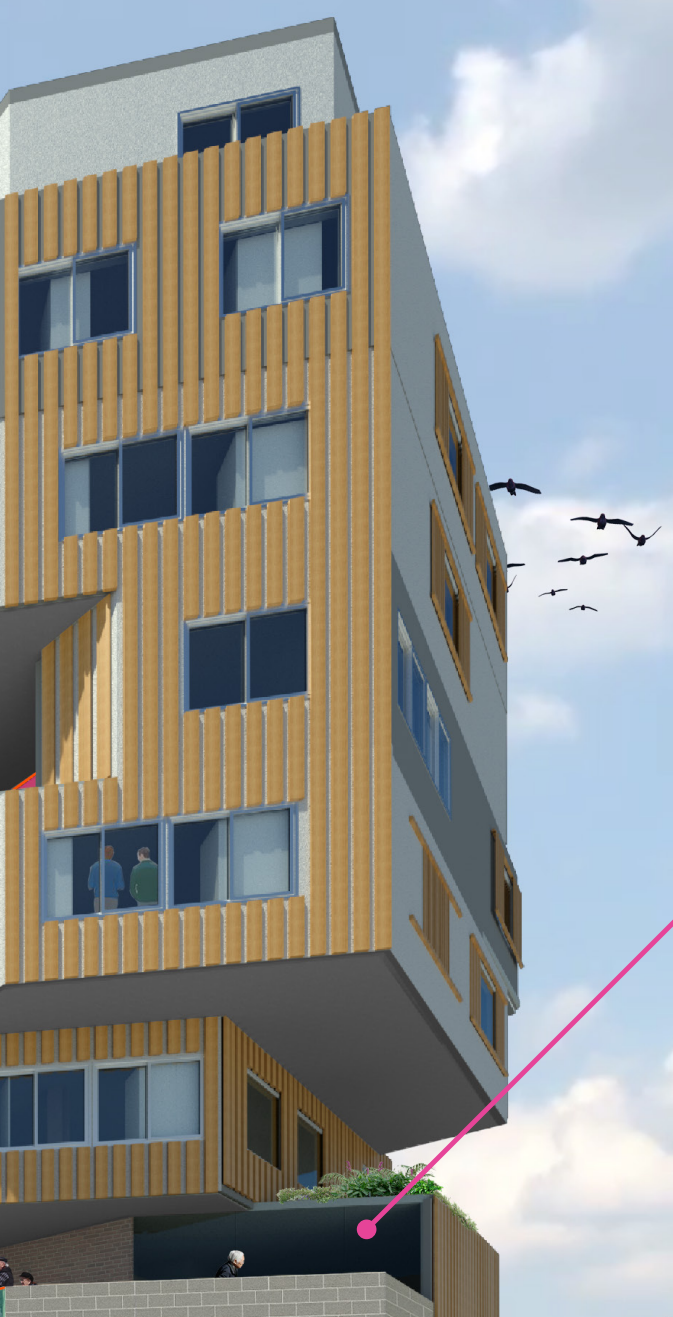

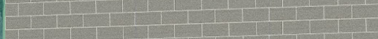

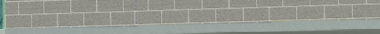
(6) 1 .

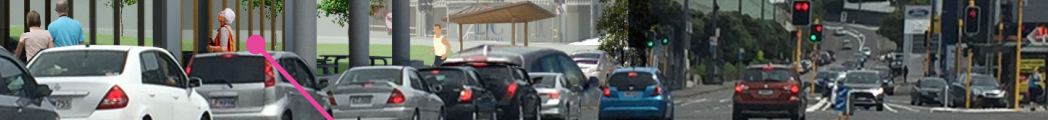

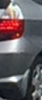
in $=$

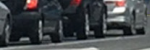
$\sin (x-1)$ aid 


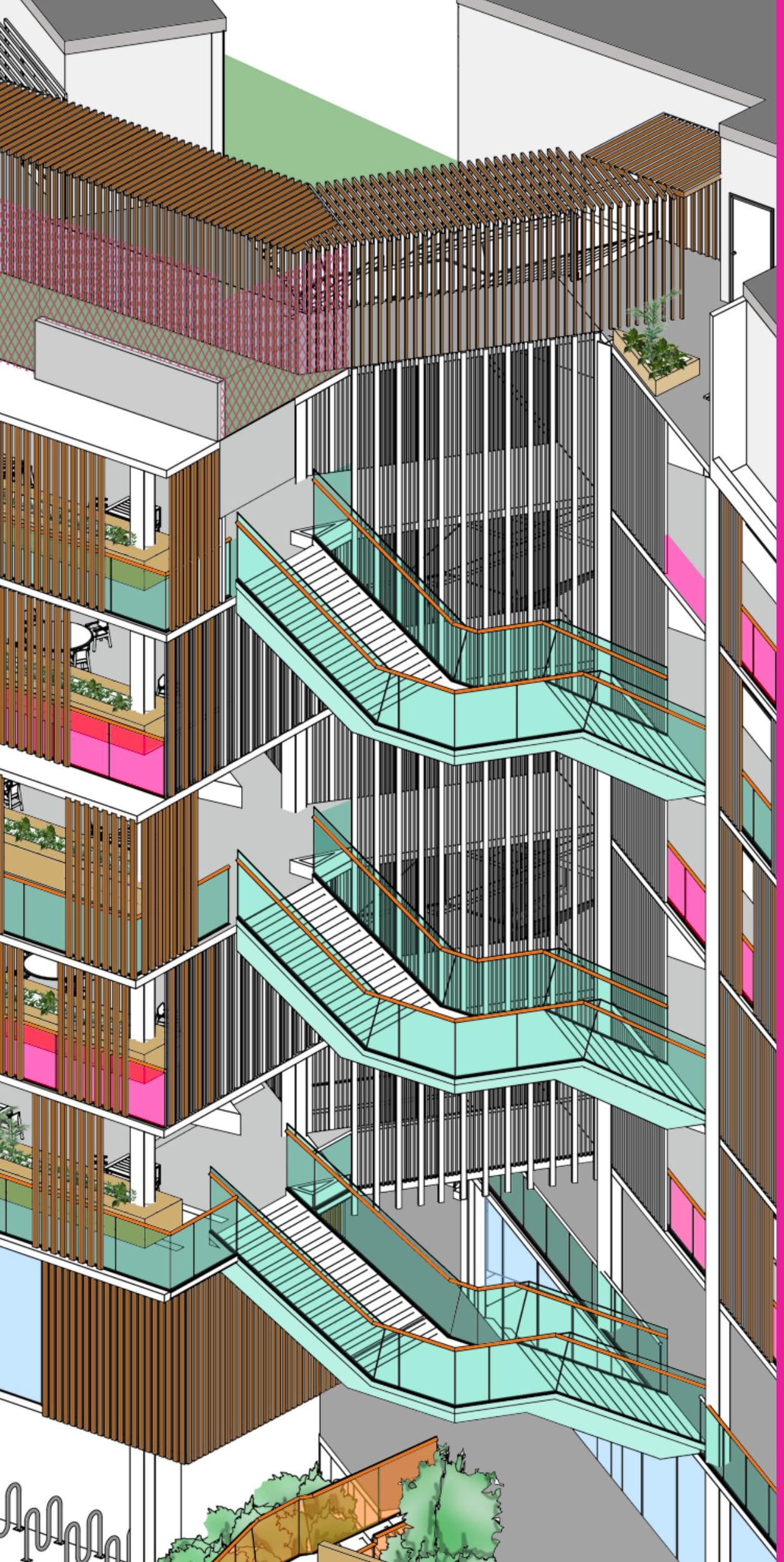


Conclusion

Critical Reflections + Implications 


\section{Conclusion}

This research investigation developed and tested a new model for aged care housing - an urban, mixed residential and intergenerational scheme. This proposal reduces the stigma produced in current aged care models (such as hospital care and independent living) through four key tactics: providing a social and community based urban environment, providing generous social circulation which facilitates interactions, designing accessible mixed housing and providing shared health and well being amenities all of which reflect that of a high quality contemporary residential architecture. This research argues that the implementation of these tactics in urban housing developments will provide better outcomes for older persons in health and well being and should be considered as a new model of older persons housing.

\section{The research question asked: As New Zealand's population ages and demand for housing for older persons increases, can a new direction in housing be created which challenges the prevailing stigma of aged care housing, by providing better social, health and support benefits for its residents?}

\section{New Direction}

A lot of New Zealand's aged care exists in suburban areas, this scheme proposes a change to an urban context. While still providing the sense of community closely tied to ageing in place in suburban areas, urban environments offer many more opportunities for older persons. The shorter walking distances to amenities provides a sense of independence, in being able to go out and eat or get groceries, safely by themselves. 


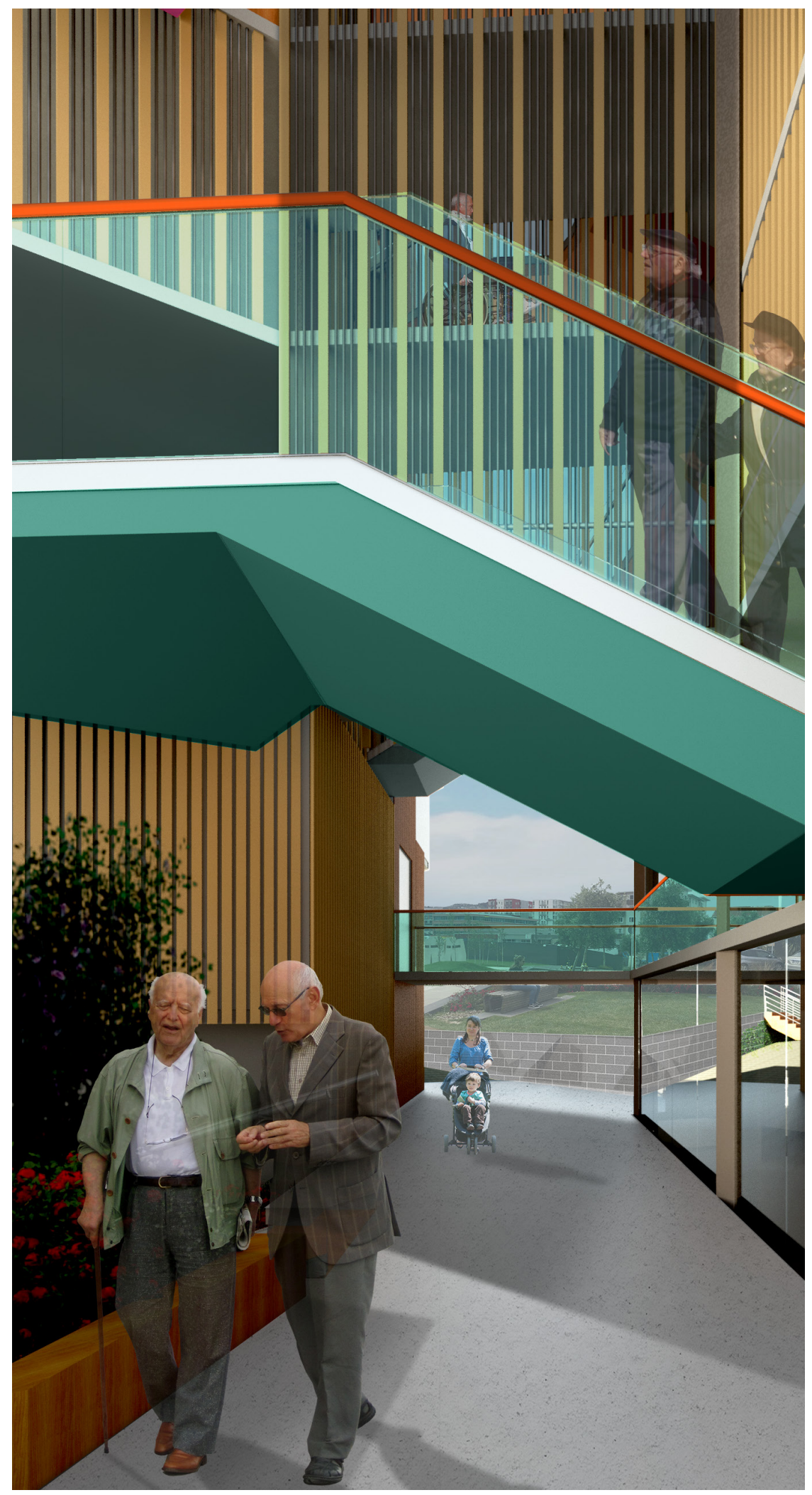


The housing scheme developed here provides intergenerational living and interactions. This creates a more accepting and understanding environment between residents. Lending opportunity for residents to ask one another for favours and seek support without feeling dependent. This directly relates to the principles of a better ageing experience in extending older persons independence.

Prioritising social circulation mean providing spaces for incidental and planned interactions as well as activating spaces. This primary focus allows the circulation to be celebrated in a building that would normally treat it as a secondary space for access.

This building provides options for more dependent care as residents age through the chosen amenities and flexibility in intergenerational housing. The ground floor café/ restaurant can provide meals for residents should they need it, on site and resident student nurses can provide a higher level of care to residents who may require it.

The type of care this building can facilitate and provide for its residents contributes to how this scheme compares to existing models of age care housing today. Principles which promote a better ageing experience such as autonomy, independence, identity and well being are focused on. The scheme offers a seamless transition between independent and dependent living in older persons and elderly by providing more support as and when it is needed, not as a default setting, through adaptable apartments, food and health services and the support of the community formed in this housing scheme.

The similarities and differences this building shares with different models of aged care are important in understanding why the architecture of these spaces could foster such improvement. This building actively works to 


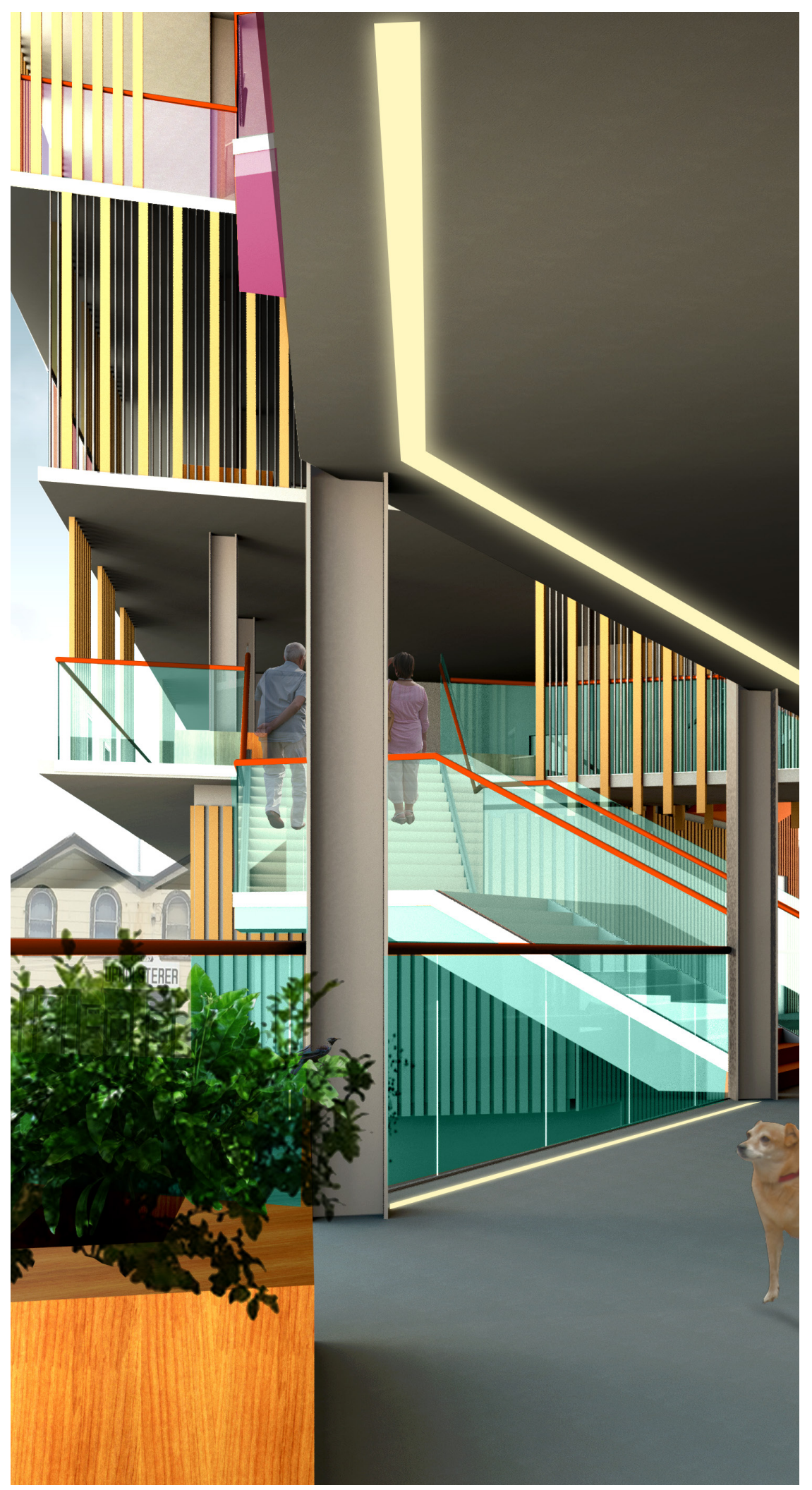


reduce stigma in an environment which still provides aged care needs through the four key tactics; urban location, social circulation, mixed housing and shared amenities.

Some key limitations in this research originate from the importance of the strategic scheme and model which focused on the shared and social spaces of the site and building, as they are the primary focus in testing an improvement through this model. This prioritising meant further research as not done into the apartment design of the building as this aspect, although important, was not addressing/ contributing to the issue of stigma as evidently as the areas in which the focus was placed.

The implications of this research include the potential for any new urban developments to better accommodate older persons, through the way the approach accessibility and circulation to the treatment of their social spaces. This research also adds a new alternative older persons housing model into discourse in aged care and age care architecture. 


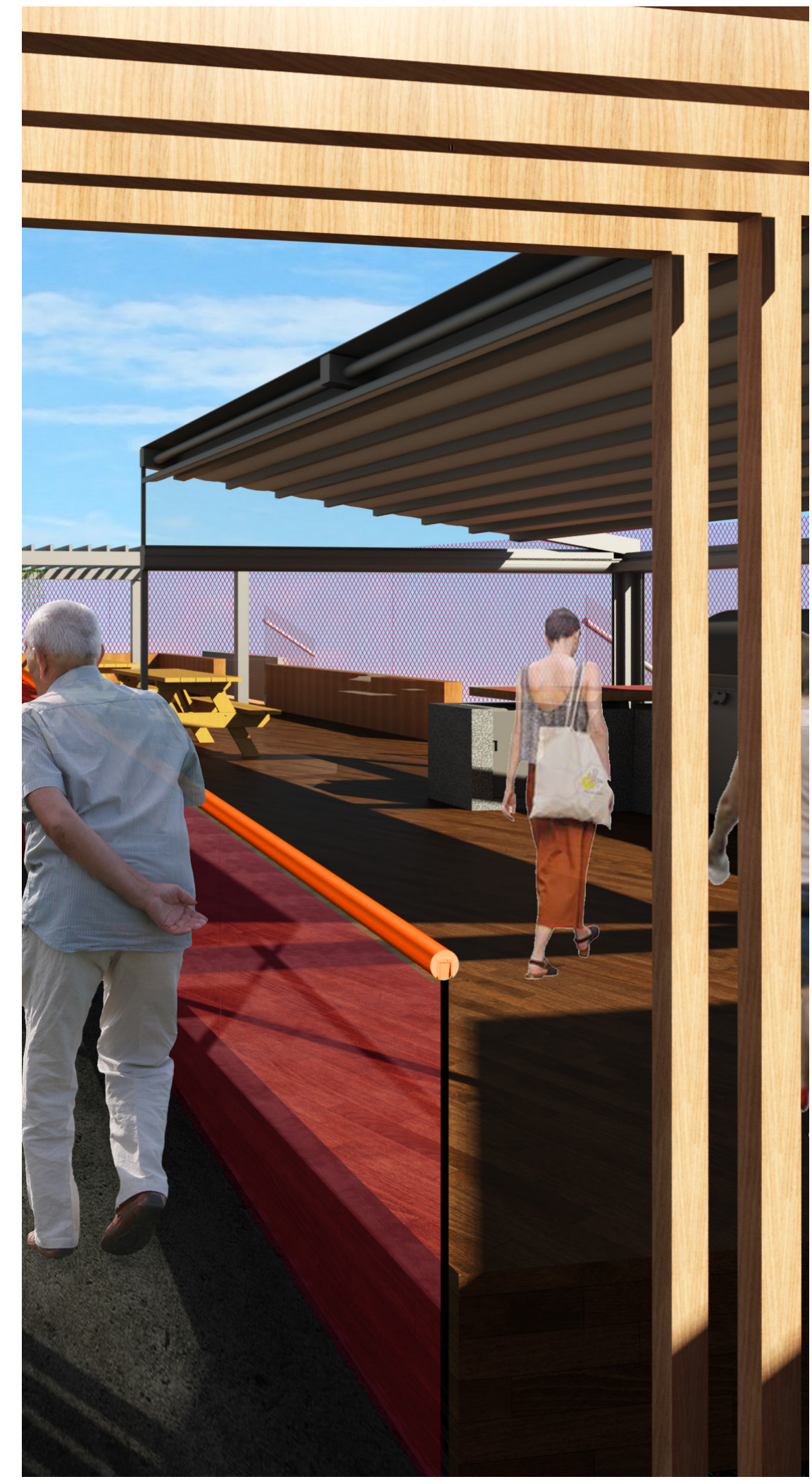




\section{Works Cited}

Abbeyfield. "Abbeyfield Is a Volunteer Effort of Goodwill." 2009. Web. 11/06/2018 2018.

Alvaro Puntoni, João Sodré, Jonathan Davies. "Simpatia Street Housing / Gruposp.” Arch Daily 2011. Web2018.

Author. "Loneliness and Isolation - Understanding the Difference and Why It Matters.” Age UK. Publisher, 2018. Web.

Council, New Zealand Planning. The Welfare State? Social Policy in the 1980s, Wellington1979. Print.

Cristea, Atelier Zündel. "Elderly Residential Home.” Arch Daily 2015. Web.

Dana Kotter-Grühn, Thomas M. Hess “The Impact of Age Stereotypes on Self-Perceptions of

Aging across the Adult Lifespan "The Journals of Gerontology, Series B: Psychological Sciences and Social Sciences (2012): 563-71. Print.

Dattner Architects, Grimshaw. "Via Verde / Grimshaw + Dattner Architects.” Arch Daily 2014. Web2018.

Davey, J., Nana, G., de Joux, V., \& Arcus, M. (2004). Accommodation, et al. "Accommodation Options for Older People in Aotearoa/New Zealand." Wellington, New Zealand: NZ Institute for Research on Ageing/Business \& Economic Research Ltd, for Centre for Housing Research Aotearoa/ New Zealand. (2004). Print. 
Diamond, Jared. "How Societies Can Grow Old Better." TED March 2013. Web2018.

Diamond, Jared. The World until Yesterday. London: Penguin Group, 2012. Print.

Graves, Lindsay DavisElizabeth LarkinStephen B. "Intergenerational Learning through Play." International Journal of Early Childhood 34.2 (2002): 42-49. Print.

Harris, Johanna. "Here's Why Some Dutch University Students Are Living in Nursing Homes." The Conversation 2016. Web2018.

Harris, Johanna. "Students Living in Nursing Homes - a Solution to Our Ageing Populations?” 2016. Web2018.

Hatton, Celia. "New China Law Says Children 'Must Visit Parents'." BBC News. Publisher, 2013. Web. July.

HOUSING, NIGHTINGALE. "A Financial Structure That Focuses on Improving the Affordability of Nightingale Apartments.”. Web2018.

Janine L. Wiles, Annette Leibing, Nancy Guberman, Jeanne Reeve, Ruth E. S. Allen. "The Meaning of "Aging in Place" to Older People." The Gerontologist 52.3 (2011): 357-66. Print.

Jansen, Tiffany R. "The Nursing Home That's Also a Dorm." 2015. Web2018.

Johnson, Cat. "Seniors Reinvent Aging through Cohousing \& Senior Villages.” SHAREABLE 2011. Web. 11/06/2018 2018. 
Julianne Holt-Lunstad, Timothy B Smith. "Loneliness and Social Isolation as Risk Factors for Cvd: Implications for Evidence-Based Patient Care and Scientific Inquiry “ BMJ Journals 102.13 (2016). Print.

Kim, Grace. "Capitol Hill Urban Cohousing an Intentional, Intergenerational Urban Village Developed by Its Residents.” schemata workshop 2016. Web2018.

Lenk, James. “Case Study: Kitagata Apartment Building.” 2015. Web2018.

M.H.Durie. "Kaumatautanga Reciprocity: Maori Elderly and Whanau." New Zealand Journal of Psychology 28.02 (1999): 102-06. Print.

Maltzan, Michael. "New Carver Apartments." Michael Maltzan Architecture 2009. Web2018.

Mangan, Lucy. “Old People's Home for 4 Year Olds Review - a Moving and Uplifting Experiment “ The Guardian 2017. Web. 11/06/2018 2018.

Mark Taylor, Laurie Buys. "Ageing in Suburbia.” 2012. Web.

McCabe, Michael. "The Hospice Movement in New Zealand - 25 Years On.” The Nathaniel Centre. Publisher, 2004. Web.

Metadata, Parliamentary Library. "Immigration Chronology: Selected Events 1840-2008.” New Zealand Parliament. Publisher, 2008. Web.

News, BBC. "What Can the Old and Young Learn from a Life Swap?" 2011. Web. 11/06/2018 2018. 
Papers, Assemble. "Backyard Bungalows: Murray Barker." Assemble papers. Web2018.

Assemble Papers “Nightingale 1.” NIGHTINGALE. Web2018.

Rawinia Higgins, Paul Meredith. "Story: Kaumātua - Māori Elders." Te Ara- the encyclopedia of New Zealand. Publisher, 2011. Web.

Reid, Georgina. "Cat Alley.” The Design Files 2015. Web2018.

Seccombe, Karen. "Children: Their Impact on the Elderly in Declining Health.” RESEARCH ON AGING 09.02 (1987): 312-26. Print.

Spink, Emily. "Elderly Going Flatting to Help Address Loneliness." Stuff 2016. Web. 11/06/2018 2018.

States, The Cohousing Association of the United. "Pdx Commons." 2017. Web2018.

Swarbrick, Nancy. “Care and Carers.” Te Ara. Publisher, 2017. Web.

Weale, Sally. "Primary School Invites in Elderly People to Work with Young Pupils “ The Guardian 2017. Web. 11/0612018 2018.

Williams, Eve. "A History of Residential Care in New Zealand.” Eldernet. Publisher, 2017. Web.

Wong, Edward. "A Chinese Virtue Is Now the Law." New York Times. Publisher, 2013. Web. July. 
Statistics New Zealand. "2013 Census Quickstats About People Aged 65 and Ove." Stats NZ. Publisher, 2013. Web.

Statistics New Zealand. "National Population Projections: 2016(Base)2068.” Stats NZ. Publisher, 2016. Web.

Statistics New. Zealand "The Social Report 2016 - Te Pūrongo Oranga Tangata." Ministry of Social Development. 2016. Web2018. 


\section{List of Figures}

1.1 Alexander Turnbull Library, Whites Aviation Collection, Haehaeora Te Rangitakatu carrying her mokopuna, Te Ara - the Encyclopedia of New Zealand, http://www.TeAra.govt.nz/en/ photograph/28365/haehaeora-te-rangitakatu-with-her-mokopuna (accessed 2 April 2019)

1.2 Diagram source: Author, Diagram information: Zealand, Statistics New. 2013 Census QuickStats about people aged 65 and ove. 2013. 2018. <http://archive.stats.govt.nz/Census/2013-census/ profile-and-summary-reports/quickstats-65-plus/household-composition-housing.aspx\#>.

1.3 Simplified model of possible direct and indirect pathways by which social connections influence disease morbidity and mortality, The Washington Post, 20-04-2016, https://www.washingtonpost. com/news/to-your-health/wp/2016/04/20/loneliness-can-literally-hurt-your-heart-scientistssay/?noredirect $=$ on\&utm_term $=$. ef504c $4260 \mathrm{fa}$

1.4 Two older persons playing with a student visiting Northpointe Christian Schools, Grand Rapids, New! Now Enrolling! Intergenerational Preschool, http://www.npchristian.org/academics/ intergenerational.cfm

1.5 Ground-floor plan showing the furniture layout, alternate routes around the central hallway and exterior deck access to the garden, Mark Taylor, Laurie Buys. "Ageing in Suburbia." 2012. Web, https://onlinelibrary.wiley.com/doi/pdf/10.1002/ad.1728

1.6 Evening view from a local pathway across Brook Stream, Mark Taylor, Laurie Buys. "Ageing in Suburbia." 2012. Web, https://onlinelibrary.wiley.com/doi/pdf/10.1002/ad.1728

1.7 Iwan Baan, Typical residential floor plan, Michael Maltzan Architecture, 2009, https:/ / www.architectmagazine.com/ajax/slideshow.ftl?id=00000149-8120-d7b5-adedf9fdee $870001 \&$ zone $=$ design. buildings $\&$ keywords $=\&$ skey $=$

1.8 Iwan Baan, The ground floor is topped by a wood and steel carousel of five residential stories, Michael Maltzan Architecture, 2009, https://www.architectmagazine.com/ajax/slideshow. $\mathrm{ftl}$ ?id=00000149-8120-d7b5-aded-f9fdee870001\&zone=design.buildings\&keywords $=\&$ skey $=$

1.9 Iwan Baan, View of the central courtyard, Michael Maltzan Architecture, 2009, https://www.architectmagazine.com/ajax/slideshow.ftl?id=00000149-8120-d7b5-adedf9fdee $870001 \&$ zone $=$ design. buildings $\&$ keywords $=\&$ skey $=$

1.10 Sergio Grazia, Elderly Residential Home exterior, Arch Daily, 2015, https://www.archdaily. com/630825/elderly-residential-home-atelier-zundel-cristea

1.11 Sergio Grazia, Elderly Residential Home, Internal circulation space, Arch Daily, 2015, https:// www.archdaily.com/630825/elderly-residential-home-atelier-zundel-cristea

1.12 PDX Commons, street view, UD+P Cohousing, UD+P, https://www.udplp.com/cohousing

1.13 Our vege beds give us nutritious fresh vegetables, Find an Abbeyfield house near you, http:// www.abbeyfield.co.nz/houses/abbeyfield-christchurch.aspx 
1.14 Abbeyfield apartment porches, Find an Abbeyfield house near you, http://www.abbeyfield. co.nz/houses/abbeyfield-ellesmere.aspx

1.15 Schemata Workshop, Common House Exterior, Capitol Hill Urban Cohousing An intentional, intergenerational urban village developed by its residents, Schemata Workshop, http://www. schemataworkshop.com/chuc

1.16 Schemata Workshop, Common House residents interact on different floors circulation, Co Housing, Schemata Workshop, http://www.schemataworkshop.com/passions-cohousing

1.17 David Sundberg, Vanni Archive, Via Verde Exterior, Arch Daily, 2014, https://wwwarchdaily. com/468660/via-verde-dattner-architects-grimshaw-architects

1.18 David Sundberg, Vanni Archive, Via Verde external circulation steps, Arch Daily, 2014, https:// www.archdaily.com/468660/via-verde-dattner-architects-grimshaw-architects

1.19 SAANA, Kitagata Apartments façade, Gifu Kitagata Apartments, http://www.msaudcolumbia. org/summer/?p=3140

1.20 SAANA, Kitagata Apartments facade circulation, saana, Gifu Kitagata Apartments https:// afasiaarchzine.com/2011/12/sanaa-18/

1.21 Nelson Kon, Residential Building exterior, Arch Daily, 2011, https://www.archdaily.com/160951/ simpatia-street-housing-gruposp-arquitetos

1.22 Nelson Kon, Residential Building ground floor pathways, Arch Daily, 2011, https://www. archdaily.com/160951/simpatia-street-housing-gruposp-arquitetos

1.23 Nelson Kon, Residential Building exterior highlighting the red balustrades and privacy screening, Arch Daily, 2011, https://www.archdaily.com/160951/simpatia-street-housing-gruposp-arquitetos

1.24 Nightingale Housing ltd, Nightingale Housing exterior, Nightingale Housing, 2018, https:// nightingalehousing.org/tours

1.25 Andrew Wuttke, Nightingale Housing, rooftop garden, Radio New Zealand, https://www. radionz.co.nz/national/programmes/ninetonoon/galleries/nightingale-housing

1.26 Ben Clement, Murray's bench on the quiet laneway, Assemble Papers, https://assemblepapers. com.au/2015/03/05/backyard-bungalows-murray-barker/

1.27 Ben Clement, Tools and clothes sit side-by-side on Murray's shelves, Assemble papers, https:// assemblepapers.com.au/2015/03/05/backyard-bungalows-murray-barker/

1.28 Daniel Shipp, The voluptuous gardens of 'Cat Alley' in Surry Hills have completely engulfed the footpath!, The Design Files, https://thedesignfiles.net/2015/05/cat-alley/

1.29 Michael MCC, Cat in an Alley, hiveminer. Flickr, https://hiveminer.com/Tags/alley\%2Csurryhills

1.30 Schemata Workshop, Residents of Capitol Hill Urban Cohousing enjoy dinner in their courtyard, Vancouver Courier, https://www.vancourier.com/real-estate/lonely-maybe-cohousing-is-one-of-thecures-1.23284118 
2.1 Author, Te Aro School site currently has a vegetable garden, 2018

2.2 Author, Te Aro School site backing onto Boyd Wilson Field and Te Puni Halls of Residence, 2018

2.3 Author, Te Aro site from Martin Square, 2018

2.4 Author, Te Aro site from Taranaki Street, 2018

2.5 Author, Te Aro site is currently used as a carpark, 2018

2.6 Author, Te Aro site boarders busy Taranaki Street, 2018

2.7 Author, Mount Cook Site from Taranaki Street, 2018

2.8 Author, Te Aro Site, 2018

3.1 All Images Authors own, 2018

4.1 Rita Angus Retirement Village, Kilbirnie Retirment Village, Ryman Healthcare, https://www. villageguide.co.nz/care-homes/rita-angus-retirement-village

4.2 Selwyn Sprott Village, Set in the perfect Wellington location, you can find Selwyn Sprott Village,

The Selwyn Foundation, https://www.selwynfoundation.org.nz/villages/residential-care/selwynsprott-village/

4.3 CCM Architects, Te Hopai Home and Hospital, CCm Architects, https://www.ccm.co.nz/ projects/healthcare/te-hopai-home-and-hospital/

4.4 Author, A positive example of Urban housing aesthetic and materials in Wellington, 2018

4.5 Author, A negative/ stigmatised example of Urban housing aesthetic and materials in Wellington, 2018

4.6 Author, A negative/ stigmatised example of Urban housing aesthetic and materials in Wellington, 2018

6.1 BMC Architecture, Strength and Sun Resistance for Retail Store, Kaynemaile, https://www. kaynemaile.com/cs-hutt-road

6.2 BMC Architecture, Strength and Sun Resistance for Retail Store, Kaynemaile, https://www. kaynemaile.com/cs-hutt-road

6.3 Amit Geron, The movable shutters create a playful facade that conceals and reveals interior spaces, Golany Architects, https://www.dwell.com/article/golany-architects-galilee-residence$88210 a 50 / 6435215545652764672$

6.4 BelAire Designer Fencing, Balustrade Glass Panel Systems, BelAire Fencing, https://www. belairefencing.co.nz/balustrade-glass-panels/?gclid=EAIaIQobChMI08ra1NCr4QIVgYuPCh3ECQ 37EAAYASAAEgKLxPD_BwE

6.5 MIROTONE, Wide Range of water based colours and effects, ICA Group, https://www. mirotone.com/wp-content/uploads/2016/05/ICA-Group-Glass-Paint.pdf 


\section{Appendix}
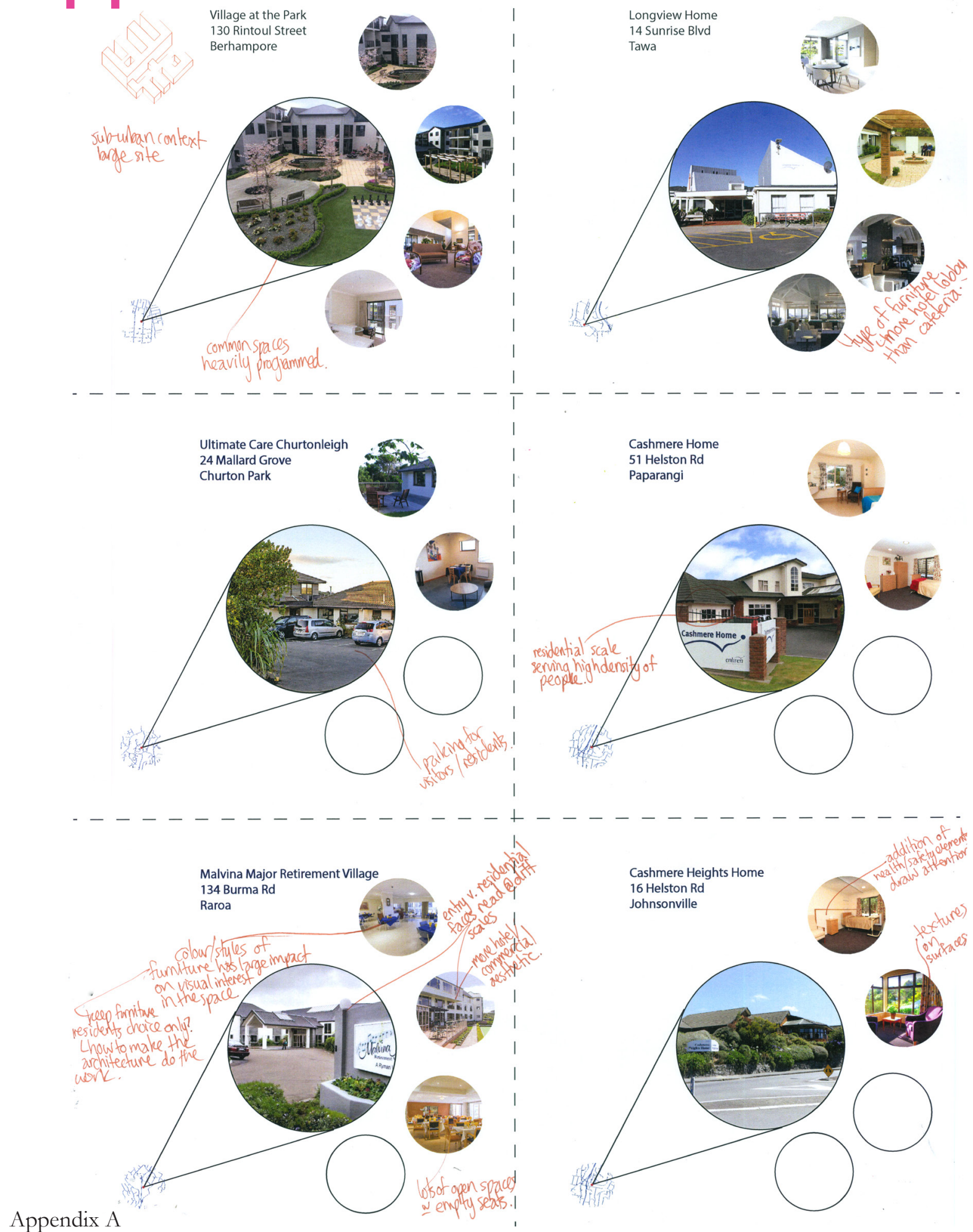

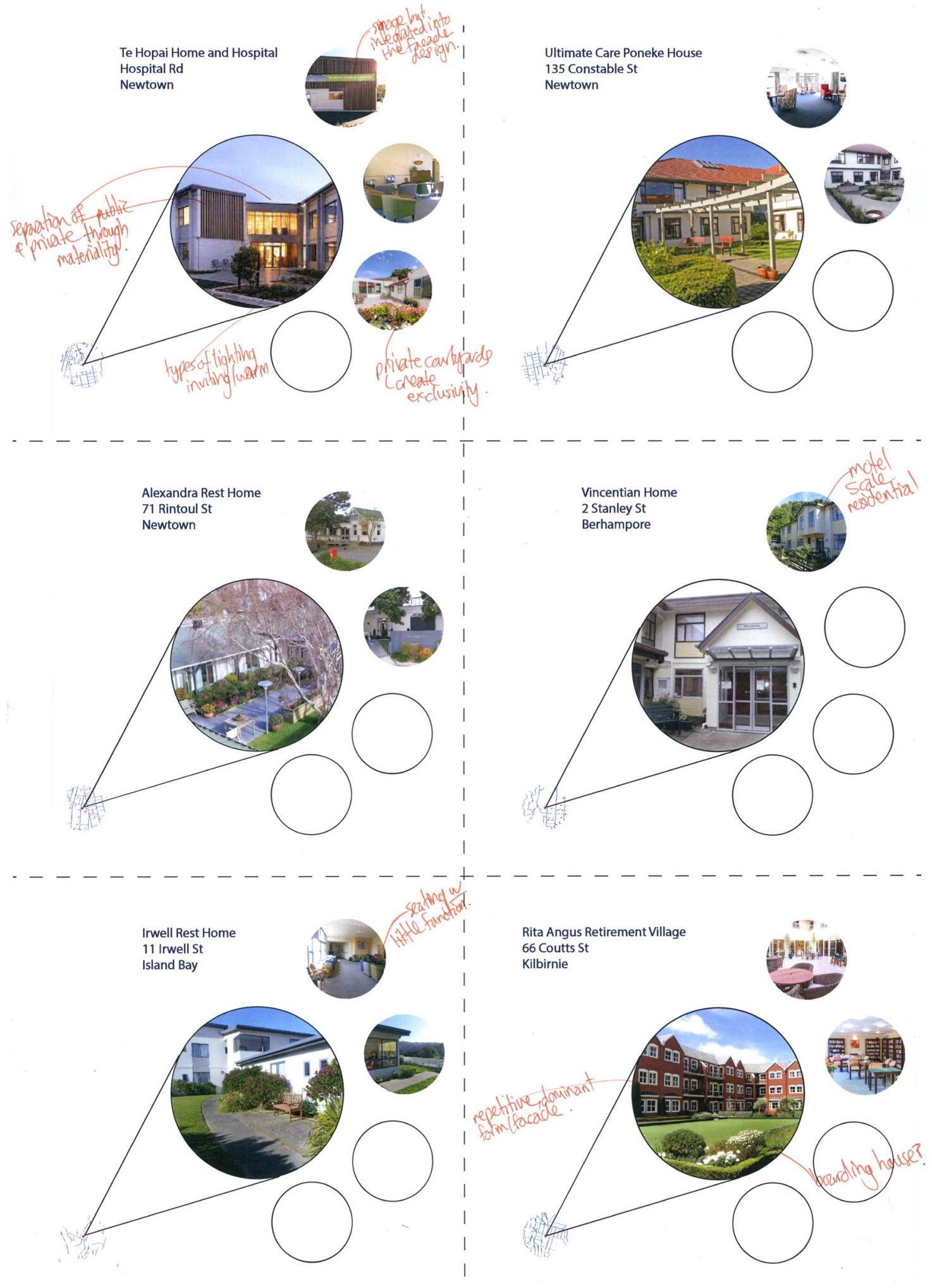


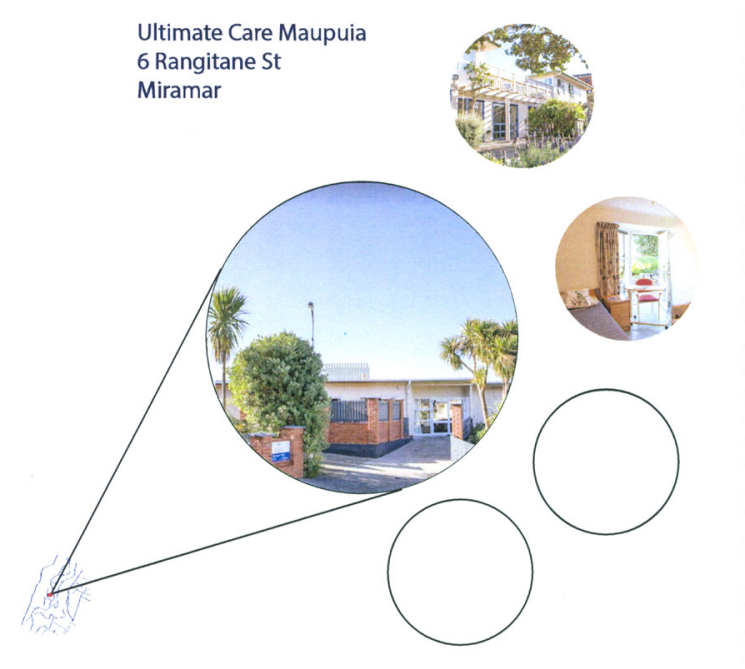

Huntleigh Home and Retirement Apartments

219/221 Karori Rd

Karori

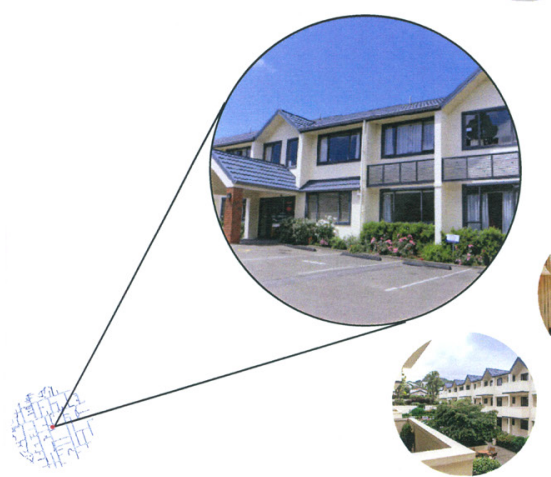

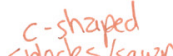

- blaces / samere

At blaks to allow (nivi IE int loop

in an. Erir circulation.
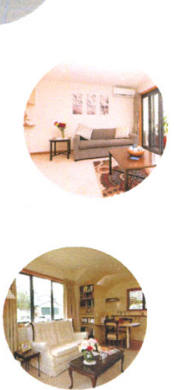

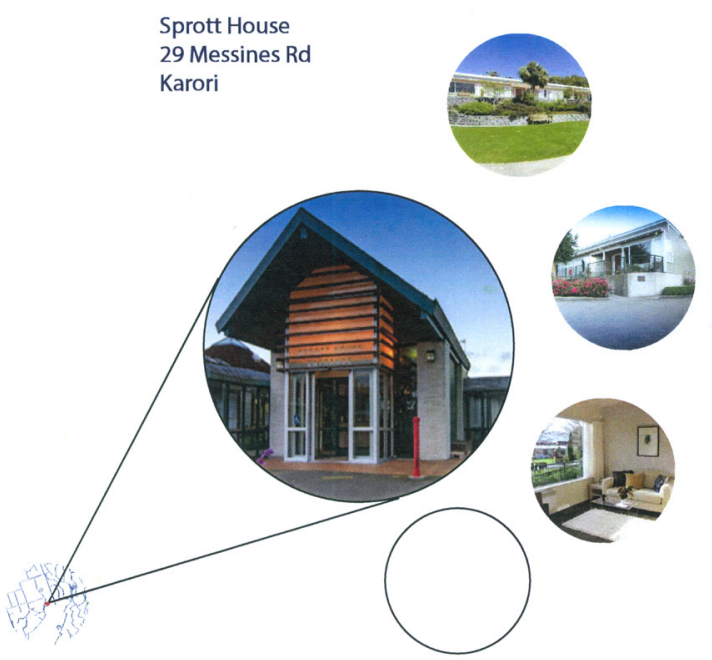

29 Messines Rd

St John of God Karori

11 Messines Rd

Karori
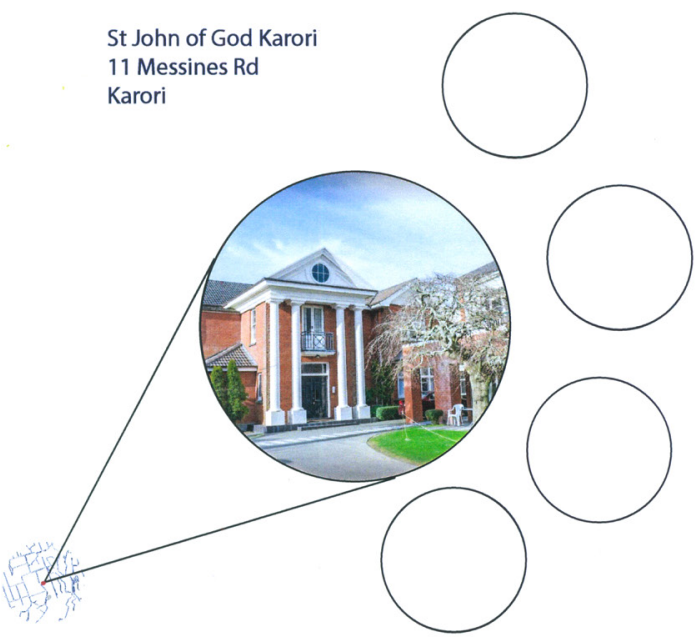

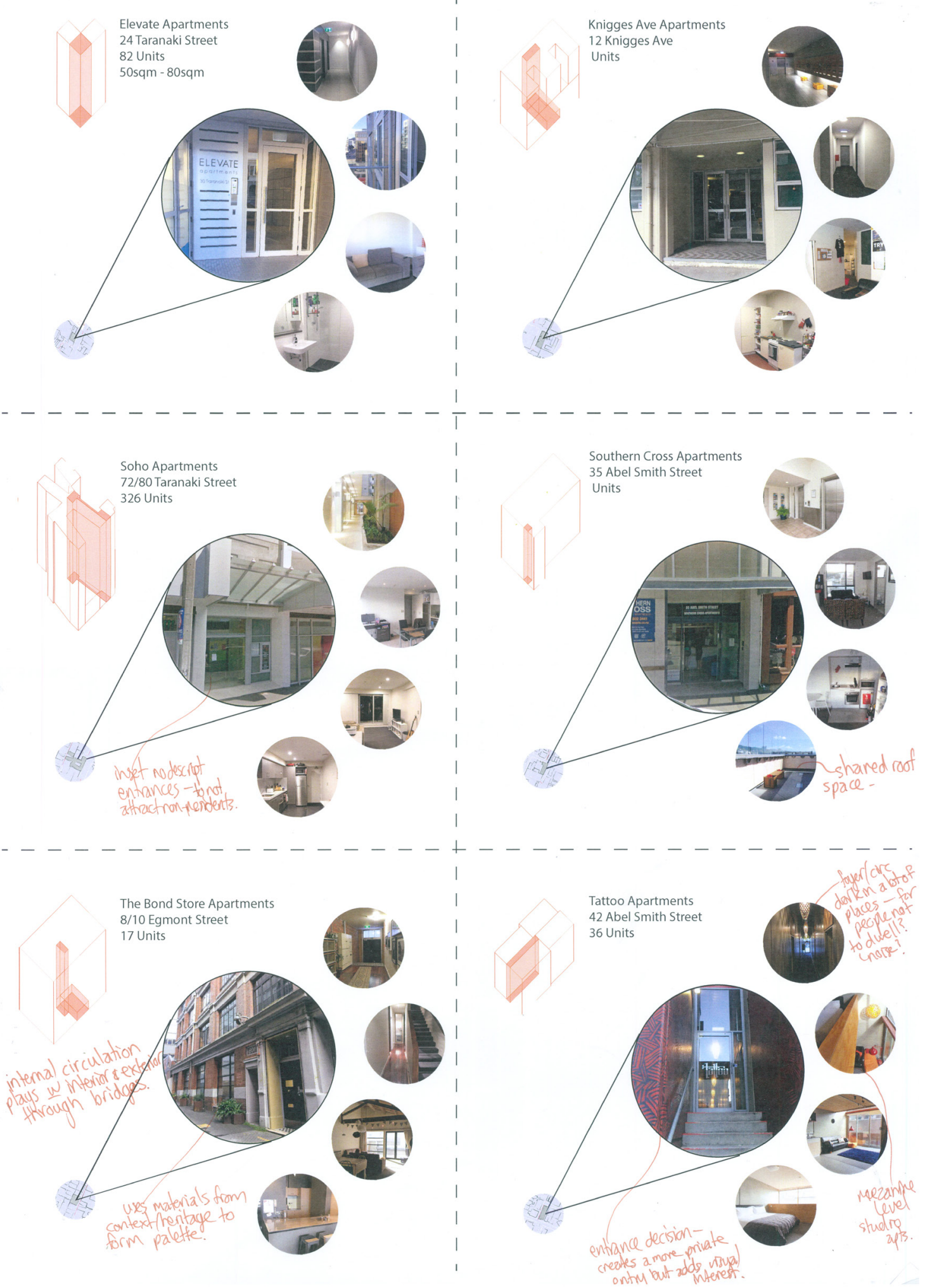


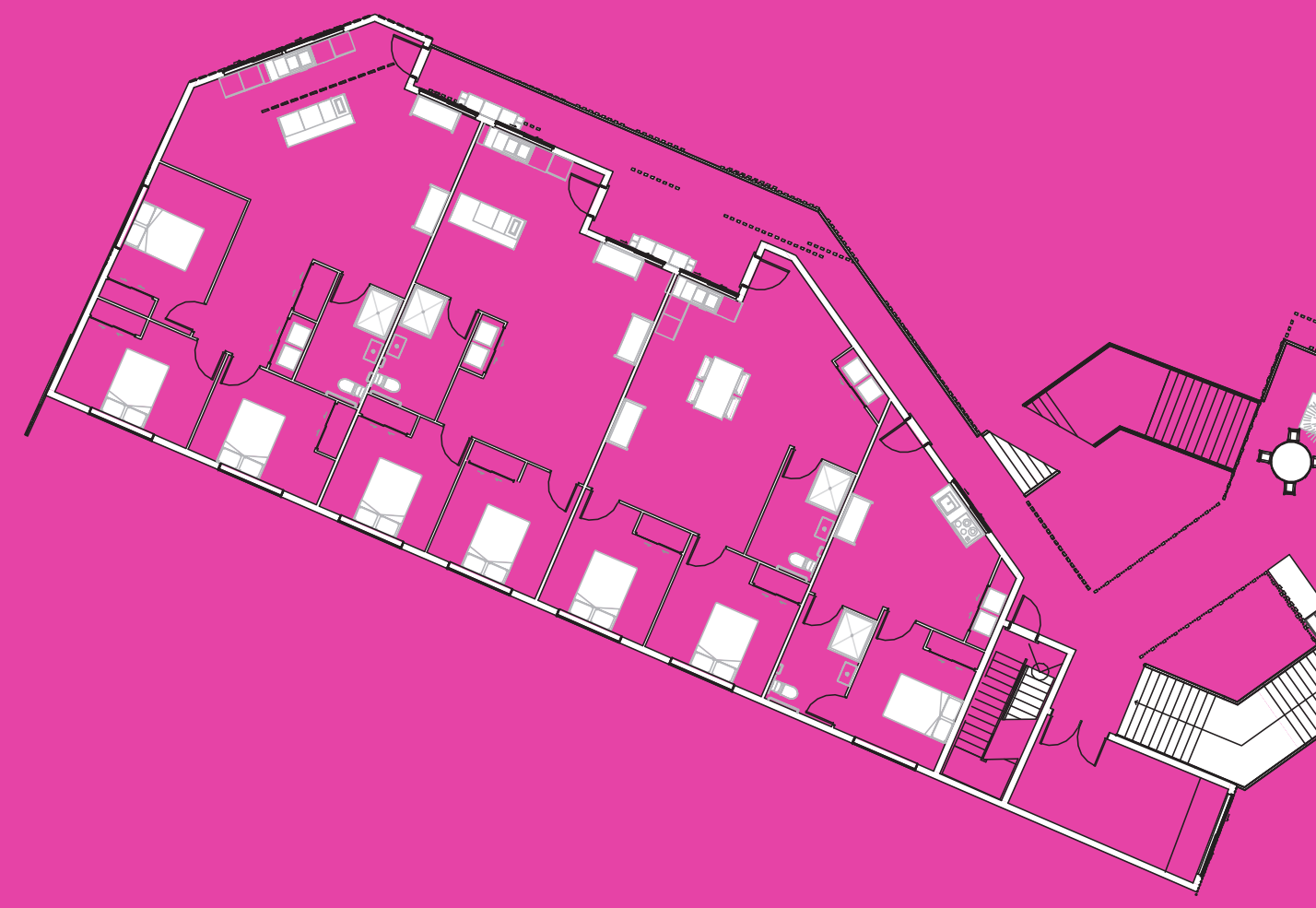

Fourth Floor

Appendix B 


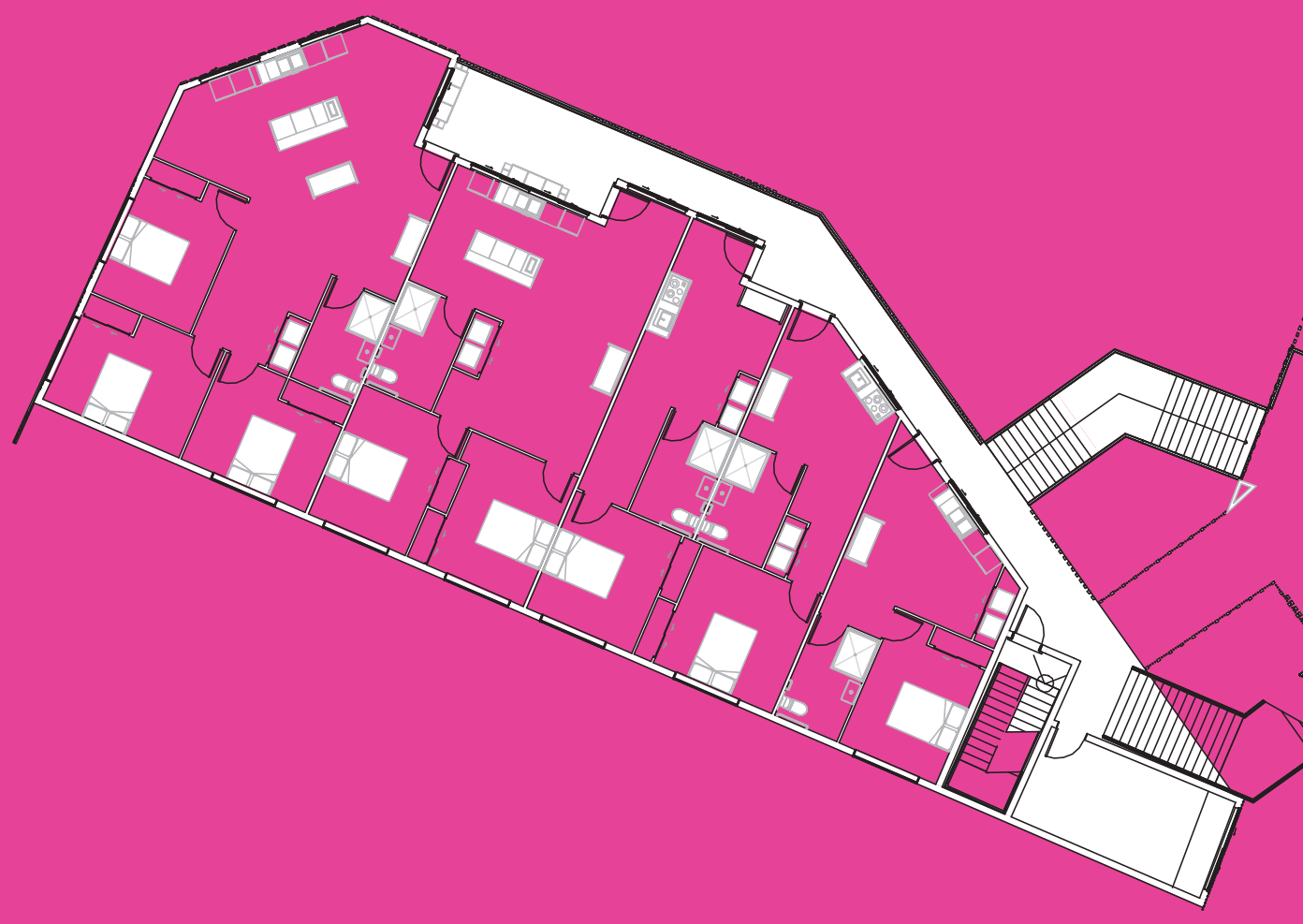

Fifth Floor 

